\title{
The influences of nutrients and snow on the spatial and temporal variability of sea ice algae
}

Francisca A.H. Vermeulen

A thesis submitted in part fulfilment of

the requirement for the degree of

Doctor of Philosophy

Victoria University of Wellington

Te Whare Wananga o te Upoko o te Ika a Maui 


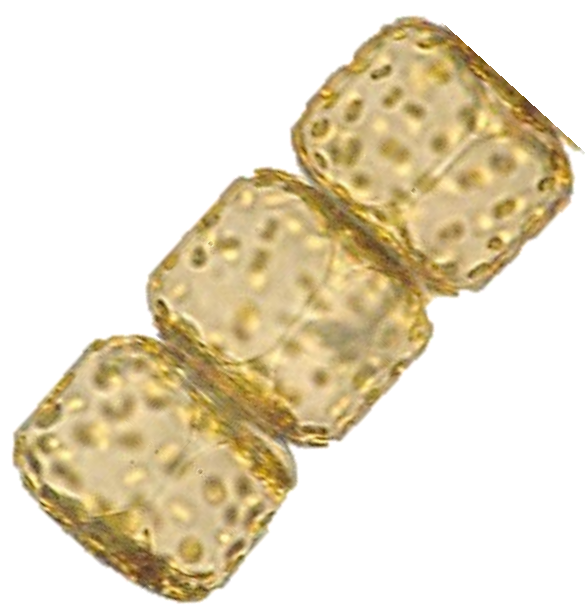

"Few objects are more beautiful than

the minute siliceous cases of the diatomaceae;

were these created that they might be examined and admired under the high powers of the microscope?"

-Charles Darwin 


\section{Acknowledgements}

After 3 years of working on a $\mathrm{PhD}$ an entire book can be written to thank people who helped me get this far. I would first like to thank my supervisors, Ken Ryan and Else Hegseth. I am very grateful for the guidance and support you have given me all these years.

Your encouragement and enthusiasm has been limitless and so often was what kept me going. Thank you for the time and energy you have put into my research.

Office colleagues, fellow students and friends have been there through all of the ups and downs that come with a PhD. Special thanks to Andrew Martin, Eileen Koh, Fernanda Piraud and Mark Heath with whom I was able to discuss my research and thanks Lisa Bryant, Christine Bylenga, David Burr for all the assistance in the lab.

All the technical and administrative support in SBS has been fantastic. My sincere thanks to, Neville Higginson, Paul Marsden, Lesley Millich, Mary Murray, Sushila Pillai, Patricia Stein, Sandra Taylor and Chris Thorn.

I want to thank Antarctic New Zealand and their entire team for all the logistical support. For funding, I thank Victoria University of Wellington, SCAR, Antarctica New Zealand, the Antarctic Research Centre (VUW).

All your encouragement and unconditional support has made it possible. 


\section{Table of contents}

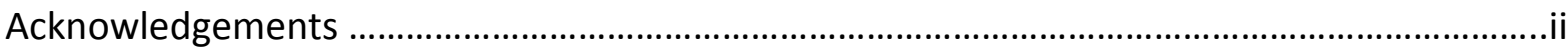

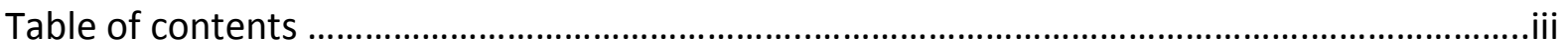

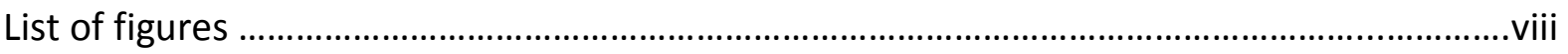

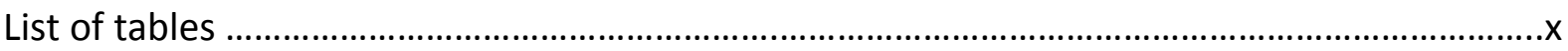

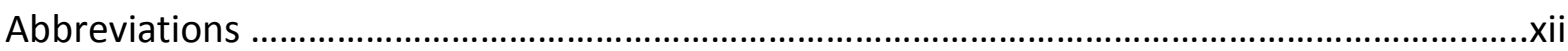

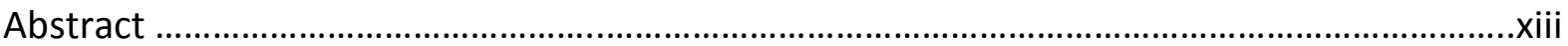

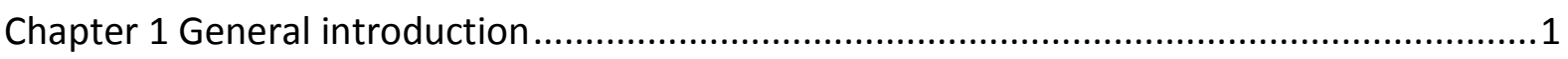

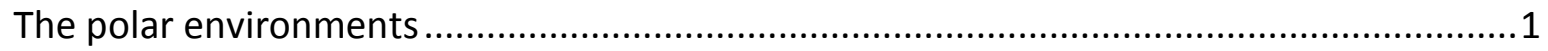

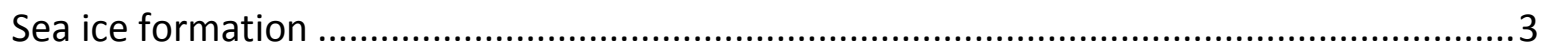

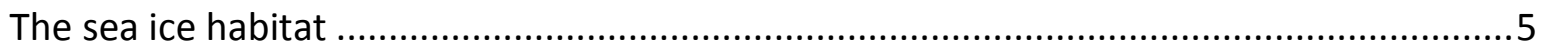

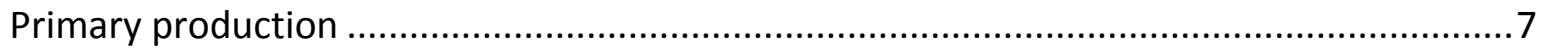

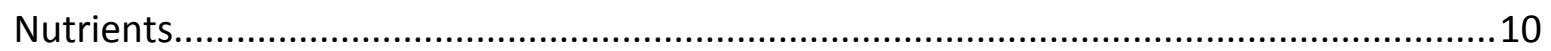

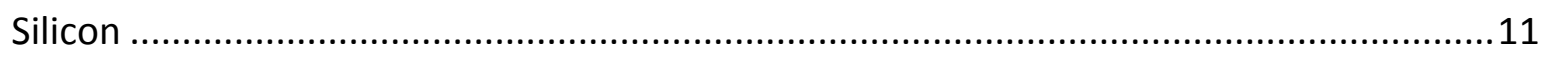

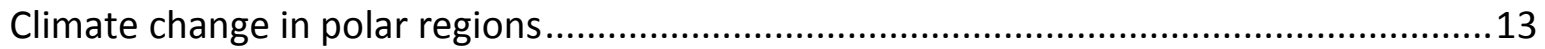

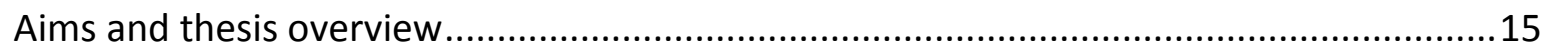

Chapter 2 Spatial and temporal comparisons of sea ice algal communities in the Ross Sea,

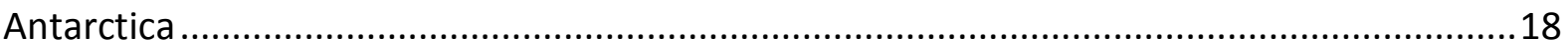

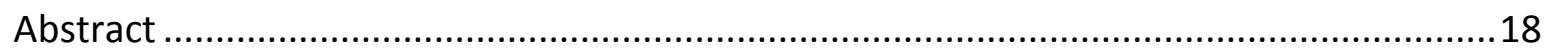

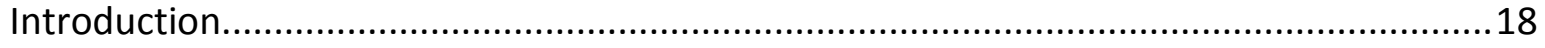

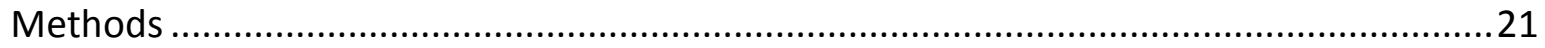

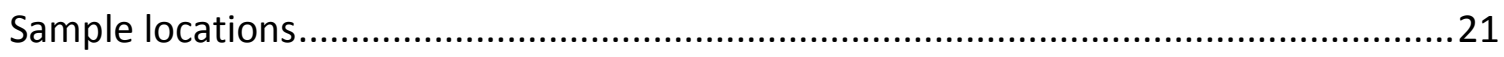

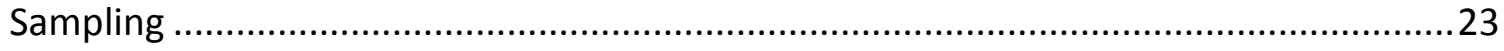

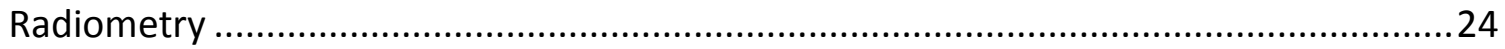

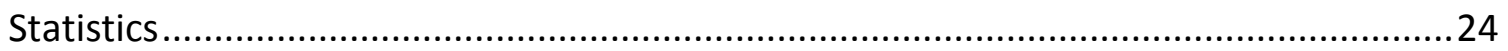

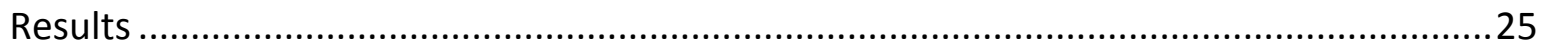

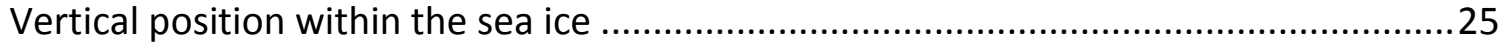

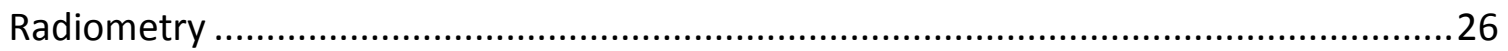

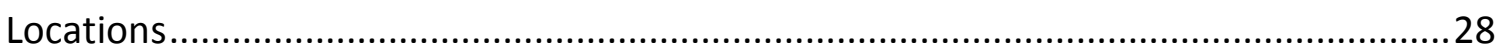


Yearly differences in sea ice algal communities

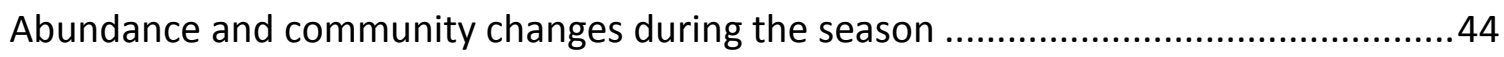

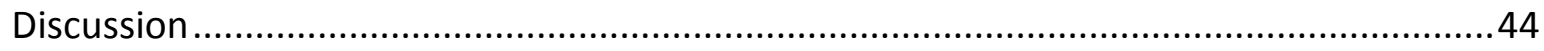

Yearly differences in sea ice algal communities .........................................................44

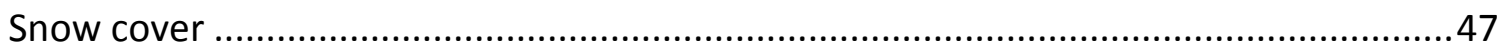

Community and abundance changes during the season ............................................48

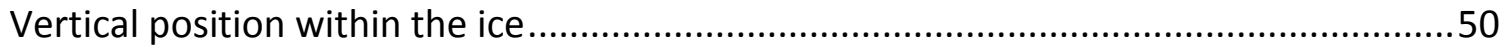

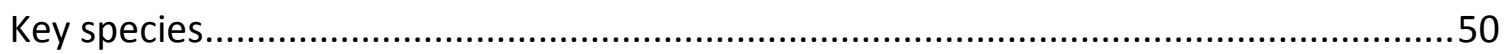

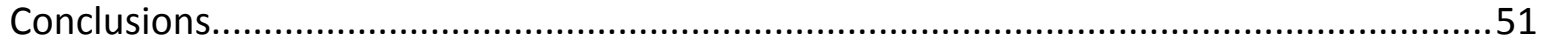

Chapter 3 The influence of snow cover on total particulate organic carbon in bottom and

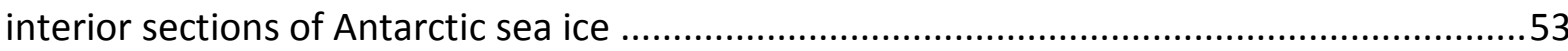

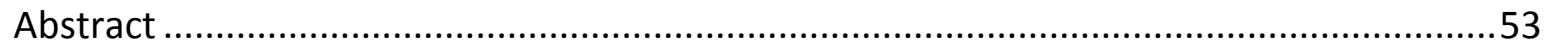

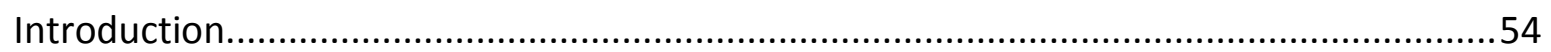

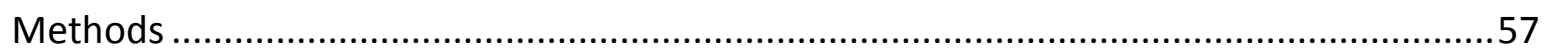

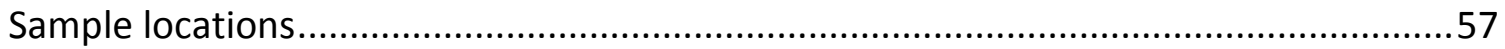

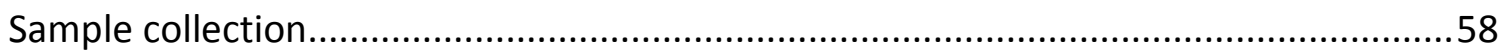

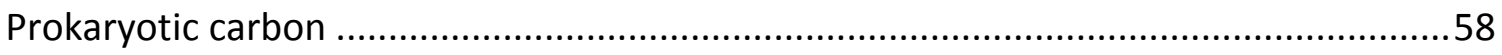

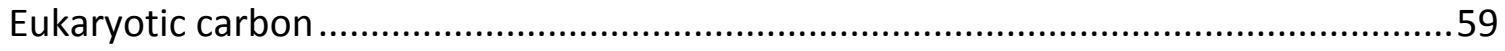

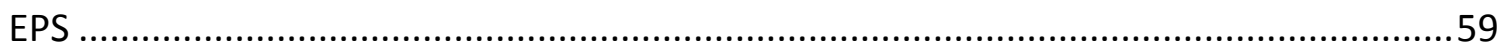

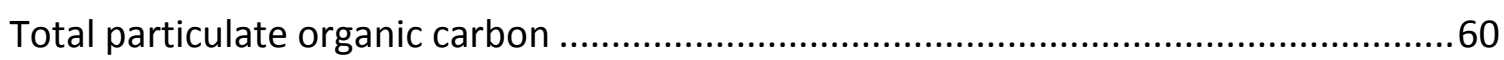

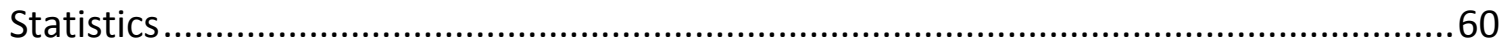

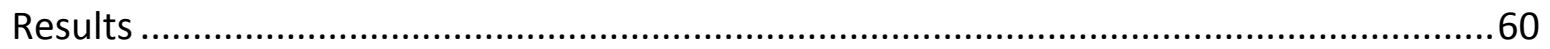

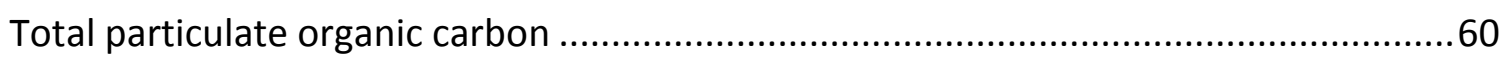

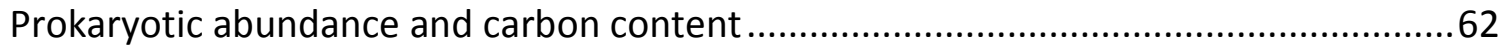

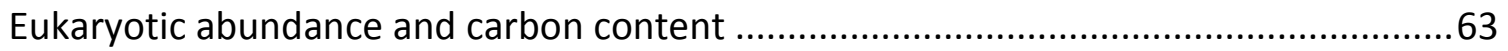

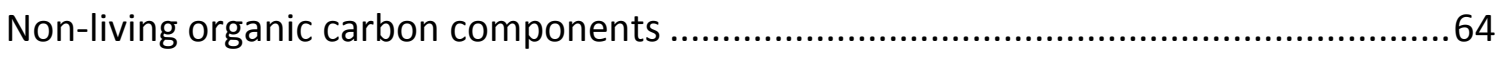

Correlation between carbon contributors ................................................................65

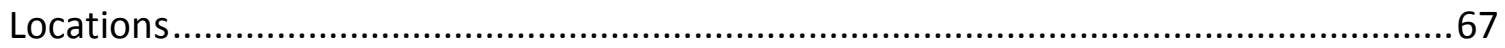

Temporal changes during in organic carbon contributors ........................................69

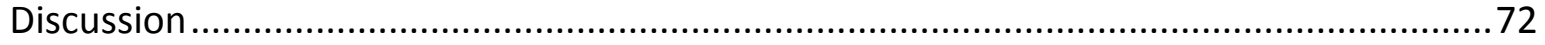

Influence of snow cover on bottom sea ice carbon ................................................... 72

Temporal changes in organic carbon in the bottom of the sea ice...............................73 
Influence of snow cover on the interior sea ice carbon ............................................... 75

Temporal changes in organic carbon in the interior of the sea ice...............................75

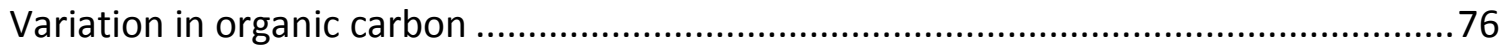

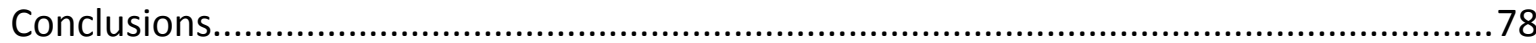

Chapter 4 Silica and phosphorus limitation occurs in sea ice brine communities but not in

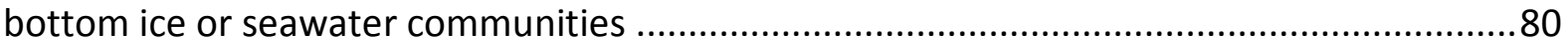

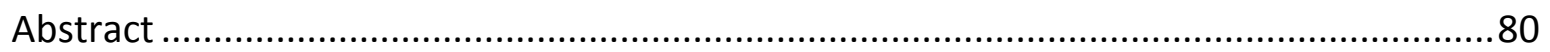

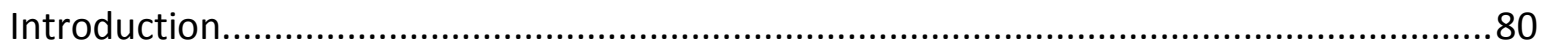

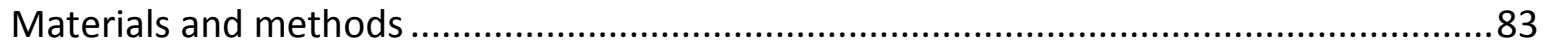

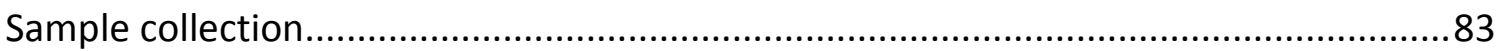

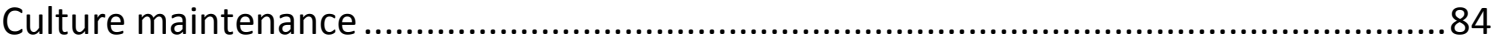

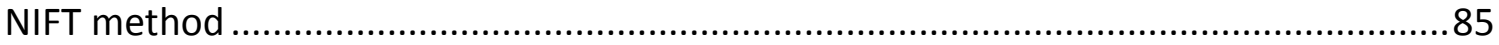

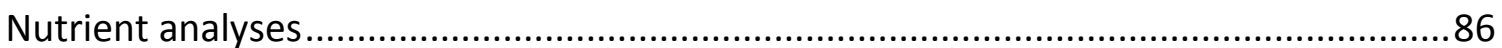

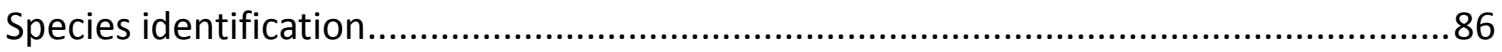

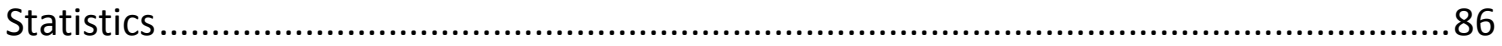

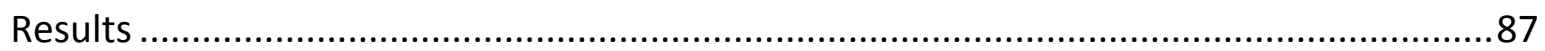

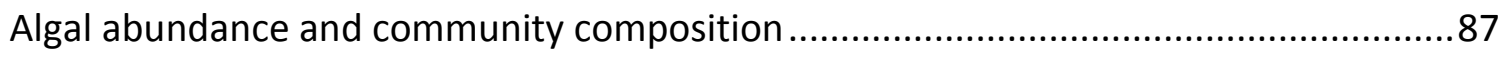

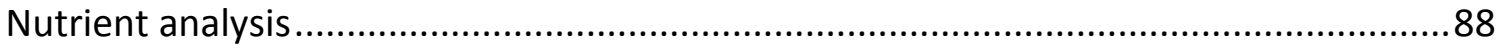

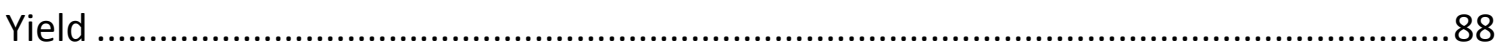

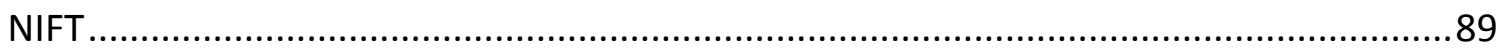

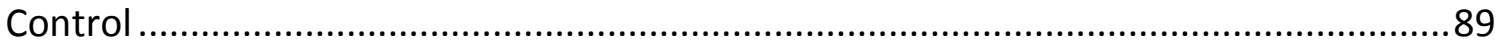

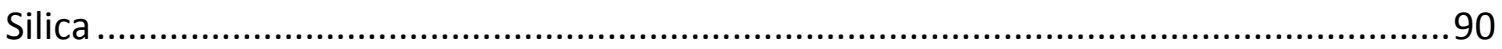

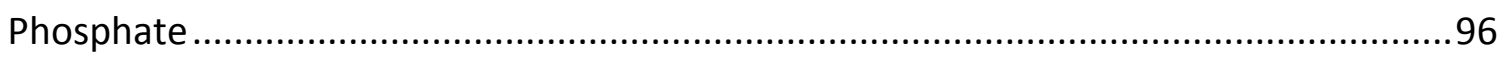

Nitrate

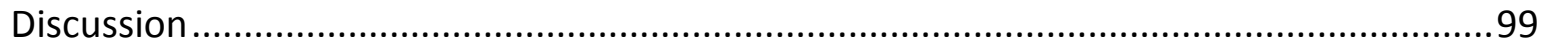

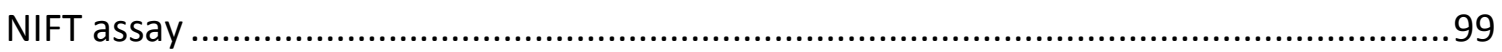

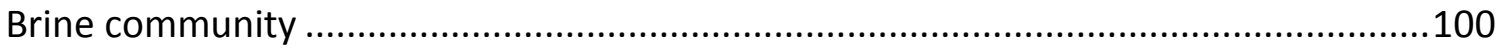

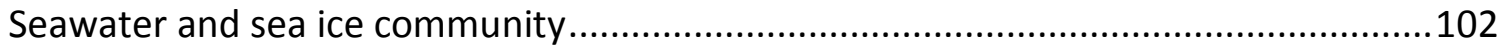

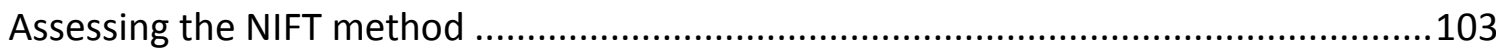

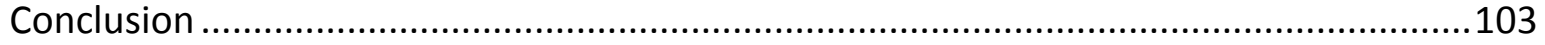

Chapter 5 Antarctic diatoms have a higher silica demand than Arctic diatoms ..................105

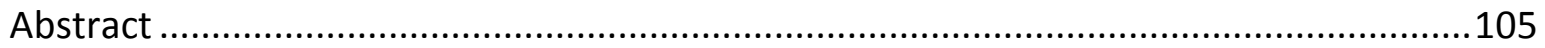




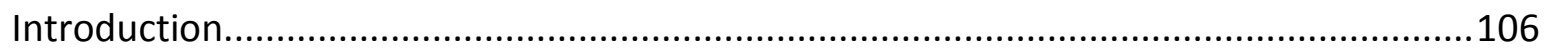

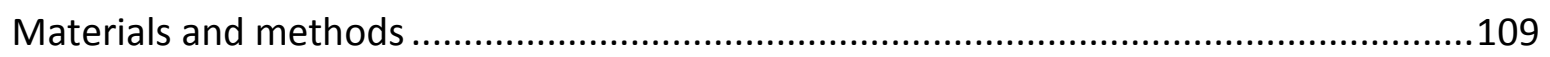

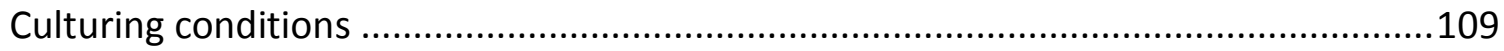

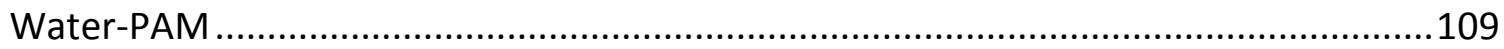

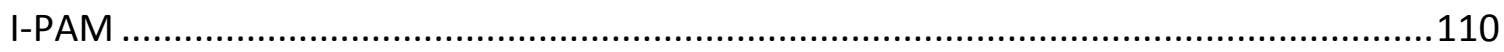

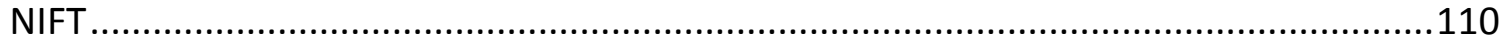

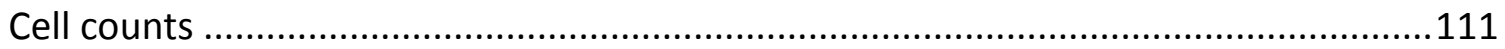

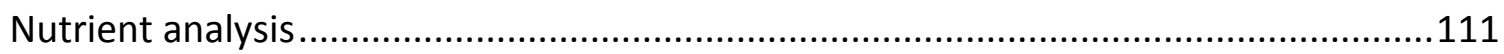

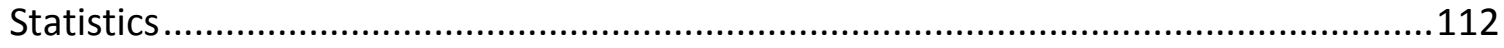

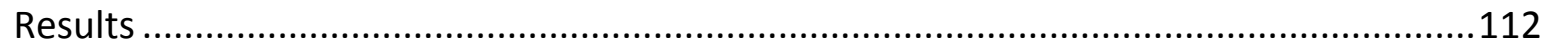

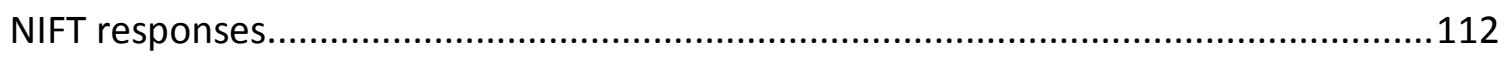

NIFT analysis of low silica cultures using the water- PAM .......................................... 114

NIFT analysis of silica rich cultures using the water- PAM ........................................116

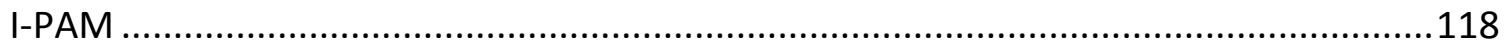

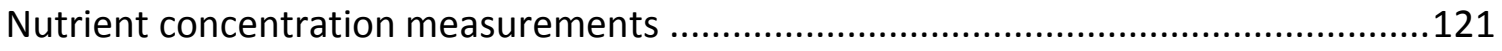

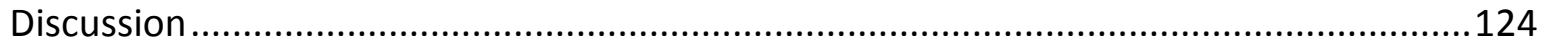

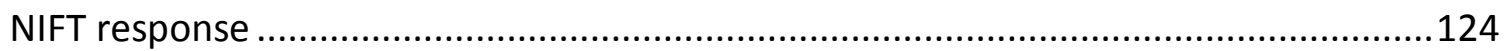

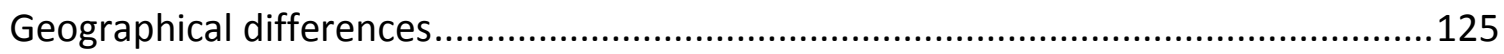

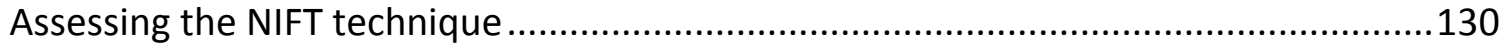

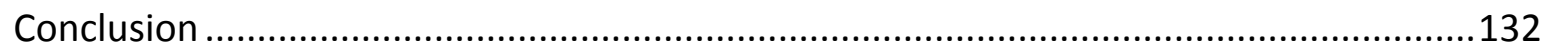

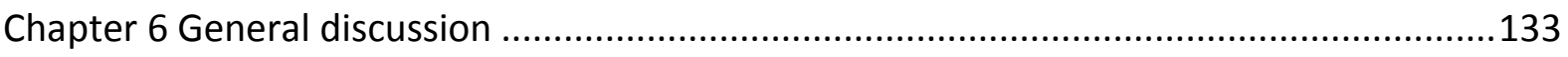

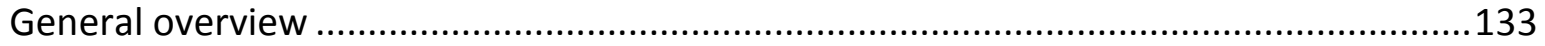

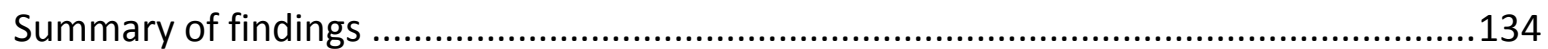

Chapter 2: Spatial and temporal comparisons of sea ice algal communities in Ross Sea,

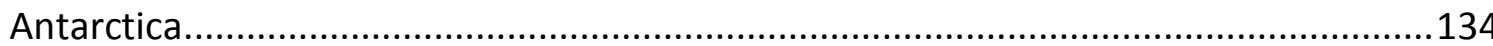

Chapter 3: The influence of snow cover on total particulate organic carbon in bottom

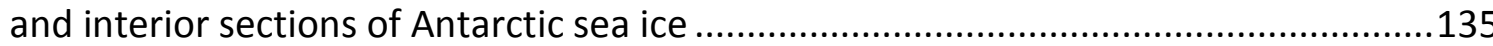

Chapter 4: Silica and phosphorus limitation occurs in sea ice brine communities but not

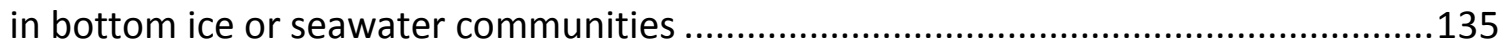

Chapter 5: Antarctic diatoms have a higher silica demand than Arctic diatoms ..........136

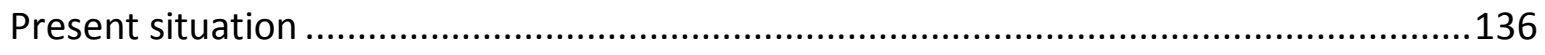

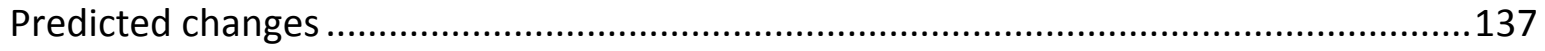


Spatial and temporal variability of the bottom sea ice communities .138

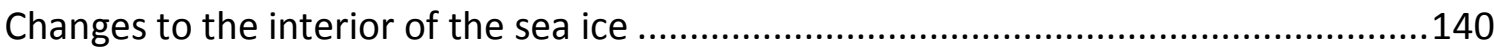

The effect of snow cover on bottom sea ice communities .........................................142

Changes to species succession due to nutrient limitation .........................................144

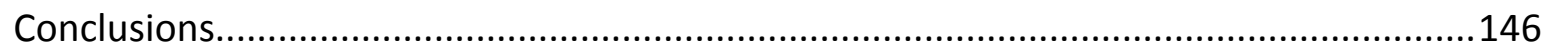

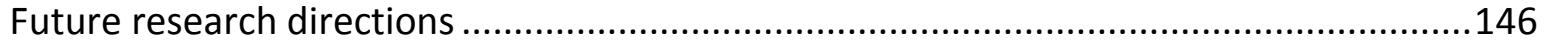

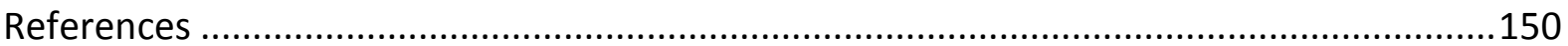

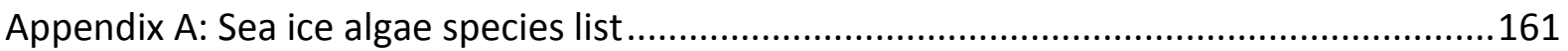

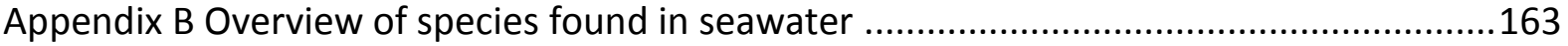

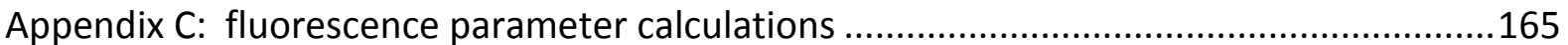




\section{List of Figures}

Figure 1-1: Differences between summer and winter sea ice extent for the Arctic and Antarctic (NSIDC 2012).

Figure 1-2: Schematic representation of the different kinds of microalgae assemblages associated with Antarctic sea (Knox 2009b).

Figure 2-1: Sample locations in Antarctica a) Antarctica, b) Ross Sea including Ross Island. The dotted line indicates the Ross Sea Ice shelf, c) A close-up of Ross Island as indicated in the box of Figure b.

Figure 2-2: Multidimensional scaling similarity plot for sea ice community species composition by position in the sea ice in the Ross Sea, 2011. Plot includes Cape Evans 2011, Terra Nova Bay 2011 and Turtle Rock 2011 for all time points sampled. Axes are arbitrary distance, and distances between samples are proportional to similarity (Bray-Curtis measure $+d$ ) between the assemblages.

Figure 2-3: a) Irradiance levels at different vertical positions in the sea ice at Terra Nova Bay 2006. b) Detail of the irradiance levels within the sea ice from 11 November to 5 December 2006. The arrow indicates when a $10 \mathrm{~cm}$ snow fall occurred (unpublished data collected by K043 Antarctic team) 27

Figure 2-4: Sea ice algal species composition at Turtle Rock 2011 for the bottom, middle and top of the sea ice with no-, low-(10-15 cm) and, high snow cover $(30-14 \mathrm{~cm})$ in relation to the different vertical position in the sea ice and, the snow cover present ( $n=4$ per sample point).

Figure 2-5: Similarities in sea ice communities by location. a) Top, b) middle, c) bottom sections of sea ice cores from 3 different locations, Turtle Rock, Cape Evans and Terra Nova Bay. The circle in a) shows a cluster of Cape Evans 2010 samples, which is significantly different from the other sampled locations. The circle in b) shows a similarity cluster of the Turtle Rock plots. In c), all locations except for TRNS and TRLS form separate clusters meaning that they differ significantly from each other in species composition. Axes are arbitrary distance, and distances between samples are proportional to similarity (Bray-Curtis measure $+d)$ between the assemblages.

Figure 2-6: Species composition (cells.L-1) at Terra Nova Bay (2010 and 2011) and Cape Evans (2010 2012), the Ross Sea, for the top $10 \mathrm{~cm}$, middle $10 \mathrm{~cm}$ and bottom $10 \mathrm{~cm}$ of the sea ice during early summer ( $n=4$ per sample point).

Figure 2-7: Chl a concentrations in the bottom $10 \mathrm{~cm}$ of the sea ice at Cape Evans in multiple years. Data are means $\pm 1 S E, n=4$ per data point.

Figure 2-8: Comparison of similarities in the bottom sea ice communities at Cape Evans for 5 years. Data were square root transformed and axes are arbitrary distance, and distances between samples are proportional to similarity (Bray-Curtis measure $+d$ ) between the assemblages.

Figure 2-9: Chl a concentrations in the bottom $10 \mathrm{~cm}$ of the sea ice at Terra Nova Bay across multiple years.

Data are means $\pm 1 S E, n=4$ per data point.

Figure 2-10: Comparison of similarities in the bottom sea ice communities at Terra Nova Bay for 5 years. Data were square root transformed and resemblance was done with Bray Curtis ( $+d)$. Axes are arbitrary distance, and distances between samples are proportional to similarity between the assemblages.

Figure 3-1: Comparison of methods to determine TPOC. Samples ( $n=3$ per data point) used were obtained from the bottom of the sea ice at TRNS. TPOC sum was derived from adding all carbon constituents together. TPOC was measured using a C:N analyser. Data are means \pm 1 SE, $n=4$ per data point)....... 
Figure 3-2: Linear regression plot between EPS, prokaryotic and eukaryotic carbon for the top, middle and bottom of the sea ice. Samples used from Turtle Rock (no snow, low snow and high snow plots), Cape Evans and, Terra Nova Bay 2011.

Figure 4-1: Community composition of seawater, sea ice and brine. Samples were collected from Turtle Rock, Ross Sea, Antarctica. The seawater and sea ice communities consisted entirely of diatoms whereas for the brine community, the dinoflagellate Pollarella sp. was present.

Figure 4-2: Increase of $F_{v} / F_{m}$ over the course of 5 days of the NIFT test. This measurement was done after 20min of dark adaptation but before the NIFT test started. Data are means $\pm 1 S E, n=4$ per data point)........88

Figure 4-3: Example of the control response in fluorescence parameters when a sterile seawater control was added to Brine. The arrow indicated when the control liquid was introduced. Immediately afterward there was a transient increase in $F^{\prime}$ and $F_{m}^{\prime}$..

Figure 4-4: Fluorescence response, per day, of a seawater sample to the addition of silica. Time 0 is when the nutrient was added.

Figure 4-5: Fluorescence response, per day, of a sea ice sample to the addition of silica. Time 0 is when the nutrient was added..

Figure 4-6: fluorescence response, per day, of a brine sample to the addition of silicate. Time 0 is when the nutrient was added..

Figure 4-7: Example of no response in fluorescence parameters after addition of orthophosphate to a non $P$ limited seawater sample. Time 0 (arrow) is where the nutrient was added. Similar responses were observed in sea ice samples.

Figure 4-8: fluorescence response, per day, of a brine sample to the addition of phosphate. Left y-axis florescence $\left(F^{\prime}, F_{m}\right)$, right y-axis yield, $X$-axis time in minutes. Time 0 is where the nutrient was added.

Figure 4-9: Example of no response in fluorescence parameters after addition of $\mathrm{NO}_{3}{ }^{-}$to a non $\mathrm{N}$-limited brine sample. Time 0 is where the nutrient or blank was added.

Figure 5-1: Example of no response to the addition of water using the Water-PAM. Similar results were obtained if a nutrient was not considered limiting. The blue line indicates when the nutrient was added, the arrows illustrates decrease or increase of fluorescence parameters caused by light reaching the EDU when the lid was lifted to add a nutrient.

Figure 5-2: Examples of variation in the strength of response after the addition of silica. $F$ and $F_{m}{ }^{\prime}$ increased after the addition of silica while NPQ decreased after the addition of silica. Yield ( $\left.\Phi_{P S I I}\right)$ remains constant throughout the measuring time. a) Porosira gliacialis antarctica day 9 showed a NPQ decrease to zero and 200 fluorensence untis increase, b) Porosira glacialis antarctica day 10, the NPQ decreased to around 1 while the fluorensence units increased by about 150. The blue line indicates when the nutrient was added, the arrow illustrates an increase of NPQ caused by light reaching the EDU when the lid was lifted to add a nutrient.

Figure 5-3: Frequency of nutrient response measured by water-PAM for diatoms grown under low silica concentrations $(n=4)$ over time since being placed in low Si media. A value of 4 on this scale indicates all 4 replicates gave positive responses. The maximum yield $\left(F_{v} / F_{m}\right)$ was determined each day after 20 min of dark adaptation. 
Figure 5-4: Frequency of nutrient response measured by water-PAM for diatoms grown under high silica concentrations $(n=4)$. The yield $\left(F_{v} / F_{m}\right)$ was obtained after 20 min of dark adaptation.

Figure 5-5: Example of a sample plate set-up for the I-PAM. The circles are individually selected regions of interest, which were used to monitor fluorescence signals during the experiment. The colour scale indicates the $F_{0}$ signal under 47 mol photons $\mathrm{m}^{-2} \mathrm{sec}^{-1}$ of PAR.

Figure 5-6: Nutrient response measured by I-PAM for diatoms grown under low silica concentrations $(n=4)$. The maximum quantum yield $\left(F_{v} / F_{m}\right)$ was obtained after 20 min of dark adaptation each day. 120

Figure 6-1: Difference in sea ice communities in the present and future in relation to increasing snow cover, when snow cover causes flooding of the sea ice. Error! Bookmark not defined. 


\section{List of Tables}

Table 2-1: Average abundance of algae (cells.L-1) at Turtle Rock no snow, low snow and high snow (TRNS, TRLS. TRHS), Cape Evans (CE) and Terra Nov Bay (TNB) sea ice during early the summer of 2011. Standard error in brackets.

Table 2-2: Mean percentage abundance of diatoms in the top $10 \mathrm{~cm}$ of sea ice during the summer of 2010, 2011and 2012. TR= Turtle Rock, $N S=$ no snow cover, $L S=$ snow cover $10-15 \mathrm{~cm}, H S=$ snow cover $30-40 \mathrm{~cm}$, CE= Cape Evans, $T N B=$ Terra Nova Bay.

Table 2-3: Mean percentage abundance of diatoms in the middle $10 \mathrm{~cm}$ of sea ice during the summer of 2010 and 2011. TR= Turtle Rock, $N S=$ no snow cover, $L S=$ snow cover $10-15 \mathrm{~cm}, H S=$ snow cover $30-40 \mathrm{~cm}, C E=$ Cape Evans, TNB= Terra Nova Bay.

Table 2-4: Mean percentage abundance of diatoms in the bottom $10 \mathrm{~cm}$ of sea ice during the summer from 1999 to 2012. TR= Turtle Rock, $N S=$ no snow cover, $L S=$ snow cover $10-15 \mathrm{~cm}, H S=$ snow cover $30-40 \mathrm{~cm}, C E=$ Cape Evans, TNB= Terra Nova Bay.

Table 2-5: Statistical analysis of differences in species composition between locations and years in the top of the sea ice. P-values obtained from PERMANOVA pair-wise tests. Numbers in bold show significant differences between locations.

Table 2-6: Statistical analysis of differences in species composition between locations and years in the middle of the sea ice. P-values obtained from PERMANOVA pair-wise tests. Numbers in bold show significant differences between locations.

Table 2-7: Statistical analysis of differences in species composition between locations and years in the bottom of the sea ice. P-values obtained from PERMANOVA pair-wise tests. Numbers in bold show significant differences between locations.

Table 2-8: Sea ice species composition of the bottom sea ice in McMurdo Sound measured over the past 30 years. Species are organised from high to low abundances and make up between 80-95\% of the total algal count. ${ }^{*}=$ this thesis. ${ }^{+}=$as reported by authors although note that many Amphiprora sp. have since been transferred to the genus Entomoneis sp. Note that table continues on next page.

Table 2-9: Bottom sea ice species composition measured over several years for Terra Nova Bay. Species are organised from high to low abundances and make up between 80-95\% of the total algal count. * this thesis. ${ }^{+}=$species as reported by authors but many Amphiprora sp. have been transferred in recent years to the genus Entomoneis sp...

Table 3-1: Comparison of methods for the determination of TPOC. Samples were obtained from the bottom of the sea ice at TRNS and analysed for TPOC by means of heat combustion and by combining measurements of EPS carbon, eukaryotic carbon and prokaryotic carbon.

Table 3-2: Two-way-MANOVA analysis of change in total organic carbon over time per location and position in the sea ice. Numbers in bold show a significant change in total particulate organic carbon concentration $(P<0.05)$

Table 3-3: Average abundances and biomass of prokaryotes in the sea ice. Biomass was obtained by determining abundance and calculating biovolume and multiplying this by the carbon per cell factor. Standard error ( \pm SE) is noted in the brackets. 
Table 3-4: Average abundance and biomass of algae in the sea ice. Biomass was obtained by measuring abundance and calculating biovolume multiplied by the carbon per cell factor. Standard error $( \pm S E)$ is noted in the brackets.

Table 3-5: Average biomass of EPS in the sea ice expressed as Xanthan Gum equivalents ( $\left.\mu g C . L^{-1}\right)$. Standard error $( \pm S E)$ is noted in the brackets.

Table 3-6: Linear regression between the different carbon contributors and TPOC. Numbers in bold (P<0.05) indicate a significant slope to the regression between the dependent and independent variables. 65

Table 3-7: Tukey post hoc analysis of two-way MANOVA analysis comparing TPOC in the bottom of the sea ice between locations and carbon sources. Numbers in bold show a significant change in carbon concentration $(P<0.05)$.

Table 4-1: Average ( $n=3)$ nutrient concentrations in $\mu$ mol. $L^{-1}$ of the 3 different habitats at day 1 of the NIFT experiment.

Table 4-2: Differences in response of $F^{\prime}, F_{m}$ and $\Phi_{\text {psI }}$ between the seawater control and the seawater after the addition of silica was tested by means of an independent T-test at each time point. To test for similarity in variance, the Levene's test for equality of variance was used. The T-test was corrected for this variance. In all cases, significant correlations were defined by $P<0.05$ and are indicated in bold.

Table 4-3: Differences in response of $F^{\prime}, F_{m}{ }^{\prime}$ and $\Phi_{\text {psI }}$ between the sea ice control and the sea ice after the addition of silica was tested by means of an unpaired T-test. To test for similarity in variance the Levene's test for equality of variance was used. The T-test was corrected for this variance. In all cases, significant correlations were defined by $P<0.05$.

Table 4-4: Differences in response of $F^{\prime}, F_{m}$ and $\Phi_{\text {psI }}$ between the brine control and the brine after the addition of silica was tested by means of an unpaired T-test. To test for similarity in variance the Levene's test for equality of variance was used. T-test was corrected for this variance. In all cases, significant correlations were defined by $P<0.05$.

Table 4-5: Differences in response of $F^{\prime}, F_{m}{ }^{\prime}$ and $\Phi_{\text {psI }}$ between the brine control and the brine after the addition of phosphate was tested by means of an unpaired T-test. To test for similarity in variance the Levene's test for equality of variance was used. The T-test was corrected for this variance. In all cases, significant correlations defined by $P<0.05$ are indicated in bold.

Table 5-1: Nutrient concentrations $(\mu M)$ in the growth medium at different time points for 6 different diatom cultures ( $n=4$ nutrient/time point/culture) standard error is shown in brackets. A) Cultures grown in low silica concentrations. B) Cultures grown in high silica concentrations. All other nutrients, trace metals and vitamins were the same starting concentration between the 2 experiments. All samples and nutrients tested had a significant reduction in concentration $(P<0.005)$.

Table 5-2: Cell counts $\left(10^{4}\right.$ cell.ml-1) of different diatom species over time $(n=4$ time point/species/concentration). Standard error in brackets $\pm 10^{4}$.

Table 5-3: Significance of changes in cell counts during the 10 days of the experiment based on one-way ANOVA analysis. Mauchly's Test of Sphericity was not significant and therefore sphericity was assumed. Significance was assumed at $P<0.05$ and is indicated in bold.

Table 5-4: Changes in maximum quantum yield $\left(F_{v} / F_{m}\right)$ during the 10 days of the experiment tested by oneway ANOVA. Mauchly's Test of Sphericity was not significant and therefore spherity was assumed. Significance was assumed at $P<0.05$ and is indicated in bold. 


\section{Abbreviations}

ACC Antarctic Circumpolar Current

ANOVA analysis of variances

BSi Biogenic particulate silica

C Carbon

CE Cape Evans

Chl $a \quad$ Chlorophyll $a$

DOC Dissolved organic matter

EDU Emitter detector unit

EPS Exopolymeric substances

HS High snow $(30-40 \mathrm{~cm})$

I-PAM Imaging PAM

LS Low snow $(10-15 \mathrm{~cm})$

LSi Lithogenic particulate silica

MANOVA Multivariate analysis of variance

MDS Multidimensional scaling

NIFT Nutrient induced fluorescent transients

N Nitrogen

NPQ Non-photochemical quenching

NS No snow

P Phosphor

PAM Pulse amplitude modulation

PAR Photosynthetically active radiation $(400-700 \mathrm{~nm})$

PERMANOVA Permutational multivariate of variance

$\mathrm{Si} \quad$ Silica

TNB Terra Nova Bay

TPOC Total Particulate Organic Carbon

TR Turtle Rock 


\section{Abstract}

Polar marine regions are dominated by sea ice, where large gradients in temperature, salinity, nutrients and light occur. Despite this, a rich community exists within the sea ice, consisting of prokaryotic organisms, several algal groups and small zooplankton. Prokaryotes are present in the largest abundance in the sea ice; however, diatoms dominate in biomass. Diatoms are the main primary producers within the ice and they form a vital food source for many organisms. However, factors determining species composition, abundance, spatial and temporal variability and nutrient requirement are relatively poorly understood. In order to increase understanding of these processes, an integrated approach was used in this thesis to provide an insight into the potential changes to the ecology of the Southern Ocean in relation to predicted climate change. In this thesis, I studied ice algal community structure, diversity and nutrient requirements at several locations in the sea ice of the Ross Sea, Antarctica. Though many previous studies have focussed on these organisms, this is the first study to I) integrate recent and historical data collected over 30 years and to compare spatial and temporal differences in sea ice communities, II) use the near real time nutrient induced fluorescence transient (NIFT) method to study nutrient limitation in sea ice and further develop this method for use with the imaging pulse amplitude modulator (I-PAM), III) show that Antarctic diatoms may be more susceptible to silica limitation than previously thought, despite the fact that the silica concentration in the Southern Ocean are relatively high. Results from these studies provide important new information on community structure and how it is influenced by and responds to the environment.

Sea ice communities are spatially and temporally highly variable. The highest biomass is found in the bottom $10 \mathrm{~cm}$ of the sea ice, where diatoms formed the largest carbon source $(>90 \%$ of the total particulate organic carbon, TPOC). An analysis of algal community composition in the Ross Sea over the previous 30 years revealed some changes in species abundances over time, and in particular the tube-forming diatom, Berkeleya adeliensis, has become increasingly prominent in the last $10-15$ years. My studies also indicated that variability in species composition is mainly due to reduced PAR irradiance and changing nutrient levels. The composition and abundance of the bottom sea ice diatom community was heavily influenced by snow cover, however, the 
abundance of bacteria was unaffected and linear regression models showed an uncoupling of the microbial loop in the bottom of the sea ice. Exopolymeric substances (EPS) on the other hand, were strongly correlated with algal abundance both in relation to light levels and seasonally. Particularly in the interior sections of the ice, EPS appears to play a much more important role than in bottom ice. EPS often formed $90 \%$ of the TPOC in these regions but in the bottom ice, its contribution was around $15 \%$. If the EPS excreted by algal cells creates a protective environment for microorganisms, then the high EPS to algal ratio found in the interior of the sea ice may reflect the harsh environment encountered there.

The internal sea ice habitat may be particularly vulnerable to nutrient limitation due to the lack of flushing with the nutrient rich waters below. This thesis documents a nutrient limitation for silicate and phosphate in internal sections of the ice during early summer. Interestingly, this limitation occurred at concentrations that were relatively high compared to the rest of the world's oceans. A comparison between Arctic and Antarctic diatoms showed that Antarctic diatoms became silica limited at concentrations that were sufficient for Arctic strains of the same diatom species.

This study showed that sea ice communities are highly temporally and spatially variable. Furthermore, light availability and nutrient limitation play a major role in determining species composition and abundance. These studies identified several 'key' species (B. adeliensis, Fragilariopsis spp. and Entomoneis kjellmannii) as important contributors to primary production and changes in their abundance are related to photosynthetic ally active radiation (PAR) or nutrient changes. Current climate models predict a possible increase in precipitation and stratification of seawater, and a reduction in the extent and thickness of sea ice. This will influence light levels reaching the sea ice and may modify nutrient concentrations in sea ice. If these scenarios do occur in the future, they will have major impact on the ice communities. 



\section{Chapter 1 General introduction}

\section{The polar environments}

A major characteristic of both polar regions is the immense scale of the sea ice. The Southern Ocean ecosystem covers approximately $10 \%$ of the world's oceans, making it the largest marine ecosystem in the world (Arndt et al. 2009). The Southern Ocean has a greater seasonal variability than the Arctic basin and the extent of its sea ice is larger but also reduces more during the Austral summer months (Moline et al. 2008). Sea ice surrounding the Antarctic continent varies in extent from $19.4 \times 10^{6} \mathrm{~km}^{2}$ in winter to $3.5 \times 10^{6} \mathrm{~km}^{2}$ in summer(NSIDC 2012), while the ice extent and retreat in the Northern Polar Region ranged from $15.2 \times 10^{6} \mathrm{~km}^{2}$ to $3.6 \times 10^{6} \mathrm{~km}^{2}$ in 2012 (NSIDC 2012)(Figure $1-1)$.

The Southern Ocean is bound at the poleward edge by the Antarctic continent and at lower latitudes by the Polar Front (Antarctic Convergence). The Antarctic Circumpolar Current (ACC), which forms a continuous belt around the continent, is unique in the world's oceans, and reaches as far north as $\sim 50^{\circ} \mathrm{S}$ in the Atlantic and Indian Oceans and $\sim 60^{\circ} \mathrm{S}$ in the Pacific Ocean (Kennish 2000b). The Arctic sea ice extends south to $44^{\circ}$ latitude in northern Japan and in the Atlantic section of the Arctic, but lies north of $70^{\circ}$ in the Barents Sea (Smetacek and Nicol 2005). The greatest density of sea ice in the Arctic lies north of the Canadian archipelago and Greenland (Smetacek and Nicol 2005).

The Arctic Ocean is characterized by a wide variety of oceanographic conditions. The seas of the Arctic regions are diverse: some are broad shallow seas and some are deep basins; some regions are covered by ice year-round while others are never covered (Carmack and Swift 1990). Some of the water masses are the saltiest in the world, while the upper layers of the Arctic Ocean are among the freshest, owing to the combined influence of river inflow, ice melt, excess of precipitation over evaporation, and inflow of low salinity water through the Bering Strait (Carmack and Swift 1990). Although some areas in the Arctic might be high in nutrients due to river run offs, most are nutrient starved. The Arctic Ocean is poor in nutrients because strong, haline stratification prevents mixture of deep, nutrient-rich water. These factors result in an ocean with one 
of the lowest nutrient concentrations the world (Hegseth 2001). Thus, there is no one 'typical' Arctic water column but a full range of oceanographic conditions, although very shallow shelves are present throughout the region (Arndt et al. 2009). In contrast, the Southern Ocean is more uniform, compared to the Arctic Ocean. There is little temperature variability in the ACC: the total temperature variation is only $4-5^{\circ} \mathrm{C}$ (Knox 2009c).
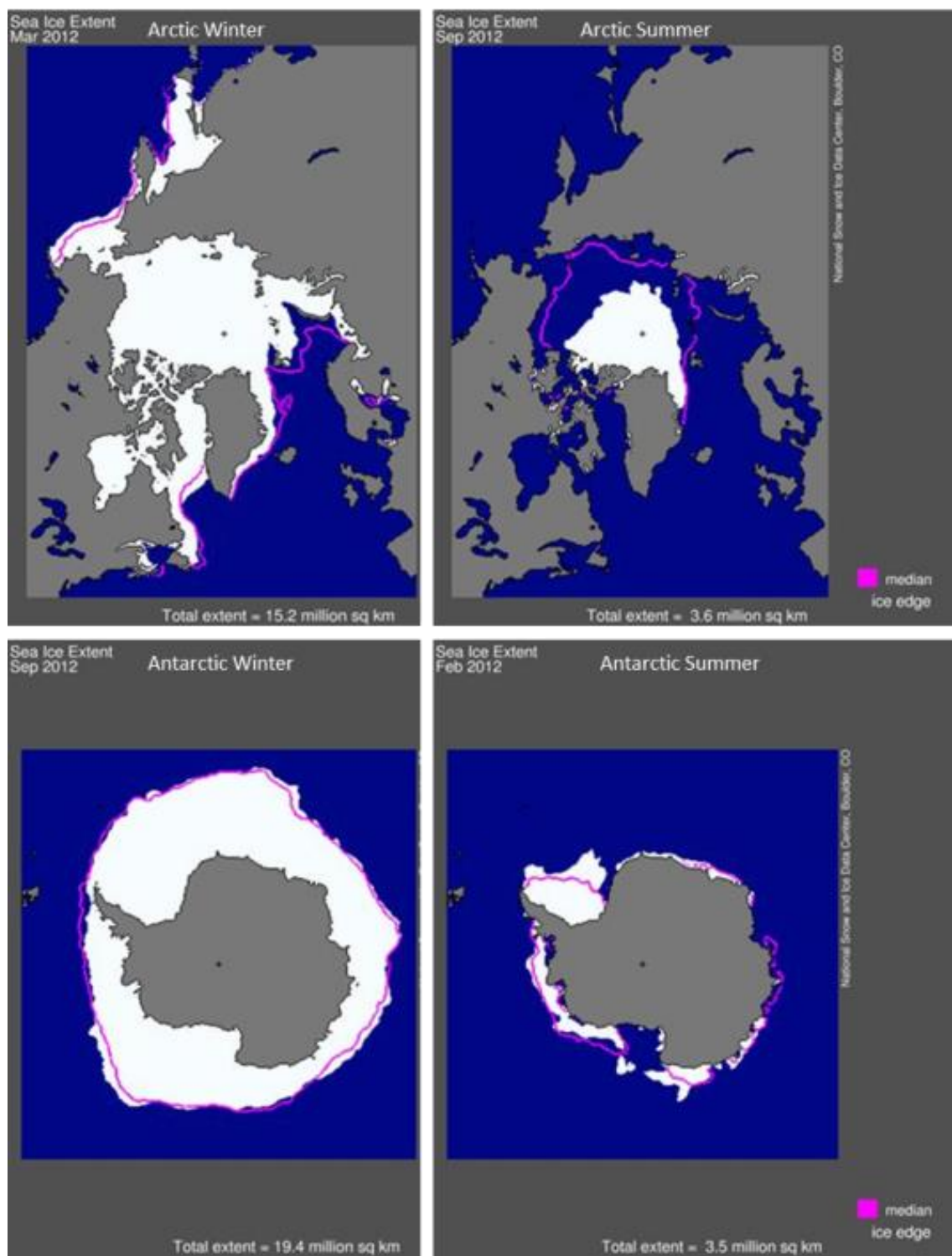

Figure 1-1: Differences between summer and winter sea ice extent for the Arctic and Antarctic (NSIDC 2012). 
Despite the general similarities in the annual cycle in the two polar regions, significant differences can be found in the physical environments of the two polar regions. Antarctic sea ice is predominantly less than a year old. In the Arctic and Sub-Arctic, there is a large range of single and multi-year ice (Squire 1990; Kennish 2000b). The pronounced seasonality in the Antarctic sea ice cover, the generally younger ice and the absence of shallow shelves effectively hinder autochthonous sympagic (= iceassociated) fauna from becoming established, and it is therefore colonised from the pelagic realm (Arndt et al. 2009). This contrasts with the Arctic where sympagic fauna establish from the benthos due to the shallow shelf and the fact that Arctic sea ice can be 5-7 years old (Arndt et al. 2009). About 50\% of the Arctic sea ice floes survive summer melting and can reach thicknesses of more than $2 \mathrm{~m}$ (Comiso 2010). In the Arctic, the sea ice melts at the surface, forming melt pools, increasing absorption of solar radiation and enhancing the melt process. In the Antarctic, melting occurs from contact with the ocean on the bottom and sides of the ice (Moline et al. 2008).

\section{Sea ice formation}

Sea ice formation and retreat are the dominant processes that shape the ecology of polar regions (Knox 2009c). Sea ice provides a stable platform for ice algae blooms to establish and this platform influences the life cycles of many high latitude marine organisms. Potential changes in extent, thickness and duration of sea ice all influence primary productivity and therefore all levels higher in the food chain. The annual formation and retreat of sea ice is highly dynamic and variable (Stammerjohn et al. 2008). It plays a crucial role in the polar environment and influences the global climate system. The initial stage of sea ice formation generally begins in the autumn through a gradual process. First, the sea reaches a slight super-cooling that causes small platelets and needles termed frazil ice to form (Petrich and Eicken 2010). Second, continued freezing results in the formation of grease ice, a soupy mixture of unconsolidated frazil crystals. Once the grease ice formation exceeds 30-40\%, the transition to a solid cover begins. In the presence of a wave field, the transition is marked by the formation of pancakes; rounded masses of semi-consolidated slush 0.3-3.0 m in diameter. Wind and ocean swell causes pancakes to bump and grind against one another, resulting in a semi-consolidated ice cover composed of ice discs with raised edges that are from a few 
centimetres to more than $10 \mathrm{~cm}$ thick. These pancakes eventually congeal into larger units by means of frazil growth and/or freezing of congelation ice to form an ice sheet (Petrich and Eicken 2010).

During the formation of sea ice, nutrients, salts and other dissolved matter are excluded from the sea ice matrix and collect in brine channels and pockets. Some of this brine may be released into the waters below. Thus, salinities and nutrient concentrations in newly formed brine may be significantly higher than in seawater, with salinities reaching as high as 155 ppt (Squire 1990; Thomas et al. 2010). The volume and salinity of brine entrapped in sea ice varies directly as a function of temperature. As sea ice grows and the brine pockets become colder, more salts and nutrients precipitate out of the brine due to gravity drainage (Thomas et al. 2010).

Dieckmann et al. (1991) measured the concentrations of nutrients within sea ice brine and found nutrient depletion to be widespread, a circumstance they attributed to widespread internal biological activity. When sea ice forms, there are still substantial microbial populations in surface waters left over from the preceding spring blooms that become incorporated into the sea ice. In the polar summer, sea ice organisms experience $24 \mathrm{~h}$ daylight, while in the winter months the sun never rises above the horizon. Light availability at the bottom of the ice gradually decreases as the ice thickens (Gleitz and Thomas 1992) and snow cover increases (Knox 2009c). Sea ice, and especially its snow cover, significantly reduces the incoming radiation. PAR (photosynthetically active radiation) beneath summer sea ice can be $<1 \mu$ mol photons $\mathrm{m}^{-2} \mathrm{~s}^{-1}$ (K.G. Ryan, pers. comm.) compared to $1700 \mu \mathrm{mol}$ photons $\mathrm{m}^{-2} \mathrm{~s}^{-1}$ at the surface (McMinn et al. 1999). Therefore, ice algae are adapted to extremely low light irradiance (2-10 $\mu \mathrm{mol}$ photons $\left.\mathrm{m}^{-2} \mathrm{~s}^{-1}\right)$ (McMinn et al. 2007; Arrigo et al. 2010) yet irradiances are usually sufficient for net photosynthesis during the spring and summer, except when snow cover exceeds $\sim 0.3 \mathrm{~m}$ (Arrigo et al. 1991; Arrigo et al. 2003). Temperature can be as low as $-16^{\circ} \mathrm{C}$ at the upper part of sea ice but rises near the bottom to attain temperatures similar to the seawater below (Knox 2009b). Sea ice therefore undergoes profound changes in both spatial and temporal abiotic factors; steep gradients in salinity, temperature and nutrient concentrations occur under a highly variable light/dark cycle. The interior of the sea ice may present some of the harshest environments on the planet for photosynthetic organisms. 


\section{The sea ice habitat}

Despite the harsh conditions present in sea ice, it harbours diverse communities of bacteria, archaea, viruses and eukaryotes such as diatoms (Bacillariophyceae) prymnesiopytes, chlorophytes, dinoflagellates (Dinophyta), chrysophytes, ciliates, Foraminifera, protists, and small invertebrates (Lizotte 2001). All these organisms provide a food source for organisms such as microfauna, meiofauna, and cryopelagic fauna present in the water layer immediately below the ice. Three categories of floristic sea ice assemblages are observed based the position of the maximum biomass in the ice column: surface assemblages, interior assemblages, and bottom assemblages (Horner 1990). These assemblages can in turn be further divided based on their origin.

At the surface, 2 different assemblages can be present (Figure 1-2). Sea ice is regularly overlaid by snow. Along cracks in the ice and at the ice edge, the snow-ice interface may become flooded with seawater and forms infiltration assemblages. In addition, surface melt pools occur when the surface of the ice thaws. These assemblages are mainly found in pack ice (Arrigo et al. 2010).

The most common interior habitat occurs in brine channels or bands between ice crystals throughout the interior of the ice. They often form long vertical tubes that allow vertical movement of the brine through the ice. In the spring, the channels become connected to form a network within the ice (Horner 1990). Brine is generally characterized by low biomass due to a combination of low nutrient availability, high brine salinity and low temperatures (Mock 2002). The highest algal biomass accumulation known for internal communities is $50 \mathrm{mg}$ Chl $a \mathrm{~m}^{-2}$ (Garrison, unpublished), with most ranging from $0.5-30 \mathrm{mg} \mathrm{Chl} a \mathrm{~m}^{-2}$. Brine channels communities are dominated by diatoms, and dinoflagellates (Stoecker et al. 1998) such as Polarella sp. (this thesis) as well as a wide range of bacteria (Brinkmeyer et al. 2003; Martin et al. 2008; Deming 2010). These sea ice organisms are physiologically well acclimated to a dynamic salinity regime enduring both hyper- and hyposaline stress (Ralph et al. 2007). Brine channels and pockets provide their inhabitants with excellent 
protection against grazing since only a few small crustaceans and protozoa can reach them (McMinn and Hegseth 2007). Interior band assemblages are formed either by accretion of new ice under a previously formed bottom ice algal layer, or by the incorporation of planktonic algae at the time of first freezing of surface waters (Horner 1990). These occur within the ice matrix at various levels and several may occur within a single ice column. Band assemblages are characteristic of multiyear ice flows and when rafting of ice-flows occur.

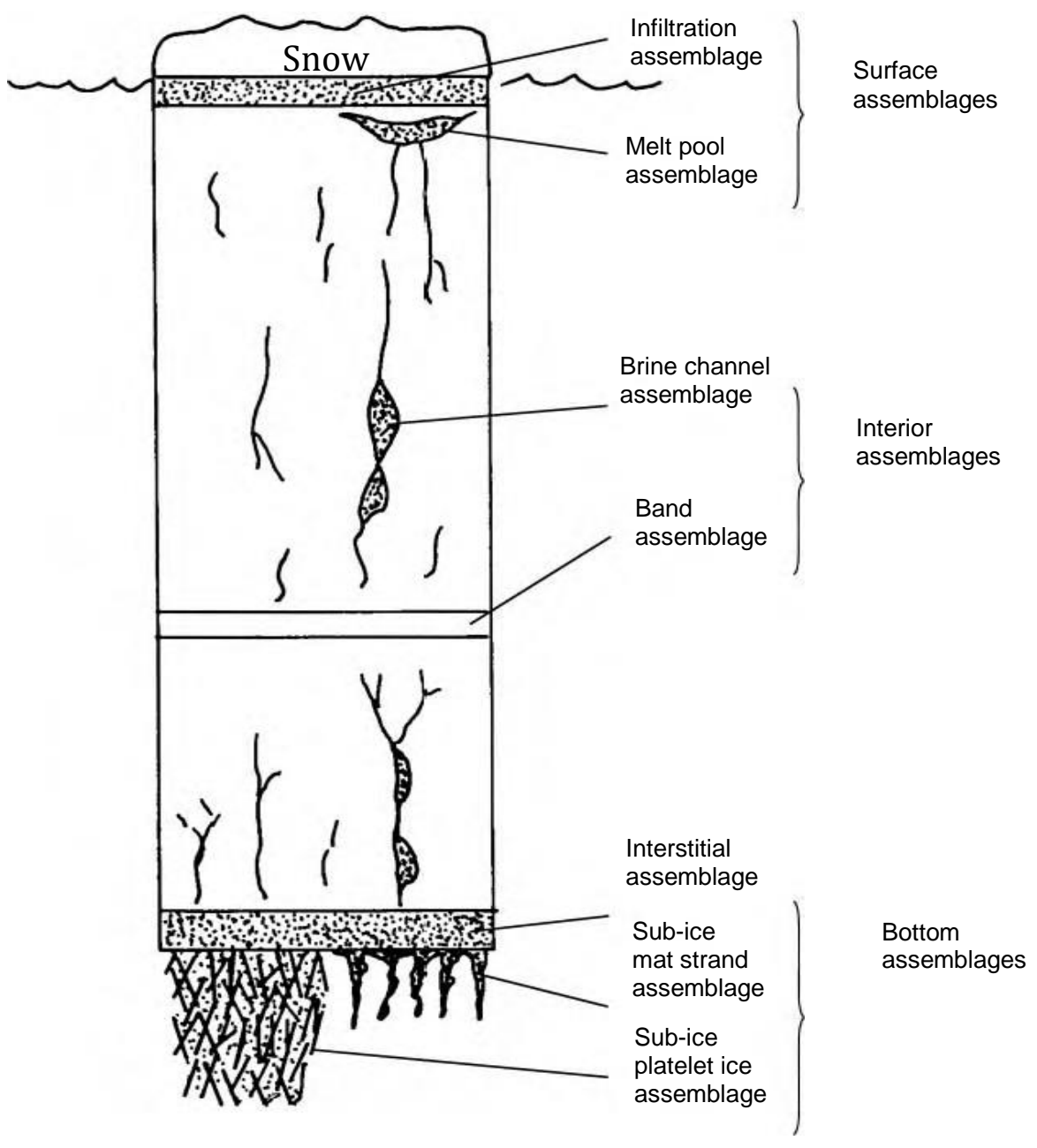

Figure 1-2: Schematic representation of the different kinds of microalgae assemblages associated with Antarctic sea (Knox 2009b).

The greatest fraction of sea ice microalgae often resides in the bottom $20 \mathrm{~cm}$ of the ice sheet where environmental conditions are generally stable and more favourable for 
growth. Bacteria numbers can range from $1.5 \times 10^{5}$ to $3 \times 10^{7} \mathrm{ml}^{-1}$ depending on time of years and ice type (Krembs and Engel 2001; Gowing et al. 2004) and algal abundances from as low as $<10^{1}$ up to $>10^{6}$ cells $\mathrm{ml}^{-1}$ (Arrigo et al. 2010) have been reported. Diatoms are important members of these bottom assemblages due to their abundance, influence on nutrient cycles, and as food for higher trophic levels. Large variations in bacterial abundance occur in the bottom of the sea ice. Bottom assemblages are the most common and well-studied assemblages (Sullivan and Palmisano 1984; Grossi and Sullivan 1985; Arrigo et al. 1997; McMinn et al. 1999; Garrison et al. 2005; Ryan et al. 2006; Mangoni et al. 2009a; Mangoni et al. 2009b; McMinn et al. 2010) and can be further divided in to three assemblages: interstitial-, sub ice-, and sub ice-platelet assemblages (Figure 1-2). Interstitial bottom assemblages occur in the bottom of the ice column and are usually associated with a solid hard layer of bottom congelation ice. These particular assemblages are most characteristic of landfast ice. Pennate diatoms (Lizotte 2001; Ryan et al. 2006) and bacteria (Martin et al. 2008; Deming 2010) are abundant in this assemblage. In some areas of the Arctic and Antarctic, there may be a sub-ice assemblage, consisting of algae floating directly beneath the sea ice or attached to the underside of the ice and forming strands that trail into the water column (Arrigo et al. 2010). Strands can vary from 10 to $15 \mathrm{~cm}$ early in the season to 50-60 cm later in the season (Knox 2009a). The most common sub ice assemblage in Antarctica is formed by the pennate diatom Berkeleya adeliensis and in the Arctic by the centric diatom Melosira arctica but other species such as Amphiprora kufferathii, and several species of Nitzschia (Arrigo et al. 2010) are also found in sub-ice assemblages. Platelet ice layers are loose aggregations of platelets that accumulate under sea ice close to the ice shelfs. Layers up to $5 \mathrm{~m}$ thick have been reported (Knox 2009a). These platelets provide a favourable environment for the development of microbial communities and can support dense diatom and bacterial assemblages which have been extensively studied (Palmisano and Sullivan 1983; Sullivan and Palmisano 1984; Ackley and Sullivan 1994; Arrigo et al. 2000).

\section{Primary production}

Primary production in the Antarctic sea ice peaks in early spring (Meiners et al. 2012); the time of year when light is sufficient for growth and there is still an extensive sea ice 
cover. During this period diatoms often dominate in biomass, while bacteria dominate in abundance (Meiners et al. 2004). This abundance in biomass declines by the end of summer when the sea ice melts and eventually drops to zero at the end of May (Arrigo and Thomas 2004). The onset of algal growth in spring is triggered by an increase in available light. Within the sea ice, microalgae such as diatoms fulfil a vital role in the food web contributing over $10 \%-30 \%$ of the total primary production in the Southern Ocean (Legendre et al. 1992; Arrigo et al. 1997; Arrigo et al. 1998b).

The contribution of sea-ice algae to the total primary productivity of the polar ecosystem is poorly understood. More accurate estimates of organic carbon budgets within the sea-ice provide a way of describing the overall functioning of a marine system (Kuzyk et al. 2009). Total particulate organic carbon (TPOC) levels in sea ice may be very high (1.5-4.0 gC.m ${ }^{-2}$ ) (Hegseth 1992; Krembs et al. 2002). This organic carbon in ice comes from various sources, detritus, non-photosynthetic bacteria, viruses, ice algae and zooplankton and carbohydrate excretion products. Sea ice algal carbon makes up 40\%-80\% of TPOC (Gradinger et al. 1999; Knox 2009b, this thesis), whereas EPS can contribute 14-32\% (Meiners et al. 2004; Riedel et al. 2006) and, bacteria 2-3\% (Riedel et al. 2006) of the TPOC. However, these contributions can vary widely during the season (Riedel et al. 2006), and this may be due to nutrient deficiency and other types of physiological stress. The ratio of bacterial carbon versus algal carbon can be used as an indication of activity, health, nutrient supply, and physiological status of sea ice communities (Tamelander et al. 2009). Generally, in marine environments, bacterial abundance tends to increase with increasing algal biomass. For example, Sherr et al. (2001) found that bacterial abundance in the Arctic Ocean increased in tandem with phytoplankton biomass during spring and summer. However, bacterial biomass generation from algal-derived DOM in Antarctic waters is highly variable across seasons and habitats. A tight coupling of bacterial and algal biomass can be expected during the spring to autumn when sufficient light is available to support high amounts of algal biomass and thus high levels of DOM for bacterial consumption (Steward and Fritsen 2004). However, within sea ice the coupling between phytoplankton and bacteria is variable (Meiners et al. 2004). Several hypotheses have been proposed to explain the uncoupling of the microbial loop in sea ice. 1) grazing 
pressure (Pusceddu et al. 2009), 2) increased prokaryotic mortality due to viral infection (Deming 2010), and 3) the release of allopathic substances by sea ice algae inhibiting prokaryotic carbon production (Pusceddu et al. 2009). However, not much is known about the actual infection rate (Deming 2010) nor about allopathic factors influencing the physiological state in which the prokaryotic community can incorporate carbon. Uncoupling is seasonally highly variable (Steward and Fritsen 2004) and small changes in the environment can favour different ways to uncouple the system (Steward and Fritsen 2004; Pusceddu et al. 2009; Deming 2010).

Diatoms, and in lesser amount bacteria, produce carbohydrate-rich exopolymeric substances (EPS), that consist mainly of simple sugars, and other photoassimilates of lipids, nucleic acids, and proteins (Underwood et al. 1995; Underwood et al. 2010). High amounts of these compounds (up to 70-80\% of algal biomass) have been measured in Antarctic sea ice from the Bellinghausen Sea (Meiners et al. 2004). This excretion product may alter the surrounding environment, creating protective microhabitats for growth (Krembs et al. 2011). EPS can protect against freezing caused by the low temperatures as well as protection from high salinity (Underwood et al. 2010). It is ecologically highly significant because the exopolymers can be utilized by bacteria, meiofauna and macrofauna as a carbon source (Decho and Moriarty 1990).

The release of high concentrations of biological matter from the ice upon melting is an important event in the seasonal sea ice cycle. This material can be in the form of dissolved or particulate organic matter. The fate of this material has consequences for biogeochemical cycling, bentho-pelagic coupling and ultimately for the sequestration of organic carbon into sediments (Armand et al. 2008). Released sea ice organisms may act as "seed" populations for ice edge plankton blooms (Lizotte 2001). This seeding is often associated with high rates of grazing by krill and other zooplankton that in turn, attract intense feeding by higher trophic levels (Arrigo et al. 1998a). However, such seeding is not ubiquitous, but is dependent among other things, on interactions of prevailing winds and vertical mixing. The "seeding hypothesis" states that the algae released from melting sea ice during the spring and summer are the seed stock for the 
subsequent blooms often observed in the melt water stabilized water column of the marginal ice zone (Lizotte 2001). The primary evidence for this view is based on the similarity of algal species composition in the water column and nearby ice (Lizotte 2001), although this is largely circumstantial evidence. However, Guglielmo et al. (2000) argued that bottom ice assemblages are typically dominated by benthic species that are not found in pelagic blooms. In vitro studies by Mangoni et al. (2009b) showed that during the transition from platelet ice to planktonic conditions, a significant compositional change occurred in the diatom assemblages, where small centric and in particular pennate diatoms may play an important role in seeding pelagic and/or under-ice blooms during the austral spring. Large diatoms, such as Amphiporora kufferathii, are more likely to sediment to deeper layers and thus be a resource for benthic filter-feeders (Mangoni et al. 2009b). Furthermore, they suggest that several pelagic species may be photosynthetically limited under the very low irradiances beneath the ice cover, and are ready to bloom as soon as the light limitation is relaxed when the ice melts (Mangoni et al. 2009b).

\section{Nutrients}

The profound affect of phytoplankton on nutrient cycling in the marine environment necessitates a better understanding of algal physiology in order to elucidate marine biogeochemical cycles. The concentration of macro nutrients in surface waters south of the Polar Front is much higher than that found in other oceanic waters (Knox 2009c). High concentrations of nutrients have been recorded in the Southern Ocean depending on location and season (Thomas and Dieckmann 2002b). During spring -summer, the average nutrient concentrations in the bottom of the sea ice range between 5-75 $\mu \mathrm{M}$ silicate, 0.25-5.6 $\mu \mathrm{M}$ nitrate, and 0.2-3.5 $\mu \mathrm{M}$ phosphate (Dieckmann et al. 1991; Hegseth and Von Quillfeldt 2002; Vancoppenolle et al. 2010). Nutrient rich water upwells at the Antarctic Divergence, spreading northward and ultimately downwells at the Polar Front. Early research in the Southern Ocean concluded that in general, nutrients probably do not limit the growth of sea-ice microalgal assemblages (Meguro et al. 1967). However, this view has been challenged by several authors e.g. Dieckmann et al. (1991), McMinn et al. (1999), Thomas and Dieckmann (2002a), and Gradinger (2009), 
who concluded that nutrient limitation could have significant effects on the biochemical composition of sea-ice assemblages.

\section{Silicon}

The total amount of dissolved silica (silicon or silicic acid) present in the world's ocean

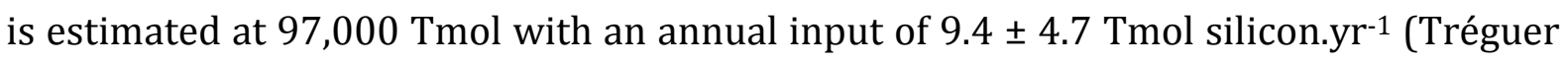
and De La Rocha 2011). The average silicon concentration is about $70.6(<2$ to $>160)$ $\mu \mathrm{M}$, (Tréguer et al. 1995). Dissolved silicon is regenerated by the dissolution of siliceous skeletal remains, while silica is released from quartz, feldspar, and clay minerals, and hydrothermal vents at the seafloor (Kennish 2000a). The surface waters of the Southern Ocean have one of the highest concentrations of silicic acid in the world; these high concentrations are due to the large numbers of hydrothermal vents in the region and upwellings that bring silicic acid to the surface (Tréguer et al. 1995). Diatoms tend to dominate sea ice blooms as well as pelagic blooms when nutrients are high (Annett et al. 2010), and they outcompete other phytoplankton species (Arrigo et al. 2000). Silica is the nutrient most likely to limit diatom growth in the advanced stages of a sea ice bloom (Dieckmann et al. 1991), and only after this nutrient is depleted do other phytoplankton species take over (Nelson and Treguer 1992). Autotrophic flagellates form the largest component of this latter group (Dieckmann et al. 1991). Diatoms absorb silicon in seawater as dissolved silicic acid $\left(\mathrm{Si}(\mathrm{OH})_{4}\right.$ ) (also known as biogenic silica, BSi) (approx. 97\%), and anionic silicate ( $\mathrm{SiO}(\mathrm{OH})^{-3}$ ) (approx. 3\%), also known as lithogenic particulate silica (LSi)(Kristiansen and Hoell 2002). BSi is incorporated into the cell wall (frustule) as hydrated glass $\left(\mathrm{SiO}_{2} \cdot \mathrm{nH}_{2} \mathrm{O}\right)$ (Armbrust 2009). Diatoms, due to their high abundance and their critical dependence on $\mathrm{Si}$, are largely responsible for the downward fluxes of biogenic silica. Specific trans-membrane proteins (Martin-Jezequel et al. 2000) actively transport silicic acid against large concentration gradients (Mock et al. 2008). It is generally believed that the frustule accounts for all but a small fraction of the silicon in diatom cells (Martin-Jezequel et al. 2000).

The frustule of a diatom is not crystalline silica (Kroger 2007), although it shows highly regular features such as patterns, ridges, and tubular structures. Ridges and tubular structures are genetically controlled, but external factors can influence the density and 
pore size of the frustules (Vrieling et al. 2007). These factors can also cause diatom sizes to be reduced by as much as $50 \%$, which often causes changes in shape as well (Bona et al. 2009). The cell wall is produced in an acidic silica-deposition vesicle and encased in an organic matrix that is rich in proteins and sugars, preventing the silica from dissolving in seawater (Armbrust 2009). From the few available datasets, a comparison of algal populations from both polar sea ice environments has suggested a major difference in their chemical compositions. The content of BSi is 9-10x higher in Antarctic sea ice diatoms than in the Arctic species ( $\mathrm{Si} / \mathrm{C} 0.46$ versus 0.05 ) (Hegseth 2001, E. Hegseth pers. comm.). The reason for this is undoubtedly that dissolved BSi

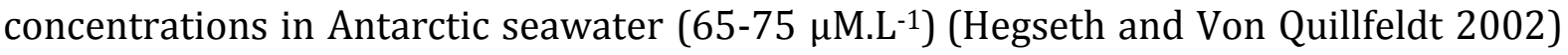
are also 9-10x higher than in the Arctic (2.3-6.5 $\mu{\left.\mathrm{M} . \mathrm{L}^{-1}\right)}^{-1}$ (Hegseth 1992). This indicates a long-term adaptation of the algal cells to the nutrient concentrations of seawater. Due to the large geographical variation in the Arctic regions this might not hold true for the entire Arctic but it does apply to the Barents Sea and Fram Strait (Hegseth 2001).

The uptake of silicate by the diatom cell is not uniform with time, but takes place mainly at cell division (Paasche 1973a). Thus, there is likely to be a certain minimum silicate concentration below which successful valve formation and hence, continued cell division and growth, cannot take place (Paasche 1973a). When silicic acid concentrations are low enough to limit uptake, cells will reduce their rate of silicification so that growth rates can be sustained in spite of the decreased silica availability (Nelson and Treguer 1992). This results in diatoms growing at near maximum growth rates, even if the dissolved silicate is well below saturation point.

Smaller diatoms might be better equipped against grazing because a higher mechanical strength is required to break the frustules (Hamm et al. 2003). Thick walls may offer an advantage to the cells in terms of rigidity and protection from grazing (Hamm et al. 2003). The degree of silicification varies widely in natural diatom populations (Paasche 1973b; Timmermans and Wagt 2010). This makes diatoms capable of outgrowing other species, and only when nutrients become severely limited do other species take over. This may occur especially towards the end of a bloom or in waters that are generally 
poor in nutrients (Sukhanova et al. 2009; Annett et al. 2010). Nelson and Treguer (1992) suggested that Antarctic diatoms may exhibit a much lower affinity for silicate than diatoms from other sectors of the world's oceans. This indicates that diatom growth could be limited by a silicic acid deficiency at concentrations that are normally saturating everywhere else in the world. However, a higher growth rate was not observed when silicic acid was added at high concentrations to a Southern Ocean phytoplankton bloom (Nelson et al. 1989). This could suggest that these blooms are not silica limited and other factors might limit the maximum growth rate, such as light. Silica uptake in heavily influenced by available iron (Marchetti and Harrison 2007; Marchetti and Cassar 2009). Iron can be high in the Ross Sea, up to 3.5 times higher than in other parts of the Southern Ocean (Fitzwater et al. 2000), however It can be rapidly depleted by plankton blooms (Arrigo et al. 2003; Arrigo and van Dijken 2004) and is often limiting in the Ross Sea polynya from December-February (Sedwick et al. 2011). This iron limitation is depended on season, wave action and ice time melt, since sea ice bring iron into the water column (Sedwick et al. 2011, Arrigo et al. 2003). Therefore early in the season iron does not seem to be limiting in sea ice of the Ross Sea.

\section{Climate change in polar regions}

It is predicted that climate change will be most severe in the polar regions (Smetacek and Nicol 2005; Turner and Overland 2009; Doney et al. 2012). For instance, the rate of polar warming in the Arctic is approximately 2 times the global mean warming (Turner and Overland 2009). Since 2000, all months show increased temperature causing an earlier ice melt in the Arctic. This has led to an increase of absorption of solar radiation and thus an increased temperature, resulting in the dramatic loss of Arctic sea ice extent in 2007 and 2012 and significant losses in the years in between (Stroeve et al. 2012). Climate change is expected to cause broad scale warming across the Arctic and Antarctic, with greater high-latitude precipitation and a reduction in the extent of the sea ice (Turner and Overland 2009). However, due to topographic differences and the different distributions of land and sea in the two polar regions that cause differences in atmospheric and oceanographic conditions, the responses will vary (Turner and Overland 2009). Warming is not spatially uniform due to varying ocean circulation, changes in wind patterns, and interaction with natural modes of climate variability such 
as El Niño/Southern Oscillation (ENSO) and the North Atlantic Oscillation (Doney et al. 2012). High inter-annual and decadal temperature variability in both polar regions makes detection of trends difficult. The future of the Antarctic sea ice, and to an extent the Arctic sea ice, have been the subject of large uncertainty and debate because of the lack of long-term in situ measurements over the Southern Ocean and the interior of the Antarctic continent (Walsh 2009).

Several changes have already been reported for the Arctic region such as an increase in river discharge, rising air temperatures and greater snowfalls (Turner and Overland 2009). Sea ice prevents the direct contact between the relatively warm ocean and the colder atmosphere. Warming is documented for all seasons leading to earlier melt onset (Stroeve et al. 2012). A rapid retreat of ice cover results in thinner first year ice the next spring. This in turn is more vulnerable to melting in summer, and thus enhancing the ice-albedo feedback (Stroeve et al. 2012). The ice-albedo is defined as: "the fraction of incident short-wave radiation reflected from the surface" (Thomas et al. 2010). Ice reflects more irradiance back but water absorbs it, increasing the temperature of the water (Moline et al. 2008). Predictions suggest that in the summer, the Arctic Ocean will be nearly ("nearly" is defined as a sea ice extent of less than 1.0 million $\mathrm{km}^{2}$ (Wang and Overland 2012) sea ice free in about 30 years (Kerr 2009).

An increase in the temperature of the ACC has been reported (Turner and Overland 2009), as well as a strong increase in air temperature (Steig et al. 2009) and large glacier losses (Rignot et al. 2008) in the Antarctic Peninsula and Western Antarctic. In contrast, at the Ross Ice Shelf a small gain in glacier mass was observed (Rignot et al. 2008), as well as a cooling over much of east Antarctica in recent decades (Steig et al. 2009). The present consensus is that the major factor contributing to the recent cooling over the east Antarctic continent has been the strengthening of the Southern Annular Mode (circumpolar Westerlies) in association with stratospheric ozone depletion (Walsh 2009). This will likely not continue and several changes have been suggested. Likely changes expected over a period of several decades include: thinner ice cover, a decrease in total ice extent of the Southern Ocean and a change in the timing of advance 
and retreat of sea ice that will directly influence blooms in the marginal ice zone (Turner and Overland 2009), and increased stratification (Arrigo et al. 1999). These changes will impact primary production and a $25 \%$ loss of sea ice over the next century would increase primary production in the Southern Ocean by approximately $10 \%$, resulting in a slight negative feedback (Arrigo and Thomas 2004). However, a switch to non-diatom species is also possible due to the increased stratification of surface waters preventing mixing with the nutrient rich deep water layers resulting in reduction in the availability of nutrients (Arrigo and Thomas 2004). Diatoms have relatively low surface to volume ratios resulting in a high carbon content but, this means that they require nutrient-rich conditions for growth in contrast to smaller phytoplankton, such as nanoor pico-plankton, with higher surface to volume ratios (Sarthou et al. 2005). This switch to non-diatom species may also influence the seeding of the ice edge bloom, which is mainly diatoms (Arrigo and Thomas 2004) and forms a valuable food source for other organisms higher up the food chain (Lizotte 2001).

Although the two polar regions show differences in climate change, it is estimated that by the mid to late 21st Century, the similarities will be greater than the differences (Holland and Bitz 2003). The projected warming in the 21st Century is somewhat smaller for the Antarctic than for the Arctic polar cap (Walsh 2009). However, while our understanding of the mechanisms driving these changes is improving, the complex interactions between the atmosphere, ocean and cryosphere pose difficulties in making reliable predictions of how the Antarctic climate will evolve over the next century. Climate models predict strong warming and circumpolar sea ice retreat around Antarctica over the next century (Schofield et al. 2010).

\section{Aims and thesis overview}

In this thesis, I try to answer the question:

How do nutrients and snow cover affect sea ice algal communities and what are the future implications in relation to climate change? 
To answer the main question, several sub-questions will be studied in the following chapters:

Can possible "key" algal species be identified that will play an important role in climate change?

How are these species influenced by changes in snow cover?

How does nutrient limitation influence algal community composition?

To obtain the answers, I examined species composition, carbon sources and nutrient requirements in sea ice communities from the Ross Sea, Antarctica. A more in-depth knowledge of this will increase our understanding of ice algal primary production, community dynamics and physiology, and will aid in predictions of diatom responses to climate change and allow us to make a better assessment of overall primary production in sea ice and the factors limiting it.

Chapter 2 examines the spatial and temporal variability of sea ice algal communities. This study brings together 30 years of data on sea ice algal community composition in the Ross Sea, Antarctica. Drivers for sea ice algae abundance and community composition will be identified and possible "key" species that can be used to assess climate change are proposed.

Chapter 3: The general objectives of this chapter were to (1) assess spatial variability of the carbon sources in sea ice, (2) identify relationships between sea-ice algal biomass and bacterial abundance under varying snow cover. I hypothesized that snow cover influences the TPOC and in particular that the algal biomass (which is dependent on light for photosynthesis) causes additional changes in EPS concentration. 
Chapter 4 investigates nutrient limitation in sea ice and the underlying water column using NIFT's (Nutrient Induced Fluorescence Transients). I hypothesise that the lower rate of nutrient replenishment in the brine communities can cause nutrient limitation.

Chapter 5 examines the silica requirements of diatoms collected in the Arctic and the Antarctic. It is suggested that Antarctic diatoms may exhibit a much lower affinity for silicate than diatoms do from other sectors of the world's oceans (Nelson and Treguer 1992). I hypothesized that by using the NIFT technique, it is possible to document differences in silica requirements between Antarctic and Arctic diatoms.

This thesis has been written with the intention to submit each chapter for publication in an international journal. With this format, there is inevitably some repetition of background material in the chapters. 


\title{
Chapter 2 Spatial and temporal comparisons of sea ice algal communities in the Ross Sea, Antarctica
}

\begin{abstract}
The community composition of microalgae within fast ice at Turtle Rock, Cape Evans and Terra Nova Bay, in the Ross Sea region of Antarctica, was described and compared with data collected from 1980 to 2012. Community composition varied with respect to the vertical position of microbes within the ice, geographical location, yearly and intraseasonally. Large variations in biomass, up to two orders of magnitude, were observed between years in the Ross Sea region. The highest biomass was found in the bottom 10 $\mathrm{cm}$ of the sea ice at each site while increasing snow cover correlated with decreased algal biomass and a change in species composition. Terra Nova Bay is much more variable in ice thickness and snow cover resulting in complete switches of species between years. These long term studies made it possible to identify the 'key' species Berkeleya adeliensis, Fragiliariopsis spp. and Entomoneis kjellmannii, it is proposed that these will endure large changes in the sea ice biomass due to predicted climate change.
\end{abstract}

\section{Introduction}

Sea ice surrounding the Antarctic continent varies in extent from $19.4 \times 10^{6} \mathrm{~km}^{2}$ in winter to $3.5 \times 10^{6} \mathrm{~km}^{2}$ in summer (NSIDC 2012), and most of this ice is less than one year old. This sea ice is not influenced by land-run-off and is largely sediment free, but upwelling of nutrient rich waters allow high concentrations of macronutrients to be incorporated during the annual formation of ice, and this supports extensive microbial life (Arndt et al. 2009).

Sea ice is a unique habitat dominated by strong gradients in temperature, salinity, nutrients, and light (Eicken 1992; McMinn et al. 1999; Thomas and Dieckmann 2002a). Though diatoms are the most abundant and most studied group of sea ice eukaryotes , sea ice also includes prymnesiophytes, chlorophytes, dinoflagellates, chrysophytes, ciliates, foraminiferea, bacteria, protists, and invertebrates (Lizotte 2001). Despite the extreme conditions, these organisms thrive in ice, and the accumulated biomass is a 
fundamental component of polar ecosystems and of critical importance to organisms higher up the food chain. Three microbial assemblages can be observed: surface assemblages, interior assemblages and bottom assemblages (Horner 1990). The Ross Sea region of Antarctica is dominated by bottom assemblages and most of the primary production takes place in the bottom $10-20 \mathrm{~cm}$ of the sea ice with only limited primary production in the middle and top sections of the sea ice (Palmisano and Sullivan 1983; McMinn et al. 1999; Ryan et al. 2006). The bottom $20 \mathrm{~cm}$ of the ice matrix can be defined as being stable with respect to temperature and salinity and is more favourable for growth due to a constant resupply of nutrients from the sea water below (Knox $2009 \mathrm{~b})$. In these bottom assemblages, pennate diatoms are the dominant taxa and dominate sea spring blooms (Ryan et al. 2006; McMinn et al. 2007; Sukhanova et al. 2009).

The primary advantage afforded by sea ice is that it provides a platform whereby sea ice algae can remain suspended in the upper ocean where light is sufficient for net growth. Except for those areas where snow cover exceeds approximately $0.3 \mathrm{~m}$, light is usually sufficient for net photosynthesis during the spring and summer (Arrigo et al. 1991; Arrigo et al. 2003). The particular suite of microbes present within the ice matrix is the result of a combination of physical processes, such as the time of formation and subsequent ice dynamics as well as biological processes such as colonization, growth, succession, grazing and death (Lizotte 2001). External factors such as temperature, light intensity, photoperiod, and nutrient limitation influence diatom growth (Vrieling et al. 2007), which will directly influence the pelagic and benthic systems below the ice.

Primary productivity in polar regions is spatially and temporally highly variable (Poulin 1990) largely due to changes in sea ice extent and the length of the sea ice season (Knox 2009c). Annual primary production in waters of the Southern Ocean (south of $50^{\circ} \mathrm{S}$ )

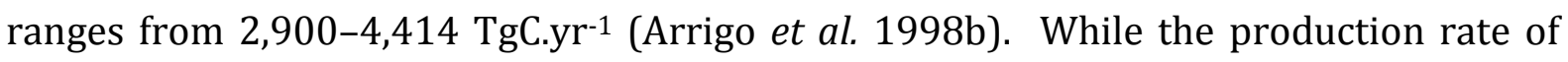

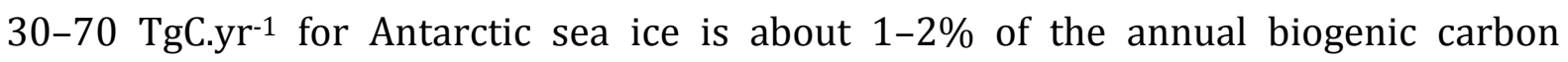
production in the entire Southern Ocean, sea ice primary production is a much larger fraction (10-28\%) of total production in ice-covered regions (Legendre et al. 1992; 
Arrigo et al. 1998b). Ice-associated microalgae may attain primary production rates of 0.1 to $1{\mathrm{gC} . \mathrm{m}^{-2} \text {.day }}^{-1}$, and this is comparable to that in the water column in productive oceanic regions (Arrigo and Thomas 2004). The standing stock of chlorophyll $a$, an important photopigment that is used as a proxy for algal biomass, is normally around 200 mg.m ${ }^{-2}$ (Arrigo et al. 1998b), but can exceed values of 400 mg.m-2 (McMinn et al. 1999; Guglielmo et al. 2000; Thomas and Dieckmann 2002a). Although the rates of primary production by sea ice algae are relatively low, they are of ecological significance (Thomas and Dieckmann 2002a). Sea ice algae are often the major source of fixed carbon for higher trophic levels in ice-covered regions (Arrigo and Thomas 2004; Arndt et al. 2009). This source is asynchronous with the primary production in the water column and therefore may extened the period of available food for grazers such as flagellates and ciliates (Thomas and Dieckmann 2002a).

The sea ice microbial community in the Ross Sea region has been studied for over 30 years. The present study compares sea ice microbial communities at Cape Evans (CE), Turtle Rock (TR) and Terra Nova Bay (TNB) within McMurdo Sound, Antarctica from 2006 to 2012. Data obtained from several published studies (Palmisano and Sullivan 1983; McGrath Grossi et al. 1984; Sullivan and Palmisano 1984; McMinn et al. 1999; Arrigo et al. 2000; Stoecker et al. 2000; Arrigo et al. 2003; Garrison et al. 2005; Ryan et al. 2006) are included in this comparison. This study aims to i) construct a picture of how ice algae communities have changed over the past 30 years, and provide a baseline with which to compare future changes in sea ice community distribution and abundance, ii) identify the drivers that determine the algal species present and iii) identify possible sea ice algal species that could act as 'indicator' species to assess the effects of environmental change. I hypothesise that the current data collected in the Ross Sea area already show trends of algal community changes which could be due to climate change despite reports suggesting that the Ross Sea has not been largely affected. 


\section{Methods}

\section{Sample locations}

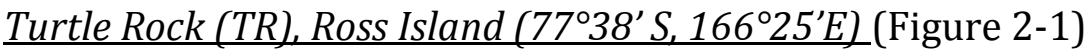

2011: Samples of first year fast ice were collected every 3-4 days over a three week period from 18 November to 6 December 2011. The ice thickness was $1.95 \mathrm{~m}$. At TR, 3 plots of 3x3 m were selected: one without snow cover ("no snow", NS); one with 10-15 cm snow ("low snow", LS); and one with 30-40 cm snow cover ("high snow", HS). The water current under the sea ice was negligible and no platelet ice was present on the underside of the sea ice. A total of 72 ice cores were collected (4 replicates, 6 time points, 3 different snow cover conditions).

Cape Evans (CE), Ross Island ( $77^{\circ} 38^{\prime} S, 166^{\circ} 25^{\prime} E, \sim 250 \mathrm{~m}$ from Scott's Hut) (Figure 2-1)

2012: Samples of first year fast ice were collected from 19 November to 23 November. The ice thickness was $1.60 \mathrm{~m}$ with no snow cover. A total of 8 ice cores were collected ( 4 replicates, 2 time points, collected by K043 Antarctic team).

2011: Samples of first year fast ice were collected from 15 November to 6 December. The ice was $1.60 \mathrm{~m}$ thick with no snow cover. The water current under the sea ice was negligible. This site was chosen as no ice platelets were present on the underside of the sea ice. A total of 12 ice cores were collected (4 replicates, 3 time points).

2010: Samples of first year fast ice were collected every 3-4 days over a three week period from 18 November to 6 December 2010. The ice thickness was $1.87 \mathrm{~m}$ with no snow cover. The water current under the sea ice was negligible and no platelets were present on the underside of the sea ice. A total of 24 ice cores were collected (4 replicates, 6 time points).

2009: Samples of first year fast ice were collected on 12 November. The ice was $1.80 \mathrm{~m}$ thick with no snow cover. A total of 4 ice cores were collected by K043 Antarctic team.

2001: Samples of first year fast ice were collected from 16 October to 2 November. The ice was $2.10 \mathrm{~m}$ thick with no snow cover. The water current under the sea ice was 
negligible. This site was chosen as no ice platelets were present on the underside of the sea ice. A total of 40 ice cores were collected ( 5 replicates, 8 time points). Data were published by (Ryan et al. 2006), but reanalyse of data was done for this thesis by means of PERMANOVA (see paragraph statistical methods).

1999: Samples of first year fast ice were collected from 28 October to 12 November. The ice was $1.90 \mathrm{~m}$ thick with no snow cover. A total of 16 ice cores were collected (4 replicates, 4 time points). Data were published by (Ryan et al. 2006), but reanalyse of data was done for this thesis by means of PERMANOVA (see paragraph statistical methods).

\section{Terra Nova Bay (TNB), Ross Sea, (74o38S, 164o13E) (Figure 2-1)}

2011: Four ice cores were collected from first year ice on 5 December. The ice thickness was $2.5 \mathrm{~m}$ and had no snow cover. This site had no ice platelets on the underside of the sea ice.

2010: Four ice cores were collected from first year ice on 24 November. Ice thickness ranged from $1.4 \mathrm{~m}$ to $1.6 \mathrm{~m}$, with no snow cover or platelet ice crystals.

2008: Late November 4 ice cores were collected by K043 Antarctic team. The ice was $1.90 \mathrm{~m}$ thick with $30 \mathrm{~cm}$ snow cover.

2007: Samples of first year fast ice were collected from 15 November to 5 December. The ice was $2.60 \mathrm{~m}$ thick with no snow cover. A total of 20 ice cores were collected (4 replicates, 5 time points, collected by K042 Antarctic team.

2006: Samples of first year fast ice were collected from 13 November till 23 November. The ice was $2.50-2.60 \mathrm{~m}$ thick with less than $3 \mathrm{~cm}$ of snow cover at the beginning of the season but increased to $\sim 10 \mathrm{~cm}$ mid-season. A total of 20 ice cores where collected (4 replicates, 5 time points, collected by K043 Antarctic team). 


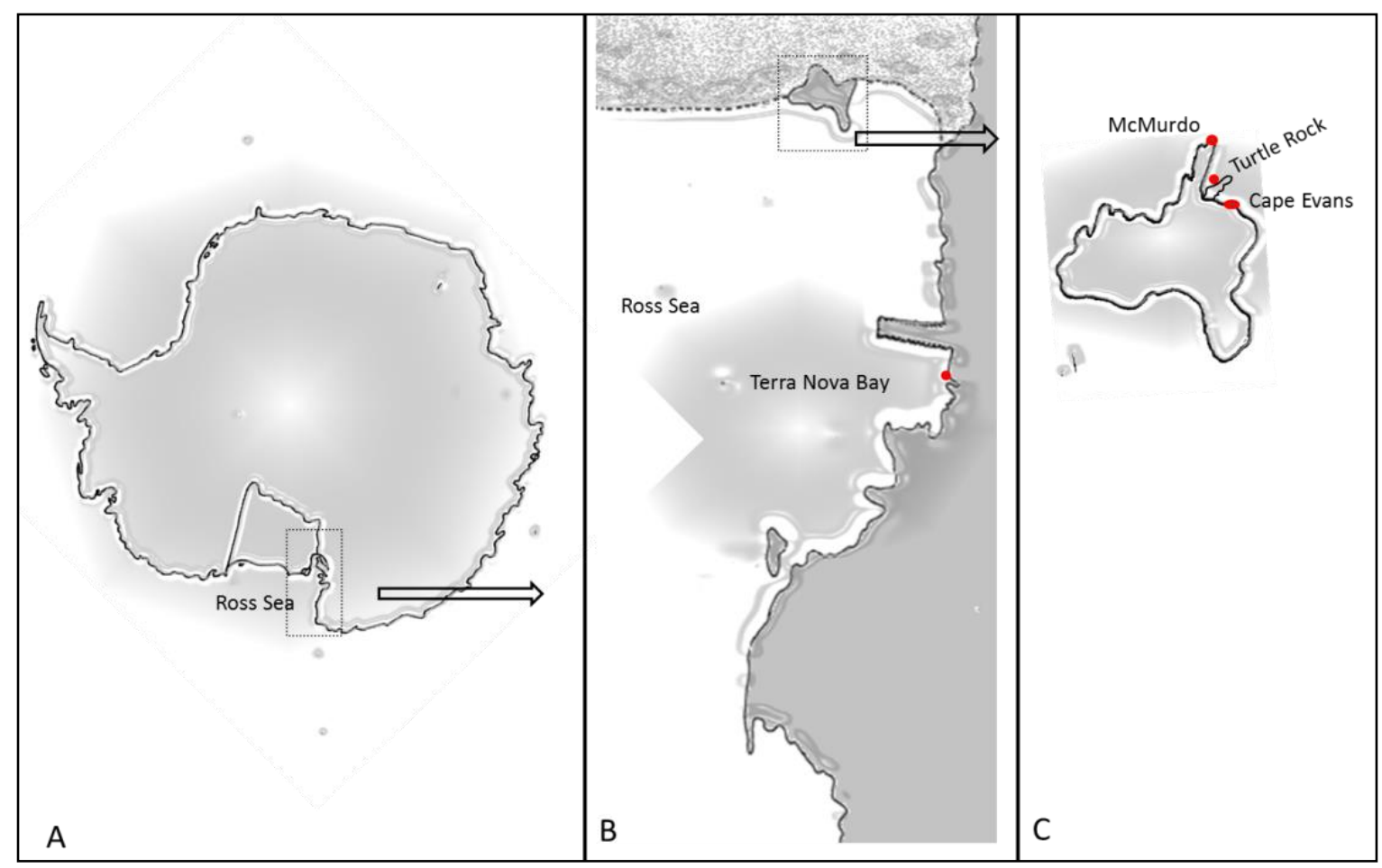

Figure 2-1: Sample locations in Antarctica a) Antarctica, b) Ross Sea including Ross Island. The dotted line indicates the Ross Sea Ice shelf, c) A close-up of Ross Island as indicated in the box of Figure b.

\section{Sampling}

Sea ice algae were collected from $140 \mathrm{~mm}$ diameter cores cut from the sea ice at several locations using a Kovaks (USA) ice corer. During collection, the cores were protected from direct sunlight damage by using a black sheet during drilling, ice core extraction, and transferring the cores into black PVC sleeves. Ten $\mathrm{cm}$ sections were cut from the top, middle and bottom of each core using an ethanol-sterilised ice saw. These ice core sections were then melted under no-light and low temperature $\left(\sim 4^{\circ} \mathrm{C}\right)$ over a period of 12 hours. Ten $\mathrm{ml}$ of melted ice core were subsequently fixed with either Lugol's iodine solution at a final concentration of $2.5 \%$ or with glutaraldehyde to a final concentration of $0.5 \%$. A minimal of $500 \mu \mathrm{l}$ of sample were counted using an inverted microscope (Zeiss, Germany). Samples with low biomass counts were done until at least 100 cells were counted. Chl $a$ was determined by filtering $100-300 \mathrm{ml}$ of the ice core section onto $47 \mathrm{~mm} \mathrm{GF} / \mathrm{F}$ filters and extracting in $10 \mathrm{ml}$ of $100 \%$ methanol over 12 hours in the dark at $4^{\circ} \mathrm{C}$. The $\mathrm{Chl} a$ concentration was measured on a digital fluorometer (Turner $10 \mathrm{AU}$ ) using the acidification protocol of Evans et al. (1987). 


\section{Radiometry}

Light levels at the surface and within the sea ice were measured by placing 4 PAR light sensors in the ice at $0 \mathrm{~m}, 0.5 \mathrm{~m}, 1.5 \mathrm{~m}$ and $2.3 \mathrm{~m}$ at the beginning of the 2006 field season (performed K043 Antarctic team). A complete core of sea ice was extracted in short $60 \mathrm{~cm}$ sections using a SIPRE drill, a slot was cut in the side of core for the data cable and the logger was oriented vertically in a small cavity sculpted in the centre of the core. The entire $2.6 \mathrm{~m}$ core was then replaced section by section, back into the sea ice. Light readings were taken at 10 min intervals. At the end of the field season the sensors were removed from the ice.

\section{Statistics}

One-way ANOVA with a 95\% confidence interval was performed using the SPSSv18 statistics package to compare total cell numbers between community location within the ice, geographical location, years and during a season. Individual pairwise tests were performed using the Sheffe test. This method was used since it applies to the set of estimates of all possible contrasts among the factor level means and can be used with unequal sample sizes. Permutational distance-based approaches were used for analyses because the relative abundances of algae were highly skewed and contained many zero counts; traditional analyses such as MANOVA were not suitable as they assume normality of errors. The PRIMER statistical package with the program PERMANOVA (permutational multivariate analysis of variance) was used to test relative species abundances. PERMANOVA, using 9999 random permutations, was used to test for differences in the algal community compositions and abundances of species between location, years and vertical position in the sea ice. Analyses were based on a zero adjusted Bray-Curtis index of similarity which takes into consideration samples that lack certain species. Data were transformed with a square root to obtain normality. Differences in communities were visualised by MDS (multidimensional scaling) plot analysis. In all cases, significant correlations were defined by $\mathrm{P}<0.05$. 


\section{Results}

Microscopic examination of the algal samples showed that different species compositions existed among TR (2011), CE (1999, 2001, 2010, 2011, 2012) and TNB (2006, 2007, 2008, 2010, 2011) samples. A full species list is given in Appendix A. However, several common species could be found at all locations and in all years. The sea ice was dominated by pennate diatoms at all locations with the second most abundant group being dinoflagellates such as Polarella sp., which were mainly found in the top and middle sections of the sea ice. Many diatoms were identified to species level but for several taxa this was not possible. Similar species could not always be distinguished. For example, Fragilariopsis spp. consisted of 2 species: F. curta and F. cylindrus; these species can only be identified when they are perfectly orientated in valve view, and so these two were grouped together as Fragilariopsis spp.

\section{Vertical position within the sea ice}

An extensive vertical profile of the sea ice in 2011 was constructed for the Ross Sea region. Overall, considerable variability in algal abundance was observed in the top and middle of the sea ice. The amount of algal cells present in the bottom were significantly different from top and middle $(\mathrm{P}<0.005)$, but middle and top sections did not differ significantly from each other (P 0.998)(Table 2-1). The vertical position within the sea ice caused the largest difference in the sea ice communities (PERMANOVA: Pseudo$\mathrm{F}=100.1, \mathrm{df}=2, \mathrm{P}=0.001$ ). Estimates of components (PERMANOVA) of species showed that vertical position can explain almost $80 \%$ of the variability in species observed. The highest species diversity was found near the water-ice interface and this decreased toward the surface. The top and middle of the sea ice have similar species compositions as illustrated by the close clustering of these habitats in the MDS plot (Figure 2-2) whereas the bottom has a clear separation from the top and middle of the sea ice habitat. 
Table 2-1: Average abundance of algae (cells. $\mathrm{L}^{-1}$ ) at Turtle Rock no snow, low snow and high snow (TRNS, TRLS. TRHS), Cape Evans (CE) and Terra Nov Bay (TNB) sea ice during early the summer of 2011. Standard error in brackets.

\begin{tabular}{|c|c|c|c|c|c|}
\hline \multicolumn{6}{|c|}{ Abundance $10^{4}$ cells. $\mathrm{L}^{-1}\left( \pm \mathrm{SE} 10^{4}\right)$} \\
\hline & $\begin{array}{l}\text { TRNS } 2011 \\
(n=24)\end{array}$ & $\begin{array}{l}\text { TRLS } 2011 \\
(n=24)\end{array}$ & $\begin{array}{l}\text { TRHS } 2011 \\
(n=24)\end{array}$ & $\begin{array}{l}\text { CE } 2011 \\
(n=12)\end{array}$ & $\begin{array}{l}\text { TNB } 2011 \\
(n=4)\end{array}$ \\
\hline Top & $\begin{array}{l}8.1 \\
(10.8)\end{array}$ & $\begin{array}{l}11.9 \\
(15.8)\end{array}$ & $\begin{array}{l}5.7 \\
(7.9)\end{array}$ & $\begin{array}{l}0.6 \\
(7.4)\end{array}$ & $\begin{array}{l}2.4 \\
(1.1)\end{array}$ \\
\hline Middle & $\begin{array}{l}3.1 \\
(3.1)\end{array}$ & $\begin{array}{l}2.9 \\
(1.5)\end{array}$ & $\begin{array}{l}0.9 \\
(0.9)\end{array}$ & $\begin{array}{l}6.6 \\
(0.8)\end{array}$ & $\begin{array}{l}5.5 \\
(0.3)\end{array}$ \\
\hline Bottom & $\begin{array}{l}2634 \\
(674)\end{array}$ & $\begin{array}{l}2220 \\
(630)\end{array}$ & $\begin{array}{l}342 \\
(133)\end{array}$ & $\begin{array}{l}897 \\
(482)\end{array}$ & $\begin{array}{l}1064 \\
(265)\end{array}$ \\
\hline
\end{tabular}

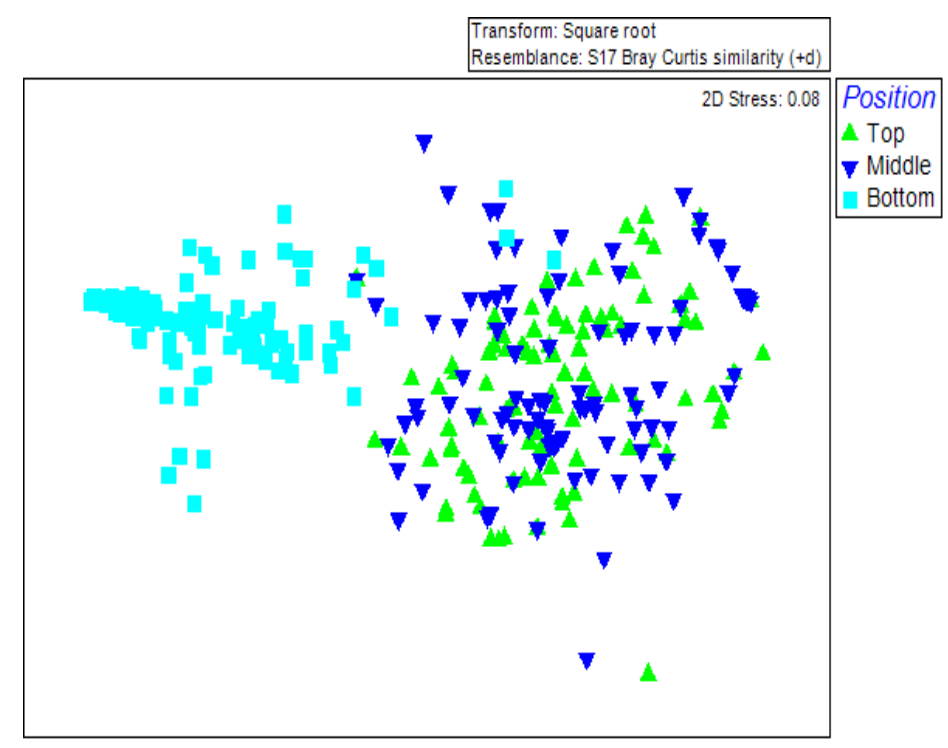

Figure 2-2: Multidimensional scaling similarity plot for sea ice community species composition by position in the sea ice in the Ross Sea, 2011. Plot includes Cape Evans 2011, Terra Nova Bay 2011 and Turtle Rock 2011 for all time points sampled. Axes are arbitrary distance, and distances between samples are proportional to similarity (Bray-Curtis measure $+d$ ) between the assemblages.

\section{Radiometry}

The irradiance was measured at TNB from November to December 2006. Sea ice significantly reduces PAR levels from $\sim 1500 \mu \mathrm{m}$ photons $\mathrm{m}^{-2} \cdot \mathrm{s}^{-1}$ at the surface to around $1.2 \mu \mathrm{m}$ photons $\mathrm{m}^{-2} \cdot \mathrm{s}^{-1}$ at the bottom of the sea ice (Figure 2-3). During this period a snow fall of about $10 \mathrm{~cm}$ occurred on 20 Nov. This caused a reduction of light (arrow, Figure 2-3B); depending on the position in the sea ice, light levels were reduced by 80 $90 \%$. This illustrates the effect of snow cover on sea ice communities, and is relevant 
for the snow-covered plot at TR discussed in the paragraphs: location, subsection Turtle Rock.
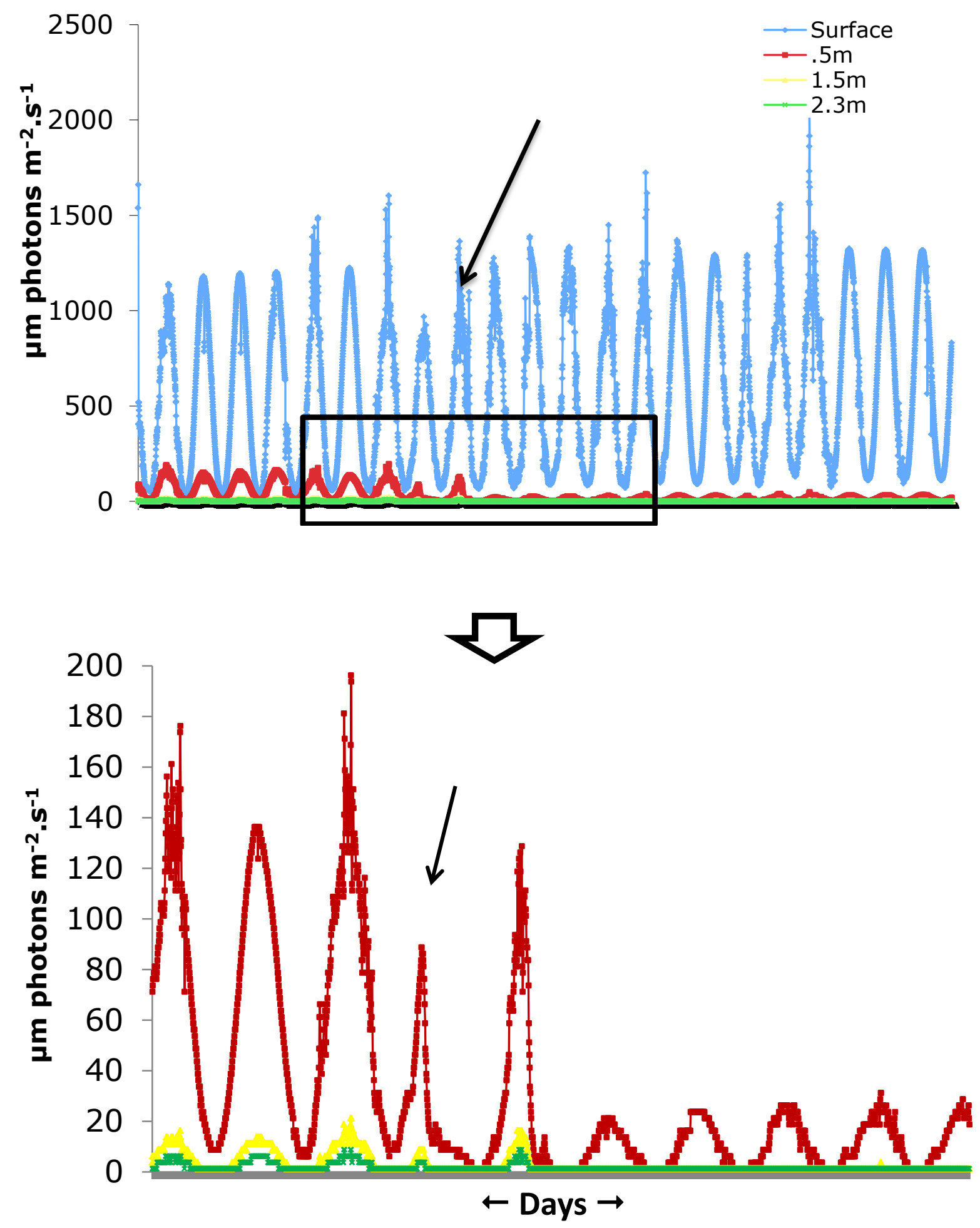

Figure 2-3: a) Irradiance levels at different vertical positions in the sea ice at Terra Nova Bay 2006. b) Detail of the irradiance levels within the sea ice from 11 November to 5 December 2006. The arrow indicates when a $\sim 10 \mathrm{~cm}$ snow fall occurred (unpublished data collected by K043 Antarctic team). 


\section{Locations}

Variations in sea ice algal species composition were found between locations (Table 24). However, several species (Berkeleya adeliensis, Nitzschia stellata, Fragilariopsis spp. and Entomoneis kjellmannii) were common in the bottom of the sea ice and were found in most years at the different locations. In general the top and middle layers had lower species diversity than the bottom of the sea ice (Table 2-4). One of the most abundant species found in the interior of the sea ice for nearly all locations was the dinoflagellate Polarella sp. This species was absent in the bottom of the sea ice.

Table 2-2: Mean percentage abundance of diatoms in the top $10 \mathrm{~cm}$ of sea ice during the summer of 2010, 2011and 2012. TR= Turtle Rock, NS=no snow cover, $\mathrm{LS}=$ snow cover 10-15 cm, HS= snow cover 30-40 $\mathrm{cm}, \mathrm{CE}=$ Cape Evans, TNB= Terra Nova Bay.

\begin{tabular}{|c|c|c|c|c|c|c|c|c|}
\hline Top & 2010 & 2011 & 2010 & 2011 & 2012 & 2011 & 2011 & 2011 \\
\hline & TNB & TNB & $\mathrm{CE}$ & $\mathrm{CE}$ & $\mathrm{CE}$ & TR NS & TR LS & TR HS \\
\hline Berkeleya adeliensis & - & - & 3.0 & - & - & 0.6 & 0.2 & 0.4 \\
\hline $\begin{array}{l}\text { Entomoneis } \\
\text { kjellmannii }\end{array}$ & - & 6.6 & 3.0 & 8.0 & - & 1.5 & 3.0 & 2.1 \\
\hline Fragilariopsis spp. & 23.5 & 68.6 & 33.0 & 22.0 & - & 6.8 & 7.0 & 10.7 \\
\hline Manguinea sp. & - & - & - & - & - & 4.3 & 0.4 & 0.6 \\
\hline Navicula sp. & 11.7 & 11.7 & 13.1 & 1.3 & 0.3 & 0.7 & 1.1 & 1.4 \\
\hline Nitzschia leicointei & - & 0.7 & 4.0 & 4.0 & - & 6.2 & 2.8 & 2.0 \\
\hline Nitzschia stellata & 58.8 & - & 36.7 & 0.7 & 0.6 & - & - & - \\
\hline Pleurosigma sp. & 0.1 & 2.9 & - & 30.0 & - & - & - & - \\
\hline Polarella sp & 0.2 & 2.9 & 2.0 & 30.0 & 99.1 & 73.6 & 82.7 & 72.1 \\
\hline Stellarima sp. & 5.9 & - & 4.0 & - & - & - & - & - \\
\hline
\end{tabular}


Table 2-3: Mean percentage abundance of diatoms in the middle $10 \mathrm{~cm}$ of sea ice during the summer of 2010 and 2011. TR= Turtle Rock, NS=no snow cover, $\mathrm{LS}=$ snow cover 10-15 cm, HS= snow cover 30-40 $\mathrm{cm}, \mathrm{CE}=$ Cape Evans, TNB= Terra Nova Bay.

\begin{tabular}{|c|c|c|c|c|c|c|c|c|}
\hline Middle & 2010 & 2011 & 2010 & 2011 & 2012 & 2011 & 2011 & 2011 \\
\hline & TNB & TNB & CE & CE & $\mathrm{CE}$ & TR NS & TR LS & TR HS \\
\hline Berkeleya adeliensis & - & - & 1.2 & - & - & 2.1 & 2.5 & 2.5 \\
\hline $\begin{array}{l}\text { Entomoneis } \\
\text { kjellmannii }\end{array}$ & - & 0.3 & 1.3 & 2.3 & - & 10.2 & 5.2 & 8.1 \\
\hline Flagellate & - & - & 32.7 & - & - & - & - & - \\
\hline $\begin{array}{l}\text { Fragilariopsis } \\
\text { obliquecostata }\end{array}$ & - & 29.0 & - & 8.5 & - & 33.8 & 30.0 & 33.0 \\
\hline Fragilariopsis nana & - & 16.4 & - & 2.0 & - & 0.1 & - & - \\
\hline Fragilariopsis spp. & 47.0 & 0.3 & 29.4 & - & - & - & - & - \\
\hline Navicula sp. & 10.6 & 29.0 & 4.0 & - & 0.6 & - & 0.4 & - \\
\hline Nitzschia pseudonana & - & 2.6 & 0.0 & 11.2 & - & 6.0 & 6.6 & 8.1 \\
\hline Nitzschia leicointei & - & 2.6 & 1.4 & 21.2 & - & 2.8 & 11.0 & 3.6 \\
\hline Nitzschia stellata & 31.8 & 10.9 & 10.3 & 9.1 & - & 7.5 & 15.8 & 8.7 \\
\hline Polarella sp. & - & 2.9 & 19.0 & 45.7 & 97.5 & 33.5 & 24.7 & 22.3 \\
\hline Stellarima sp. & 9.1 & 0.0 & 0.2 & - & - & - & - & - \\
\hline
\end{tabular}

Table 2-4: Mean percentage abundance of diatoms in the bottom $10 \mathrm{~cm}$ of sea ice during the summer from 1999 to 2012. TR= Turtle Rock, NS=no snow cover, $\mathrm{LS}=$ snow cover 10-15 cm, HS= snow cover 30$40 \mathrm{~cm}, \mathrm{CE}=$ Cape Evans, TNB= Terra Nova Bay.

\begin{tabular}{|c|c|c|c|c|c|c|c|c|c|c|c|c|c|}
\hline Bottom & 2006 & 2007 & 2008 & 2010 & 2011 & 1999 & 2001 & 2010 & 2011 & 2012 & 2011 & 2011 & 2011 \\
\hline & TNB & TNB & TNB & TNB & TNB & CE & CE & $\mathrm{CE}$ & CE & CE & $\begin{array}{l}\text { TR } \\
\text { NS }\end{array}$ & $\begin{array}{l}\text { TR } \\
\text { LS }\end{array}$ & $\begin{array}{l}\text { TR } \\
\text { HS }\end{array}$ \\
\hline $\begin{array}{l}\text { Berkeleya } \\
\text { adeliensis }\end{array}$ & 6.8 & 41.7 & - & 7.9 & 1.2 & 18.7 & - & 15.2 & 5.2 & 26.1 & 39.1 & 36.9 & 10.0 \\
\hline $\begin{array}{l}\text { Entomoneis } \\
\text { kjellmannii }\end{array}$ & 14.3 & 31.0 & 3.3 & 2.1 & 3.6 & 19.3 & 14.0 & 2.7 & 4.3 & 1.4 & 7.9 & 10.9 & 36.5 \\
\hline $\begin{array}{l}\text { Fragilariopsis } \\
\text { obliquecostata }\end{array}$ & 1.1 & - & 8.1 & - & 20.7 & - & 1.6 & - & - & - & - & - & - \\
\hline $\begin{array}{l}\text { Fragilariopsis } \\
\text { spp. }\end{array}$ & 13.9 & 3.1 & 14.1 & 37.8 & 7.2 & 9.8 & 6.7 & 21.7 & 1.7 & 6.2 & 8.1 & 10.2 & 5.3 \\
\hline haptophyte & 41.2 & - & - & - & - & - & 6.2 & - & - & - & - & - & - \\
\hline $\begin{array}{l}\text { Manganuinea } \\
\text { sp. }\end{array}$ & - & - & - & - & - & 5.2 & 9.5 & - & - & - & - & - & - \\
\hline Navicula sp. & 19.5 & 7.4 & 6.0 & 5.7 & 2.5 & 5.2 & 9.5 & 20.6 & 51.9 & 16.8 & 7.1 & 7.4 & 11.6 \\
\hline $\begin{array}{l}\text { Nitzschia } \\
\text { leicointei }\end{array}$ & - & - & 5.4 & 2.9 & - & 19.7 & 2.2 & 8.8 & 14.7 & 15.7 & 16.4 & 15.3 & 14.0 \\
\hline $\begin{array}{l}\text { Nitzschia sp. } \\
\text { (large) }\end{array}$ & - & - & - & - & 61.2 & - & - & - & - & - & - & - & - \\
\hline $\begin{array}{l}\text { Nitzschia } \\
\text { stellata }\end{array}$ & 3.5 & 12.9 & 25.7 & 32.1 & 2.3 & 19.7 & 22.0 & 26.9 & 21.4 & 29.9 & 17.3 & 14.8 & 10.7 \\
\hline $\begin{array}{l}\text { Nitzschia } \\
\text { subcurvata }\end{array}$ & - & - & - & - & - & - & 30.6 & - & - & - & - & - & - \\
\hline Pinnularia sp. & - & - & - & - & - & - & 15.5 & - & - & - & - & - & - \\
\hline Pleurosigma sp. & - & - & - & - & - & - & 14.1 & - & - & - & - & - & - \\
\hline Porosira sp. & - & 1.0 & 13.2 & - & - & - & - & 1.3 & - & & - & - & 5.1 \\
\hline $\begin{array}{l}\text { Pseudonitzschia } \\
\text { sp. }\end{array}$ & - & - & - & - & - & - & 3.8 & - & - & - & - & - & - \\
\hline Stellarima sp. & - & 1.3 & 23.3 & 9.0 & - & - & - & 0.8 & - & & - & - & - \\
\hline
\end{tabular}




\section{Turtle Rock (TR)}

The top and middle sections of the ice under different snow cover at TR were very similar with respect to species composition (Table 2-2, 2-3). Algal abundances in the top section of sea ice under "no snow"(NS) and "high snow" (HS) sampling plots increased significantly during the sampling period (one-way ANOVA: TRHS F=3.120, $\mathrm{P}=0.042$; TRNS $\mathrm{F}=2.935, \mathrm{P}=0.048$ Figure $2-4$ ). The middle was highly variable and did not follow any trend (one-way ANOVA: TRNS P=0.380, TRLS P=0.269, TRHS P=0.569) (Figure2-4). Algal abundances were higher in the top sections of the ice than in the middle.

The bottom sections of TRNS and TRHS were highly significantly different in the total abundance of cells (ANOVA: $\mathrm{F}=47.070 \mathrm{P}<0.005$ ) and the lowest concentrations of bottom ice algae were found in the highest snow covered plots. The same community of species was present at all TR plots although the dominant species varied. Community composition at TR plots NS and LS were similar with the same relative abundance of species (Table 4). Under no- and low snow cover, B. adeliensis was the dominant species (39\% and 37\% respectively); while for HS, the dominant species was $E$. kjellmannii (36\%). Also, under this high snow cover, the centric species Porosira glacialis and Chaetoceros socialis were in higher abundance relative to the no- and low snow plots. Fragilariopsis spp., N. stellata and Navicula sp. contributed most of the biomass in the bottom of the sea ice, but the composition and abundance differed by site and by year. 


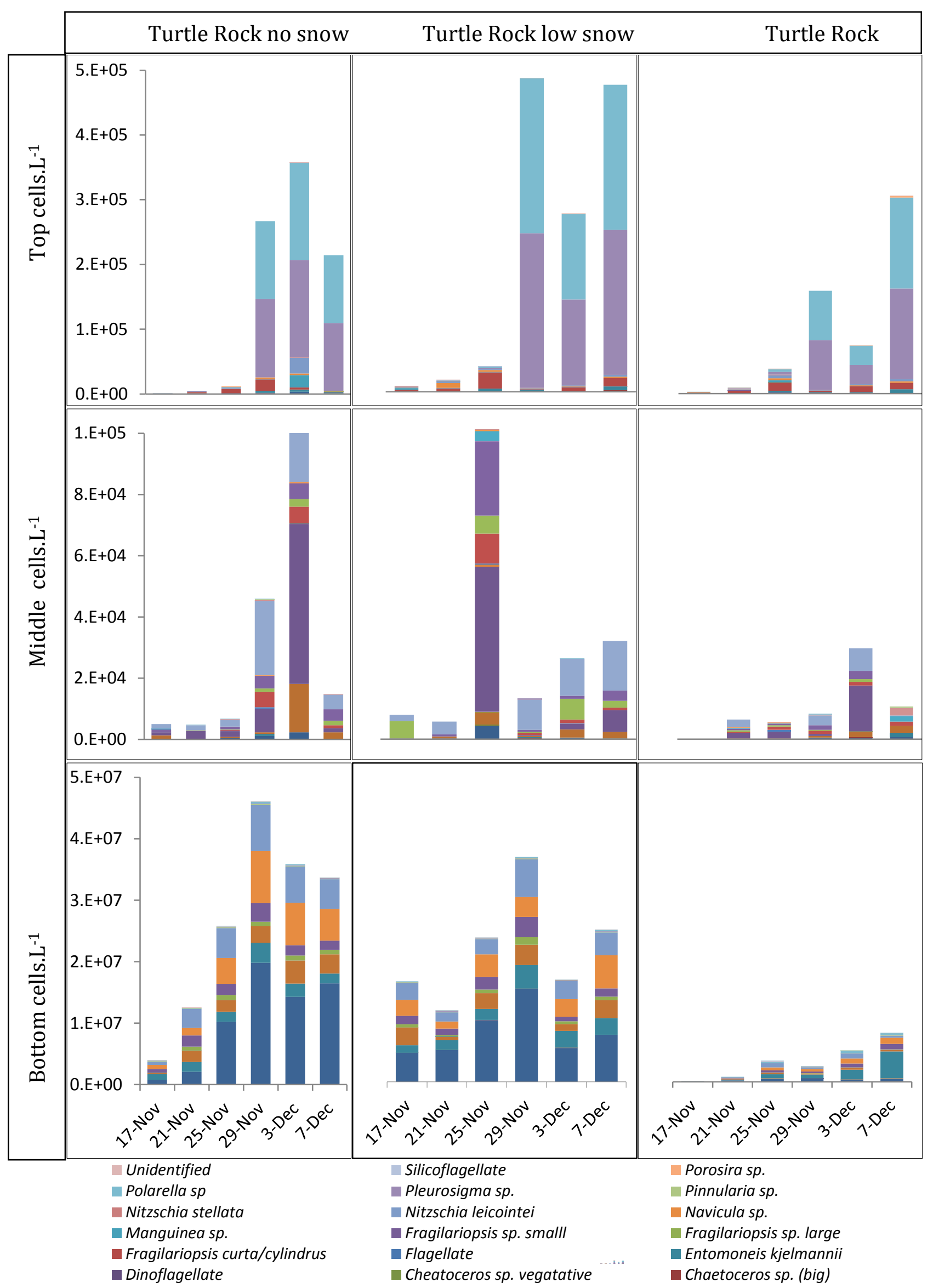

Figure 2-4: Sea ice algal species composition at Turtle Rock 2011 for the bottom, middle and top of the sea ice with no-, low-(10-15 cm) and, high snow cover $(30-14 \mathrm{~cm})$ in relation to the different vertical position in the sea ice and, the snow cover present ( $n=4$ per sample point). 


\section{Cape Evans (CE)}

The biomass in the top section of the sea ice at CE was highly variable. The biomass in the middle of the sea ice in this location increased considerably in 2010 and 2011. The top section of the sea ice at CE in 2012 consisted almost entirely of Polarella sp. In 2011, the ice was dominated by Pleurosigma sp., Polarella sp. and in lesser amounts by Fragilariopsis spp., while in 2010 the equivalent CE samples were dominated by $N$. stellata and Fragilariopsis spp. The middle-ice species composition differed substantially from year to year and some species, Fragilariopsis spp. (29\%) in 2010 and Fragilariopsis obliquecostata (8.5\%) and Nitzschia pseudonana (11\%) were only present in 2011, while Pollarella dominated 2012 with $>97 \&$. Due to the high variability within a sampling season there was no significant difference in cell concentration for the top and middle (one-way ANOVA: top, $\mathrm{F}=3.078 \mathrm{P}=0.082$, middle, $\mathrm{F}=1.682 \mathrm{P}=0.197$ ) between years at CE.

The biomass differed significantly (one-way ANOVA: $\mathrm{F}=22.125, \mathrm{P}<0.005$ ) between years as well as the community compostion. During 2010 in the bottom of the sea ice at CE, the species were more equally distributed with just 4 species making up $85 \%$ of the total, N. stellata, Fragilariopsis spp., Navicula sp. and B. adeliensis (Table 2-4). In contrast, at CE 2011, Navicula directa made up about half of the population (Table 2-4). In 2012 , the sea ice algal community closely resembled the community that was present in 2010 .

\section{Terra Nova Bay (TNB)}

TNB had very different dominant species in the top of the sea ice. For both years, one species made up more than half of the total abundance: in 2010 it was N. stellata (59\%) and in 2011, Fragilariopsis spp. (69\%). The middle also differed significantly in composition (Table 2-3) between years, although most of the same species were present in both years. However, Stellarima sp. (2008) and F. obliquecostata (2011) dominated in one year but were absent in the other years. In 2010, Fragilariopsis spp. (47\%), dominated this region of the sea ice while in 2011 F. obliquecostata and Navicula sp. were co-dominant. 
A large variation in community composition was found in the bottom of TNB cores and the dominant species changed each year (Table 2-4). TNB was the only location sampled where haptophytes (c.f. Pyramimonas sp.) were found as the dominant species (2006). In 2011, the dominant species was Nitzschia sp. (large) (61\%). Both of these species were absent in other years. Biomass differed significantly between years for the top, middle and bottom $(\mathrm{F}=1.378 \mathrm{P}<0.005)$.

\section{Comparison of locations}

The MDS similarity plot (Figure 2-5a) illustrates that species located in the top of the sea ice were highly variable causing less grouping and more overlap between locations. However, the CE 2010 data were distinct from most of the other locations in the top section (circles in Figure 2-5a and bold in Table 2-5). In the middle of the sea ice, clustering is visible between the TRNS/LS with TRHS, but not between TRNS/LS and CE 2011 (circle in Figure 2-5b). All other locations were significantly different from each other (Table 2-6). The bottom-ice communities clustered with location (Figure 5c), and differences were evident between the CE 2011 and the NS and LS plots at TR, which were not visible in the middle-ice communities. Apart from TRNS and TRLS, the community compositions at all sampling locations in the bottom sections of the ice core were highly significantly different from each other (Table 2-7). 


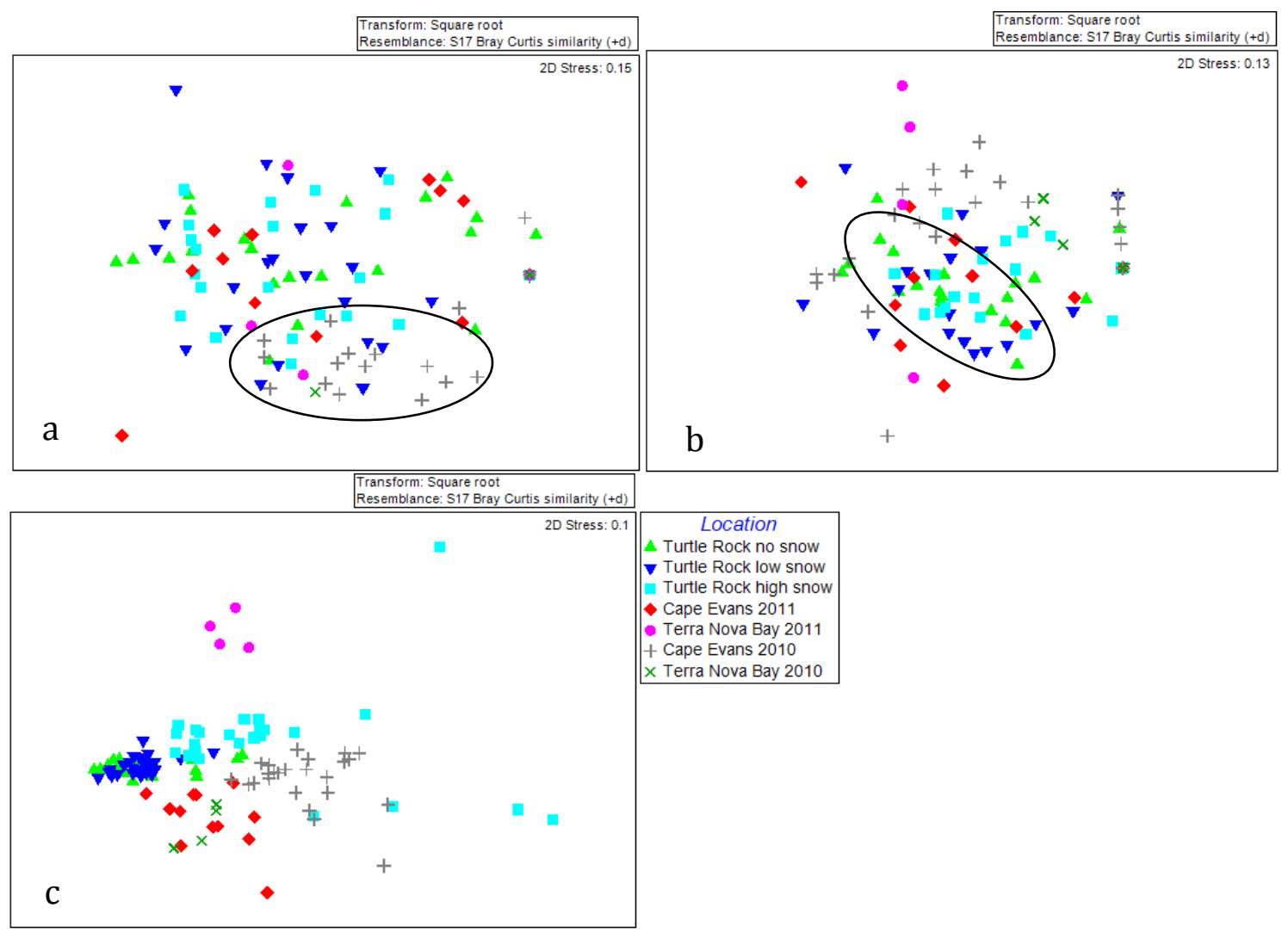

Figure 2-5: Similarities in sea ice communities by location. a) Top, b) middle, c) bottom sections of sea ice cores from 3 different locations, Turtle Rock, Cape Evans and Terra Nova Bay. The circle in a) shows a cluster of Cape Evans 2010 samples, which is significantly different from the other sampled locations. The circle in b) shows a similarity cluster of the Turtle Rock plots. In c), all locations except for TRNS and TRLS form separate clusters meaning that they differ significantly from each other in species composition. Axes are arbitrary distance, and distances between samples are proportional to similarity (Bray-Curtis measure $+\mathrm{d}$ ) between the assemblages.

Table 2-5: Statistical analysis of differences in species composition between locations and years in the top of the sea ice. P-values obtained from PERMANOVA pair-wise tests. Numbers in bold show significant differences between locations.

\begin{tabular}{|c|c|c|c|c|c|c|}
\hline & 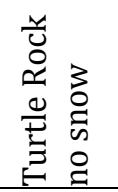 & 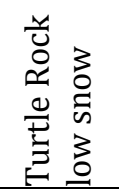 & 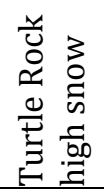 & 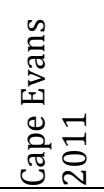 & 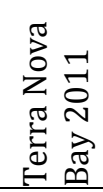 & 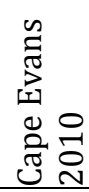 \\
\hline Turtle Rock low snow & 0.288 & & & & & \\
\hline Turtle Rock high snow & 0.353 & 0.987 & & & & \\
\hline Cape Evans 2011 & 0.434 & 0.208 & 0.146 & & & \\
\hline Terra Nova Bay 2011 & 0.405 & 0.495 & 0.551 & 0.552 & & \\
\hline Cape Evans 2010 & 0.002 & 0.001 & 0.001 & 0.022 & 0.303 & \\
\hline Terra Nova Bay 2010 & 0.185 & 0.026 & 0.038 & 0.311 & 0.308 & 0.593 \\
\hline
\end{tabular}


Table 2-6: Statistical analysis of differences in species composition between locations and years in the middle of the sea ice. P-values obtained from PERMANOVA pair-wise tests. Numbers in bold show significant differences between locations.

\begin{tabular}{|c|c|c|c|c|c|c|}
\hline & 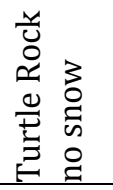 & 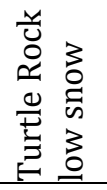 & 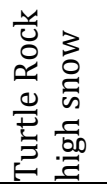 & 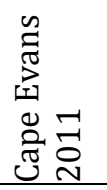 & 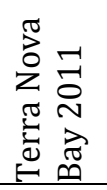 & 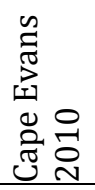 \\
\hline Turtle Rock low snow & 0.196 & & & & & \\
\hline Turtle Rock high snow & 0.001 & 0.001 & & & & \\
\hline Cape Evans 2011 & 0.197 & 0.094 & 0.001 & & & \\
\hline Terra Nova Bay 2011 & 0.001 & 0.002 & 0.001 & 0.006 & & \\
\hline Cape Evans 2010 & 0.010 & 0.009 & 0.001 & 0.031 & 0.003 & \\
\hline Terra Nova Bay 2010 & 0.038 & 0.023 & 0.045 & 0.026 & 0.030 & 0.048 \\
\hline
\end{tabular}

Table 2-7: Statistical analysis of differences in species composition between locations and years in the bottom of the sea ice. P-values obtained from PERMANOVA pair-wise tests. Numbers in bold show significant differences between locations.

\begin{tabular}{|c|c|c|c|c|c|c|}
\hline & 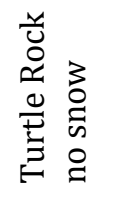 & 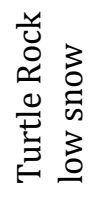 & 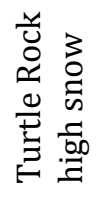 & 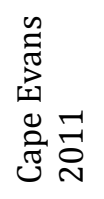 & 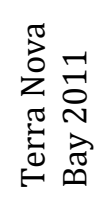 & 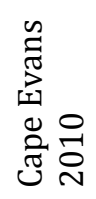 \\
\hline Turtle Rock low snow & 0.3615 & & & & & \\
\hline Turtle Rock high snow & 0.001 & 0.001 & & & & \\
\hline Cape Evans 2011 & 0.001 & 0.001 & 0.001 & & & \\
\hline Terra Nova Bay 2011 & 0.001 & 0.002 & 0.002 & 0.001 & & \\
\hline Cape Evans 2010 & 0.001 & 0.001 & 0.001 & 0.001 & 0.001 & \\
\hline Terra Nova Bay 2010 & 0.001 & 0.001 & 0.006 & 0.001 & 0.028 & 0.001 \\
\hline
\end{tabular}

\section{Yearly differences in sea ice algal communities}

A detailed depiction of the differences in species composition at TNB and CE for the years 2010, 2011 and 2012 for the top middle and bottom of the sea ice is shown in Figure 2-6. This shows large differences in species composition especially for the bottom ice, and a large variability in biomass in the top and middle. 

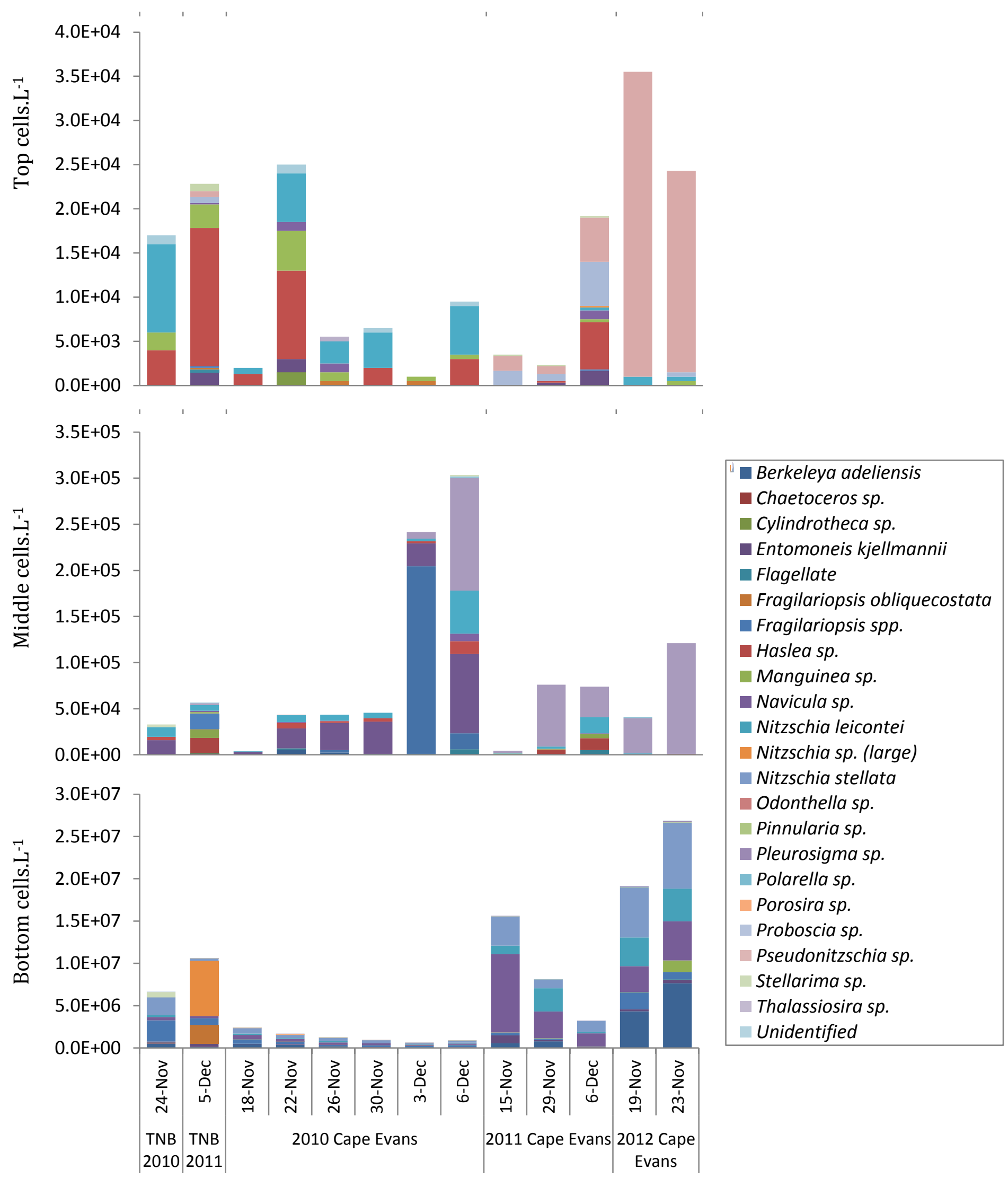

Figure 2-6: Species composition (cells.L-1) at Terra Nova Bay (2010 and 2011) and Cape Evans (2010 2012), the Ross Sea, for the top $10 \mathrm{~cm}$, middle $10 \mathrm{~cm}$ and bottom $10 \mathrm{~cm}$ of the sea ice during early summer ( $n=4$ per sample point). 
Chlorophyll (Chl a) data for the years 1999 and 2001 were taken from Ryan et al. (2006) to allow an extension of the study of yearly changes in sea ice algal community composition at CE. Each year around the same period, samples were taken for Chl $a$, from the bottom $10 \mathrm{~cm}$ of the sea ice. The sea ice was each year about $1.8 \mathrm{~m}$ thick. Yet, a large variation can be observed ranging from $<1$ to $175 \mathrm{mg} \cdot \mathrm{m}^{-2}$. Chl $a$ is an indirect measurement for algal biomass. A comparison of Chl $a$ concentrations of multiple years at CE is shown in Figure 2-7. Large variations in biomass exist between years but on average the highest biomass can be found in late October to early November (Figure 27).

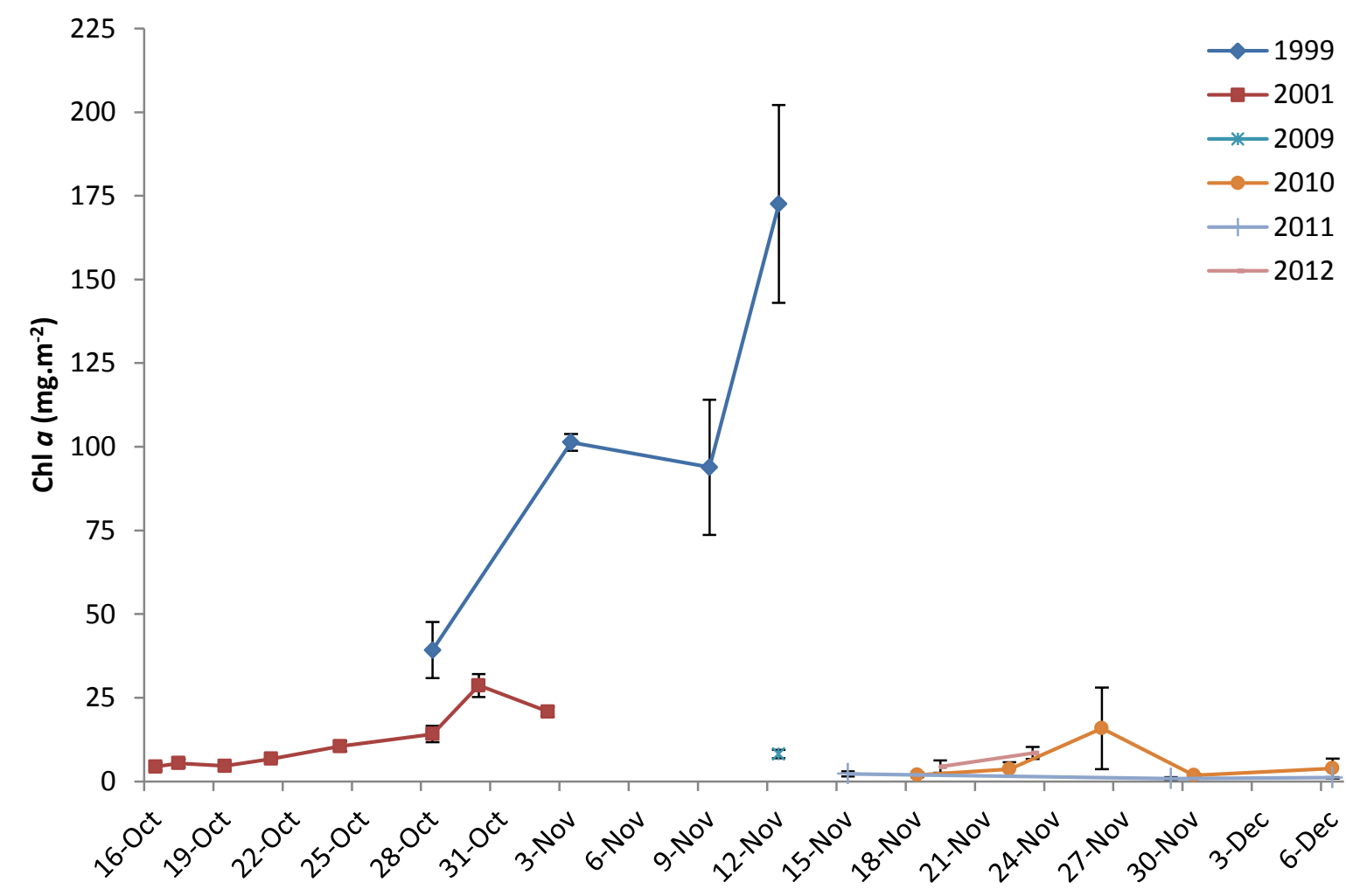

Figure 2-7: $\mathrm{Chl} a$ concentrations in the bottom $10 \mathrm{~cm}$ of the sea ice at Cape Evans in multiple years. Data are means $\pm 1 \mathrm{SE}, n=4$ per data point.

All years analysed at CE differed significantly from each other in community composition (PERMANOVA: df 4, Pseudo-F 35.995, P=0.0001; Figure 2-8). However, the years 1999, 2001, 2010 group closer together in the MDS plot (Figure 2-8) suggesting a similarity in algal sea ice community, while 2011 and 2012 from completely separate clusters with a large scatter. A large scatter is indicative of variation is community 
composition within that sampling years. A time line of species composition at Cape Evans was constructed spanning 30 years using previous published studies (Table 2-8). Several species in the bottom of the sea ice at CE reoccur most years (e.g. E. kjellmannii, Nitzschia spp. Fragilariopsis spp.) though their abundance shows large variations each year (Table 2-8). B. adeliensis was first recorded in 1996 in low abundance but, in following years became one of the dominant species.

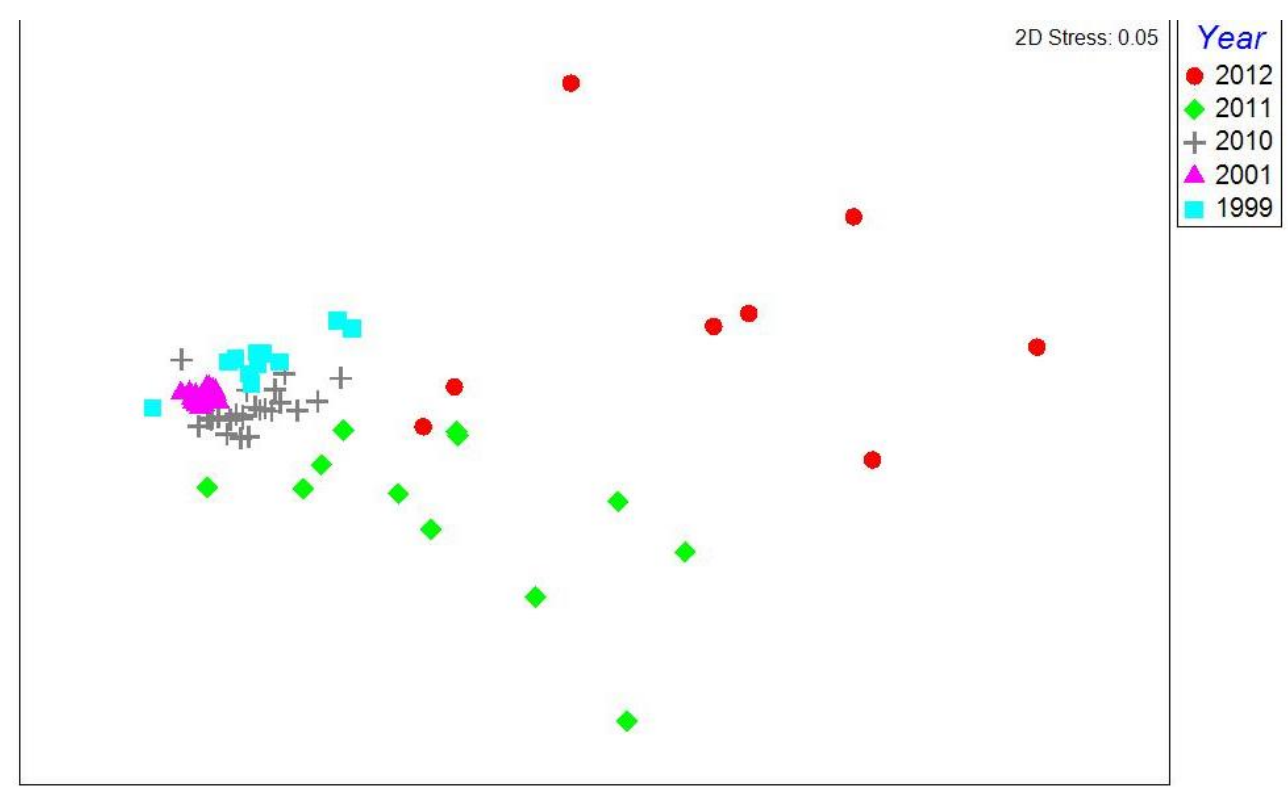

Figure 2-8: Comparison of similarities in the bottom sea ice communities at Cape Evans for 5 years. Data were square root transformed and axes are arbitrary distance, and distances between samples are proportional to similarity (Bray-Curtis measure $+\mathrm{d}$ ) between the assemblages. 
Table 2-8: Sea ice species composition of the bottom sea ice in McMurdo Sound measured over the past 30 years. Species are organised from high to low abundances and make up between $80-95 \%$ of the total algal count. ${ }^{*}=$ this thesis. ${ }^{+}=$as reported by authors although note that many Amphiprora sp. have since been transferred to the genus Entomoneis sp. Note that table continues on next page.

\begin{tabular}{|c|c|c|c|c|c|c|c|}
\hline ָ̃ & 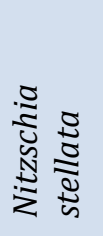 & 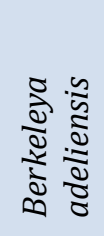 & 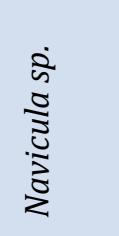 & 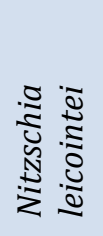 & 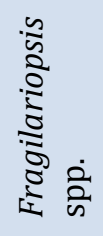 & & * \\
\hline$\underset{\text { Dे }}{\bar{N}}$ & 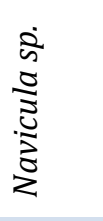 & 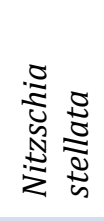 & 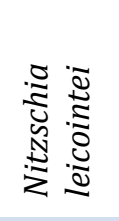 & & & & * \\
\hline $\overrightarrow{\text { s. }}$ & 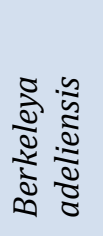 & 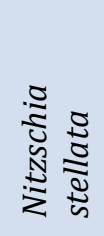 & 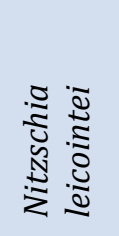 & 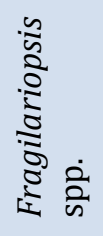 & 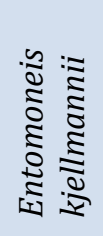 & 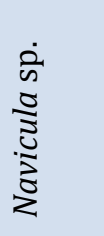 & * \\
\hline$\stackrel{\circ}{\stackrel{2}{N}}$ & 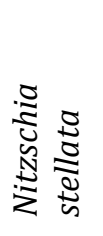 & 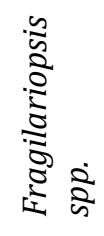 & 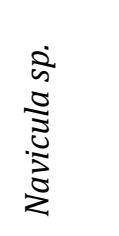 & 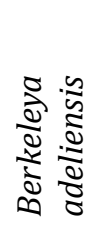 & 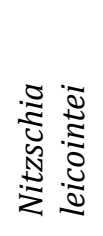 & & * \\
\hline ¿્ડ & 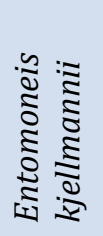 & 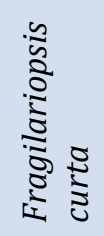 & 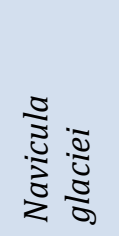 & 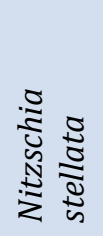 & & & 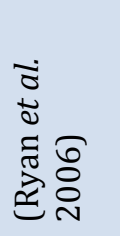 \\
\hline & 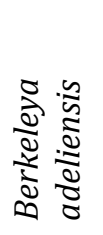 & 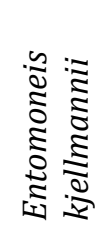 & 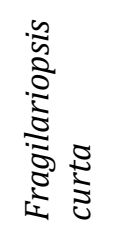 & 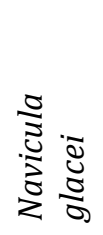 & 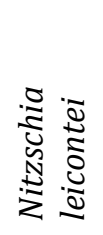 & 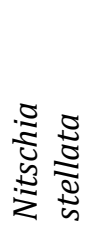 & 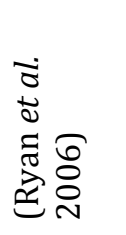 \\
\hline ڤू & 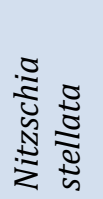 & & & & & & 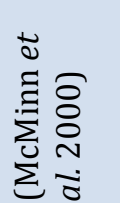 \\
\hline ڤू & 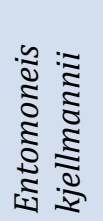 & 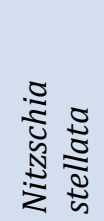 & 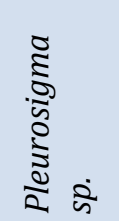 & 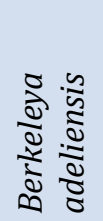 & 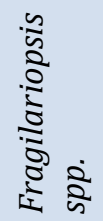 & 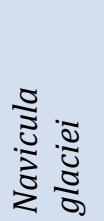 & 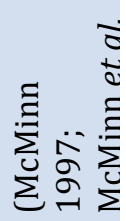 \\
\hline
\end{tabular}


Table 2.8 continued

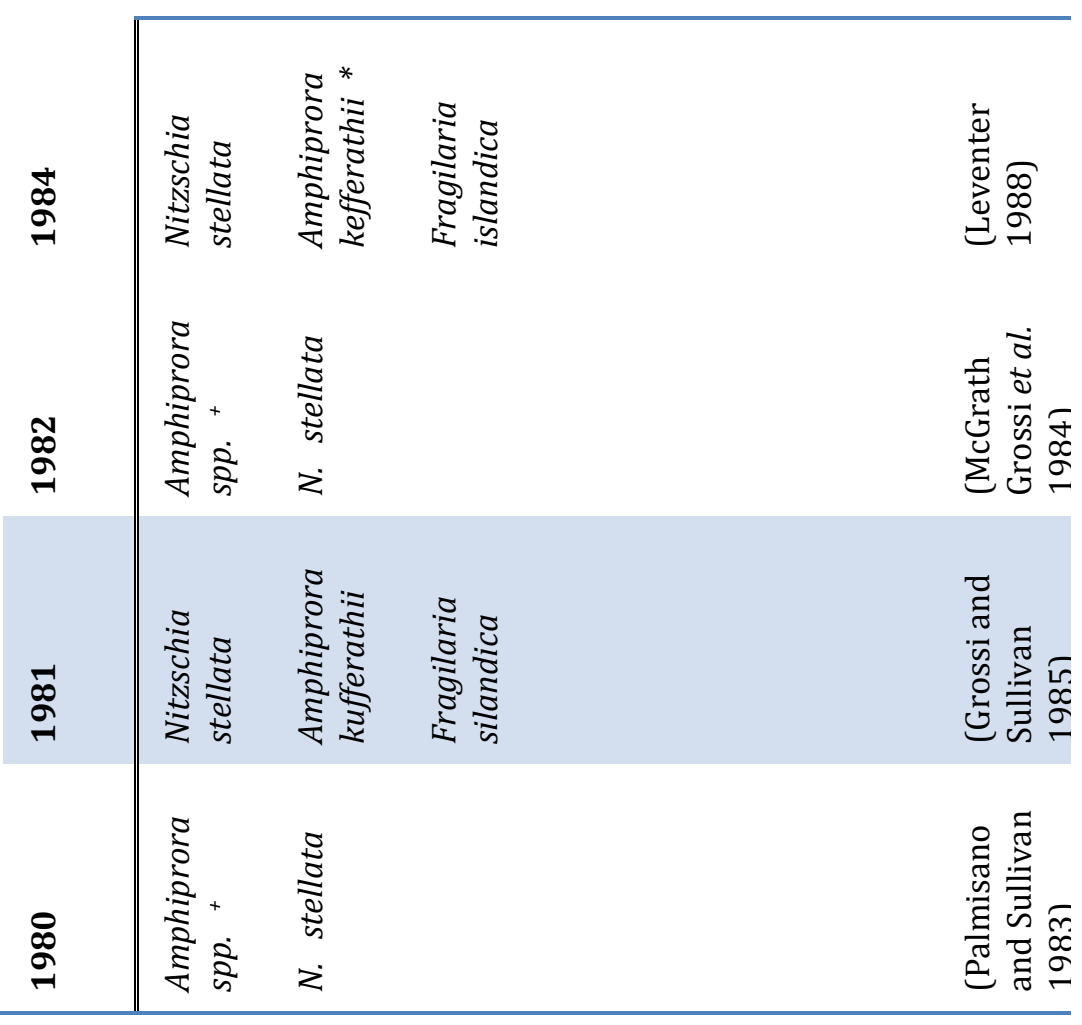


Sea ice thickness at TNB ranged from $<2.5 \mathrm{~m}$ in 2006, 2007, and 2011 to $<2 \mathrm{~m}$ in 2008 and 2010. This location also showed large variations in chl $a$ each year ranging from $<1$ to $>350$ mg.m ${ }^{-2}$ (Figure 2-9).

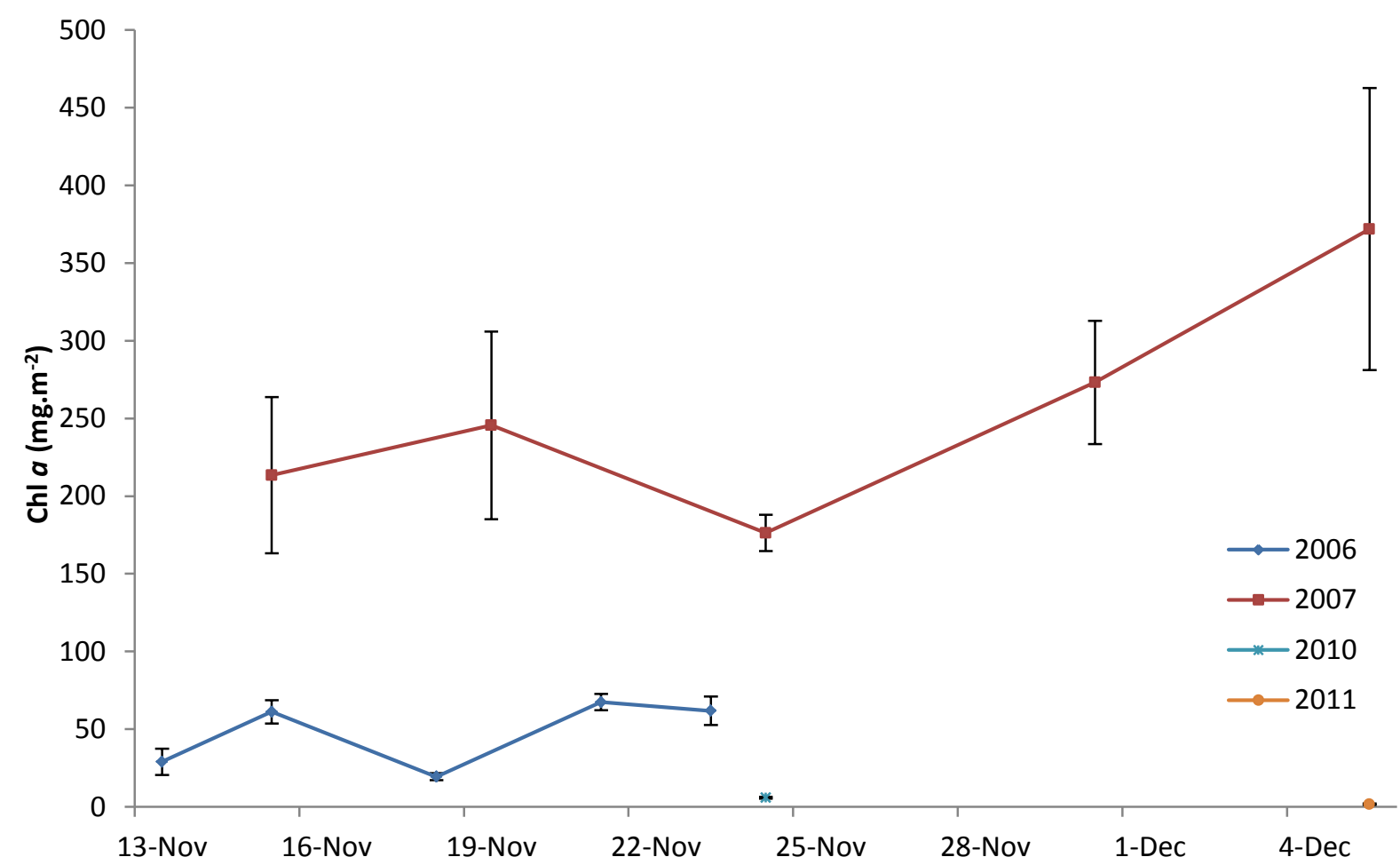

Figure 2-9: $\mathrm{Chl} a$ concentrations in the bottom $10 \mathrm{~cm}$ of the sea ice at Terra Nova Bay across multiple years. Data are means $\pm 1 \mathrm{SE}, n=4$ per data point.

Species compositions differed significantly from each other (PERMANOVA: df 4, PseudoF 25.354, $\mathrm{P}=0.0001$; Figure 2-10). All years form separate clusters, and the 2011 community was the most distinct in species composition from any of the other years. The years 2010 and 2008 and the years 2007, 2006 have several species in common (Table 2-9) resulting in a smaller distance on the MDS plot. 


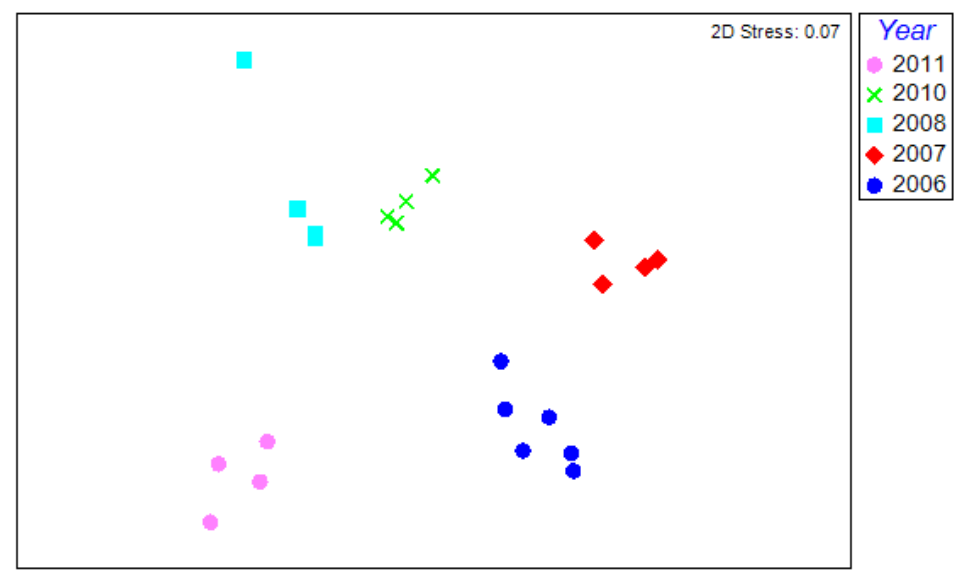

Figure 2-10: Comparison of similarities in the bottom sea ice communities at Terra Nova Bay for 5 years. Data were square root transformed and resemblance was done with Bray Curtis $(+d)$. Axes are arbitrary distance, and distances between samples are proportional to similarity between the assemblages.

Data from several published studies were incorporated to make a time line of sea ice algal composition at TNB spanning more than 15 years (Table 2-9). TNB has had several complete changes of species composition, notably in the years 2006-2008 (Table 2-9). In 2006, haptophytes dominated the bloom with $41 \%$ abundance. In 2007 , $B$. adeliensis was not only reported for the first time at this location, but also it also dominated the sea ice bloom. A similar pattern occurred in 2008 when a species not found earlier at this location, Stellarima sp., was one of the most abundant species present. 
Table 2-9: Bottom sea ice species composition measured over several years for Terra Nova Bay. Species are organised from high to low abundances and make up between $80-95 \%$ of the total algal count. *= this thesis. ${ }^{+}=$species as reported by authors but many Amphiprora sp. have been transferred in recent years to the genus Entomoneis sp.

\begin{tabular}{|c|c|c|c|c|c|c|c|}
\hline$\underset{\text { 규 }}{\stackrel{-}{0}}$ & 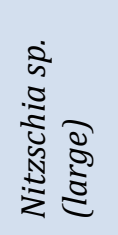 & 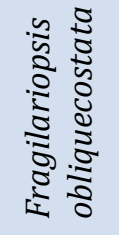 & 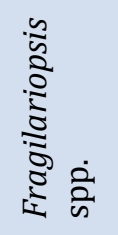 & & & & * \\
\hline 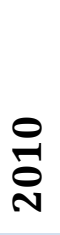 & 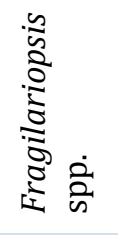 & 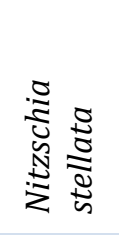 & 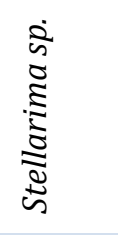 & 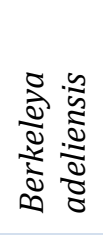 & 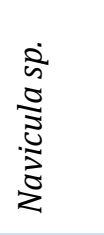 & & . \\
\hline $\begin{array}{l}\infty \\
\stackrel{\infty}{\delta} \\
\stackrel{\text { N }}{ }\end{array}$ & 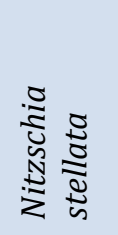 & 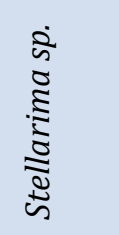 & 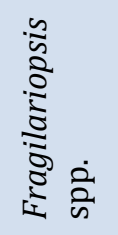 & 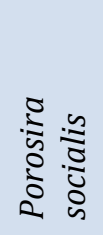 & 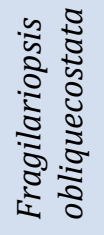 & & 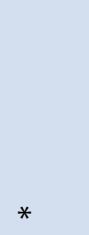 \\
\hline $\begin{array}{l}\hat{O} \\
\stackrel{\circ}{\circ} \\
\text { N }\end{array}$ & 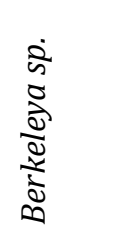 & 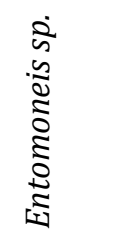 & 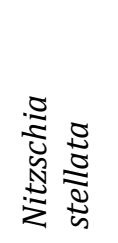 & 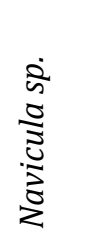 & & & * \\
\hline $\begin{array}{l}\text { ○̊ } \\
\text { ঠ }\end{array}$ & $\begin{array}{l}\text { गे } \\
\frac{\pi}{2} \\
0 \\
\frac{a}{\pi} \\
\frac{\pi}{1}\end{array}$ & 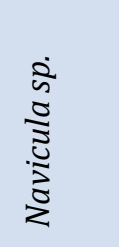 & 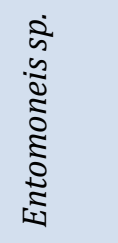 & 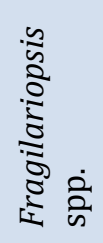 & & & * \\
\hline 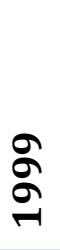 & 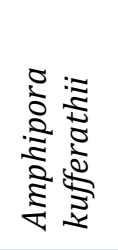 & 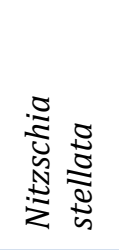 & 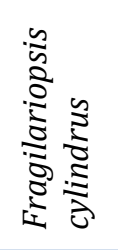 & 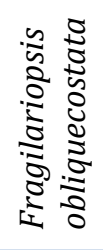 & 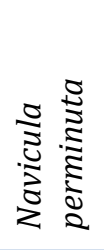 & & 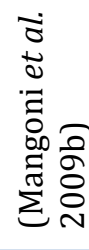 \\
\hline$\hat{\sigma}$ & $\begin{array}{l}0 \\
0 \\
0 \\
0 \\
0 \\
\frac{2}{2} \\
\frac{1}{2} \\
\frac{1}{2}+\end{array}$ & 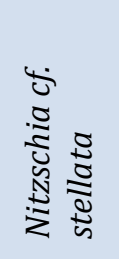 & 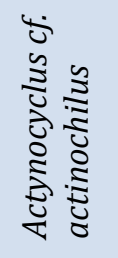 & 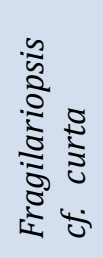 & $\begin{array}{l}5 \\
5 \\
0 \\
5 \\
5 \\
5 \\
5 \\
0 \\
\frac{0}{2} \\
\frac{0}{2}\end{array}$ & 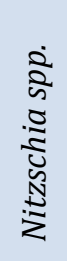 & 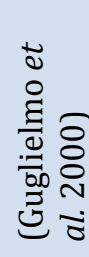 \\
\hline $\begin{array}{l}n \\
\text { } \\
\end{array}$ & 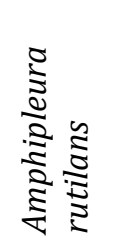 & 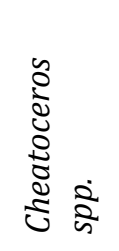 & 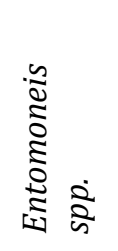 & 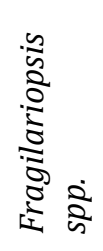 & 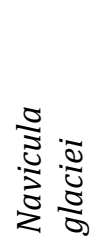 & & 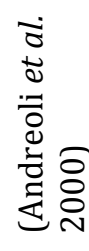 \\
\hline
\end{tabular}




\section{Abundance and community changes during the season}

While initial biomass values were low in the bottom of the ice, they rapidly increased at TR during the sampling period. In contrast, at CE biomass declined during the sampling period in the bottom of the sea ice (Figure 2-6). Growth rates were 0.126 day $^{-1}$ (doubling time $=7.9$ days) for TRNS, 0.080 day $^{-1}$ (doubling time $=12.5$ days) for TRLS and 0.267 (doubling time 3.7 days) for TRHS. Changes in sea ice community composition were observed during the sampling season (Pseudo-F=4.9786, $\mathrm{df}=12, \mathrm{P}=$ 0.001). Further pairwise statistical analysis of this showed that this trend for changing community composition held true for all for all locations and positions within the sea ice.

\section{Discussion}

A sea ice species composition for the Ross Sea was constructed stretching over 30 years. Sea ice algal composition showed high spatial and temporal variability. Several reasons for this have been identified and will be discussed.

\section{Yearly differences in sea ice algal communities}

Large differences were found in biomass and community composition between years in the bottom of the sea ice at TNB (Table 2-9) with some complete switches in dominant species being recorded. Snow cover, ice thickness and algal biomass may vary considerably between years in this region (Guglielmo et al. 2004), and this was confirmed in my study. Sea ice thickness in this study varied from 1.5 to $2.5 \mathrm{~m}$ in 2010 and 2006 respectively, with varying snow cover. My data show that ice thickness was not directly related to algal biomass in the bottom of the sea ice. Snow cover influences light levels and is a further driver of community composition (Mundy et al. 2007). TNB has a stable recurring polynya that persists throughout winter, although it varies in extent from less than $1 \mathrm{~km}^{2}$ to $5000 \mathrm{~km}^{2}$, due to changes in the patterns of katabatic winds at TNB (Knox 2009c). This results in yearly differences in the time that sea ice forms and the period it remains. When sea ice forms, the local seawater phytoplankton community is incorporated into the sea ice (Eicken 1992). When the timing of sea ice 
formation varies each year, it will result in large variation in species composition in the sea ice community from year to year, as different populations of phytoplankton may be incorporated into the ice at different times of the year. The sea ice is an extreme environment with many factors affecting primary production e.g., high salinity, low temperature, unfavourable $\mathrm{pH}$ levels, low $\mathrm{CO}_{2}$ and low micro- and macro nutrient concentration (Arrigo et al. 1999; Arrigo et al. 2000; Thomas and Dieckmann 2002a; Mangoni et al. 2009a; Vancoppenolle et al. 2010). The limited data on these sites make it difficult to determine the causes of variation in species composition.

Many more studies have been done at CE (Palmisano and Sullivan 1983; McGrath Grossi et al. 1984; Sullivan and Palmisano 1984; McMinn et al. 1999; Arrigo et al. 2000; Stoecker et al. 2000; Arrigo et al. 2003; Garrison et al. 2005; Ryan et al. 2006) and not only on algal taxonomy but also on physiological (Arrigo et al. 1998a; Robinson et al. 1998; McMinn et al. 1999; Ryan et al. 2006; McMinn et al. 2010) and oceanography (Arrigo et al. 2000; Arrigo and van Dijken 2003; Dinniman et al. 2007) parameters. Interpretations made for this location could possibly be extrapolated to other locations.

The ice at CE was approximately the same thickness with minimal to no snow cover each year, at approximately $1.8 \mathrm{~m}$ thick. (McMinn et al. 2007) noted that chl $a$ was correlated with ice thickness, however, my results show that algal biomass varied by up to 2 orders of magnitude with the same ice thickness. There was a massive biomass reduction during the austral summer of 2000-2001 compared to 1999 (Figure 2-7). This may have been due to the disruption in sea-ice retreat caused by the presence of several large icebergs that calved off the face of the Ross Ice Shelf (B-15, 2000 and C-19, 2002) in the early 2000's and significantly modified sea ice extent in the Ross Sea region (Dinniman et al. 2007). These icebergs blocked the movement of sea ice north and resulted in multiyear fast ice in regions previously dominated by first-year sea ice (Arrigo and van Dijken 2003). Icebergs can modify under-ice currents, and affect heat, salt, and other advective fluxes (Arrigo et al. 2003; Dinniman et al. 2007). Icebergs reduced the phytoplankton growth and biomass (Schwarz and Schodlok 2009) by reducing the advective input of organic matter in the region (Dinniman et al. 2007). 
Despite this severity of change in abiotic factors and large decrease in biomass, the sea ice algal community composition showed little variation in relation to dominant species present.

Multidimensional scaling analysis illustrates that the species present at CE formed discrete clusters with respect to sampling year. This separation is based on community composition as well as relative species abundance. It should be noted that Ryan et al. (2006) sampled slightly earlier in the 1999 and 2001 seasons compared to the present studies 2010-2012. While the species composition at CE was described as being relatively consistent from year to year (Ryan et al. 2006), a more detailed reexamination using PERMANOVA reveals significant differences between years. This could be attributed to Berkeleya adeliensis, which increased in abundance in the later part of the season in 1999 (Ryan et al. 2006). This trend infers a succession of species within the ice matrix from low light tolerant species to "high" light tolerant species (McMinn et al. 2010).

My analysis shows that since 1999 there has been an increasing prevalence of $B$. adeliensis and Fragillariopsis spp. in McMurdo Sound. Early studies (McGrath Grossi et al. 1984, Palmisano and Sullivan 1983, Grossi and Sullivan 1985) in the McMurdo Sound region in the 1980's showed that several species, Amphiprora spp. and Nitzschia stellata, were present in relatively high abundances each year between late October and early December (Table 2-8). This early work did not report Fragilariopsis spp. or $B$. adeliensis, which are now generally found in high abundances at the same time of the year. However, these particular species were present in other parts of the Southern Ocean (Palmisano and Sullivan 1983). Later studies (after the year 2000) have reported that the community is dominated by species such as E. kjellmannii, N. stellata, $B$. adeliensis, Fragilariospsis spp. Nitzschia lecointei, Navicula sp. (McMinn 1997; Ryan et al. 2004) (Table 2-8). Results to date suggest that while many species re-occur each year, their relative abundance changes significantly between years. The reason for the increasing prevalence of $B$. adeliensis is unclear. The first appearance of this species occurred before the large icebergs arrived (B-15, 2000 and C-19, 2002) so it is unlikely 
that changing circulation patterns are responsible. Similarly, ice thickness was similar between years and snow cover was minimal suggesting that it was not due to changes in light availability.

\section{Snow cover}

Snow cover significantly reduced the amount of PAR available to sea ice microbial communities (Figure 2-3). Except for those areas where snow cover exceeds $\sim 0.3 \mathrm{~m}$, there is usually sufficient light for net photosynthesis during the spring and summer (Arrigo et al. 1991; Arrigo et al. 2003). The snow fall recorded at TNB in 2006 was only $10 \mathrm{~cm}$ and there was no major effect on biomass. Similarly TRNS and TRLS, had similar biomasses and the snow cover was only 10-15 cm. At the TRHS site, the snow cover was $30-40 \mathrm{~cm}$, yet a slight increase in bottom ice algal biomass was observed over a 3 week period. These algae are highly shade adapted (Knox 2009b; Ryan et al. 2009; Mangoni et al. 2009a) and these results indicate that light-saturated photosynthesis may occur at even lower irradiances than proposed by Arrigo et al (2003).

Similarly, Mundy et al. (2007) found that snow thickness induced a variable response in ice algal biomass. In general, thin snow cover results in a thermal effect leading to early ice melt which subsequently reduces the growth season, whereas ice covered by deep snow remains thermally insulated from the warming atmosphere (Mundy et al. 2005; Mundy et al. 2007). Therefore, although thicker snow cover limits algal growth early in the season, the thermal effect allows algae to increase the length of their growth season. These results stress the importance of knowing the snow depth history. Unfortunately, the history of the duration of the snow cover in the current study is not known.

The three TR sampling sites were in close proximity and therefore were exposed to similar temperature, salinity and nutrient regimes. The only significant variable was solar irradiance. It is likely therefore that snow cover would have had different effects on the sea ice algal community. The microalgal species composition and biomass was similar between the no snow and low-snow $(10-15 \mathrm{~cm})$ sampling sites at TR, but under 
high snow cover the community composition changed when compared to the lower- or no- snow cover plots. Light levels were reduced so much due to the snow cover that several species were unable to dominate the community. In the HS site, B. adeliensis was less abundant than in the NS and LS plots where it was replaced by E. kjellmannii, suggesting that the latter species tolerates lower light levels. E. kjellmannii and $N$. stellata are both usually associated with interstitial ice, while species such as $B$. adeliensis form strand communities, and may prefer higher light (snow-free ice) (McMinn 1997). This is also illustrated by data from Ryan et al. (2006) who compared samples from CE at a snow covered site and a non-snow covered site, and showed a similar trend where the ratio of E. kjellmannii to B. adeliensis increased under snow cover. Microalgal samples taken from the ice/water interface at a number of coastal sites around Davis Station in Eastern Antarctica had species compositions that were also determined by the extent of snow cover (McMinn 1997). Sites which had a snow cover between 2 and $10 \mathrm{~cm}$ were dominated by E. kjellmannii and N. stellata. Snow-free sites were dominated by B. adeliensis and Thalassiosira australis. Together these data suggest that $B$. adeliensis has a higher demand for light than E. kjellmannii, and it is possible that E. kjellmannii can outcompete B. adeliensis under low light conditions.

TNB is $>300 \mathrm{~km}$ from $\mathrm{TR}$ and $\mathrm{CE}$ and is therefore exposed to very different environmental conditions and ice cover. This was evident in the multidimensional scaling analysis where TNB 2011 forms the most distant cluster (Figure 2-2c). Interestingly, CE is close to TR and should encounter many similar environmental conditions, yet the communities differ and form clusters with little overlap. This may suggest that the ice froze at different times at the start of winter in the two locations and different algal species were sequestered into the ice.

\section{Community and abundance changes during the season}

At TR, biomass increased 10 fold during the 3 week sampling period. The doubling time for these algae was similar to those found by (McMinn et al. 2010) who documented doubling times of between 7.3 and 13.9 days. In contrast, there was a decline in the total algal biomass at CE in 2010 and 2011. Ryan et al. (2006) found a higher biomass at 
CE 1999 and 2001 compared to 2010 and 2011, and also observed an increase in biomass during the season (chl $a$ and cell numbers) in 1999 and 2001. The period sampled by Ryan et al. (2006) was earlier in the season than this current study and it is possible that the growth had already reached its maximum. It is also likely that bottom ice algae ablate from the underside of the sea ice early in November, as has been observed in previous years (K.G. Ryan, pers. comm.). During the CE 2010 sampling, high numbers of amphipods (Orchomenoid spp.) could be seen under the ice suggesting that there was a high grazing pressure which reduced the biomass (pers. obs.).

Despite the changes observed in biomass at TR and CE, the species present at the end of the sampling period were the same as those at the beginning, however the relative abundances changed. When the ice forms, the sea ice community is likely to be comparable to that found in the waters from which the organisms were recruited. However, during the season a shift in population and dominance of species occurs with a gradual reduction in the numbers of large centric diatom species and an increase in small pennate diatoms (Arrigo and Thomas 2004). A similar transition has been observed for sea ice bacteria (Junge et al. 2004) whereby psychrophilic species dominate following the initial inoculation event.

Sea ice biomass often displays a high level of spatial heterogeneity, which has the potential to confound time course measurements (Fiala et al. 2006). This heterogeneity might be an issue for the top and middle of the sea ice, which showed no trends in growth rates (except for TRHS) due to high variability in biomass between sampling days and between replicates. Biomass in the top and middle of the sea ice was found in brine pockets and channels, and therefore a bias may have been introduced by sampling a biomass "hot spot" such as a large brine pocket. Also the biomass is relatively low in these regions within the ice, increasing the risk of skewed data. Stoecker et al. (2000) reported that physical and chemical properties of the brine can be highly variable among samples collected from replicate ice cores. 


\section{Vertical position within the ice}

The largest differences in biomass and community composition can be found at different vertical positions within the sea ice. Possibly, this is because the top and middle sea ice environment differs physically from the bottom of the sea ice. The interior and upper sections of the sea ice are a more extreme environment with very low temperatures, low nutrients and high salinity levels (Stoecker et al. 2000). These physiochemical conditions considerably modify the sea ice algal species composition (Ryan et al. 2004). This part of the sea ice is often dominated by halo- and cryotolerant species (Stoecker et al. 2000). Species that are better able to cope with salinity (Stoecker et al. 2000), variable light, $\mathrm{pH}$ and temperature changes have an advantage and become the dominant species in the brine. The similarities in community abundance and species composition between years in the top and middle could suggest that only a limited number of species can live in the middle and top of the sea ice.

\section{Key species}

The predicted loss of annual sea ice and thus the increase of the permanently open ocean zone may favour non-diatom species (Arrigo et al. 1999). This change in community composition can be caused by a change in stratification of the water column. Diatoms dominate in shallow highly stratified waters, whereas Phaeocystis Antarctica, a very abundant haptophyte, dominates more mixed waters. Stratification and mixing is dependent on melt water from sea ice or glaciers (Annett et al. 2010), whereas wind and wave action cause mixing of the water column (Knox 2009a). Weather mixing or stratification occurs is also dependent on ice thickness, the timing of the melt and the extent and duration of the ice cover (Knox 2009a). Increased stratification of surface waters in polar regions may favour an increase in the abundance of diatoms, which additionally have a much lower N:P requirement (Arrigo et al. 1998b). A change in community composition to larger diatoms could increase nutrient utilization efficiency and further increase rates of production in the Southern Ocean. Therefore, it is crucial to gain a better understanding of the contribution of sea ice primary productivity to the Southern Ocean ecosystem. Change to the ecosystem could be studied via the prevalence of several "key" species. For example, B. adeliensis is a sub-ice mat strand assemblage and can be dislodged in strong currents. Given that changes are expected in 
the degree of stratification in the water column (Priddle et al. 1992; Arrigo and Thomas 2004), B. adeliensis may represent a valuable indicator species. Furthermore, stratification prevents mixture of deep nutrient-rich waters (Arrigo and Thomas 2004), which could influence nutrient concentrations (Priddle et al. 1992). Fragilariopsis spp. (especially F. cylindrus) is heavily frustulised (Tomas 1997), with a high silicate demand, while in contrast, E. kjellmannii is weakly frustulised and is very well adapted to the low light levels associated with snow cover. Enhanced precipitation (in the form of snow) is predicted to increase in the future with climate change (Turner and Overland 2009). In addition, E. kjellmannii can also occur in the seawater it possibly important in future ice-edge blooms, making it is an important species for future study.

\section{Conclusions}

My findings show large differences in biomass and community composition between years, between locations geographically close to each other, and during the growing season. This suggests that sea ice is spatially highly heterogeneous and local differences in physicochemical characteristics have large influences on total biomass and species composition.

The general trend shows a reduction of biomass with increasing snow cover. Yet the reduction of light alone is not sufficient to explain the amount of biomass present in the bottom of the sea ice. Cape Evans has a very consistent ice thickness between years yet algal biomass can vary as much as 2 orders of magnitude within the same ice thickness.

Many species re-occur each year, but their relative abundance changes significantly between years. Most notably, since 1999 there has been an increasing prevalence of $B$. adeliensis sp. and Fragilariopsis spp. at CE. A change in species composition may be caused by changes in snow cover, nutrient availability, ice thickness, and the timing of sea-ice formation, all of which are all related to climate change. Several "key" species have been identified which will be useful is assessing future changes. It illustrates the 
importance to continue further studies which also incorporate the analyses of abiotic factors such as temperature, salinity, currents, ice thickness and snow cover. 


\title{
Chapter 3 The influence of snow cover on total particulate organic carbon in bottom and interior sections of Antarctic sea ice
}

\begin{abstract}
In this study I attempted to quantify sea ice algal, EPS and prokaryotic carbon under varying snow covers, and characterize seasonal trends and spatial variability of organic carbon sources in sea ice. During the early Austral summer of 2011/2012, large differences in sea ice particulate organic carbon content (TPOC) were found vertically in the sea ice of the McMurdo Sound, Antarctica. Diatoms formed the largest carbon source in the bottom of the sea ice at up to $9,000 \mu \mathrm{g} \mathrm{C.L-1}$ or $90 \%$ of the TPOC, while the interior of the sea ice was dominated by EPS at a concentration of $\sim 350 \mu \mathrm{g} \mathrm{C.L-1}$. At this concentration, EPS comprised 90\% of the TPOC. Increasing snow cover significantly reduced the amount of diatoms and EPS present in the bottom of the sea ice, while prokaryotic abundance remained constant. In contrast, no significant changes in particulate organic carbon could be found in the interior of the sea ice in relation to increasing snow cover or in relation to season progress. Over the sampling period, measurements showed an increase in algal cells and EPS, but no difference in prokaryotic abundance was observed. This suggests an uncoupling of the microbial loop either by a substrate limitation due to release of allopathic substances by algae or a high bacteriophage infection. Light levels in the interior of the sea ice are higher than at the bottom of the sea ice. Yet, no significant increase in TPOC or any of the carbon sources could be observed in the interior of the sea ice in relation to decreasing snow cover or when the season progressed. This indicates that the interior of the sea ice is limited by a factor(s) other than light.
\end{abstract}




\section{Introduction}

Organisms in the sea ice provide a major carbon source for many animals; therefore it is important to study factors (such as reduced PAR and nutrient deficiency) that can influence the carbon budget in the sea ice. Particulate organic carbon levels in sea ice can be very high (1.5-4.0 g C.m $^{-2}$ ) (Hegseth 1992; Krembs et al. 2002), however estimates vary widely. This is due to a range of factors, including local and seasonal differences in the amount of ice-free water, nutrient supply and light regimes, and the various methodologies used for calculating production (Tamelander et al. 2009). In the sea ice, the main carbon contributors are: prokaryotes, algae and exopolymeric substances (EPS).

The dominant primary producers ice in sea ice are diatoms, which, due to their high abundance and relatively large size, may contribute more than $90 \%$ of the total algal biomass and $>40 \%$ of the total particulate organic carbon (Arndt et al. 2009; Arrigo et al. 2010). Diatom standing stocks of up to $1,000 \mu \mathrm{g}$ chlorophyll. $\mathrm{L}^{-1}$ have been measured in sea ice which is significantly higher than the values of 0 to $5 \mu \mathrm{g}$ chlorophyll. $\mathrm{L}^{-1}$ for surface waters of the Southern Ocean (Thomas and Dieckmann 2002a). Primary production in the sea ice contributes $10 \%-30 \%$ to the total annual primary production of ice-associated regions of the Southern Ocean (Arrigo and Thomas 2004). This relatively low contribution is in fact highly significant, given that sea ice microbes provide a concentrated food source that extends the short period of primary production in the water column (Thomas and Dieckmann 2002a).

Prokaryotes are the most abundant organisms throughout the ice matrix (Deming 2010). Their growth is fuelled by large pools of dissolved organic matter consisting largely of carbohydrates produced by the death and lysis of sea ice organisms, as well as EPS by algae and bacteria (Thomas and Dieckmann 2002a). Prokaryotic abundance tends to increase with increasing algal biomass, however for the polar regions this system can be uncoupled (Meiners et al. 2004) depending on seasons, habitats and available DOM (Steward and Fritsen 2004). However, within sea ice the coupling between phytoplankton and bacteria is variable. 
Non-living carbon sources such as detritus and faecal matter generally contribute small amounts to the carbon budget compared to the living particulate organic matter (Alldredge et al. 1993). However, high rates of particle aggregation of polysaccharides exuded by phytoplankton and bacteria have been found in seawater and sea ice (Meiners et al. 2004; Underwood et al. 2010). This EPS is primarily composed of polysaccharides, leachates, and other photoassimilates (Underwood et al. 1995), but may also contain significant amounts of proteins and lipids (Bellinger et al. 2010). These polymeric gel-like substances form abiotically from dissolved and colloidal organic matter (Engel and Passow 2001). Bacteria as well as algae can excrete EPS, but the main contributor in the sea are algae (Riedel et al. 2006; Underwood et al. 2010). High concentrations of EPS (up to $70-80 \%$ of algal biomass) have been measured in Antarctic sea ice from the Bellinghausen Sea (Meiners et al. 2004) and this may significantly alter the morphology of brine pore space and the permeability for solutes and microorganisms within the ice matrix (Krembs et al. 2011). Glycoproteins, a constituent of EPS, may modify the surfaces and optical properties of ice around microalgae and/or increase the ability of cells to adhere to ice crystals. In dense accumulations of algae and bacteria, it is possible that matrices akin to biofilms develop within brine channels. EPS is thought to provide protection against environmental stress and may also serve as a cryoprotectant and buffer to fluctuations in $\mathrm{pH}$ (Krembs et al. 2002; Krembs and Deming 2008). It is also likely that the production of an extracellular matrix of polymers is used by cells to regulate extracellular water availability and to provide a diffusion barrier whereby salts are excluded and stress protectants, such as glycerol, remain in close proximity to the cell (Krembs and Deming 2008, Decho and Moriarty 1990). EPS is of significant ecological interest because the exopolymers can be utilized by bacteria, meiofauna and macrofauna as a carbon source (Decho and Moriarty 1990).

Current climate change models predict an increase of precipitation in the form of snow over the next century in Antarctica (Turner and Overland 2009, Convey et al. 2009). Currently $\sim 6 \mathrm{~mm}$ of precipitation falls per year, but this varies widely from region to region (Convey et al. 2009). It may increase by $20 \%-50 \%$ over the next century (Mayewski et al. 2009). Small variations in snow thickness have a major impact on total 
PAR reaching sea ice communities as a result the high attenuation coefficient of snow (Sturm et al. 2010). Snow depth has a negative log linear relationship with algal biomass in the bottom of the sea ice (Mundy et al. 2007). Any marked change in snow thickness, distribution and properties will have a complex and major impact on the sea ice community, primary production and the TPOC of sea ice, depending on season and the thickness of the sea ice. In winter and spring, snow cover insulates the ice from the colder air, and later in the season when the air temperature is warmer, the ice is protected from melting and primary production can continue (Mundy et al. 2005). This could mean that low snow cover could be beneficial for primary production in the longer term. Snow cover significantly reduces the incoming light, but photosynthesis has been recorded at extremely low light conditions $\left(2-10 \mu \mathrm{mol}\right.$ photons $\left.\mathrm{m}^{-2} \mathrm{~s}^{-1}\right)$ (McMinn et al. 2007; Arrigo et al. 2010) for a snow cover of up to $0.3 \mathrm{~m}$ (Arrigo et al. 1991; Arrigo et al. 2003). Ice algae are therefore adapted to extremely low light intensities, and any changes in algal biomass will have an influence on EPS production. Furthermore, in many marine environments, bacterial abundance tends to increase with increasing algal biomass (Steward and Fritsen 2004). However, within sea ice, the coupling between phytoplankton and bacteria is variable (Meiners et al. 2004) and it is unclear how snow cover influences this coupling. Most work in this area has focused on the bottom $10 \mathrm{~cm}$ of the sea ice. In this study, the influence of snow cover on the TPOC of the interior of the sea and the role of ice algae - bacterial coupling was also assessed.

The objectives of this research were to (1) evaluate the relative concentrations of different carbon sources under high and low snow cover, and identify relationships with sea ice algal biomass and bacterial abundance, (2) characterize seasonal trends in carbon concentrations in the sea ice and the contribution of the 3 carbon sources that make up TPOC, and (3) assess spatial variability of the carbon sources in sea ice. For the purpose of this study, TPOC was subdivided based on its origin: 1) prokaryotic carbon, 2) eukaryotic carbon (i.e. algal carbon) and 3) non-living carbon source EPS. Snow cover significantly reduces the light availability to the underlying sea ice (Mundy et al. 2007), therefore, I hypothesized that the snow cover influences the TPOC and in particular the algal biomass which is depended on light for photosynthesis. TPOC would be highest under low snow cover and lowest under high snow cover. 


\section{Methods}

\section{Sample locations}

Turtle Rock, Ross Island $\left(77^{\circ} 38^{\prime} S, 166^{\circ} 25^{\prime} E\right)$

Samples of first year fast ice $(1.95 \mathrm{~m})$ were collected every $3-4$ days between the $18^{\text {th }}$ of November and $6^{\text {th }}$ of December 2011. Three sampling sites were established: one site without snow cover, one with 10-15 cm snow cover, and one with 30-40 cm snow cover. The history of snow cover was unknown, but considering local wind conditions, these sites were likely to have had similar snow covers for the previous 2-4 weeks. For each sampling day and plot, samples were taken from the top $10 \mathrm{~cm}$, middle $10 \mathrm{~cm}$ and bottom $10 \mathrm{~cm}$ of the sea ice. The water current under the sea ice was negligible. No ice platelets were present on the underside of the sea ice. A total of 216 ice cores were collected ( 4 replicates $\mathrm{x} 6$ time points $\mathrm{x} 3$ locations $\mathrm{x} 3$ vertical positions).

\section{Cape Evans, Ross Island $\left(77^{\circ} 38^{\prime} S, 166^{\circ} 25^{\prime} E\right)$}

Samples of first year fast ice were collected at time points between $15^{\text {th }}$ of November and $6^{\text {th }}$ December 2011. The ice thickness was $1.60 \mathrm{~m}$ with no snow cover. No ice platelets were present on the underside of the sea ice and the water current was minimal. A total of 72 ice cores were collected ( 4 replicates $\times 3$ time points $\times 3$ vertical positions).

Terra Nova Bay, Victoria Land $\left(7^{\circ} 38 S, 164^{\circ} 13 E\right)$

On the $5^{\text {th }}$ of December 2011, 12 ice cores (4 replicates x 3 vertical positions) were collected from first year ice. The ice thickness was $2.5 \mathrm{~m}$ with no snow cover and there were no ice platelets on the underside of the sea ice.

As far as possible these sites represented the range of conditions of sea ice in the region. 


\section{Sample collection}

Sea ice algae were collected using a $140 \mathrm{~mm}$ diameter Kovaks (USA) ice corer. During collection, the cores were protected from light damage by performing all operations underneath a black sheet and transferring the cores into black plastic containers. Ten $\mathrm{cm}$ samples were collected from the top, middle and bottom of the ice core. These ice core sections were melted under low-light and low temperature $\left(\sim 4^{\circ} \mathrm{C}\right)$ over a period of $12 \mathrm{~h}$. After melting, each sample was divided into subsamples and processed for further analyses of total particulate organic carbon, prokaryotic carbon, algal carbon and EPS as described below.

\section{Prokaryotic carbon}

Prokaryotic carbon sample $(400 \mu \mathrm{l})$ was pipetted into a flow tube and $25 \mu \mathrm{l}$ of SYBR Gold (Molecular Probes) (working solution $4 \mathrm{ml}$ DMSO added to $50 \mu \mathrm{l}$ vial of SYBR Gold) was added. Samples were vortexed briefly, and left in the dark for approximately five minutes. TruCount solution $(75 \mu \mathrm{l})$ was added prior to running each sample. TruCount solution was made by adding $500 \mu \mathrm{l}$ double distilled $\mathrm{H}_{2} \mathrm{O}$ to a Becton Dickinson TruCount tube.

Samples were analysed on a Becton Dickinson (USA) FACSCalibur flow cytometer. Initial instrument calibration was performed using Becton Dickinson CaliBRITE reference beads. The sheath fluid was double distilled $\mathrm{H}_{2} \mathrm{O}$ (Beckmann, USA). To avoid coincidence, samples were run on a low flow rate with less than 800 events per second (average 200). Each sample was run till 10,000 events were detected. Bacterial cell populations and TruCount beads were visualised on density plots of SSC vs. FL1. Flowjo software was used for all sample and data analyses.

Carbon content per cell was calculated using bacteria cell size data from Martin (2005). These data were based on calculating cell biovolume and then converting this to bacterial carbon per cell. Biovolume calculation used the formula of Fry and Davies (1985) for rod-shaped cells: $V=(d 2 \pi / 4)(l-d)+\pi d 3 / 6$ where $l=$ cell length and $d=$ cell width. The biovolume of cocciod shaped cells was calculated using the equation of 
Sherr et al. (2001): $V=(\pi / 4) d 2(l-d) / 3$. This calculation makes the assumption that cell shape approximates a cylinder with hemispherical ends and that cell depth is equal to cell width. Biovolume was converted to bacterial carbon biomass by the biovolumespecific formula of Simon and Azam (1989). CC $=88.6$ x vol0.59 x 1.042 where CC = average carbon content per cell (fg) and vol = average cell volume.

\section{Eukaryotic carbon}

Undiluted melted ice core were fixed with Lugol's iodine solution to a final concentration of $2.5 \%$ and $500 \mu \mathrm{l}$ of the sample were counted using an inverted microscope (Zeiss, Germany) to obtain total cell counts. The length, width, height or diameter of at least 50 cells per species/location/sea ice position were measured and averaged. All calculations were based on these average dimensions. The carbon content of sea ice diatoms was determined by calculating their biovolume based on equations described by Hillebrand et al. (1999) and converting these volumes to carbon using equations described by Menden-Deuer and Lessard (2000). The cellular carbon content was determined from the biovolume values based on the relationship: pgCarbon/cell $=a^{*}$ Volume $\left(\mu \mathrm{m}^{3}\right)^{0.811}$, where $a$ is 0.117 for diatoms bigger than $3,000 \mu \mathrm{m}^{3}$ and 0.288 for diatoms smaller than $3,000 \mu \mathrm{m}^{3}$ (Menden-Deuer and Lessard 2000). The carbon content of dinoflagellates was determined using the following formula: pgCarbon/cell $=0.760 \mathrm{x}$ volume $\left(\mu \mathrm{m}^{3}\right)^{0.819}$ (Menden-Deuer and Lessard 2000).

\section{EPS}

The terminology to describe EPS varies within the literature. Here I use the definition of Riedel et al. (2007) where EPS represents particulate $(>0.4 \mu \mathrm{m})$ exopolysaccharides as measured by the Alcian blue method of Passow and Alldredge (1995). Alcian Blue is a cationic copper phthalocyanine dye that complexes carboxyl (-COO-) and half-ester sulphate $\left(\mathrm{OSO}_{3}-\right)$ reactive groups of acidic polysaccharides (Engel and Passow 2001). This aqueous dye solution at $\mathrm{pH} 2.5$ without extra electrolyte will stain both carboxyl and sulphated polysaccharides instantaneously, but not neutral sugars (Alldredge et al. 1993). EPS was quantified as Gum Xanthan equivalent as described by Passow and (Alldredge 1995). The Gum Xanthan equivalent was converted using the formula 
Carbon $\left[\mu \mathrm{g} . \mathrm{L}^{-1}\right]=(0.75)$ [TEP; $\mu \mathrm{g}$ Xant. Equiv.L $\left.\mathrm{L}^{-1}\right]+(110)$ as described by Engel and Passow (2001).

\section{Total particulate organic carbon}

For the top and middle of the sea ice between $400-500 \mathrm{ml}$, and for the bottom $\sim 100 \mathrm{ml}$ of melted sea ice were filtered through a pre-ashed and pre-weighed $25 \mathrm{~mm}$ GF/F filter (pore size $0.45 \mu \mathrm{m}$ ) and stored at $-20^{\circ} \mathrm{C}$ until further processing. Samples were dried at $40^{\circ} \mathrm{C}$ for $48 \mathrm{~h}$ and weighed. Filters were transferred to $5 \times 9 \mathrm{~mm}$ aluminium cups and analysed by combustion on a Eurovector elemental analyser coupled to an Isoprime mass spectrometer. All results are reported with respect to VPDB and N-Air, normalized to an internal standard, leucine $(-22.7 \%$ or $\delta 13 \mathrm{C}, 2.2 \%$ or $\delta 15 \mathrm{~N})$. The analytical precision for these measurements is $0.3 \%$ for $\delta 15 \mathrm{~N}$ and $0.2 \%$ for $\delta 13 \mathrm{C}$.

\section{Statistics}

Statistics were performed using SPSS version 18. Changes in bacterial carbon, algal carbon and EPS carbon were compared over time, between locations and position in the sea ice using one-way-ANOVA. One-way and two-way MANOVA were used to test for a change of proportions in particulate organic carbon contributors over time and between locations. When significant differences were observed a Tukey Post hoc analysis was done to determine which carbon contributor changed. To test if the TPOC measurement from the elemental analyser and TPOC measurement obtained from combining EPS, eukaryote and prokaryote carbon differed from each other a T-test was used. Data were tested for similarity in variance by the Levene's test for equality of variance and the T-test was corrected accordingly.

\section{Results}

\section{Total particulate organic carbon}

TPOC was determined by the heat combustion method and by combining measurements of EPS carbon, eukaryotic carbon and prokaryotic carbon. These 
methods of measurements were compared with each other per time point (Figure 3-1 and Table 3-1). Except for time point 7-December, all samples had a similarity in variance. There were no significant differences found between the methods of measurement for any of the time points. The remaining results and discussion will use the values obtained from the additive TPOC method.

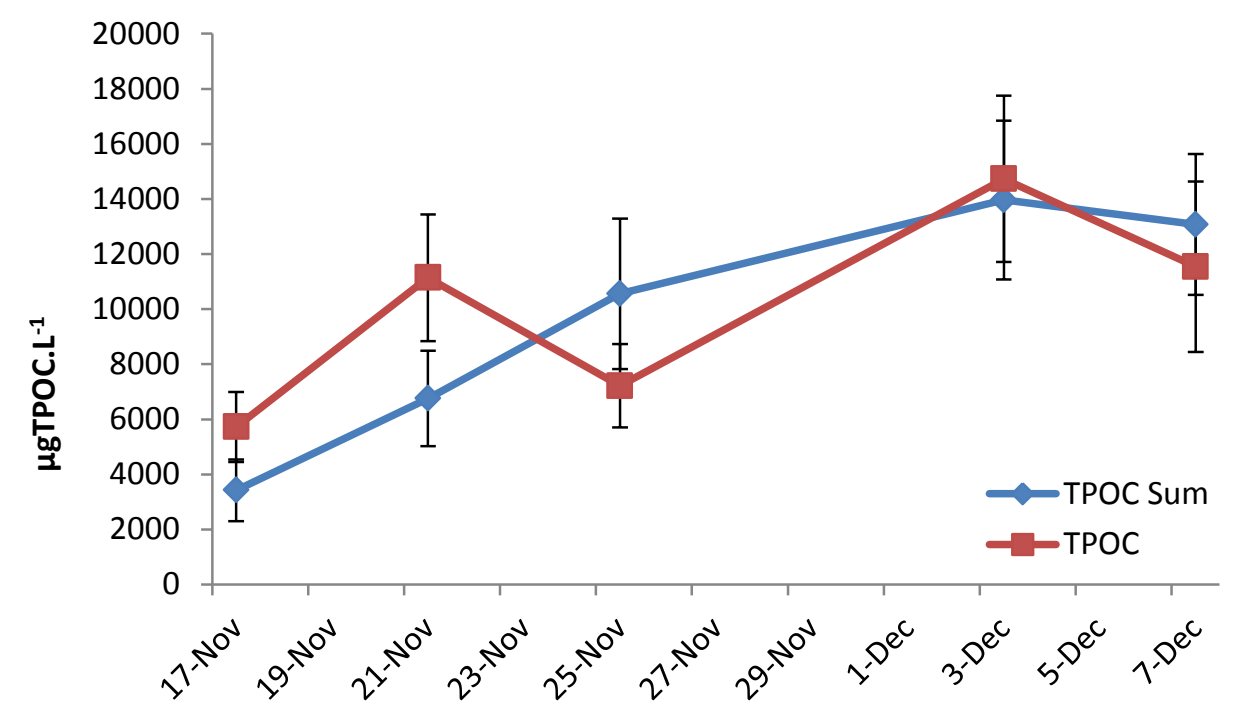

Figure 3-1: Comparison of methods to determine TPOC. Samples ( $n=3$ per data point) used were obtained from the bottom of the sea ice at TRNS. TPOC sum was derived from adding all carbon constituents together. TPOC was measured using a C:N analyser. Data are means $\pm 1 \mathrm{SE}, n=4$ per data point).

Table 3-1: Comparison of methods for the determination of TPOC. Samples were obtained from the bottom of the sea ice at TRNS and analysed for TPOC by means of heat combustion and by combining measurements of EPS carbon, eukaryotic carbon and prokaryotic carbon.

\begin{tabular}{llccc}
\hline & \multicolumn{2}{l}{ Levene's Test for Equality of Variances } & \multicolumn{2}{c}{ T-test for Equality of Means } \\
\hline Date & F & Sig. & df & Sig. (2-tailed) \\
17-Nov & 2.081 & 0.223 & 4 & 0.198 \\
21-Nov & 0.277 & 0.627 & 4 & 0.199 \\
25-Nov & 0.422 & 0.551 & 4 & 0.265 \\
3-Dec & 0.304 & 0.611 & 4 & 0.930 \\
7-Dec & 10.439 & $\mathbf{0 . 0 3 2}$ & 2.087 & 0.568 \\
\hline
\end{tabular}


There was a significant difference in TPOC between the bottom samples (one-way ANOVA: $\mathrm{F}=6.719, \mathrm{P}<0.0005$ ) at all locations, but there was no significant difference between the top (one-way ANOVA: $\mathrm{F}=0.391, \mathrm{P}=0.815$ ) and the middle (one-way ANOVA: $\mathrm{F}=0.188, \mathrm{P}=0.945$ ) samples (Table 3-2). During the sampling season, TPOC increased in TRHS samples. No significant change was observed in samples from the other locations (Table 3-2).

Table 3-2: Two-way-MANOVA analysis of change in total organic carbon over time per location and position in the sea ice. Numbers in bold show a significant change in total particulate organic carbon concentration $(\mathrm{P}<0.05)$.

\begin{tabular}{llclc}
\hline & \multicolumn{2}{l}{ Levene's Test for Equality of Variances } & \multicolumn{2}{c}{ T-test for Equality of Means } \\
\hline Date & F & Sig. & df & Sig. (2-tailed) \\
17-Nov & 2.081 & 0.223 & 4 & 0.198 \\
21-Nov & 0.277 & 0.627 & 4 & 0.199 \\
25-Nov & 0.422 & 0.551 & 4 & 0.265 \\
3-Dec & 0.304 & 0.611 & 4 & 0.930 \\
7-Dec & 10.439 & $\mathbf{0 . 0 3 2}$ & 2.087 & 0.568 \\
\hline
\end{tabular}

\section{Prokaryotic abundance and carbon content}

Prokaryotes dominated in abundance at all vertical positions in the sea ice (Table 3-3), but due to their relatively small size compared to eukaryotes, the biomass $\left(\mu g C . \mathrm{L}^{-1}\right)$ was low. Prokaryotic abundance was highest in the bottom $10 \mathrm{~cm}$ of the sea ice and decreased with vertical position in the sea ice. The prokaryotic carbon content followed a similar pattern, with the highest values in the bottom followed by the middle and top sections of the annual sea ice (Table 3-3). 
Table 3-3: Average abundances and biomass of prokaryotes in the sea ice. Biomass was obtained by determining abundance and calculating biovolume and multiplying this by the carbon per cell factor. Standard error $( \pm \mathrm{SE})$ is noted in the brackets.

\begin{tabular}{|c|c|c|c|c|c|c|c|c|c|c|}
\hline & \multicolumn{5}{|c|}{ Abundance $10^{8}$ cells.L $\mathrm{L}^{-1}( \pm \mathrm{SE})$} & \multicolumn{5}{|c|}{ Biomass $\mu \mathrm{gC.} \cdot \mathrm{L}^{-1}( \pm \mathrm{SE})$} \\
\hline & $\begin{array}{l}\text { TRNS } \\
n=24\end{array}$ & $\begin{array}{l}\text { TRLS } \\
n=24\end{array}$ & $\begin{array}{l}\text { TRHS } \\
n=24\end{array}$ & $\begin{array}{l}\text { CE } \\
n=12\end{array}$ & $\begin{array}{l}\text { TNB } \\
n=4\end{array}$ & $\begin{array}{l}\text { TRNS } \\
n=24\end{array}$ & $\begin{array}{l}\text { TRLS } \\
n=24\end{array}$ & $\begin{array}{l}\text { TRHS } \\
n=24\end{array}$ & $\begin{array}{l}\text { CE } \\
n=12\end{array}$ & $\begin{array}{l}\text { TNB } \\
n=4\end{array}$ \\
\hline Top & $\begin{array}{l}5.4 \\
(2.5)\end{array}$ & $\begin{array}{l}5.2 \\
(3.8)\end{array}$ & $\begin{array}{l}2.8 \\
(1.1)\end{array}$ & $\begin{array}{l}3.4 \\
(0.4)\end{array}$ & $\begin{array}{l}4.7 \\
(1.1)\end{array}$ & $\begin{array}{l}25 \\
(2.5)\end{array}$ & $\begin{array}{l}22 \\
(3.8)\end{array}$ & $\begin{array}{l}18 \\
(1.1)\end{array}$ & $\begin{array}{l}19 \\
(0.4)\end{array}$ & $\begin{array}{l}26 \\
(1.1)\end{array}$ \\
\hline Middle & $\begin{array}{l}10 \\
(2.9)\end{array}$ & $\begin{array}{l}7.7 \\
(1.7)\end{array}$ & $\begin{array}{l}7.5 \\
(1.0)\end{array}$ & $\begin{array}{l}8.0 \\
(1.2)\end{array}$ & $\begin{array}{l}5.1 \\
(0.4)\end{array}$ & $\begin{array}{l}56 \\
(2.9)\end{array}$ & $\begin{array}{l}43 \\
(1.7)\end{array}$ & $\begin{array}{l}42 \\
(1.0)\end{array}$ & $\begin{array}{l}44 \\
(1.2)\end{array}$ & $\begin{array}{l}29 \\
(0.4)\end{array}$ \\
\hline Bottom & $\begin{array}{l}19 \\
(12.6)\end{array}$ & $\begin{array}{l}17 \\
(6.2)\end{array}$ & $\begin{array}{l}9.3 \\
(3.1)\end{array}$ & $\begin{array}{l}9.9 \\
(2.7)\end{array}$ & $\begin{array}{l}110 \\
(31.5)\end{array}$ & $\begin{array}{l}111 \\
(12.6)\end{array}$ & $\begin{array}{l}105 \\
(6.2)\end{array}$ & $\begin{array}{l}51 \\
(3.1)\end{array}$ & $\begin{array}{l}55 \\
(2.7)\end{array}$ & $\begin{array}{l}600 \\
(31.2)\end{array}$ \\
\hline
\end{tabular}

\section{Eukaryotic abundance and carbon content}

The highest abundance and concentration of eukaryotic carbon were found in the bottom ice samples for all sites (Table 4-4), and abundances decreased with increase in snow cover.

The main contributors to the eukaryotic carbon were diatoms followed by dinoflagellates (Chapter 2, Table 2-1 to 2-3). No zooplankton was detected in the sea ice samples. At all locations, the abundance of algal cells in the bottom sections were several orders of magnitude higher than in sections closer to the surface. At TR, there were generally more cells in the top section than in the middle, but at the other 2 locations, there were fewer cells in the top section (Table 3-4). The size and shape of the algal cells were used to estimate cell volume and thereby derive carbon content. Since dinoflagellates are significantly more carbon dense than diatoms (Menden-Deuer and Lessard 2000), the carbon content per cell was higher than in the top and middle than at the bottom of the sea ice. However, due to the large abundance of algal cells in the bottom sections of the sea ice, this part still contained the most total algal carbon. The carbon contribution in the bottom section contained $\sim 150 \mathrm{x}$ more carbon than the top and $\sim 500 \mathrm{x}$ more than the middle (Table 3-4). For the bottom section, eukaryotes were the main carbon contributors in the sea ice contributing between 50 and $80 \%$ of the TPOC. 
Table 3-4: Average abundance and biomass of algae in the sea ice. Biomass was obtained by measuring abundance and calculating biovolume multiplied by the carbon per cell factor. Standard error ( \pm SE) is noted in the brackets.

\begin{tabular}{|c|c|c|c|c|c|c|c|c|c|c|}
\hline & \multicolumn{5}{|c|}{ Abundance $10^{4}$ cells. $\mathrm{L}^{-1}\left( \pm \mathrm{SE} 1^{4}\right)$} & \multicolumn{5}{|c|}{ Biomass $\mu \mathrm{gC} . \mathrm{L}^{-1}( \pm \mathrm{SE})$} \\
\hline & $\begin{array}{l}\text { TRNS } \\
(n=24)\end{array}$ & $\begin{array}{l}\text { TRLS } \\
(n=24)\end{array}$ & $\begin{array}{l}\text { TRHS } \\
(n=24\end{array}$ & $\begin{array}{l}\text { CE } \\
(n=12)\end{array}$ & $\begin{array}{l}\text { TNB } \\
(n=4)\end{array}$ & $\begin{array}{l}\text { TRNS } \\
(n=24)\end{array}$ & $\begin{array}{l}\text { TRLS } \\
(n=24)\end{array}$ & $\begin{array}{l}\text { TRHS } \\
(n=24)\end{array}$ & $\begin{array}{l}\text { CE } \\
(n=12)\end{array}$ & $\begin{array}{l}\text { TNB } \\
(n=4)\end{array}$ \\
\hline Top & $\begin{array}{l}8.1 \\
(10.8)\end{array}$ & $\begin{array}{l}11.9 \\
(15.8)\end{array}$ & $\begin{array}{l}5.7 \\
(7.9)\end{array}$ & $\begin{array}{l}0.6 \\
(0.7)\end{array}$ & $\begin{array}{l}2.4 \\
(1.1)\end{array}$ & $\begin{array}{l}16 \\
(23.0)\end{array}$ & $\begin{array}{l}17 \\
(31.1)\end{array}$ & $\begin{array}{l}11 \\
(13.9)\end{array}$ & $\begin{array}{l}2 \\
(2.1)\end{array}$ & $\begin{array}{l}8 \\
(4.0)\end{array}$ \\
\hline Middle & $\begin{array}{l}3.1 \\
(3.0)\end{array}$ & $\begin{array}{l}2.9 \\
(1.5)\end{array}$ & $\begin{array}{l}0.9 \\
(0.9)\end{array}$ & $\begin{array}{l}6.6 \\
(8.8)\end{array}$ & $\begin{array}{l}5.5 \\
(2.6)\end{array}$ & $\begin{array}{l}23 \\
(24.6)\end{array}$ & $\begin{array}{l}19 \\
(36.2)\end{array}$ & $\begin{array}{l}7 \\
(18.2)\end{array}$ & $\begin{array}{l}18 \\
(18.2)\end{array}$ & $\begin{array}{l}49 \\
(24.3)\end{array}$ \\
\hline Bottom & $\begin{array}{l}2634 \\
(674)\end{array}$ & $\begin{array}{l}2220 \\
(630)\end{array}$ & $\begin{array}{l}342 \\
(133)\end{array}$ & $\begin{array}{l}897 \\
(482)\end{array}$ & $\begin{array}{l}1064 \\
(265)\end{array}$ & $\begin{array}{l}9024 \\
(4499)\end{array}$ & $\begin{array}{l}8724 \\
(5130)\end{array}$ & $\begin{array}{l}2403 \\
(1359)\end{array}$ & $\begin{array}{l}2315 \\
(1472)\end{array}$ & $\begin{array}{l}6057 \\
(3028)\end{array}$ \\
\hline
\end{tabular}

\section{Non-living organic carbon components}

Extracellular organic carbon components such as glycoproteins excreted by both eukaryotes and prokaryotes can be measured collectively and termed as EPS. The highest concentration of EPS was found in the bottom $10 \mathrm{~cm}$ of the sea ice at all the locations sampled, where it comprised $10-20 \%$ of the TPOC (Table 3-5). EPS is the main contributor to the total carbon content in the top and middle sections (up to 80-90\%) of the sea ice. The middle and top of the sea ice have comparable values of EPS, which is approximately 4 times less than found at the bottom (Table 3-5).

Table 3-5: Average biomass of EPS in the sea ice expressed as Xanthan Gum equivalents $\left(\mu g C . L^{-1}\right)$. Standard error $( \pm \mathrm{SE})$ is noted in the brackets.

\begin{tabular}{llllll}
\hline \multicolumn{5}{l}{ Biomass $\boldsymbol{\mu g C . L}^{-\mathbf{1}} \mathbf{( \mathbf { S E } )}$} \\
\hline & TRNS $(n=24)$ & TRLS $(n=24)$ & TRHS $(n=24)$ & CE $(n=12)$ & TNB $(n=4)$ \\
Top & $374(55.9)$ & $397(97.8)$ & $350(49.6)$ & $337(48.8)$ & $368(12.8)$ \\
Middle & $378(45.7)$ & $350(48.6)$ & $340(42.9)$ & $365(31.2)$ & $428(13.9)$ \\
Bottom & $1247(457)$ & $1332(444)$ & $778(438)$ & $609(318)$ & $1340(214)$ \\
\hline
\end{tabular}

A significant difference in EPS carbon concentration was evident between the bottom and the middle sections $(\mathrm{F}=3.078 \mathrm{P}<0.0005)$ and bottom and top $(\mathrm{F}=1.682 \mathrm{P}<0.0005)$ but not between middle and top ( $\mathrm{F}=0.837 \mathrm{P}=0.999)$. 


\section{Correlation between carbon contributors}

In the top and the middle of the sea ice there was no correlation between any of the carbon contributors (Figure 3-2, Table 3-6). However, linear regression models for the bottom of the sea ice, showed that an increase in eukaryotic TPOC is strongly correlated with an increase in EPS (Figure 3-2, Table 3-6, $\mathrm{R}^{2}=0.995$ ). This trend is also supported by the regression between eukaryote abundance (cell numbers) and TPOC in the bottom section of the ice $\left(\mathrm{R}^{2}=0.52, \mathrm{p}<0.001\right.$, Table $\left.3-6\right)$. Good correlations are also evident in the regressions between EPS and TPOC in all 3 positions within the ice (Table 3-6). All other correlations show very low $\mathrm{R}^{2}$ values (Table3-6).

Table 3-6: Linear regression between the different carbon contributors and TPOC. Numbers in bold $(\mathrm{P}<0.05)$ indicate a significant slope to the regression between the dependent and independent variables.

\begin{tabular}{|c|c|c|c|c|c|c|c|}
\hline & & Position & & & AN & DA & \\
\hline $\begin{array}{l}\text { Independent } \\
\text { variable }\end{array}$ & $\begin{array}{l}\text { Dependent } \\
\text { variable }\end{array}$ & & $\mathbf{R}$ & $\mathbf{R}^{2}$ & df & $\mathbf{F}$ & Sig \\
\hline Eukaryote & Prokaryote & Top & 0.136 & 0.018 & 77 & 1.42 & 0.237 \\
\hline & & Middle & 0.147 & 0.022 & 75 & 1.64 & 0.204 \\
\hline & & Bottom & 0.099 & 0.010 & 87 & .851 & 0.359 \\
\hline Prokaryote & EPS & Top & 0.074 & 0.005 & 87 & 0.473 & 0.494 \\
\hline & & Middle & 0.043 & 0.002 & 86 & 0.156 & 0.694 \\
\hline & & Bottom & 0.043 & 0.002 & 87 & 0.163 & 0.688 \\
\hline Eukaryote & EPS & Top & 0.351 & 0.123 & 77 & 10.67 & 0.002 \\
\hline & & Middle & 0.196 & 0.038 & 75 & 2.96 & 0.090 \\
\hline & & Bottom & 0.723 & 0.523 & 87 & 94.30 & 0.000 \\
\hline TPOC & Eukaryote & Top & 0.919 & 0.844 & 77 & 412.05 & 0.000 \\
\hline & & Middle & 0.718 & 0.516 & 75 & 78.85 & 0.000 \\
\hline & & Bottom & 0.998 & 0.995 & 87 & 17262 & 0.000 \\
\hline TPOC & Prokaryote & Top & 0.043 & 0.002 & 87 & .158 & 0.692 \\
\hline & & Middle & 0.539 & 0.290 & 86 & 34.76 & 0.000 \\
\hline & & Bottom & 0.120 & 0.014 & 87 & 1.26 & 0.265 \\
\hline TPOC & EPS & Top & 0.698 & 0.487 & 87 & 81.68 & 0.000 \\
\hline & & Middle & 0.702 & 0.493 & 85 & 82.66 & 0.000 \\
\hline & & Bottom & 0.767 & 0.588 & 87 & 122.92 & 0.000 \\
\hline
\end{tabular}



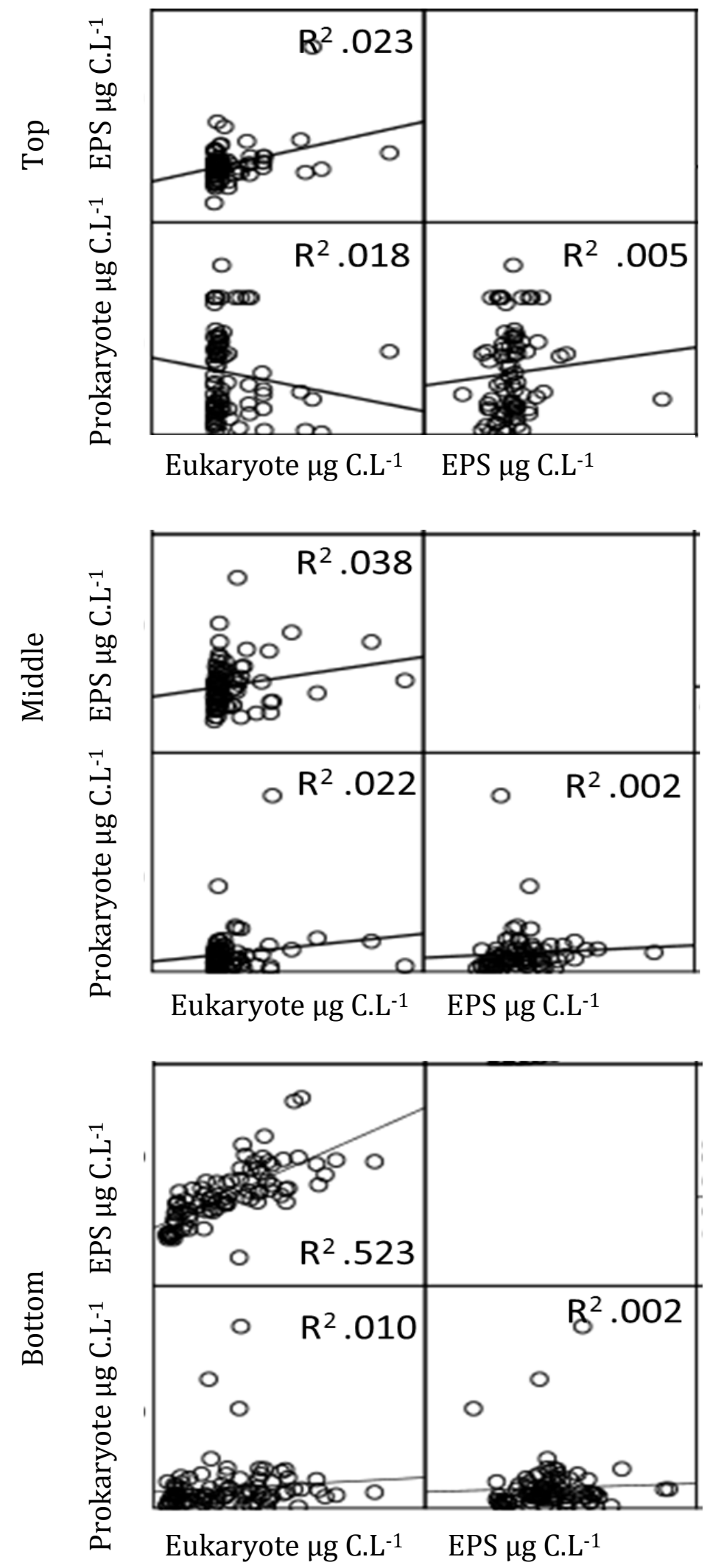

Figure 3-2: Linear regression plot between EPS, prokaryotic and eukaryotic carbon for the top, middle and bottom of the sea ice. Samples used from Turtle Rock (no snow, low snow and high snow plots), Cape Evans and, Terra Nova Bay 2011. 


\section{Locations}

Snow cover reduces the light flux that reaches the bottom of the sea ice (see Chapter 2, Figure 2-7). In the top and middle of the sea ice, snow cover does not significantly influence the abundance any of the carbon sources (two-way MANOVA: Top: $F=1.018$ $\mathrm{P}=0.439$, Middle $\mathrm{F}=1.155, \mathrm{P}=0.330$ ). However in the bottom of the sea ice, eukaryotic biomass decreased with increasing snow cover (Table 3-7, Figure 3-3). Similarly, EPS decreased with increasing snow cover at the bottom, while there was no change in prokaryote carbon (stats Table 3-7).

Table 3-7: Tukey post hoc analysis of two-way MANOVA analysis comparing TPOC in the bottom of the sea ice between locations and carbon sources. Numbers in bold show a significant change in carbon concentration $(\mathrm{P}<0.05)$.

\begin{tabular}{|c|c|c|c|c|c|}
\hline & & 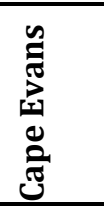 & 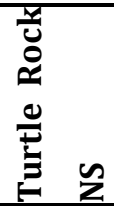 & 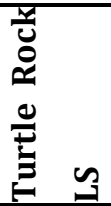 & 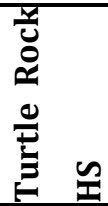 \\
\hline \multirow[t]{3}{*}{ Turtle Rock NS } & Prokaryote & 0.594 & & & \\
\hline & Eukaryote & 0.000 & & & \\
\hline & EPS & 0.001 & & & \\
\hline \multirow[t]{3}{*}{ Turtle Rock LS } & Prokaryote & 0.509 & 1.000 & & \\
\hline & Eukaryote & 0.000 & 0.999 & & \\
\hline & EPS & 0.001 & 0.999 & & \\
\hline \multirow[t]{3}{*}{ Turtle Rock HS } & Prokaryote & 1.000 & 0.415 & 0.336 & \\
\hline & Eukaryote & 1.000 & 0.000 & 0.000 & \\
\hline & EPS & 0.663 & 0.020 & 0.008 & \\
\hline \multirow[t]{3}{*}{ Terra Nova Bay } & Prokaryote & 0.000 & 0.000 & 0.000 & 0.000 \\
\hline & Eukaryote & 0.564 & 0.699 & 0.775 & 0.505 \\
\hline & EPS & 0.085 & 1.000 & 1.000 & 0.359 \\
\hline
\end{tabular}

The total concentrations of EPS, eukaryotic and prokaryotic carbon in different sea ice communities are illustrated in Figure 3-3, and the relative proportions of these components are given in Figure 3-4. The top and middle of the sea ice showed no significant difference between locations in the amount of any of the measured carbon constituents as well as proportion, due to the large variability within a single location (top-MANOVA: $\mathrm{F}=0.732 \mathrm{P}=0.717$; middle-MANOVA: $\mathrm{F}=1.274 \mathrm{P}=0.239$ ). 
The carbon allocation in communities in the bottom sections of ice at TRNS and TRLS were very similar, while those in TRHS were similar to CE (Figure 3-3B). A different pattern of carbon allocation was evident at TNB, which is $>300 \mathrm{~km}$ from TR and CE and encounters different environmental factors such as time of ice formation, currents, and ice thickness. This location was characterised by higher eukaryotic and prokaryotic carbon in the bottom ice than at CE (Figure 3-3 and 3-4). The prokaryotic abundance at TNB was significantly different (Table 3-8, Figure 3-3) from any other location sampled both in total amount and percentage of TPOC.

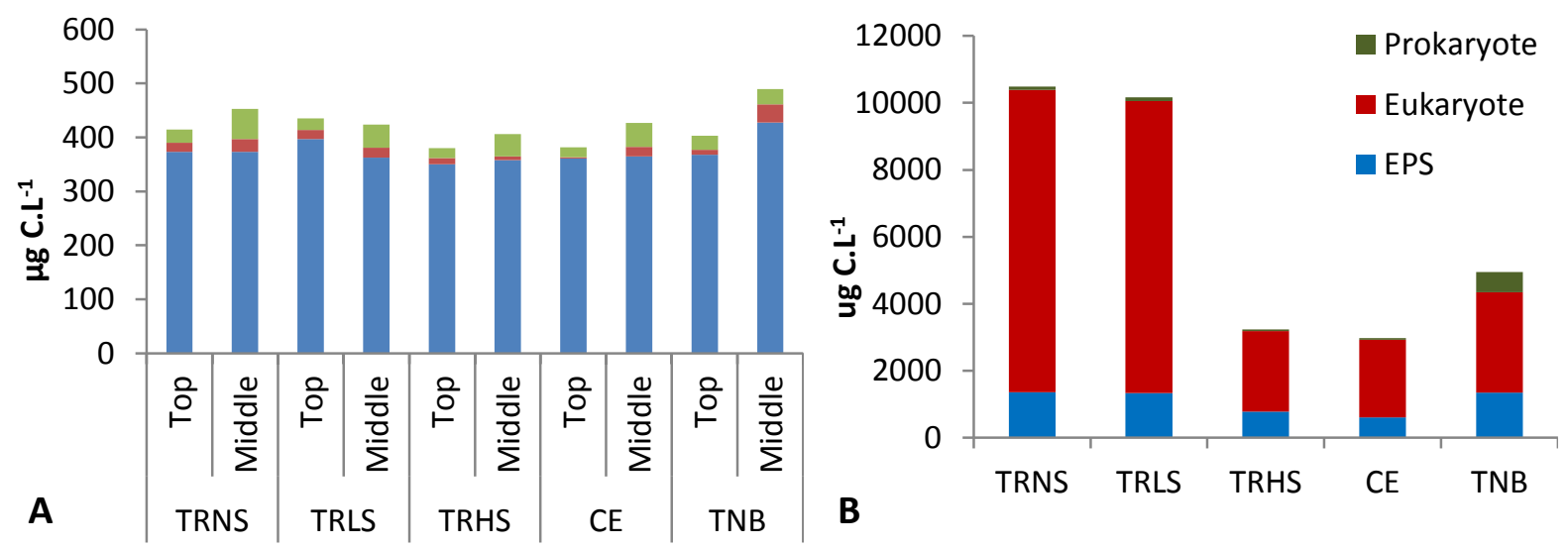

Figure 3-3: Different constituents of TPOC through the sea ice. A) top and middle of the sea ice B) bottom of the sea ice. TRNS= Turtle Rock no snow, TRLS= Turtle Rock low snow, TRHS= Turtle Rock high snow, $\mathrm{CE}=$ Cape Evans, $\mathrm{TNB}=$ Terra Nova Bay. $N=4$ per sample point of carbon constituent.

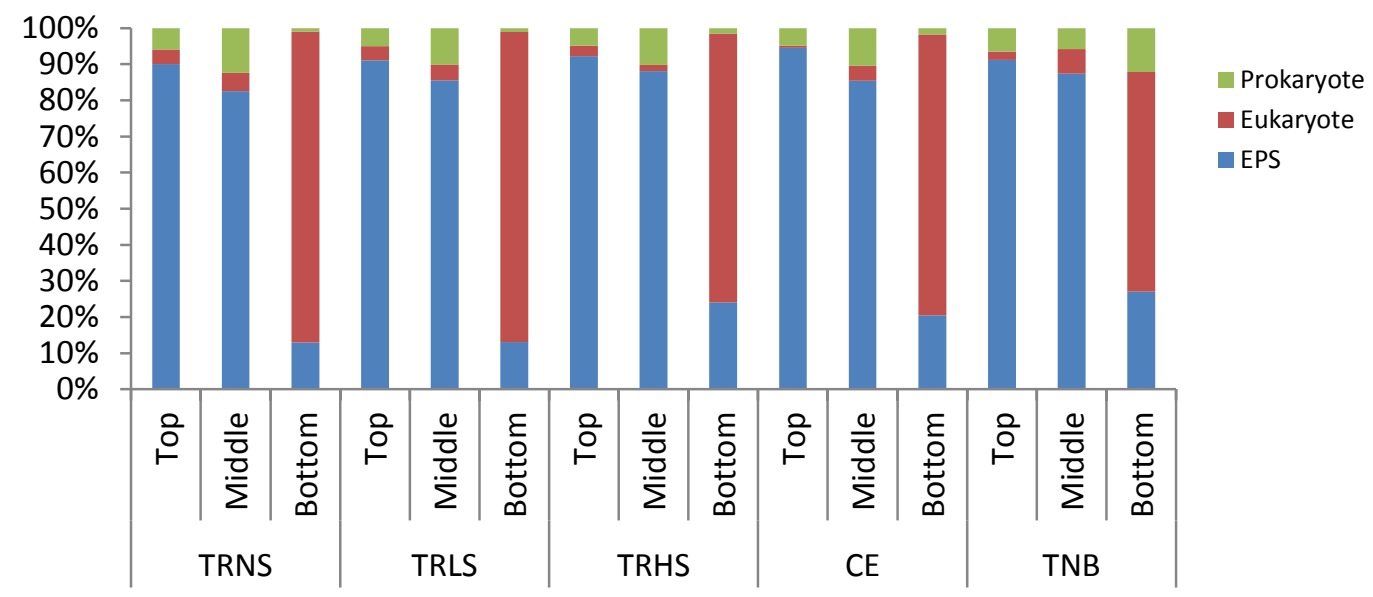

Figure 3-4: Proportions of the different constituents of particulate organic carbon. TRNS= Turtle Rock no snow, TRLS= Turtle Rock low snow, TRHS $=$ Turtle Rock high snow, CE $=$ Cape Evans, TNB $=$ Terra Nova Bay. $N=4$ per sample point of carbon constituent. 


\section{Temporal changes during in organic carbon contributors}

During the sample season there were several changes in proportions of the carbon source (Figure 3-5B). The largest change happened for the bottom of the high snow cover site at TR (TRHS) in both abundance (Figure 3-5A, stats Table 3-8) and proportional carbon source (Figure 3-5B). At this site, the total carbon concentration increased over the sampling period due primarily to an increase of eukaryotic carbon of approximately 2 orders of magnitude (Figure 3-6). EPS increased also at this site but by only 4x (Figure 3-7), and as a result, the relative proportions of carbon sources changed with eukaryotic carbon comprising a larger and larger proportion of TPOC over time (Figure 3-5B). The arrows in Figure 3-5A, B illustrates that the proportions in the different carbon constituents changes with an increase or decrease in the total carbon biomass. At CE, the opposite trend was evident where eukaryotic carbon decreased during the sampling period, while the level of EPS stayed approximately the same. At both locations, low TPOC is characterised by relatively high EPS and high overall TPOC is characterised by relatively low EPS. In general, prokaryotic carbon concentrations tended to peak in mid- season in the bottom sections of the ice and did not change in internal sections of the ice. 


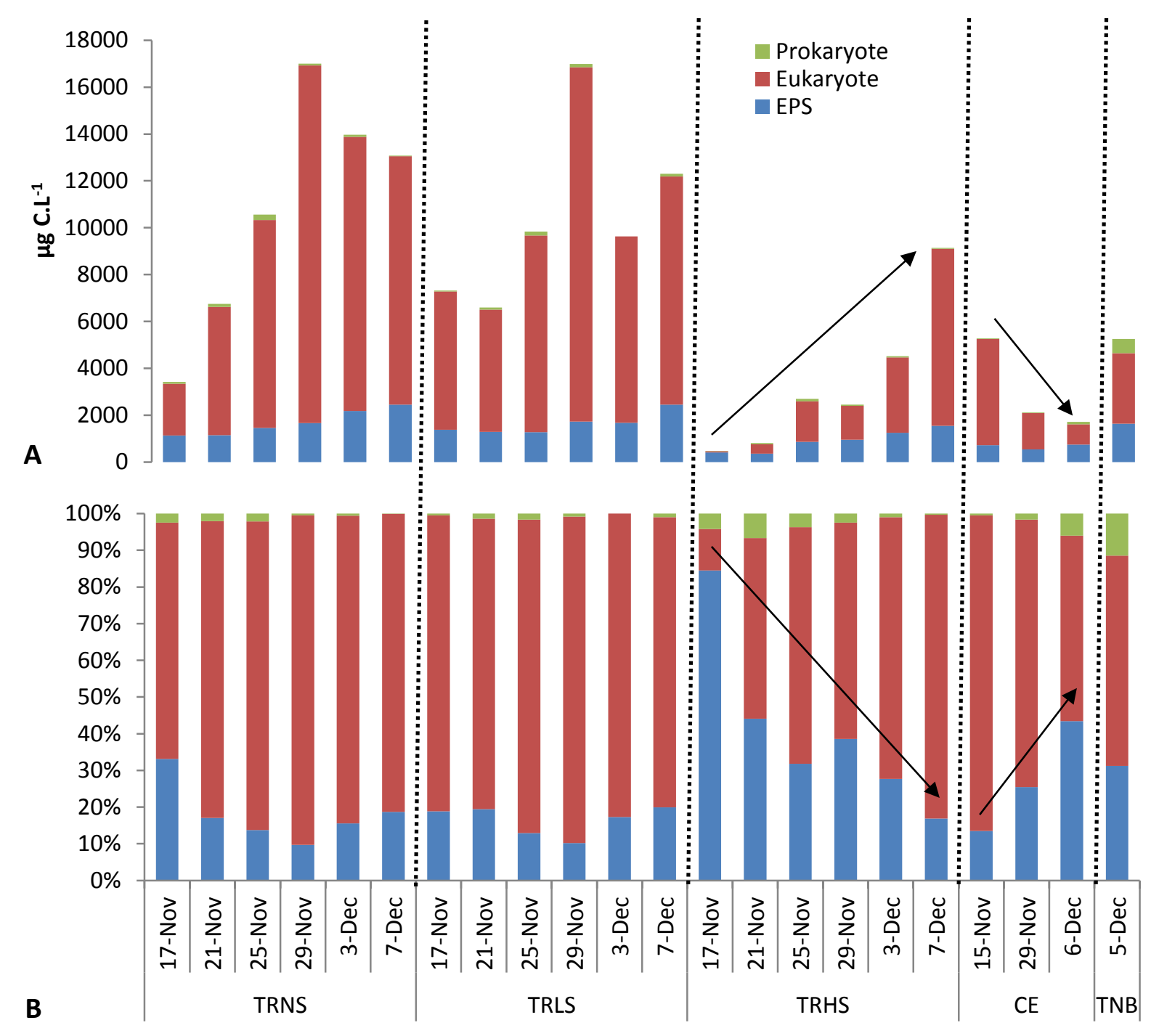

Figure 3-5: Different constituents of particulate organic carbon in the bottom of the sea ice per location over time. A) Total carbon constituents B) Percentage of the carbon constituents Arrows illustrate the proportional change in carbon constituents with decreasing or increasing carbon biomass $((n=4$ per sample point of carbon constituent). 
Table 3-8: Two-way-MANOVA statistical analysis of change in carbon constituents during a growth season at different locations and sea ice positions. Numbers in bold show a significant $(\mathrm{P}<0.05)$ change in carbon concentration.

\begin{tabular}{|c|c|c|c|c|c|c|c|}
\hline & & \multicolumn{2}{|l|}{ Top } & \multicolumn{2}{|c|}{ Middle } & \multicolumn{2}{|c|}{ Bottom } \\
\hline & & $\bar{F}$ & $\bar{P}$ & $\bar{F}$ & $\mathrm{P}$ & $\bar{F}$ & $\bar{P}$ \\
\hline \multirow[t]{3}{*}{ Cape Evans } & Prokaryote & 70.433 & 0.005 & 3.174 & 0.091 & 10.006 & 0.000 \\
\hline & Eukaryote & 7.984 & 0.016 & 0.452 & 0.652 & 6.432 & 0.018 \\
\hline & EPS & 0.194 & 0.827 & 6.319 & 0.019 & .949 & 0.423 \\
\hline \multirow[t]{3}{*}{ Turtle Rock NS } & Prokaryote & 10.072 & 0.000 & 0.740 & 0.605 & 2.959 & 0.042 \\
\hline & Eukaryote & 2.935 & 0.048 & 1.145 & .380 & 25.857 & 0.000 \\
\hline & EPS & 3.168 & 0.032 & 6.926 & 0.001 & 2.658 & 0.060 \\
\hline \multirow[t]{3}{*}{ Turtle Rock LS } & Prokaryote & 2.989 & 0.041 & 0.967 & 0.464 & 6.273 & 0.004 \\
\hline & Eukaryote & 2.164 & 0.117 & 0.871 & 0.523 & 6.199 & 0.002 \\
\hline & EPS & 1.827 & 0.158 & 2.530 & 0.069 & 2.972 & 0.040 \\
\hline \multirow[t]{3}{*}{ Turtle Rock HS } & Prokaryote & 3.205 & 0.049 & 0.440 & 0.814 & 3.566 & 0.023 \\
\hline & Eukaryote & 3.120 & 0.042 & 0.760 & 0.569 & 21.929 & 0.000 \\
\hline & EPS & 0.122 & 0.986 & 0.742 & 0.602 & 35.990 & 0.000 \\
\hline
\end{tabular}

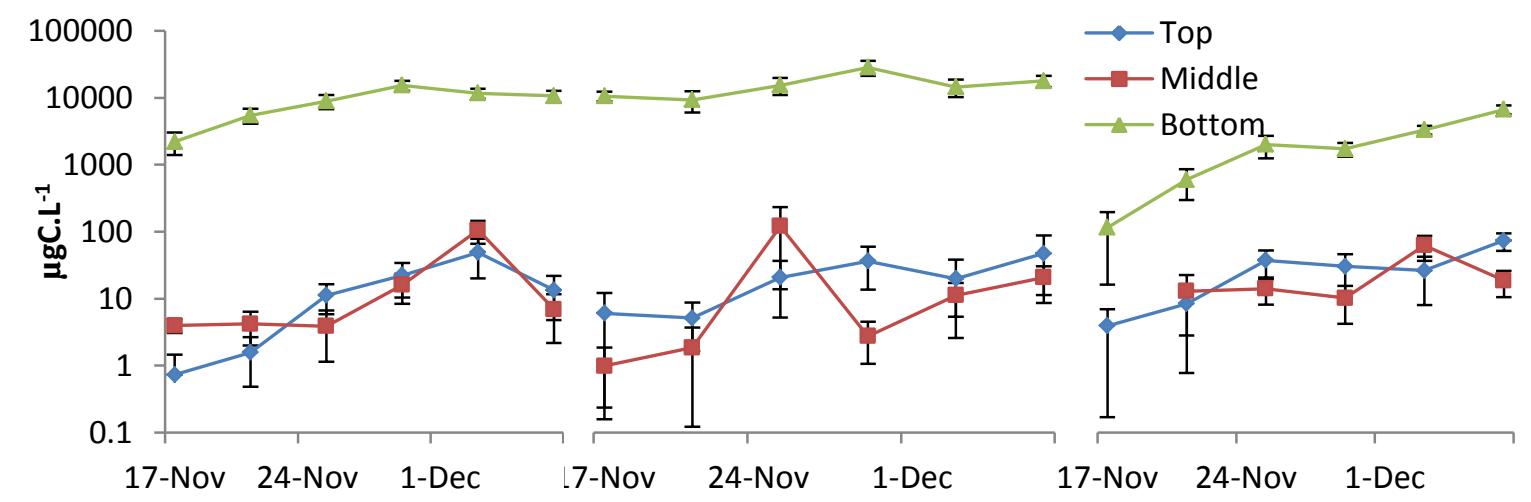

Figure 3-6: Difference in eukaryotic carbon concentration $\mu$ g C.L $L^{-1}$ during the sampling season at Turtle Rock in 2011. Rows from left to right: Turtle Rock no snow, Turtle Rock low snow, Turtle Rock high snow. Note logarithmic vertical scale Data are means $\pm 1 \mathrm{SE}, n=4$ per data point). 


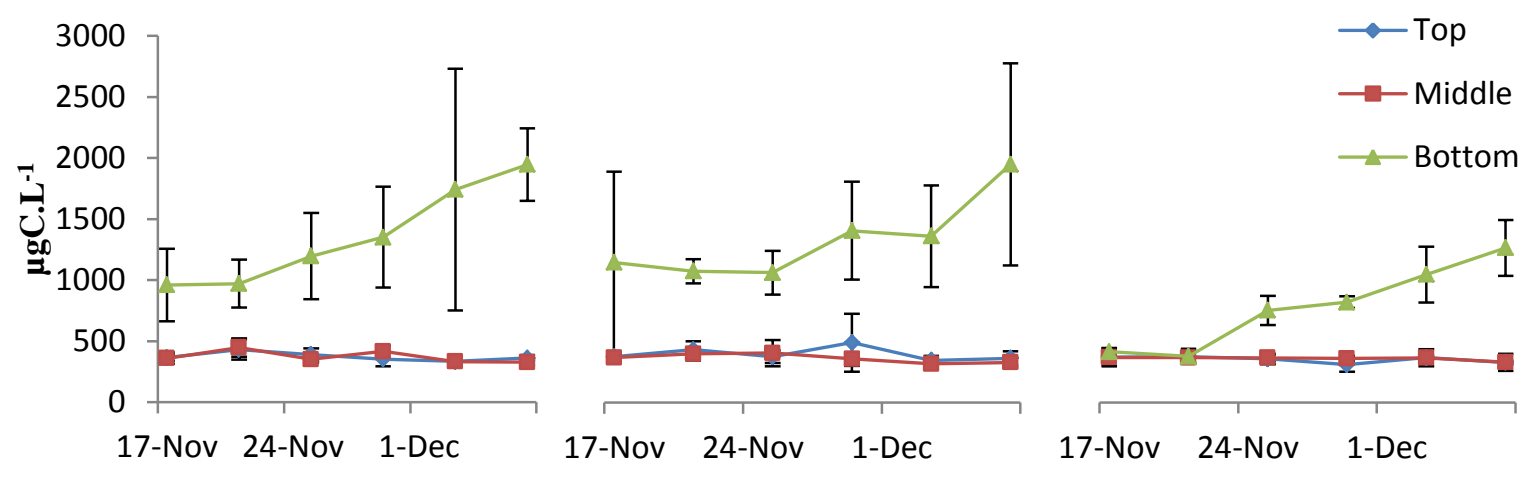

Figure 3-7: Difference in EPS carbon concentration $\mu \mathrm{g}$ C. $\mathrm{L}^{-1}$ during the sampling season at Turtle Rock 2011. Rows from left to right Turtle Rock no snow, Turtle Rock low snow, Turtle Rock high snow. Data are means $\pm 1 \mathrm{SE}, n=4$ per data point).
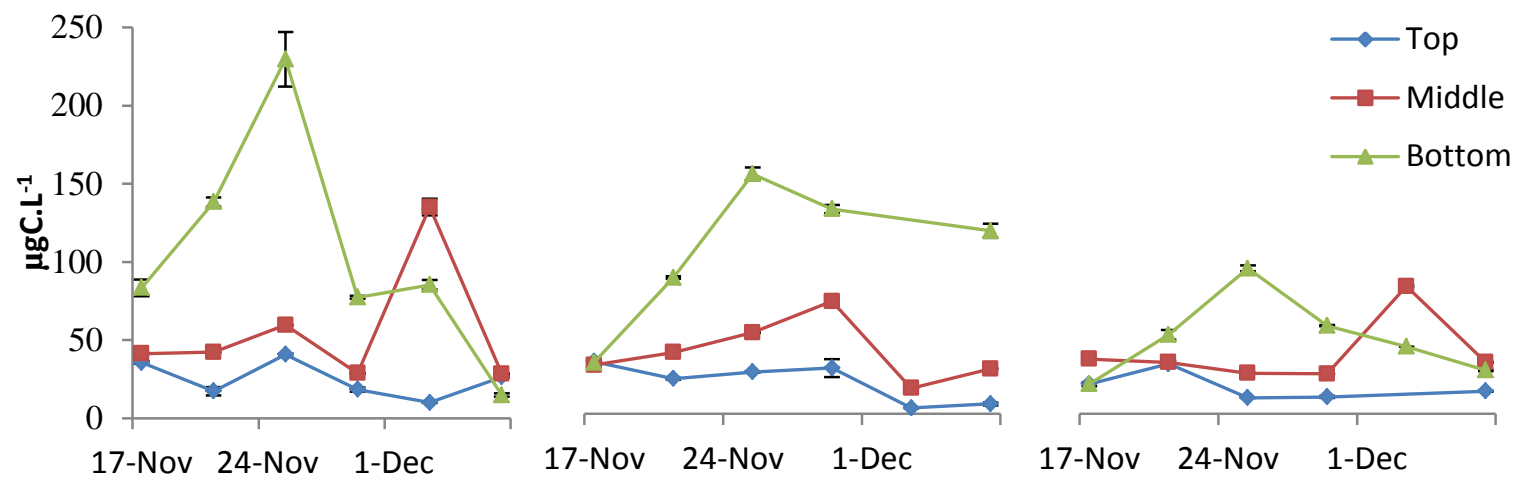

Figure 3-8: Difference prokaryote in carbon concentration $\mu \mathrm{g}$ C. $\mathrm{L}^{-1}$ during the sampling season at Turtle Rock 2011. Rows from left to right Turtle Rock no snow, Turtle Rock low snow, Turtle Rock high snow. Data are means \pm 1 SE, $n=4$ per data point).

\section{Discussion}

\section{Influence of snow cover on bottom sea ice carbon}

It can be presumed that the salinity, current, temperature, and nutrient availability in the bottom of the sea ice were the same throughout the TR sampling area since the sites were separated by only $10-20 \mathrm{~m}$. The only variable was the snow cover, which influences light throughout the ice and stabilizes temperatures in interior sections due to its insulating properties. 
The main carbon contributor in the bottom of the sea ice were algae followed by EPS, and together these made up $90-95 \%$ of the TPOC. The main trend that can be observed in the bottom of the sea ice was a 3 fold decrease of algal and EPS biomass with increasing snow cover, while prokaryotic abundance remained the same. This means that algal biomass and EPS are strongly correlated, while prokaryotes do not correlate with any of the other carbon sources. These results are similar to other studies where snow cover did not significantly alter prokaryotic abundance (McGrath Grossi et al. 1984) (Riedel et al. 2006) but did influence algal biomass (Riedel et al. 2006). Several studies (Thomas et al. 1995; Meiners et al. 2004; Underwood et al. 2010) have reported large variability of EPS concentration in sea ice habitats. They attribute this variability to small-scale habitat characteristics, such as steep nutrient, salinity and temperature gradients in the sea ice, snow cover and seasonal differences of algal species. The results here support this view in which snow cover (this chapter) and the differences between algal compositions (Chapter 2) result in different EPS concentrations. The majority of EPS present in sea ice is produced by algae (Krembs et al. 2002) though a small proportion comes from bacteria (Meiners et al. 2004; Collins et al. 2008). The significant correlation between EPS and algal concentrations under different snow covers in this study indicates that the sea-ice algae in the western Ross Sea in 2011 were primarily responsible for the production of EPS in the sea ice.

\section{Temporal changes in organic carbon in the bottom of the sea ice}

During the season at TR, algal and EPS carbon increased but prokaryotic carbon did not. Linear regression models illustrated the close correlation between algal biomass and EPS biomass. Similar relationships have been extensively documented (Riedel et al. 2006; Riedel et al. 2007; Juhl et al. 2011). Generally, in marine environments, bacterial abundance tends to increase with increasing algal biomass, however this relationship can be highly variable in sea ice environments (Steward and Fritsen 2004), and in the present study, linear regression models between algal increase and prokaryotes showed no correlation. Variability and lags in the relationship between bacterial abundance and chlorophyll concentration have previously been observed including apparent independence of bacterial production from primary production (Deming 2010). A tight coupling of bacterial and algal biomass can be expected during the spring 
to autumn when sufficient light is available to support high amounts of algal biomass and thus high levels of DOM for bacterial consumption (Steward and Fritsen 2004). High amounts of $1300 \mu \mathrm{gC} . \mathrm{L}^{-1}$ of EPS were found in the bottom of the sea ice at approximately $15-35 \%$ of the TPOC. EPS is an important substrate for sea-ice bacteria (Meiners et al. 2004; Meiners et al. 2008), potentially supporting increased microbial activity through carbohydrates released as breakdown products (Underwood et al. 2010). This prokaryotic biomass generation from algal-derived DOM is temporal and may be spatially highly variable (Dumont et al. 2009).

At TR, the lack of correlation between algal and prokaryote carbon suggests an uncoupling of the microbial loop. Several hypotheses have been proposed to explain uncoupling of the microbial loop in sea ice: 1) grazing pressure (Pusceddu et al. 2009) 2) increased prokaryotic mortality due to viral infection (Deming 2010), and 3) the release of allopathic substances by sea ice algae inhibiting prokaryotic carbon production (Pusceddu et al. 2009). Grazing pressure seems unlikely since, at the time of sampling, no zooplankton were found in the sea ice samples (Chapter 2) nor in the seawater (Appendix B: Seawater community composition). Little is known of viral infection in sea ice microbes (Deming 2010), although viral abundance at the start of the ice-algal bloom can be very high $\left(6.3 \times 10^{5} \mathrm{ml}^{-1}\right.$ in a bottom habitat to $\left.1.19-10^{8} \mathrm{ml}^{-1}\right)$ (Garrison et al. 2005). High levels of viruses require actively growing bacteria (Deming 2010). Bacteria at TR showed no increase in abundance during the period indicating either a lack of growth or growth is offset by grazing, however, no zooplankton was observed in the brine (Appendix A: Species list) Viruses must contact bacteria for infection, but bacteria in dense clusters or surrounded by EPS might be protected from infection, (Gowing et al. 2004; Deming 2010). In this study, EPS concentration was high $\left(\sim 1300 \mu \mathrm{gC} . \mathrm{L}^{-1}\right)$ providing bacteria with a possible protection against infection, and I suggest therefore that the role of viruses may be insignificant in TR. The third explanation for microbial loop uncoupling suggests that sea ice algae release substances that can also inhibit growth. (Pusceddu et al. 2009) showed that DOM produced by algae in the bottom of the sea ice inhibited prokaryotic growth. The DOM altered the physiological state of the prokaryotic community reducing their capability of incorporating degraded carbon (Pusceddu et al. 2009). At TR, an increase of algal 
biomass with increasing light was observed and this coincided with an increase of EPS, yet the prokaryotic community was unaffected. Our results are therefore consistent with this allelopathic hypothesis but at this stage the cause of the uncoupling of the microbial loop is still unclear.

\section{Influence of snow cover on the interior sea ice carbon}

The interior of the sea ice was dominated by EPS, which reached concentrations of 800$1850 \mu \mathrm{g} \mathrm{C.l} \mathrm{l}^{-1}$ or $85-90 \%$ of the TPOC, while the algal biomass made up only $8-10 \%$ of the TPOC. In the upper and middle sections of sea ice, the restricted nutrient supply, high salinity at low temperatures mean that algal biomass is generally low (Stoecker et al. 2000). High amounts of EPS are not unusual for the interior of the sea ice (Krembs et al. 2000; Krembs et al. 2002; Meiners et al. 2004; Krembs and Deming 2008; Underwood et al. 2010), but can vary widely by location. Some EPS is secreted as mucilaginous slime coating the cells, and this protective cover is thought be a defence against freezing and a barrier against hypersalinity, such as that encountered in the brine environment (Krembs et al. 2002; Krembs and Deming 2008). Eukaryotic abundance was low in the interior of the sea ice. It is possible that EPS incorporated when sea ice forms persisted relatively unchanged (Juhl et al. 2011). Eukaryote carbon had a stronger decline towards the upper sections of the ice in relation to the bottom than prokaryotic carbon or EPS. Meiners et al. (2004) found a similar trend in an ice floe in the Bellinghausen Sea, Antarctica, where a strong vertical gradient in algal and bacterial biomass was found, with algal abundances declining more than bacteria.

\section{Temporal changes in organic carbon in the interior of the sea ice}

No significant increases in algal, EPS or prokaryotic biomass were observed at any of the TR plots in the mid and top sections of the sea ice. This limitation in growth can have several causes. While this study showed that at least in the bottom of the sea ice, algal and EPS concentrations were heavily influenced by available PAR, this seems unlikely to be the reason for interior sections of the sea ice since no change in biomass was observed during the season for any of the different snow covers. The interior of the sea ice received more light than bottom ice and growth at the bottom is still possible 
even at the sites with extensive snow cover. Algal cells could be photoinhibited due to the higher light levels in upper sections, but there was no growth in the interior of the sea ice regardless of snow cover. Photoinhibition should be less under high snow cover, and we should have seen some growth in those locations if this explanation is to be accepted. Another factor which could have limited growth and is of special importance for brine communities is nutrients. Flushing of the brine decreases toward the centre and top of the sea ice (Vancoppenolle et al. 2010) because brine pockets are formed in sea ice when seawater freezes and this leds to a more closed environment in mid sections of the ice (Golden et al. 1998). During this process, salt and nutrients are excreted from the ice matrix and collect in brine pockets. Early in the season, brine pockets and channels are high in nutrients but this reduces rapidly as the season progresses (Dieckmann et al. 1991). Brine forms a semi-closed environment where nutrients are not regularly resupplied, and this could cause nutrient limitation to occur relatively soon in the growth season. This hypothesis will be further examined in chapter 4 , but if this is the cause it will have consequences for the overall primary production since nutrients will not be regularly refreshed in this environment and primary production in the brine could be nutrient limited for extensive periods.

High amounts of EPS were found in the interior of the sea ice in this study. The main producers of EPS are algal cells (Riedel et al. 2006; Underwood et al. 2010). EPS also constitutes an important substrate for sea-ice bacteria (Meiners et al. 2004), potentially supporting increased microbial activity. Despite these high amounts of EPS, it was not utilised by prokaryotes to increase growth. While bacterial metabolic activity was not directly quantified in the current study, Martin (2009) showed that sea-ice bacteria have high membrane integrity and up to $32 \%$ of the cells are typically undergoing active respiration. This suggests that at least some growth should be visible.

\section{Variation in organic carbon}

Riedel et al. $(2006,2007)$ found that sea-ice EPS concentrations increased seasonally, following the trend in sea-ice algal biomass ( $\mathrm{chl} a$ ). However, sea-ice EPS and chl $a$ concentrations became decoupled at the end of the season when a rapid decline in chl $a$ 
concentrations was observed, but stable and high EPS concentrations in the sea ice (Riedel et al. 2006). At CE, TPOC decreased over time (Figure 3-6A) and this coincided with a decrease of the proportion of eukaryotic carbon and an increase in the proportion of EPS (Figure 3-6B). Earlier studies at CE showed that a large algal biomass can develop there consisting of $B$. adeliensis at the bottom of the ice which tends to slough off during late November and be replaced by a new algal layer (K.G. Ryan, pers. comm.). The algal biomass released from the sea ice at a faster rate than EPS could indicate that not all EPS was attached to algal cells within the sea ice. Free EPS would remain longer in the sea ice than attached EPS (Riedel et al. 2006; Juhl et al. 2011). This theory makes the reasonable assumption that EPS production by bacteria is limited and the remaining algal community does not increase EPS production. This retention of EPS could provide organisms in the water column with an extra pulse of organic carbon after the majority of sea-ice algal biomass has been released (Riedel et al. 2006; Juhl et al. 2011).

In contrast to the decrease of algal cell and stable EPS at CE, in TRHS the opposite trend occurred. Algal biomass increased but EPS remained more or less stable resulting in a change of algal:EPS ratio. EPS can be found in sea ice in winter (Krembs et al. 2002) and early spring (Juhl et al. 2011) where it forms a protective environment against freezing and the higher salinity (Underwood et al. 2010) for the few algal cells present. This small community of algae can start growing as soon as light reaches a favourable level. The thick snow cover reduced light levels significantly to reduce growth until late November when sufficient light could finally reach the bottom ice community, resulting in a high EPS to algal ratio still being present in late November. The changes between EPS and algal carbon at TRHS illustrate what happens in the sea ice in early spring when the first light reaches the ice community. Towards mid-December EPS forms $\sim 15 \%$ and algal $\sim 80 \%$ of the TPOC. This ratio is similar as observed for the other TR plots suggesting that this ratio of EPS to algal carbon is sufficient to provide a protective role in the bottom $10 \mathrm{~cm}$ of the sea ice. 
The production of EPS varies widely among algal species, both in the amount and chemical structure (Thomas et al. 1995; Meiners et al. 2004; Underwood et al. 2010). The large variability in EPS concentrations in the bottom of the sea ice (600-1300 $\mu \mathrm{g}$ C.L ${ }^{-1}$ ) may be due to difference in the species composition. Pennate diatoms of the genera Nitzschia and Navicula are the most important producers of EPS within sea ice (Decho and Moriarty 1990; Krembs and Engel 2001). This is important because high snow cover causes a switch of diatoms species (Chapter 2) to those with a lower EPS production. Though these particular species were not the most dominant species in the sea ice (Chapter 2) they were an important constituent of the sea ice microbial community and a significant percentage decrease in these particulate species can be observed with increasing snow cover. This switch to lower EPS producing species will have influences on many organisms since EPS can be an important carbon source for bacteria, and zooplankton grazing, when present, at the underside of the sea ice. The fact that diatom species determine the amount of EPS is especially illustrated at TNB. It has a smaller concentration of algae (in number and biomass) while the EPS concentration remained similar to other sites. Nitzschia sp., which dominates this community, produces large amounts of EPS and together with Fragilariopsis sp. makes up almost $95 \%$ of the algal community there (Chapter 2). Thus, algal species compositions have significant influences on the EPS concentration and thus the proportion of the carbon contributors will vary spatially and temporally.

\section{Conclusions}

In this study I attempted to quantify sea ice algal, EPS and prokaryotic carbon under varying snow covers, and characterize seasonal trends and spatial variability of organic carbon sources in sea ice. Large differences can be found vertically in the sea ice. Diatoms form the largest carbon source in the bottom of the sea ice with up to 9,000 $\mu \mathrm{gC} . \mathrm{L}^{-1}$ or $90 \%$ of the TPOC, while the interior of the sea ice is dominated by EPS, which reaches a concentration of $\sim 350 \mu \mathrm{g} \mathrm{C.L} \mathrm{L}^{-1}$ or $90 \%$ of the TPOC. Increasing snow cover significantly reduced the abundance/concentration of algal cells and EPS present in the bottom of the sea ice, while the prokaryotic abundance remained constant. Temporal measurements showed an increase in algal cells and EPS, but no difference in prokaryotic abundance was observed. This suggests an uncoupling of the microbial 
loop either by a substrate limitation due to release of allopathic substances by the algae or a high bacteriophage infection. Light levels in the interior of the sea ice are higher than the bottom of the sea ice, yet no significant increase in TPOC or any of the carbon sources could be observed in the interior of the sea ice in relation to decreasing snow cover or when the season progressed. This indicates that the interior of the sea ice is limited by a factor other than light. The role of nutrients as a possible limiting factor for the interior of the sea ice and will be discussed further in chapter 4 . 


\title{
Chapter 4 Silica and phosphorus limitation occurs in sea ice brine communities but not in bottom ice or seawater communities
}

\begin{abstract}
The nutrient status of algae is important in assessing the physiological limits to primary production. Field samples from 3 different Antarctic habitats (seawater, sea ice and brine) were analysed for nutrient limitation by the nutrient induced fluorescence transient (NIFTs) method. This approach is highly appropriate for the study of nutrient limitation in sea ice as it generates a near instantaneous nutrient limitation assessment. Nutrient concentrations were similar for all habitats at the start of the experiment. Even so, only brine communities responded immediately to the NIFTs treatment and this indicated that they were already silicate and phosphate limited. In contrast, no immediate responses were observed after the addition of $\mathrm{PO}_{4}{ }^{-3}$ or $\mathrm{NO}_{3}{ }^{-}$to seawater and sea ice samples, but a delayed response occurred for silicate, and this was likely due to the high demand for silicate by diatoms. Brine communities from the mid-section of the sea ice consisted of diatoms and dinoflagellates, while diatoms dominated seawater and bottom sea ice communities. These 2 different phylogenetic groups have different nutrient requirements and therefore a dual nutrient limitation of $\mathrm{Si}$ and $\mathrm{P}$ was evident in the brine but not in the bottom ice community or in the seawater. The brine community was collected in early December and these results suggest that it was already nutrient limited. Generally, sea ice primary production can continue until January when the ice breaks up, and it is therefore likely that the nutrient limitation in the brine severely limits primary production in this part of the sea ice. No immediate nutrient limitation was found in the seawater at the bottom of the sea ice and therefore primary production in those habitats will be limited by other factors e.g. light or temperature.
\end{abstract}

\section{Introduction}

Generally, high levels of nutrients are found in the Ross Sea, and therefore phytoplankton communities rarely show evidence of nutrient limitation (Knox 2009b). Due to the structure of the sea ice, exchange of nutrients occurs at the ice/water 
interface, and therefore, the bottom sea ice microbial community obtains nutrients from the flushing of the under-ice surface by seawater, either via ocean swell, tidal forcing (Arrigo and Thomas 2004), or internal convection (Fritsen et al. 1994). This result in temperatures and nutrient concentrations in the bottom ice that is similar to seawater. Despite the similarities in temperature, salinity and light between the seawater and bottom of the sea ice, species community composition in the two habitats are significantly different (see chapter 2). However, this flushing decreases toward the centre and top of the sea ice (Arrigo and Thomas 2004) because brine pockets are formed in sea ice when seawater freezes and this leads to a more closed environment in mid sections of the ice. During the freezing process, salts and nutrients are excreted from the ice matrix and collect in brine pockets. Early in the season, brine pockets and channels are high in nutrients but this reduces rapidly as the season progresses (Dieckmann et al. 1991), and thus, nutrient availability may limit ice algal primary production in the interior of the sea ice later in the season. Dieckmann et al. (1991) measured the concentrations of nutrient within sea ice brine and found nutrients depletion to be widespread, a circumstance they attributed to extensive internal biological activity.

Nutrient availability is a major cause of limitation in primary production. The ability to identify limiting nutrients is of considerable importance to our understanding of the ecology of algae. The most common limiting macro nutrient is nitrate followed by phosphate and then silicate. Silica is mainly limiting at locations that are dominated by diatoms. Diatoms are present in all aquatic systems but are most abundant in the polar regions. Nelson and Treguer (1992) suggested that Antarctic diatoms may exhibit a higher requirement for silicate than do diatoms from other regions and this could result in diatom growth being limited by silicate at concentrations that are normally thought to be saturating everywhere else in the world.

Aquatic environments are very dynamic systems where changes constantly occur due to currents, upwelling and wave action. A rapid and reliable technique for determining algal nutrient status is thus highly desirable. Determining the nutrient status of 
phytoplankton based on growth or the measurement of physiological parameters, while possible in laboratory cultures, has historically been very difficult in natural populations (Beardall et al. 2001a). The problem is multifaceted; many different phytoplankton taxa often co-occur in a single location, different taxa within an assemblage may have their growth limited by different factors, and current monitoring techniques and equipment are often unable to distinguish between taxa. The main drawback of most techniques is that they are time consuming, running over several days to weeks leading to a considerable time lag between collecting and processing Previously employed methods for investigating nutrient limitation include bioassays (Holland et al. 2004), in situ fertilization experiments (Coale et al. 1998; Boyd et al. 2000), cellular nutrient ratios (McMinn et al. 1999; Geider and La Roche 2002; Ho et al. 2003; Leonardos and Geider 2004), nutrient uptake kinetics (Riegman et al. 1990), and molecular assays (Geider et al. 1998). However, each of these methods has flaws, as has been extensively reviewed by Beardall et al. (2001b).

The Nutrient Induced Fluorescent Transient (NIFT) technique for assessing phytoplankton nutrient status is relatively new and has several advantages. In contrast to most other approaches, NIFTs rapidly identifies the growth-limiting nutrient, making the method fast and inexpensive as well as reducing errors associated with long term incubation experiments (Shelly et al. 2010). NIFT's have been extensively tested in the lab (Lippemeier et al. 2001; Young and Beardall 2003; Shelly et al. 2007; Petrou et al. 2008; Roberts et al. 2008) but only limited studies have been attempted with field samples (Wood and Oliver 1995; Holland et al. 2004). The NIFT technique monitors chlorophyll $a$ fluorescence in real time. After the addition of a limiting nutrient to nutrient deprived algae, a rapid change in fluorescence is typically observed (Young and Beardall 2003; Holland et al. 2004; Shelly et al. 2007; Petrou et al. 2008; Roberts et al. 2008). By running a series of enrichment experiments while monitoring the fluorescence signal, the nutrient that first gives a response signal should be the limiting nutrient. The response may be an increase or decrease in one of the fluorescence parameters, depending on the limiting nutrient (Roberts et al. 2008; Shelly et al. 2010). These responses are short- lived however, lasting for only a few seconds to minutes depending on the concentration and type of nutrient added. The physiological and 
biochemical responses behind this is still poorly understood, although it is believed that a transient change in fluorescence is attributable to a relocation of energy to nutrient uptake (Holland et al. 2004), either to increase photochemistry (decreased fluorescence emission) or to increase some other cellular reaction (increased fluorescence emission).

Previous studies (Chapter 2, 3 this thesis) found no increases in algal biomass in the brine communities of Turtle Rock over the 3 week study period. In contrast, in the bottom of the sea ice (Chapter 2, 3 this thesis) and seawater (Appendix B: Seawater community composition), algal biomass increased significantly. This lack of growth in the brine could not be attributed to a limitation of light, as there is obviously higher irradiance to the surface than at the bottom. Here, I assess the application of NIFT assays for determining nutrient limitation in marine field samples collected from seawater, sea ice and brine from Turtle Rock, Antarctica. This is the first time a NIFT assay has been used for sea ice microbial communities. The main aims of the study were to determine whether the NIFT assay is an effective method for the assessment of nutrient status in sea ice, and then to quantify nutrient limitation in Antarctic brine or bottom ice samples as well as the underlying water column. Due to the lower rate of nutrient replacement in the internal brine communities, it is expected that nutrient limitation will occur in these communities but not in seawater or bottom sea ice.

\section{Materials and methods}

\section{Sample collection}

Microalgae were collected from 3: habitats; the brine community $(0.8 \mathrm{~m})$, the bottom ice community (1.95 -1.85 m) and the water column at Turtle Rock, Ross Island $\left(77^{\circ} 38^{\prime} \mathrm{S}\right.$, $166^{\circ} 25^{\prime} \mathrm{E}$ ) in mid-December 2011. There was little to no snow cover present and the water current under the sea ice was negligible. The PAR levels measured under the sea ice, with a LiCor $2 \pi$ sensor, were $\sim 20 \mu \mathrm{mol}$ photons $\mathrm{m}^{-2} \mathrm{~s}^{-1}$ and in the brine located midway through the ice cores was $\sim 50 \mu \mathrm{mol}$ photons $\mathrm{m}^{-2} \mathrm{~s}^{-1}$, respectively. 
Sea ice algae from the bottom of the ice were collected using a $140 \mathrm{~mm}$ diameter ice coring drill (Kovaks, USA). Ten centimetre sections were collected from the bottom of the ice core $(n=3)$. The ice core was melted at $4^{\circ} \mathrm{C}$ under low-light conditions over a period of 12 hours. This was done by adding 2 parts by volume of sterile filtered $(0.2$ $\mu \mathrm{m})$ seawater to one part ice sea ice core. Brine $(n=3)$ was collected by drilling a hole from the surface of the ice to the middle of the sea ice using a Kovacs drill and waiting 30-60min until the hole partly filled with brine. Water samples $(n=3)$ were collected from $5 \mathrm{~m}$ depth using a 2.3 L NISKIN Bottle (USA). During all collections, samples were protected from light damage by performing all operations underneath a black sheet and transferring the ice cores, brine or seawater samples into black plastic containers.

\section{Culture maintenance}

The phytoplankton in the samples was concentrated by filtering $350-500 \mathrm{ml}$ of seawater, melted sea ice or brine through a GF/F filter by means of gravity. The concentrate was then re-suspended in $200 \mathrm{ml}$ of $0.2 \mu \mathrm{m}$ filtered sterile seawater, melted sea ice or brine. Sea ice, seawater and brine samples collected directly from the field were stabilised in culture in the dark and water was regularly refreshed with filtered sterile seawater or brine collected during sampling so that the nutrient concentration remained the same before the experiment was started. Samples were returned to New Zealand for analysis within a week.

During the 5 days duration of the experiment, seawater and sea ice samples were maintained under a $12 \mathrm{~h}: 12 \mathrm{~h}$ day:night cycle at $4^{0} \mathrm{C}$ with $\sim 20 \mu \mathrm{mol}$ photons $\mathrm{m}^{-2} \mathrm{~s}^{-1}$ visible light from a fluorescent source (Phillips, TL80W) and the brine samples were cultured at $\sim 50 \mu \mathrm{mol}$ photons $\mathrm{m}^{-2} \mathrm{~s}^{-1}$. These light intensities approximate those measured at the bottom of the sea ice and the middle of the sea ice at Turtle Rock in November 2011. Seawater, sea ice and brine communities consist largely of diatoms (see Chapter 2). Since, diatoms critically depend on the availability of silica, which could leach from glass containers; all culture equipment was either polycarbonate or polyethylene. One key container that did contain silica was the quartz measuring cuvette used to hold samples within the WATER-PAM (Heinz Walz GmbH). The optical 
quality of the cuvette needs to be high to limit background noise. Leaching of silica from the quartz was assumed to be minimal due to the short duration of the measurement.

\section{NIFT method}

The experimental design was modified from Holland et al. (2004) and Merwe and McMinn (unpubl.). All NIFT tests were monitored using a Water-PAM fluorometer and WinControl software (Heinz Walz GmbH). Three ml sub-samples of seawater, sea ice or brine were transferred into $5 \mathrm{ml}$ cuvettes and dark adapted for 20 minutes prior to testing. The sub-samples were then placed in the emitter detector unit (EDU) of the Water-PAM instrument. The EDU was kept at $4^{0} \mathrm{C}$ to prevent temperature stress. Care was taken to eliminate ambient light exposure to the sample during the transfer. During the dark adaptation and the measurements, the sample was kept at $4^{0} \mathrm{C}$. Initial fluorescence $\left(\mathrm{F}_{0}\right)$ was measured and immediately after the determination of $\mathrm{F}_{0}, \mathrm{a}$ saturating pulse was delivered to measure maximal fluorescence $\left(\mathrm{F}_{\mathrm{m}}\right)$ and maximum quantum yield $\left(\mathrm{F}_{\mathrm{v}} / \mathrm{F}_{\mathrm{m}}\right)$ was calculated. This was followed by activating the actinic light (47 $\mu \mathrm{mol}$ photon $\mathrm{m}^{-2} \mathrm{sec}^{-1}$ of PAR) to initiate photochemistry. The clock function in WinControl was used to perform saturating pulses every 20 seconds for sea ice and seawater samples and every 30 seconds for brine samples and thus allow real time monitoring of minimum fluorescence in the presence of actinic light $\left(F^{\prime}\right)$, maximal fluorescence in actinic light $\left(\mathrm{F}_{\mathrm{m}}{ }^{\prime}\right)$, effective quantum yield $\left(\Delta \mathrm{F} / \mathrm{F}_{\mathrm{m}}{ }^{\prime}\right.$ or $\left.\Phi_{\mathrm{psII}}\right)$, and nonphotochemical quenching $\left(\mathrm{NPQ}=\left(\mathrm{F}_{\mathrm{m}}-\mathrm{F}_{\mathrm{m}}{ }^{\prime}\right) / \mathrm{F}_{\mathrm{m}}{ }^{\prime}\right)$. See also appendix $\mathrm{C}$ for definitions and calculations of the different fluorescent parameters. A stable $\mathrm{F}_{0}$ base line was not achieved for brine at 20 seconds intervals between the saturation pulses and so they were increased to 30 seconds.

After approximately 2.5 minutes, or once the $\mathrm{F}^{\prime}$ reading had stabilised, $25 \mu \mathrm{L}$ of $\mathrm{PO}_{4}{ }^{-3}$, $\mathrm{NO}_{3}$ - or $\mathrm{SiO}_{2}$ were added to the sub-sample to achieve a final concentration of nutrient equal to that proscribed for $\mathrm{f} / 2$ medium (Guillard 1975). All nutrients were made up in sterile artificial seawater. In order to test that the response came from the nutrient addition, control NIFT's were run by adding $25 \mu$ of sterile artificial (Instant Ocean, USA) seawater or brine with no detectable levels of $\mathrm{PO}_{4}^{-3}, \mathrm{NO}_{3}^{-}$or $\mathrm{SiO}_{2}$. The nutrient 
spike was administered directly to the sub-sample using a plastic pipette. The EDU was covered to limit direct ambient light affecting the reading during the nutrient spike. After the spike, the samples were monitored for a further 18 minutes. At the end of this procedure, the cuvette sample was discarded. This protocol was followed for all samples.

\section{Nutrient analyses}

Subsamples were taken from the seawater, sea ice and brine ice cultures, filtered with a $0.8 \mu \mathrm{m}$ filter to remove all cellular material and then analysed for $\mathrm{PO}_{4}^{-3}$ and $\mathrm{SiO}_{2}$ using a MC 500-10 Multi-Parameter Colometer (Orbeco, Hellige, USA). Nitrate was analysed using the low range nitrate lab test kit (The Nitrate Elimination Company Inc., USA).

\section{Species identification}

Ten ml subsamples $(n=12)$ of the different habitats $(n=3)$ were fixed with Lugol's iodine solution at a final concentration of $2.5 \%$. $500 \mu \mathrm{l}$ of the sample were placed on an inverted microscope (Zeiss, Germany) and taxa were determined to at least genus level as appropriate.

\section{Statistics}

Prior to statistical analysis, homogeneity of variance was tested using a Cochran's test. The data variances were homogenous and therefore did not need to be transformed. A one-way ANOVA was performed using the SPSSv18 statistics package to assess differences in nutrient concentrations between habitats and changes in maximum quantum yield $\left(\mathrm{F}_{\mathrm{v}} / \mathrm{F}_{\mathrm{m}}\right)$ during the 5 days of culturing. When significant differences were observed a post hoc Sheffe test was also carried out. Differences in response between the control sample and the nutrient added sample were tested by means of an independent T-test. To test for similarity in variance in the samples, the Levene's test for equality of variance was used. The T-test was corrected for this variance if necessary. The T-test was used for the parameters $F_{0}, F_{m}$ and effective quantum yield $\Phi_{\text {psII }}$ for all days and all habitats after the addition of a nutrient. In all cases, significant differences were defined by $\mathrm{P}<0.05$. 


\section{Results}

\section{Algal abundance and community composition}

Cells concentrations after adjustment were: seawater $4.4 \times 10^{6}$ cells. $\mathrm{L}^{-1}$, sea ice $3.7 \times 10^{6}$ cells. $\mathrm{L}^{-1}$, and brine $5.1 \times 10^{6}$ cells. $\mathrm{L}^{-1}$ (One-way ANOVA: $\mathrm{F}=18.912, \mathrm{P}=0.057$ ) showed no significant difference in the cell concentration between habitats. Sea ice and water samples consisted entirely of diatoms, whereas brine was comprised of $85 \%$ diatoms, and $15 \%$ dinoflagellates of the species Polarella sp. (Figure 4-1). Seawater had approximately equal concentrations of Fragilariopsis spp., Nitzschia leicointei, and $N$. stellata (Figure 2). The main species in the sea ice were $N$. leicontei and Entomoneis kjellmannii followed by Navicula sp., N. stellata and Fragilariopsis spp. Brine was dominated by Fragilariopsis spp. (<50\%), followed by Navicula sp., N. stellata and Polarella sp., which together made up $>35 \%$ (Figure 4-1). Fragilariopsis spp. consisted of 2 species: F. curta and F. cylindrus. These species can only be distinguished from each other when they are perfectly orientated in valve view, and therefore they were grouped together as Fragilariopsis spp.

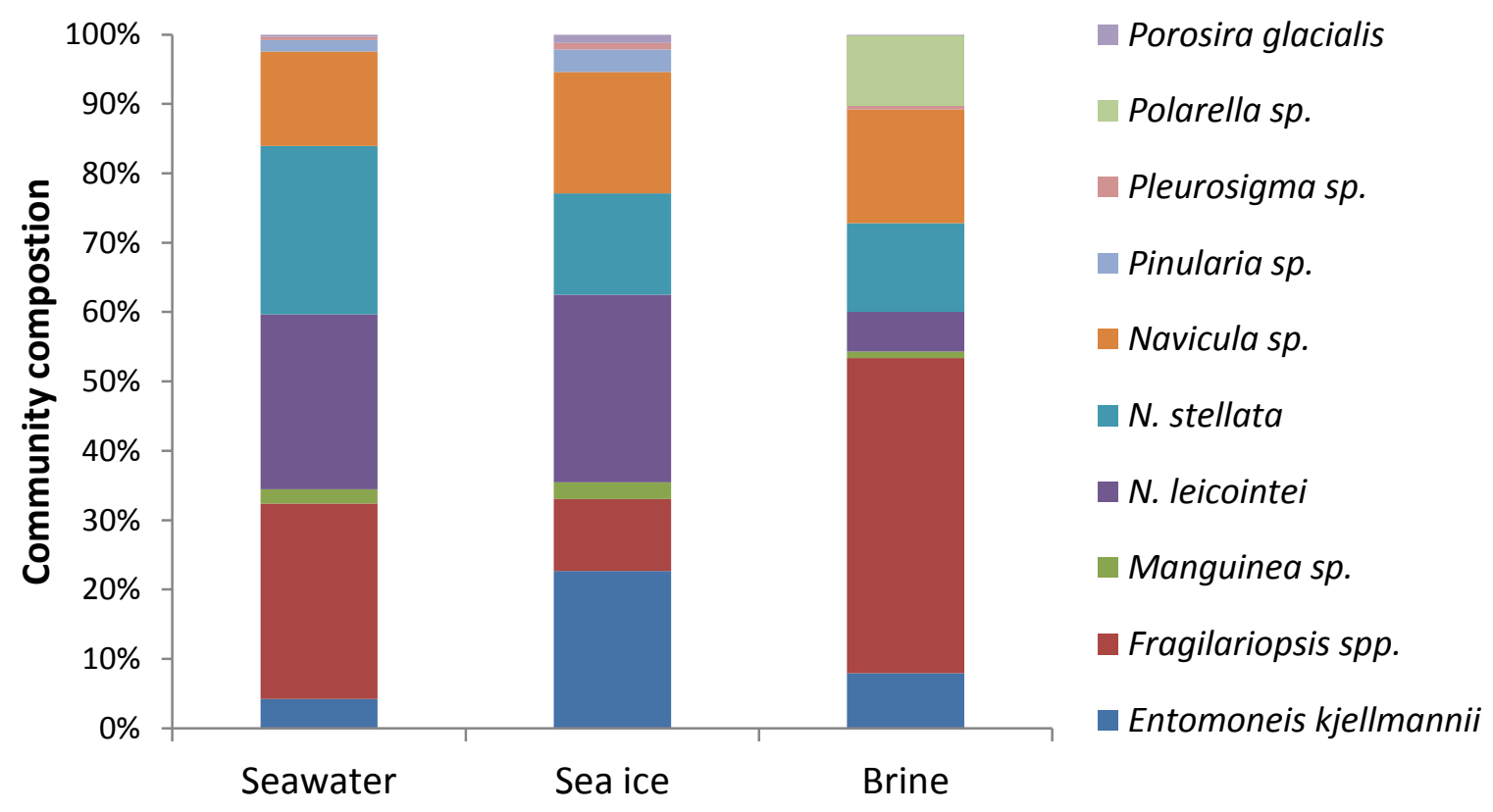

Figure 4-1: Community composition of seawater, sea ice and brine. Samples were collected from Turtle Rock, Ross Sea, Antarctica. The seawater and sea ice communities consisted entirely of diatoms whereas for the brine community, the dinoflagellate Pollarella sp. was present. 


\section{Nutrient analysis}

Silica concentrations were similar for the seawater, sea ice or brine samples (ANOVA: $\mathrm{F}=0.431, \mathrm{P}=0.653)$. Phosphate and nitrate concentrations were also similar between seawater and sea ice (Sheffe post hoc: $\mathrm{P}=0.741$ and $\mathrm{P}=0.476$ respectively) but the brine samples had significantly higher concentrations of these nutrients than seawater and sea ice (Sheffe Post hoc: $\mathrm{P}<0.005)$. During the experiment, no significant change in nutrient concentration could be detected. Average concentrations are given in Table 41.

Table 4-1: Average $(n=3)$ nutrient concentrations in $\mu$ mol.L-1 of the 3 different habitats at day 1 of the NIFT experiment.

\begin{tabular}{llll}
\hline & Silica \pm SE & Phosphate \pm SE & Nitrate \pm SE \\
\hline Seawater & $67 \pm 8.3$ & $3 \pm 0.4$ & $9 \pm 1.6$ \\
Sea ice & $69 \pm 9.1$ & $2 \pm 0.3$ & $9 \pm 3.6$ \\
Brine & $69 \pm 19$ & $13 \pm 1.9$ & $79 \pm 2.6$ \\
\hline
\end{tabular}

\section{Yield}

The maximum quantum yield $\left(\mathrm{F}_{\mathrm{v}} / \mathrm{F}_{\mathrm{m}}\right)$ of photosynthesis measured after dark adaption increased significantly for brine by $40 \%(\mathrm{~F}=7.981, \mathrm{P}=0.004)$ and sea ice $100 \%$ $(\mathrm{F}=163.136, \mathrm{P}>0.005)$, but not seawater $(\mathrm{F}=1.415, \mathrm{P}=0.298)$ throughout the 5 days during which the experiment was run (Figure 4-3).

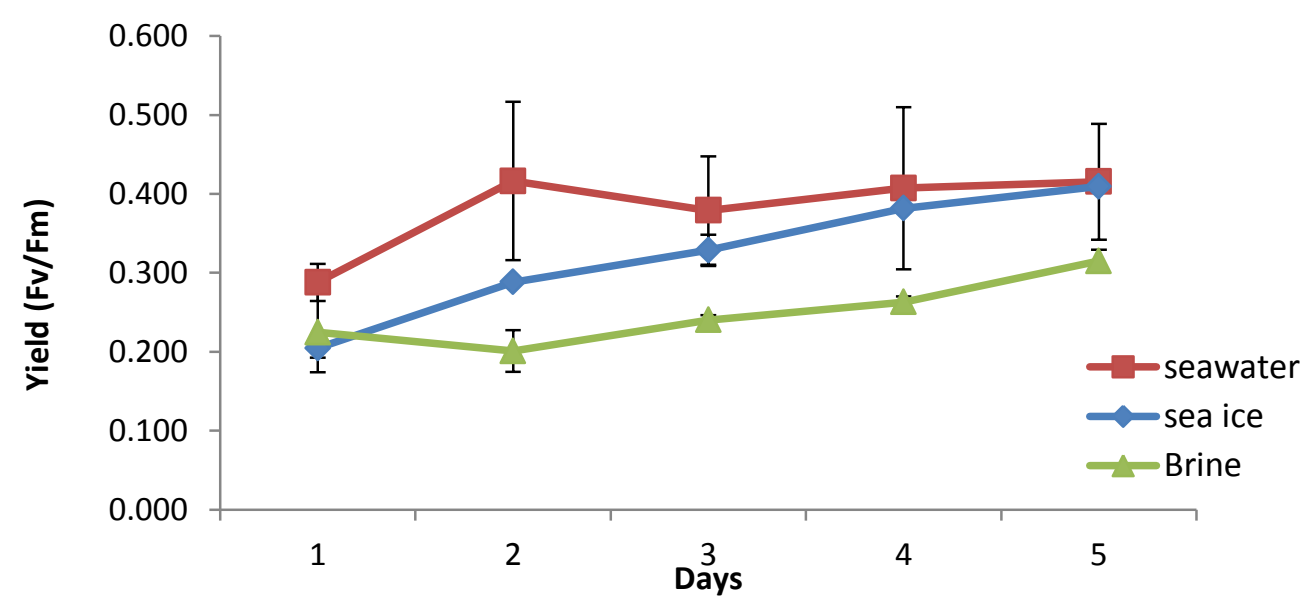

Figure 4-2: Increase of $F_{v} / F_{m}$ over the course of 5 days of the NIFT test. This measurement was done after $20 \mathrm{~min}$ of dark adaptation but before the NIFT test started. Data are means $\pm 1 \mathrm{SE}, n=4$ per data point). 


\section{NIFT}

Algal cells from the 3 different habitats were grown for 5 days in the original medium. Each day, separate sub-samples from these cultures were tested for a NIFT response for silica, phosphate and nitrate. After the addition of a nutrient, the fluorescence response was monitored for $\sim 15 \mathrm{~min}$. A negative response was defined as no change in $\mathrm{F}, \mathrm{F}_{\mathrm{m}}$ ' or $\Phi_{\text {psII, }}$ during the time after the nutrient spike was added. A positive NIFT response was characterized as a rise or drop in $\mathrm{F}^{\prime}, \mathrm{F}_{\mathrm{m}}$ ' or $\Phi_{\mathrm{psII}}$, depending on the nutrient and was observed 2.5-4 min after the addition of the nutrient and was sustained for the duration ( $\sim 15$ minutes) of the NIFT test.

\section{Control}

Addition of sterile artificial seawater (without detectable levels of $\mathrm{Si}, \mathrm{P}$ or $\mathrm{N}$ ) was used as a control. Addition of the control caused an immediate short spike in $\mathrm{F}^{\prime}$ and $\mathrm{F}_{\mathrm{m}}$. This signal returned within 20-40 sec back to the original value (Figure 4-3). This same spike was also visible when a nutrient was added. Though the greatest care was taken to avoid ambient light reaching the EDU when the nutrient or control was added there was still a spike visible in the $\mathrm{F}^{\prime}$ and $\mathrm{F}_{\mathrm{m}}$, and this may have been caused by residual ambient light reaching the EDU (Merwe and McMinn unpubl.)

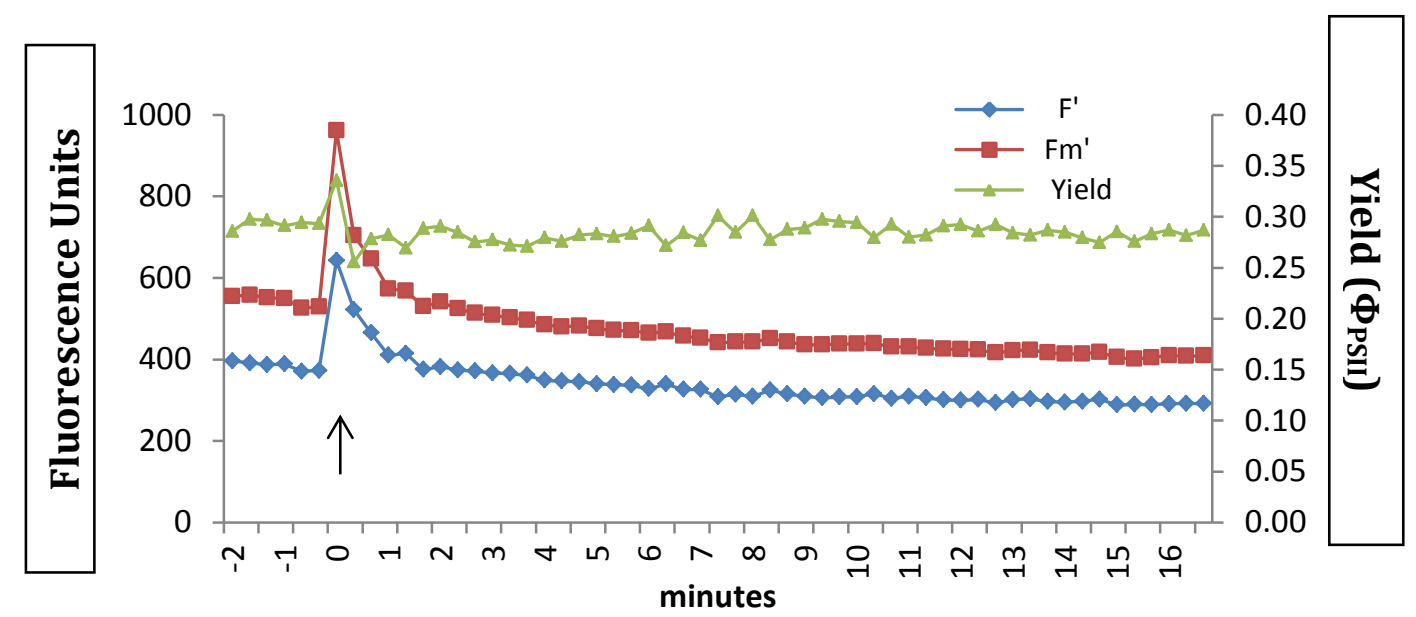

Figure 4-3: Example of the control response in fluorescence parameters when a sterile seawater control was added to Brine. The arrow indicated when the control liquid was introduced. Immediately afterward there was a transient increase in $\mathrm{F}^{\prime}$ and $\mathrm{F}_{\mathrm{m}}{ }^{\prime}$. 


\section{Silica}

After the addition of $25 \mu \mathrm{L}$ silicate, the fluorescence response was monitored for 15min. For all 3 sample habitats, silica limitation was found (Figures 4-4 to 4-6), but the day that nutrient limitation was observed differed. The NIFT response was characterized by an increase of $F_{m}$ ' and $F^{\prime}$ during the first 2.5-4 min which was sustained for the duration ( $\sim 15$ minutes) of the NIFT test.

\section{Seawater}

No differences between the control and treated samples in any of the photometric parameters were observed in the first 3 days (Table 4-2). The small response observed at day 2 (Figure 4-4) does not differ significantly from controls (Table 4-2). On the $4^{\text {th }}$ and $5^{\text {th }}$ days, an increase of $\mathrm{F}^{\prime}$ and $\mathrm{F}_{\mathrm{m}}$ ' of $101 \%$ and $89 \%$ (day 4 ) and $60 \%$ and $80 \%$ (day 5), respectively was observed after the injection with silica (Figure 4-4, day 4 and day 5). These changes were statistically significant (Table 4-2). The steepest increase occurred in the first 5 min followed by a steady and sustained increase in F' and $\mathrm{F}_{\mathrm{m}}$ '. 


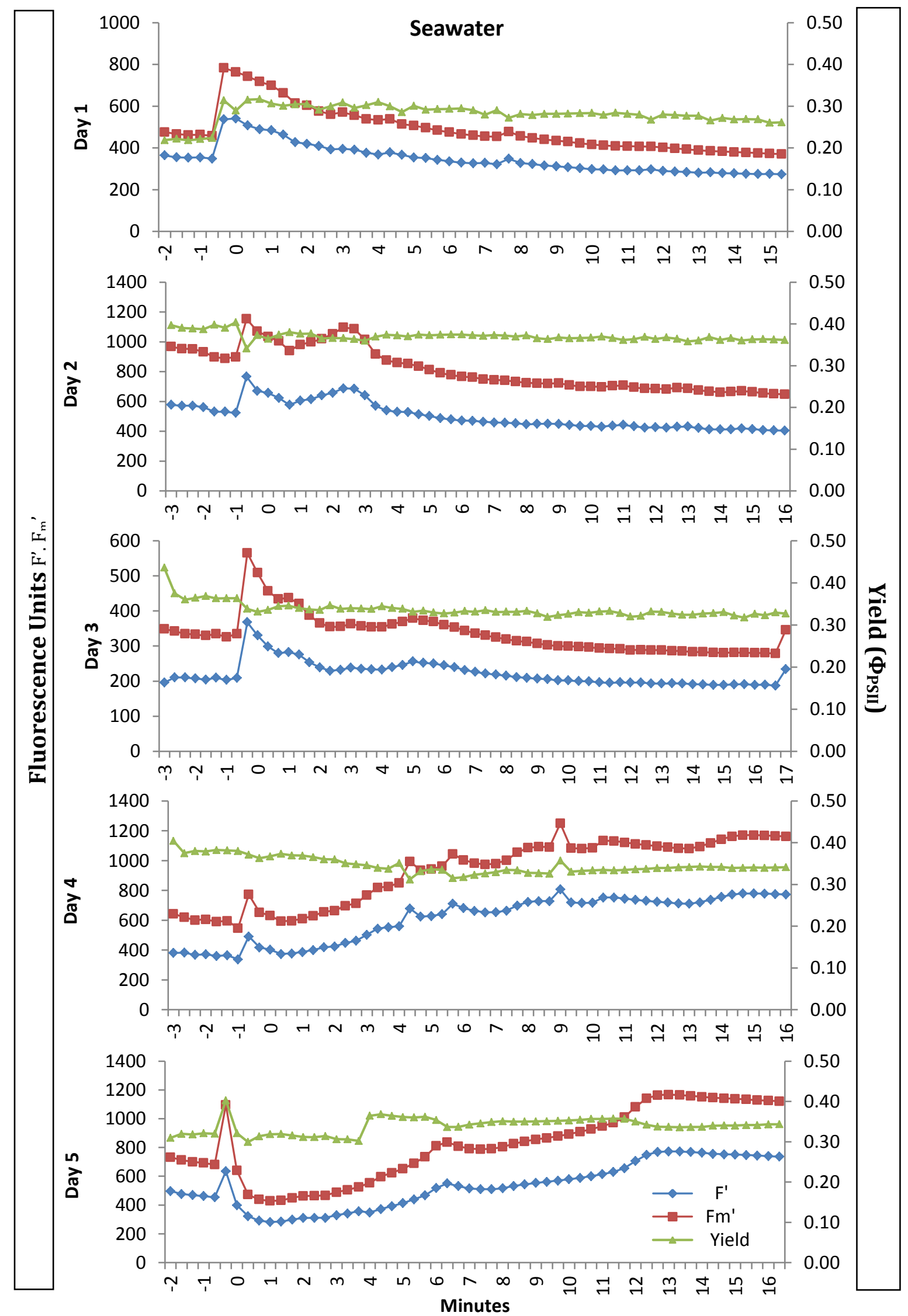

Figure 4-4: Fluorescence response, per day, of a seawater sample to the addition of silica. Time 0 is when the nutrient was added. 
Table 4-2: Differences in response of $F^{\prime}, F_{m}$ and $\Phi_{\mathrm{psII}}$ between the seawater control and the seawater after the addition of silica was tested by means of an independent T-test at each time point. To test for similarity in variance, the Levene's test for equality of variance was used. The T-test was corrected for this variance. In all cases, significant correlations were defined by $\mathrm{P}<0.05$ and are indicated in bold.

\begin{tabular}{llllll}
\hline Day & Parameter & \multicolumn{2}{c}{ Levene's Test for Equality of Variances } & \multicolumn{2}{c}{ Unpaired T-Test } \\
\hline & & $\mathrm{F}$ & Sig. & $\mathrm{df}$ & Sig. (2-tailed) \\
$\mathbf{1}$ & $\mathrm{F}^{\prime}$ & 6.690 & 0.061 & 4 & 0.162 \\
$\mathbf{2}$ & $\mathrm{F}^{\prime}$ & 0.053 & 0.830 & 4 & 0.745 \\
$\mathbf{3}$ & $\mathrm{F}^{\prime}$ & 4.234 & 0.109 & 4 & 0.090 \\
$\mathbf{4}$ & $\mathrm{F}^{\prime}$ & 1.860 & 0.244 & 4 & $\mathbf{0 . 0 0 0}$ \\
$\mathbf{5}$ & $\mathrm{F}^{\prime}$ & .289 & 0.619 & 4 & $\mathbf{0 . 0 2 1}$ \\
$\mathbf{1}$ & $\mathrm{F}_{\mathrm{m}}^{\prime}$ & 2.565 & 0.185 & 4 & 0.192 \\
$\mathbf{2}$ & $\mathrm{F}_{\mathrm{m}}^{\prime}$ & 4.228 & 0.109 & 4 & 0.706 \\
$\mathbf{3}$ & $\mathrm{F}_{\mathrm{m}}^{\prime}$ & 8.376 & 0.044 & 2.130 & 0.130 \\
$\mathbf{4}$ & $\mathrm{F}_{\mathrm{m}}^{\prime}$ & 9.381 & 0.038 & 2.041 & $\mathbf{0 . 0 0 4}$ \\
$\mathbf{5}$ & $\mathrm{F}_{\mathrm{m}}^{\prime}$ & 3.550 & 0.133 & 4 & $\mathbf{0 . 0 2 1}$ \\
$\mathbf{1}$ & $\Phi_{\text {psII }}$ & 4.109 & 0.113 & 4 & 0.450 \\
$\mathbf{2}$ & $\Phi_{\text {psII }}$ & 0.052 & 0.830 & 4 & 0.858 \\
$\mathbf{3}$ & $\Phi_{\text {psII }}$ & 0.224 & 0.661 & 4 & 0.902 \\
$\mathbf{4}$ & $\Phi_{\text {psII }}$ & 0.001 & 0.983 & 4 & 0.713 \\
$\mathbf{5}$ & $\Phi_{\text {psII }}$ & 2.615 & 0.181 & 4 & 0.626 \\
\hline
\end{tabular}

\section{$\underline{\text { Sea ice }}$}

No differences between the control and treated samples in any of the photometric parameters were observed in the first 2 days (Table 4-3). The onset of the response to silica injection started at day 3 (Figure 4-5, day 3, Table 4-3) as a rapid increase in F' and $\mathrm{F}_{\mathrm{m}}$ ' within 2-4 minutes followed by stabilization at a higher level. In contrast, on days 4 and 5 , the response occurred slightly later at $\sim 4$ minutes after injection, and increased for a further 6 minutes before it stabilised. The increase of $F_{0}$ and $F_{m}$ ' was $36 \%$ and 31\%, respectively, at day 3 (Figure 4-5, day 3). This was followed by an increase of $117 \%$ and $95 \%$ on day 4 (Figure 4-5, day 4 ) and $102 \%$ and $83 \%$ on day 5 (Figure 4-5, day 5). The strongest increase occurred in the first 5 minutes during days 3 between 5 and $10 \mathrm{~min}$ on day 4 . 


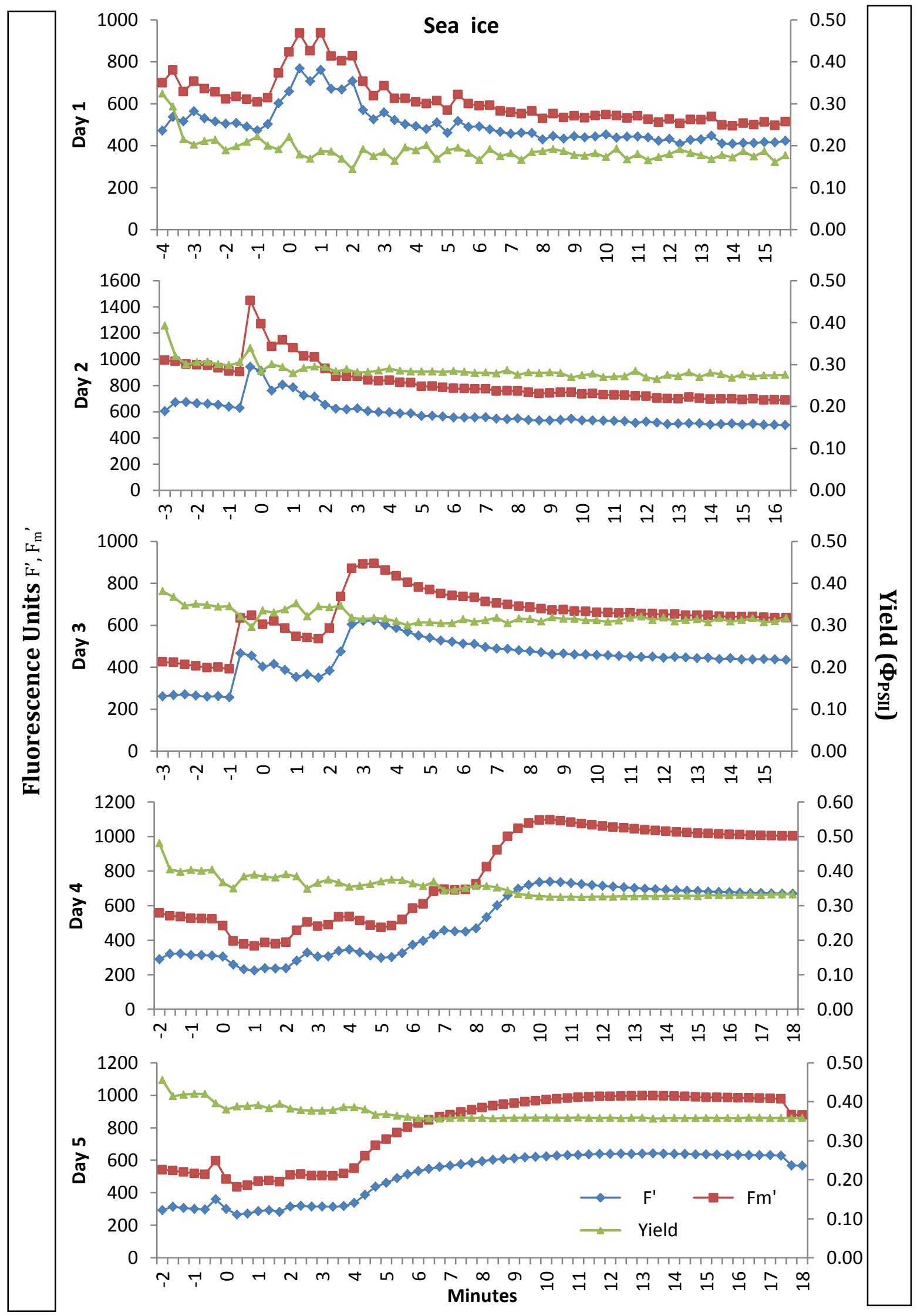

Figure 4-5: Fluorescence response, per day, of a sea ice sample to the addition of silica. Time 0 is when the nutrient was added. 
Table 4-3: Differences in response of $F^{\prime}, F_{m}{ }^{\prime}$ and $\Phi_{\text {psII }}$ between the sea ice control and the sea ice after the addition of silica was tested by means of an unpaired T-test. To test for similarity in variance the Levene's test for equality of variance was used. The T-test was corrected for this variance. In all cases, significant correlations were defined by $\mathrm{P}<0.05$.

\begin{tabular}{llllll}
\hline Day & Parameter & \multicolumn{2}{l}{$\begin{array}{l}\text { Levene's Test for Equality of } \\
\text { Variances }\end{array}$} & \multicolumn{2}{l}{ Unpaired T-test } \\
\hline $\mathbf{1}$ & & $\mathrm{F}$ & Sig. & $\mathrm{df}$ & Sig. (2-tailed) \\
$\mathbf{2}$ & $\mathrm{F}^{\prime}$ & 0.456 & 0.537 & 4 & 0.080 \\
$\mathbf{3}$ & $\mathrm{F}^{\prime}$ & 9.397 & 0.037 & 2.020 & 0.058 \\
$\mathbf{4}$ & $\mathrm{F}^{\prime}$ & 1.365 & 0.308 & 4 & $\mathbf{0 . 0 2 7}$ \\
$\mathbf{5}$ & $\mathrm{F}^{\prime}$ & 6.101 & 0.069 & 4 & $\mathbf{0 . 0 3 9}$ \\
$\mathbf{1}$ & $\mathrm{F}^{\prime}$ & 0.411 & 0.556 & 4 & $\mathbf{0 . 0 0 0}$ \\
$\mathbf{2}$ & $\mathrm{F}_{\mathrm{m}}^{\prime}$ & 0.012 & 0.918 & 4 & 0.101 \\
$\mathbf{3}$ & $\mathrm{F}_{\mathrm{m}}^{\prime}$ & 1.846 & 0.246 & 4 & 0.603 \\
$\mathbf{4}$ & $\mathrm{F}_{\mathrm{m}}^{\prime}$ & 5.229 & 0.084 & 4 & $\mathbf{0 . 0 2 8}$ \\
$\mathbf{5}$ & $\mathrm{F}_{\mathrm{m}}^{\prime}$ & 3.520 & 0.134 & 4 & $\mathbf{0 . 0 3 1}$ \\
$\mathbf{1}$ & $\mathrm{F}_{\mathrm{m}}^{\prime}$ & 0.007 & 0.937 & 4 & $\mathbf{0 . 0 0 0}$ \\
$\mathbf{2}$ & $\Phi_{\text {psII }}$ & 5.658 & 0.076 & 4 & 0.410 \\
$\mathbf{3}$ & $\Phi_{\text {psII }}$ & 1.894 & 0.241 & 4 & 0.799 \\
$\mathbf{4}$ & $\Phi_{\text {psII }}$ & 6.316 & 0.066 & 4 & 0.475 \\
$\mathbf{5}$ & $\Phi_{\text {psII }}$ & 6.328 & 0.066 & 4 & 0.405 \\
\hline
\end{tabular}

\section{$\underline{\text { Brine }}$}

After the addition of silica, an average increase in $\mathrm{F}^{\prime}, \mathrm{F}_{\mathrm{m}}{ }^{\prime}$ and $\Phi_{\text {psII }}$ over the control samples of 26\%, 24\% and 13\%, respectively, occurred on the first day (Figure 4-6, Table 4-4). This early response contrasts with those observed for the other 2 habitats. (Figure 4-7). Furthermore, the percentage increases of $F^{\prime}$ and $F_{m}{ }^{\prime}$ was much lower than in seawater and bottom ice, and there was an increase in $\Phi_{\text {psII }}$ during the measurement, which did not occur in the other habitats. Finally, the $\mathrm{F}^{\prime}$ and $\mathrm{F}_{\mathrm{m}}$ ' response was no longer observed after the third day, although an increase in $\Phi_{\text {psII }}$ was still evident on day 5. 


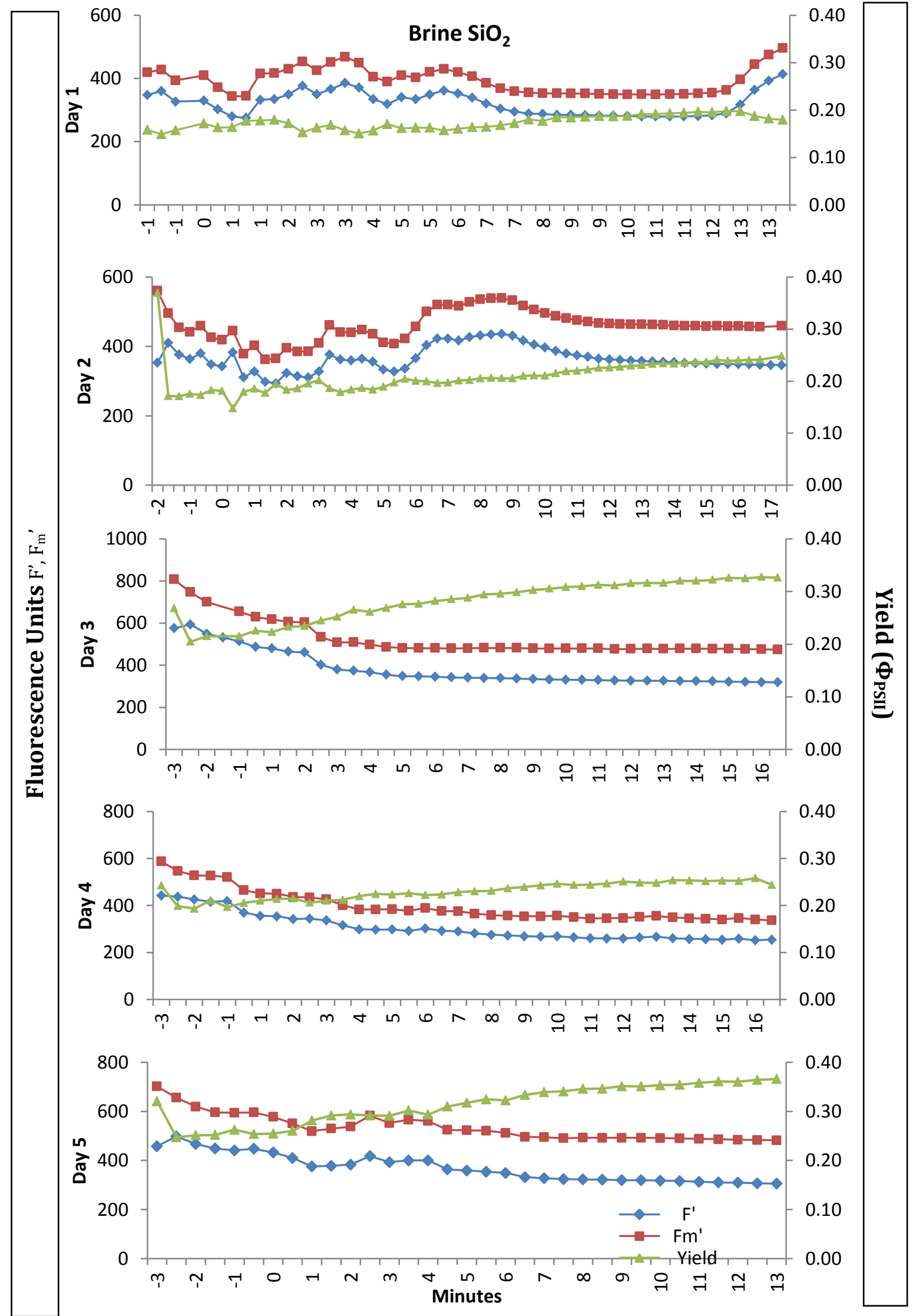

Figure 4-6: fluorescence response, per day, of a brine sample to the addition of silicate. Time 0 is when the nutrient was added. 
Table 4-4: Differences in response of $F^{\prime}, F_{m}{ }^{\prime}$ and $\Phi_{\text {psII }}$ between the brine control and the brine after the addition of silica was tested by means of an unpaired T-test. To test for similarity in variance the Levene's test for equality of variance was used. T-test was corrected for this variance. In all cases, significant correlations were defined by $\mathrm{P}<0.05$.

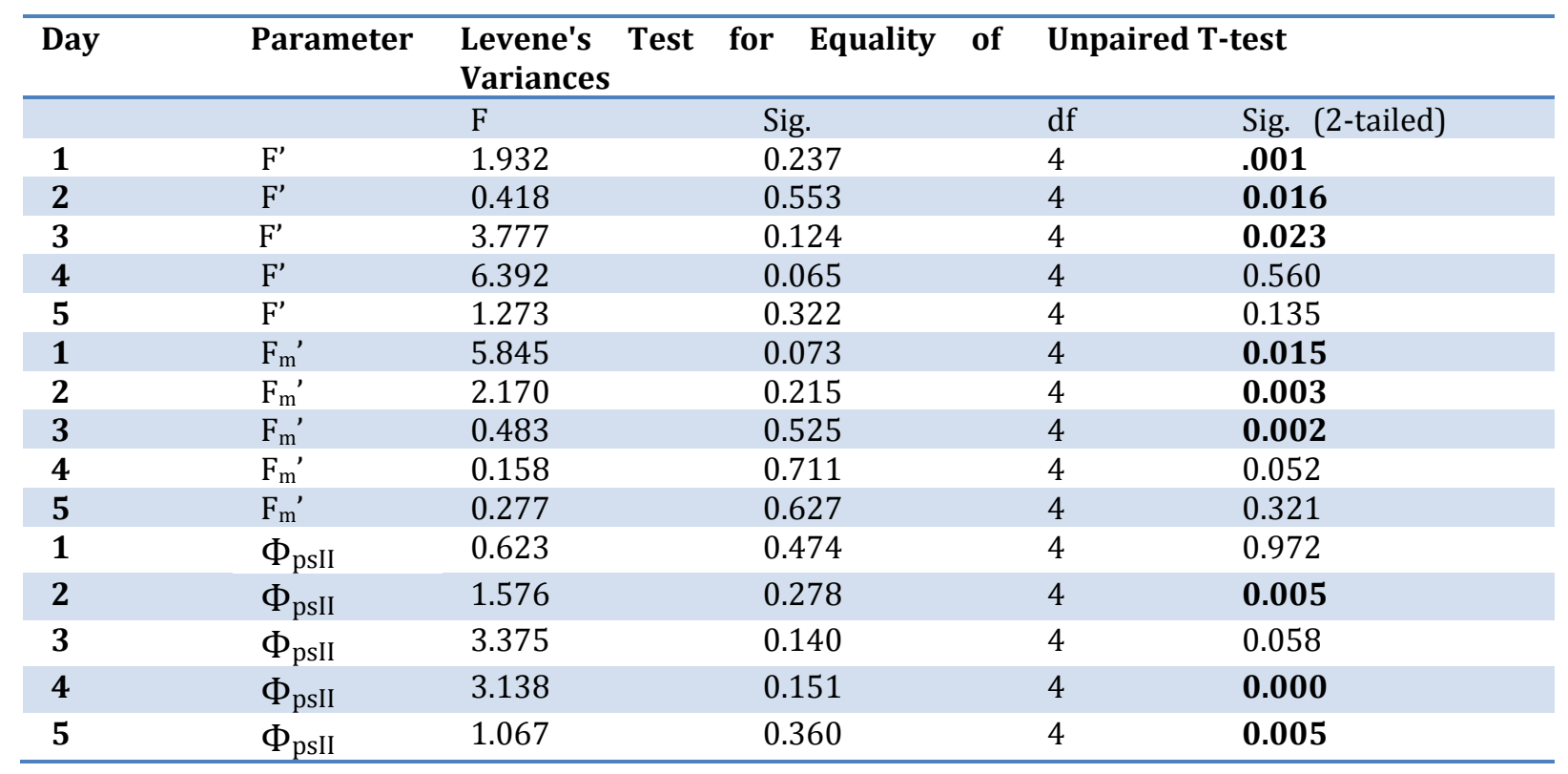

\section{Phosphate}

No changes were observed in the seawater and sea ice samples after injection of phosphate (Figure 4-7). However, in the brine samples, the $\Phi_{\text {psII }}$ increased approximately 1-2 minutes after the addition of orthophosphate (Figure 4-8). This response started on the second day and was observed on all the remaining days of the experiment (Table 4-5).

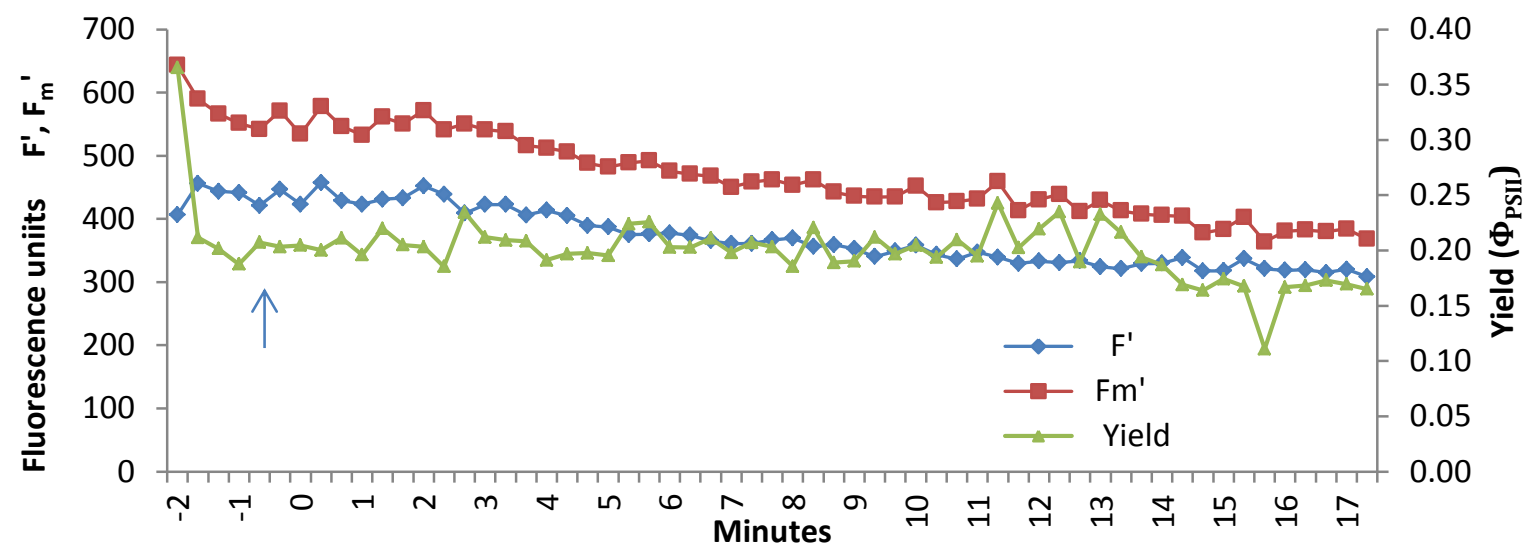

Figure 4-7: Example of no response in fluorescence parameters after addition of orthophosphate to a non P-limited seawater sample. Time 0 (arrow) is where the nutrient was added. Similar responses were observed in sea ice samples. 
Table 4-5: Differences in response of $\mathrm{F}^{\prime}, \mathrm{F}_{\mathrm{m}}{ }^{\prime}$ and $\Phi_{\mathrm{psII}}$ between the brine control and the brine after the addition of phosphate was tested by means of an unpaired T-test. To test for similarity in variance the Levene's test for equality of variance was used. The T-test was corrected for this variance. In all cases, significant correlations defined by $\mathrm{P}<0.05$ are indicated in bold.

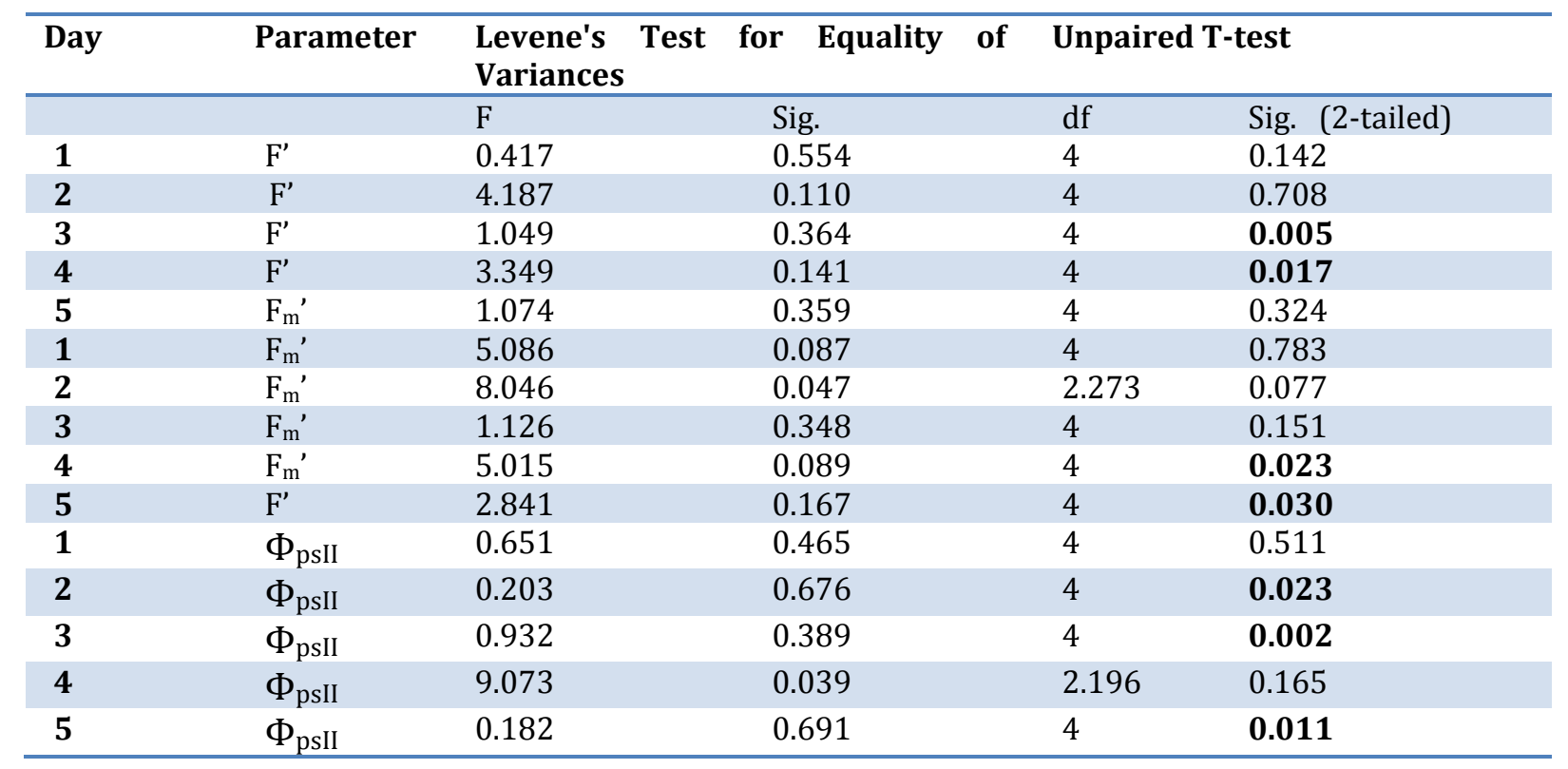




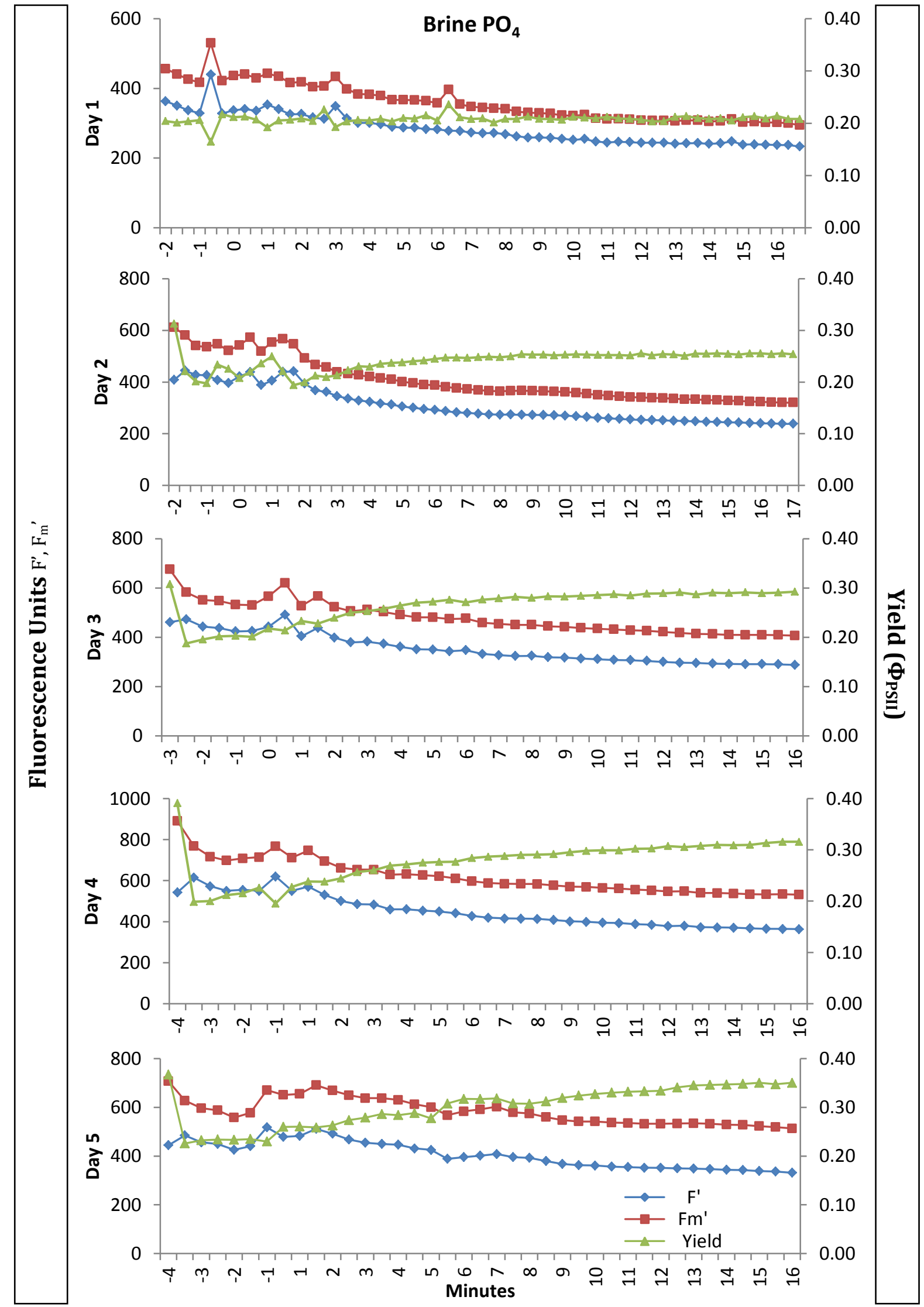

Figure 4-8: fluorescence response, per day, of a brine sample to the addition of phosphate. Left y-axis florescence $\left(\mathrm{F}^{\prime}, \mathrm{F}_{\mathrm{m}}{ }^{\prime}\right)$, right $\mathrm{y}$-axis yield, $\mathrm{X}$-axis time in minutes. Time 0 is where the nutrient was added. 


\section{Nitrate}

Nitrate addition did not produce a response in any of the photosynthetic parameters in any of the habitats (Figure 4-9). Throughout the experiment, the photochemical responses to the addition of nitrate did not differ from the control.

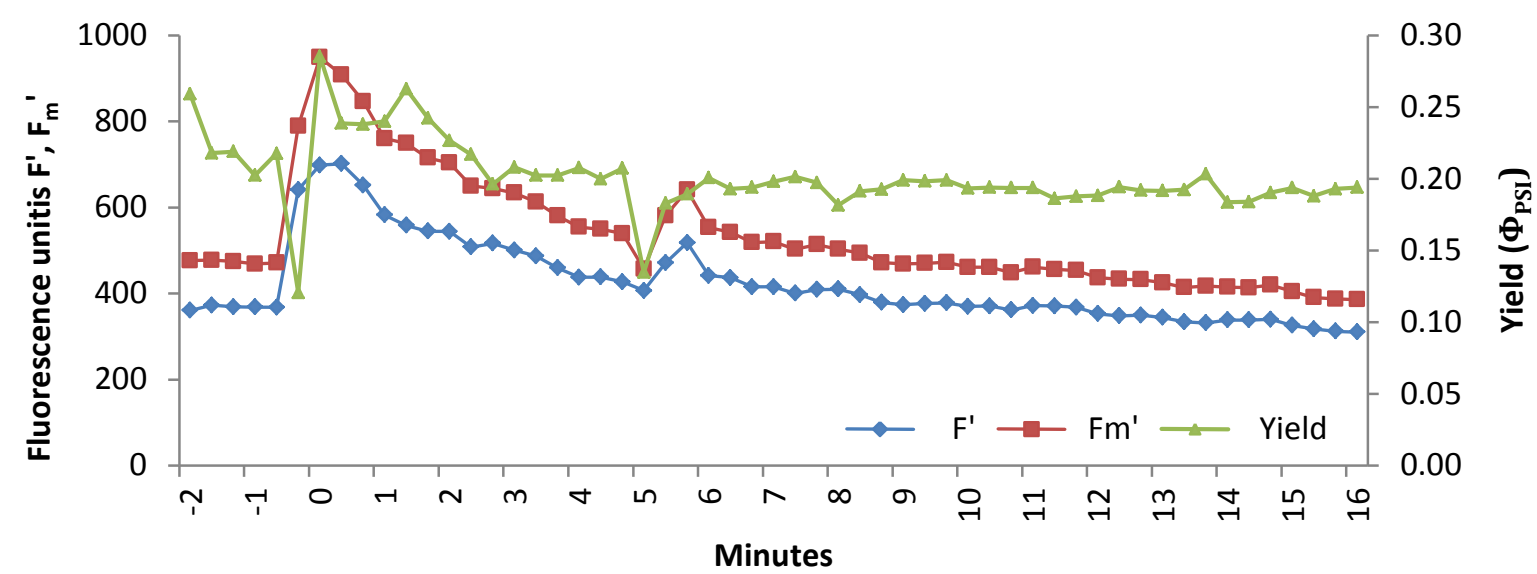

Figure 4-9: Example of no response in fluorescence parameters after addition of $\mathrm{NO}_{3}$ - to a non $\mathrm{N}$-limited brine sample. Time 0 is where the nutrient or blank was added.

\section{Discussion}

\section{NIFT assay}

This is the first study to employ the NIFTs assay to qualify nutrient limitation in Antarctic sea ice algae. The NIFT method generates an almost instantaneous assessment of nutrient limitation and is sensitive enough to detect dual nutrient limitation in a taxonomically diverse sample. Importantly, the NIFT responses described in this study are consistent with other reports (Holland et al. 2004; Shelly et al. 2007; Petrou et al. 2008). For example, Lippemeier et al. (1999), also showed that after the addition of silica to cultures of Thalassiosira weissflogii, $\mathrm{F}, \mathrm{F}_{\mathrm{m}}^{\prime}$ and yield rose exponentially over $\sim 2.5$ hours. Although Merwe and McMinn (unpubl.) used a shorter experimental time frame, the results, with respect to silica, are also comparable. 


\section{Brine community}

In this study, microalgae from the brine habitat responded positively to the addition of $\mathrm{Si}$ and $\mathrm{P}$ on the first day of sampling, which implies a nutrient limitation. Previous studies on the brine communities at TR (chapter 2, 3 this thesis) found no increases in algal biomass during the spring/summer of 2011 from no to high snow cover. In contrast, in the bottom of the sea ice (chapter 2, 3 this thesis) algal biomass increased. This lack of growth in the brine could not be attributed a limitation of light (chapter 3). The data presented here support the hypothesis originally proposed in chapter 3 , that the brine algal community is nutrient limited. Brine forms a semi-closed environment where nutrients are not regularly resupplied (Arrigo et al. 2010) and this suggests that nutrient limitation is likely to occur relatively early in the growth season. Generally, the sea ice primary production continues until late austral summer when the ice breaks up (Knox 2009a). A recent study in estimated the contribution of interior sea ice communities to be nearly equal to those of bottom and surface communities (Meiners et al. 2012). Interior assemblages are more commonly found in under-sampled thick, deformed ice, and they might contribute more than previously suspected to overall chl $a$ biomass (Meiners et al. 2012). This means that the strong nutrient limitation in the brine identified here could mean that large volumes of ice are potentially limited in primary production. Furthermore, models of primary production in sea ice algae (Arrigo et al. 1997; Arrigo et al. 2008) need to take the entire ice core into account to accurately estimate ice algal primary production in Southern Ocean sea ice.

The brine samples were also unique in that they were the only ones that showed an immediate photochemical response to two nutrients. Phytoplankton growth can be limited by multiple resources simultaneously due to differences in community structure (Arrigo 2005). The main difference between seawater/ice and the brine is the species composition. The brine community had a high percentage of diatom species (e.g. Fragilariopsis spp.) that have high nutrient requirements, especially for silica. Fragilariopsis species are heavily frustulated (Tomas 1997), especially compared to species such as Entomoneis sp., which was more prevalent in the bottom of the sea ice. This could mean that nutrient limitation may occur earlier in communities dominated by Fragilariopsis spp. such as those found in the brine. The brine community also 
contains dinoflagellates, which do not depend on silica but have other nutrient requirements. Despite the fact that phosphate concentration was significantly higher in the brine than the other two habitats, it was still a limiting nutrient, which could be due to the relatively high abundance of Polarella sp. in this environment. It is possible also that Fragilariopsis spp. has a higher requirement for phosphate than other diatoms, due the generally higher silicified frustule.

The average Redfield ratio for plankton is N:P is 16:1 (Geider and La Roche 2002), but , however my study showed ratio between 3:1 and 6:1. The Redfield ratio can vary depending on species and taxa up to a factor 20 when normalized against P (Ho et al. 2003). This could explain why the brine which has a high abundance of Fragilariopsis spp., a diatom with a high nutrient demand as described in the previous paragraph, can cause a deviation from this ratio. Furthermore, this ratio is influenced by daylight, irradiance, salinity and temperature (Geider and La Roche 2002). These particular factors are especially strong in the sea ice of polar regions. Though the ratio found might be low it still falls within the range, but further analyses of polar diatom cultures in which varies day length, irradiance, salinity or temperature is varied could be helpful in further understanding the nutrient limitation found in the brine.

When samples are extremely nutrient limited, they can give a false positive response to another nutrient such as illustrated by Wood and Oliver (1995) who showed that a sample responded to the addition of $\mathrm{NH}^{4+}$ even though it was P-limited. It is impossible to determine the reason for the phosphorus response in the brine community and more field studies that examine community composition and responses to addition of different nutrients as well as other methods in determining nutrient limitation are necessary. However, in previous studies where a false positive was observed, the additional response only occurred several days after the true nutrient limitation was detected (Holland et al. 2004). Furthermore, the response was minor compared to the real limiting nutrient (Holland et al. 2004). My results show an immediate response of both nutrient and the response was strong with an increase between 13-16\% depending of the parameter measured. Tests done with monocultures in the lab show 
similar changes of NIFT parameters when a culture became nutrient limited (Chapter 5). Therefore, the NIFT response to phosphate observed here is most likely a true response and thus the brine community is limited by both silica and phosphate.

The response to silica in brine cultures changed towards the end of the NIFT experiment. There was no longer an increase in $\mathrm{F}^{\prime}$ or $\mathrm{F}_{\mathrm{m}}$ '. NIFT responses can appear in nutrient-starved cultures, and then disappear again sometime later as starvation progresses (Holland et al. 2004). There may only be a brief period in which some NIFT responses will occur, and these specific conditions may not occur regularly in nature.

\section{Seawater and sea ice community}

The bottom ice and seawater phytoplankton did not show a positive NIFTs response to Si and P addition, until day 4 (bottom sea ice) and day 3 (seawater). Therefore, it is likely that the seawater and sea ice phytoplankton populations are not silica, or phosphate limited. The lack of any response to nitrate indicates that these communities are not limited by nitrate either. Several authors (Wood and Oliver 1995; Holland et al. 2004) have reported no initial NIFT response in field samples, which they also attribute to high nutrient availability. Bottom ice algae are highly efficient at light harvesting and active growth has still been measured at irradiances of between 0.2 and $3.5 \mu \mathrm{mol}$ photons.m-2.s-1 (McMinn et al. 1999). The cultures in the present study were maintained at light conditions similar to those under the ice at the time of harvest (20 $\mu \mathrm{mol}$ photons $\mathrm{m}^{-2} \mathrm{~s}^{-1}$ ). During all measurements, temperature and salinity were kept constant to prevent stress. Maximum quantum efficiency $\left(\mathrm{F}_{\mathrm{v}} / \mathrm{F}_{\mathrm{m}}\right)$ is a measure of the intrinsic efficiency of PSII. A decline in $\mathrm{F}_{\mathrm{v}} / \mathrm{F}_{\mathrm{m}}$ indicates a decline in the quantum yield of PSII photochemistry and a disturbance or damage to the photosynthesis apparatus (Lichtenthaler et al. 2005; Hawes et al. 2012). Initial maximum quantum yield ( $\left.\mathrm{F}_{\mathrm{v}} / \mathrm{F}_{\mathrm{m}}\right)$ was low at $\sim 0.3$, but in the range with samples collected by other studies: 0.140 to 0.320 for sea ice, (McMinn et al. 2010), 0.212 for brine and $0.4-0.5$ for the bottom of the sea ice (McMinn and Hegseth 2004). The recovery of the maximum quantum yield during the 5 days of measurement showed some stress for the sea ice environment. Growth can be limited by several other environmental factors e.g. salinity, temperature, 
pH levels, $\mathrm{CO}_{2}$, and micro- and macro nutrients (Priddle et al. 1992; Thomas and Dieckmann 2002a), which need to be studied further to determine the cause of the low yield.

\section{Assessing the NIFT method}

Beardall et al. (2001b) concluded that the NIFTs may be a useful measure of nutrient limitation in natural populations. Kruskopf and Flynn (2006) argued that the fluorescence parameters monitored during NIFT assays, when used as an indicator of physiological status, should be used with caution, as values derived with fluorescence based methods can differ from those of traditional methods. Many "traditional" bioassay and nutrient enrichment studies are indicating a Liebig limitation, which is a limitation of maximum biomass achievable and do not reflect a limitation by a particular nutrient at the time of sampling (Shelly et al. 2010) as obtained by the NIFT. Despite possible variation in results between techniques, the application of NIFT in field studies could provide a fast and direct phytoplankton nutrient status analysis technique.

\section{Conclusion}

Even though the Southern Ocean is generally characterized with high silica levels, nonetheless, an immediate limitation of silica was observed in brine samples. The species present in the different habitats have large influences on when nutrient starvation occurs. The brine, seawater and sea ice used in this study all had similar silica levels but different nitrate and phosphate concentrations at the time of sampling, but brine communities showed an immediate silica limitation. This could be attributed to the high abundance of the heavily frustulated Fragilariopsis spp. in the brine environment. Brine habitats may be particularly vulnerable to nutrient limitation due to the lack of flushing with the nutrient rich waters of the Ross Sea (Arrigo et al. 2010) as illustrated by the severe nutrient limitations in early December. This nutrient limitation in the brine severely limits primary production in internal regions of the sea ice. 
The assay is very sensitive, and identifies the specific nutrient limitation of the algal population. The technique is simple and rapid. As these measurements reflect an instantaneous nutrient limitation, investigation of temporal changes in nutrient limitation may be possible. NIFT type analyses show promise as a rapid and sensitive means of detecting limitation of phytoplankton by specific nutrients. 


\title{
Chapter 5 Antarctic diatoms have a higher silica demand than Arctic diatoms
}

\begin{abstract}
The nutrient status of algae is important in assessing the physiological limits to primary production. Diatoms collected from the Arctic and Antarctic were analysed for their silica requirements. Diatoms were cultured under silica limiting and silica rich conditions and the onset of limitation was followed by water-PAM and I-PAM measurement. Positive silicate-NIFT responses were observed in all diatoms tested. These responses consisted of an exponential increase in $\mathrm{F}^{\prime}$ and $\mathrm{F}_{\mathrm{m}}$ ' after the addition of silicate to Si limited cultures, as well as a strong and immediate decrease in NPQ. Antarctic diatoms tend to have a faster and much stronger response to nutrient limitation compared to their Arctic counterparts, and they were silica limited at concentrations that Arctic diatoms were not. This means that Antarctic diatoms have a much higher requirement for silica than Arctic diatoms. This surprising result is important in future studies of nutrient limitation in the Southern Oceans, since these results show that there can be a nutrient limitation despite relatively high nutrient levels present. Species specific differences in nutrient limitation were observed with Porosira sp. having the highest silica requirement followed by Thalassiosira sp. Chaetoceros sp. had the lowest silica demand and in field situations it may outcompete other species. This species is also less dependent on the sea ice for winter survival, which could give it an advantage in the future with predicted climate change where the extent of annual sea ice may reduce in the future. The I-PAM and water-PAM detected nutrient limitation in all cultures. The benefit of the I-PAM over the water-PAM is that multiple samples and thus multiple nutrients can be tested at the same time, resulting in an almost instantaneous detection of nutrient limitation in samples.
\end{abstract}




\section{Introduction}

Restricted nutrient availability is the main cause of reduced primary production in marine ecosystems. Diatoms are largely responsible for the downward fluxes of the nutrient silica (Bidle et al. 2002). Furthermore, they are likely to play a larger than previously estimated role in the biological carbon pump due to the efficiency by which these generally large cells transport carbon to the ocean floor (Brzezinski et al. 2001). Diatoms are often limited by silica, and a rapid and robust method for assessing this limitation will advance our understanding of the factors controlling primary production, and our understanding of the ecology of phytoplankton. Silicate concentrations in Antarctic sea water (65-75 $\mu$ M.L-1) (Hegseth and Von Quillfeldt 2002) are 9-10x higher than in the Arctic (2.3-6.5 $\mu \mathrm{M} . \mathrm{L}^{-1}$ ) (Hegseth 1992). Generally, high concentrations of macro nutrients are found in the Ross Sea. Phytoplankton communities in this environment therefore rarely show evidence of nutrient limitation (Tréguer et al. 1995; Knox 2009c); but as shown in the previous chapter (Chapter 4) nutrient limitation does occur in interior sections of the sea ice. Many species of phytoplankton in the Arctic and Antarctica have a circumpolar distribution (Priddle 1990; Arndt et al. 2009; Knox $2009 \mathrm{~b}$ ) and several diatoms have a bipolar distribution. This large distribution means that these organisms encounter a wide range of nutrient levels. These bipolar species thrive in both environments despite the large differences in silicate and other nutrients, as well as differences in trace metal concentrations in the water column and the sea ice.

Previously used methods to study nutrient limitation include; nutrient uptake kinetics (Riegman et al. 1990), in situ fertilization experiments (Coale et al. 1998; Boyd et al. 2000), cellular nutrient ratios (McMinn et al. 1999; Geider and La Roche 2002), molecular assays (Geider et al. 1998) and bioassays (Holland et al. 2004). However, none of these methods is without flaws as summarised by (Beardall et al. 2001b; Shelly et al. 2010) and in Chapter 4.

A different and relatively unknown method for assessing nutrient limitation in phytoplankton is Nutrient Induced Fluorescence Transients (NIFT's). This method has the potential to almost instantaneously identify the nutrient that is limiting growth, and 
thus give a more realistic idea of nutrient status. The NIFT method is inexpensive and fast, and it reduces the errors associated with long term incubation experiments (Shelly et al. 2010). The NIFT technique utilise fluorometers, which allow real time monitoring of chlorophyll $a$ fluorescence. Light energy absorbed by chlorophyll can follow one of 3 pathways. It can be re-emitted as heat, do photochemical work or is re-emitted as fluorescence. These pathways compete with each other making it possible to determine the photochemical work done by measuring the re-emitted fluorescence based on the amount of light provided. This makes fluorescence a tool to indirectly measure photochemical performance. Photochemical work is influenced by the nutrient status of the cell and damage to the photochemical apparatus. The photosynthetic light harvesting and energy transduction apparatus is biochemically rich in $\mathrm{N}$ and $\mathrm{P}$, and plays a crucial role is cellular metabolism. Even though silica does not directly play a role in photosynthesis, limitation of this nutrient will affect photosynthesis. Thus, if the cell is nutrient starved, the photochemical apparatus will not function optimally, but addition of a nutrient can restore physiological function. Uptake of a limited nutrient will occur relatively fast and a measurable change in $\mathrm{F}^{\prime}, \mathrm{F}_{\mathrm{m}}$ ' and yield can be measured in minutes (Holland et al. 2004; Roberts et al. 2008). The qualitative nature of the response depends on the nutrient that is limiting. Therefore, after the addition of a limiting nutrient to nutrient deprived algal cultures, rapid perturbations in fluorescence have been observed (Turpin and Weger 1988; Young and Beardall 2003; Holland et al. 2004). Conversely, no response is observed after the addition of a non-limiting nutrient. Therefore, by running a series of enrichment experiments while monitoring the fluorescence signal, the nutrient that gives the largest perturbation should be the limiting nutrient. The response may be an increase or decrease in the fluorescence parameters, usually dependent on the limiting nutrient (Roberts et al. 2008; Shelly et al. 2010). The responses are usually short lived, lasting for only a few seconds to minutes depending on the concentration of the nutrient spike. The physiological and biochemical responses behind these are poorly understood, although it is believed that a transient change in fluorescence is attribute to a relocation of energy to nutrient uptake (Holland et al. 2004), either to increase photochemistry (decreased fluorescence emission) or increase some other cellular reaction (increased fluorescence emission). Difference in response depends as well on the amount of nutrients added and the extent of limitation (Young and Beardall 2003). 
At present, the majority of NIFT studies have focused on $\mathrm{N}$ and $\mathrm{P}$ limitation in freshwater algae (Turpin and Weger 1988; Wood and Oliver 1995; Beardall et al. 2001a; Young and Beardall 2003). However, none of these have reported specific NIFT responses to silica in marine diatoms. The only studies done were by Lippemeier et al.( 1999, 2001) in which they identified, changes in fluorescence emission over several hours to days after nutrient enrichment to assess changes in photosynthesis. This could be interpreted as possible evidence than a NIFT response can occur in diatoms which are silica limited (Shelly et al. 2010).

Water-PAM has been used in previous studies to examine NIFT responses, and this has been limited to $\mathrm{N}$ and P-starved algal cultures. This study is a comprehensive study of the NIFT responses to silicate limitation in diatom cultures. Though the water-PAM NIFTs method has many advantages it has one major drawback: it is only possible to analyse one sample at the time. In field situations, this might be sufficient since often only one sampling can be done at the time. For laboratory situations this can be a disadvantage when trying to compare samples. Using the I-PAM, a multi-well plate allows multiple samples to be run at the same time making it possible to test multiple nutrients as well as running the control samples at the same time.

Nelson and Treguer (1992) suggested that Antarctic diatoms may exhibit a much lower affinity for silicate than diatoms from other sectors of the world's oceans. This means that diatom growth could be limited by a silicate deficiency at concentrations that are normally thought to be saturating everywhere else in the world. My results in Chapter 4 illustrated that McMurdo Sound sea ice communities may be limited in Si despite relatively high natural Si levels in the Ross Sea. Here I use 3 species of bipolar diatoms (Thalassiosira antarctica, Chaetoceros socialis, Porosira glacialis) to study whether differences in silica requirements can be observed within the same species collected from geographically separated locations in the Arctic and Antarctica. I hypothesise that there will be an earlier response of silica limitation occurring in Antarctic diatoms than Arctic diatoms. 


\section{Materials and methods}

\section{Culturing conditions}

Anoxic cultures of Chaetoceros socialis (H.S.Lauder, 1864) (collected from Svalbard, Arctic and the Weddel Sea, Antarctica), Porosira glacialis (Grunow. Jorgensen, 1905) (Svalbard, and the Weddell Sea, Antarctica), Thalassiosira antarctica (Comber, 1896) (Svalbard, and the Ross Sea, Antarctica) were maintained under a 12h:12h light/dark regime at $4^{0} \mathrm{C}$ with $50 \mu \mathrm{mol}$ photons $\mathrm{m}^{-2} \cdot \mathrm{s}^{-1}$ light (Phillips, TL80W). Cultures were grown in artificial seawater (Instant Ocean, USA) at a salinity of 34 ppt with added f/2 silica rich medium $(150 \mu \mathrm{M})(n=4$ per species $)$ or $\mathrm{f} / 2$ silica-poor medium $(<50 \mu \mathrm{M})(n=4$ per species). This seawater mix was then filtered through $0.2 \mu \mathrm{m}$ filter to remove undissolved salt residues and then sterilized by means of autoclaving. Stock cultures were maintained in exponential phase at the time of transferring them to the experimental conditions. Growing diatom cultures in a silicate limited state is problematic as most of the equipment in any culture facility is glass. Although the leaching of silica into the cultures from glassware is likely to be insignificant, this possibility was avoided by using only polycarbonate or polyethylene material during the culturing and measuring process. One key container was the quartz measuring cuvette used to hold samples within the water-PAM. The optical quality of the cuvette needs to be high to limit background noise. Leaching of silica from the quartz is considered minimal due to the short duration of the measurement.

\section{Water-PAM}

The experimental design was modified from Holland et al. (2004) and Merwe and McMinn (unpubl.). All NIFT tests were monitored using a water-PAM fluorometer (Heinz Walz GmbH) and WinControl software (Heinz Walz GmbH). Three ml subsamples of seawater, sea ice or brine were transferred into $5 \mathrm{ml}$ cuvettes and dark adapted for 20 minutes prior to testing. The samples were then placed in the emitter detector unit (EDU). Care was taken to eliminate ambient light exposure to the subsample during the transfer. During the dark adaptation and the measurements, the sample was kept at $4^{\circ} \mathrm{C}$ by placing the EDU in a refrigerated cool box. Initial fluorescence $\left(\mathrm{F}_{0}\right)$ was measured and immediately after the determination of $\mathrm{F}_{0}$, a 
saturating pulse was delivered to measure maximal fluorescence $\left(\mathrm{F}_{\mathrm{m}}\right)$ and maximum quantum yield $\left(\mathrm{F}_{\mathrm{v}} / \mathrm{F}_{\mathrm{m}}\right)$ was calculated. This was followed by activating the actinic light (47 $\mu \mathrm{mol}$ photons $\mathrm{m}^{-2} \mathrm{sec}^{-1}$ of PAR) to initiate photochemistry. The clock function in WinControl was used to perform saturating pulses every 30 seconds thus allowing real time monitoring of minimum fluorescence in the presence of actinic light $\left(\mathrm{F}^{\prime}\right)$, maximal fluorescence in actinic light $\left(\mathrm{F}_{\mathrm{m}}{ }^{\prime}\right)$, effective quantum yield $\left(\Phi_{\mathrm{PSII}}\right)$ and nonphotochemical quenching (NPQ).

\section{I-PAM}

The experimental design was modified from Holland et al. (2004) and Merwe and McMinn (unpubl.). All NIFT tests were monitored using the I-PAM fluorometer (Heinz Walz $\mathrm{GmbH}$ ) and ImageWin software (V2.40b, Heinz Walz GmbH). From the cultures, 2 $\mathrm{ml}$ of sub-samples were transferred into 24-well plates and dark adapted for 20 minutes prior to testing. The plate with sub-samples was then placed on the mounting stand. Care was taken to limit ambient light exposure to the sub-sample during the transfer. During the dark adaptation and measurements, the sample was kept at $4^{\circ} \mathrm{C}$. During the measurement this was done by placing an ice tray under the 24-wells plate. Initial fluorescence $\left(\mathrm{F}_{0}\right)$ was measured, immediately followed by a saturating pulse to measure maximal fluorescence $\left(\mathrm{F}_{\mathrm{m}}\right)$, and maximum quantum yield $\left(\mathrm{F}_{\mathrm{v}} / \mathrm{F}_{\mathrm{m}}\right)$ was calculated. This was followed by activating the actinic light $\left(47 \mu \mathrm{mol}\right.$ photons $\mathrm{m}^{-2} \mathrm{sec}^{-1}$ of PAR) to initiate photochemistry. The clock function was used to perform saturating pulses every 30 seconds and thus allowing real time monitoring of minimum fluorescence in the presence of actinic light $\left(\mathrm{F}^{\prime}\right)$, maximal fluorescence in actinic light $\left(\mathrm{F}_{\mathrm{m}}{ }^{\prime}\right)$, effective quantum yield $\left(\Phi_{\mathrm{PSII}}=\left(\Delta \mathrm{F} / \mathrm{F}_{\mathrm{m}}{ }^{\prime}\right)\right.$ and non-photochemical quenching (NPQ $\left.=\left(F_{m}-F_{m}{ }^{\prime}\right) / F_{m}{ }^{\prime}\right)$. Calculations and definitions of the different fluorescence parameters can be found in appendix $\mathrm{C}$.

\section{NIFT}

After approximately 2.5 minutes, or once the readings of $\mathrm{F}_{\mathrm{m}}{ }^{\prime}$ and $\mathrm{F}_{0}{ }^{\prime}$ had stabilised, $20 \mu \mathrm{l}$ (I-PAM) or $30 \mu \mathrm{l}$ (water-PAM) of $\mathrm{SiOH} 9 \mathrm{H}_{2} \mathrm{O}$ were added to the sub-sample to achieve a final concentration equal to that in $\mathrm{f} / 2$ medium $(107 \mu \mathrm{M}$ ) (Guillard 1975) assuming that 
there was no silica in the medium of the sub-sample. All nutrients were made up in sterile water. In order to test that the response came from the nutrient addition, control NIFT's were run by adding $20 \mu \mathrm{l}$ (I-PAM) or $30 \mu \mathrm{l}$ (water-PAM) of sterile seawater.

The EDU of the water-PAM and the 24-well plate in the I-PAM was covered to limit direct ambient light affecting the reading during the nutrient spike. After the spike, the samples were monitored for a further minimum of 10 minutes. This protocol was run for all samples and repeated every day for 14 days. At the end of this procedure, the cuvette sample or 24-well plate was discarded. This protocol was followed for all samples. By running the experiment for a long period information was obtained of the physiology of the early onset of silica starvation as well as advanced stages of silica starvation.

\section{Cell counts}

Subsamples $(10 \mathrm{ml})$ for cell counts were taken every $5^{\text {th }}$ day and fixed with $500 \mu \mathrm{l}$ of Lugol's iodine solution to a final concentration of $2.5 \%$. Samples were sonicated (Merck, Digitech) for 1-2min at $40 \mathrm{~Hz}$ before cell counts were performed on a Beckman Coulter counter Multisizer 3 (USA). A $100 \mu \mathrm{m}$ aperture was used with the running fluid Isotone II (Beckman, USA). Settings used for the Multisizer 3 instrument were: detecting threshold $>2.5 \mu \mathrm{m}$, current $100 \mu \mathrm{A}$ and, gain 32. A volume of $500 \mu \mathrm{l}$ per sample was counted 3 times and averaged. Samples were coincidence corrected and a background subtraction was performed.

\section{Nutrient analysis}

Subsamples for nutrient analysis of silica, phosphate, and nitrate were taken every $5^{\text {th }}$ day. Analyses for silica and phosphate were done using a MC 500-10 colorimeter MultiParameter (Orbeco, Hellige, USA). Nitrate was analysed using the low range nitrate lab test kit (The Nitrate Elimination Company Inc., USA). 


\section{Statistics}

All statistics were performed using SPSSv18 statistics package. Prior to statistical analysis, Mauchly's Test of Sphericity was used. If sphericity was not achieved, the data were transformed accordingly. A repeated measures ANOVA was used to determine the changes in cell densities, nutrient concentrations and yield during the 10 days in which the experiment was run. A one-way ANOVA was used to assess differences in nutrient concentrations over time and, changes in yield over time. In all cases, significant differences were defined by $\mathrm{P}<0.05$.

\section{Results}

\section{NIFT responses}

After the addition of silicate, the fluorescence response was monitored for $\sim 15 \mathrm{~min}$. A negative response was defined as no change in $F, F_{m}$ ' or NPQ during the time after the nutrient spike was added (Figure 1, see also Chapter 4). A positive NIFT response was characterized by an increase of $\mathrm{F}_{\mathrm{m}}$ ' and $\mathrm{F}$ during the first 2.5-4 min which was sustained for the duration ( $\sim 15$ minutes) of the NIFT test. Cultures that were nutrient limited had a low NPQ signal prior to silicate addition. After the addition of silicate; a short increase of NPQ was followed by a decrease for the remaining time in which a NIFT was run. The decrease in NPQ coincided with the increase of $\mathrm{F}_{\mathrm{m}}$ ' and F (Figure 5-2). A weak increase is described as an increase of $<15 \%$ in $\mathrm{F}_{\mathrm{m}}$ ' and $\mathrm{F}$ whereas strong response could be an increase up to $30 \%$ for the I-Pam and $70 \%$ for the water-PAM during the 15 min of the experiment. Removing the EDU lid in the water-PAM or the wells plate in the I-PAM in order to spike the sample usually caused an immediate short spike in fluorescence parameters (arrow Figure 5-1, 5-2). This signal returned within 20-40 sec back to the original value and is not part of the response to the nutrient. It is likely caused by ambient light reaching the EDU and not the addition itself. 


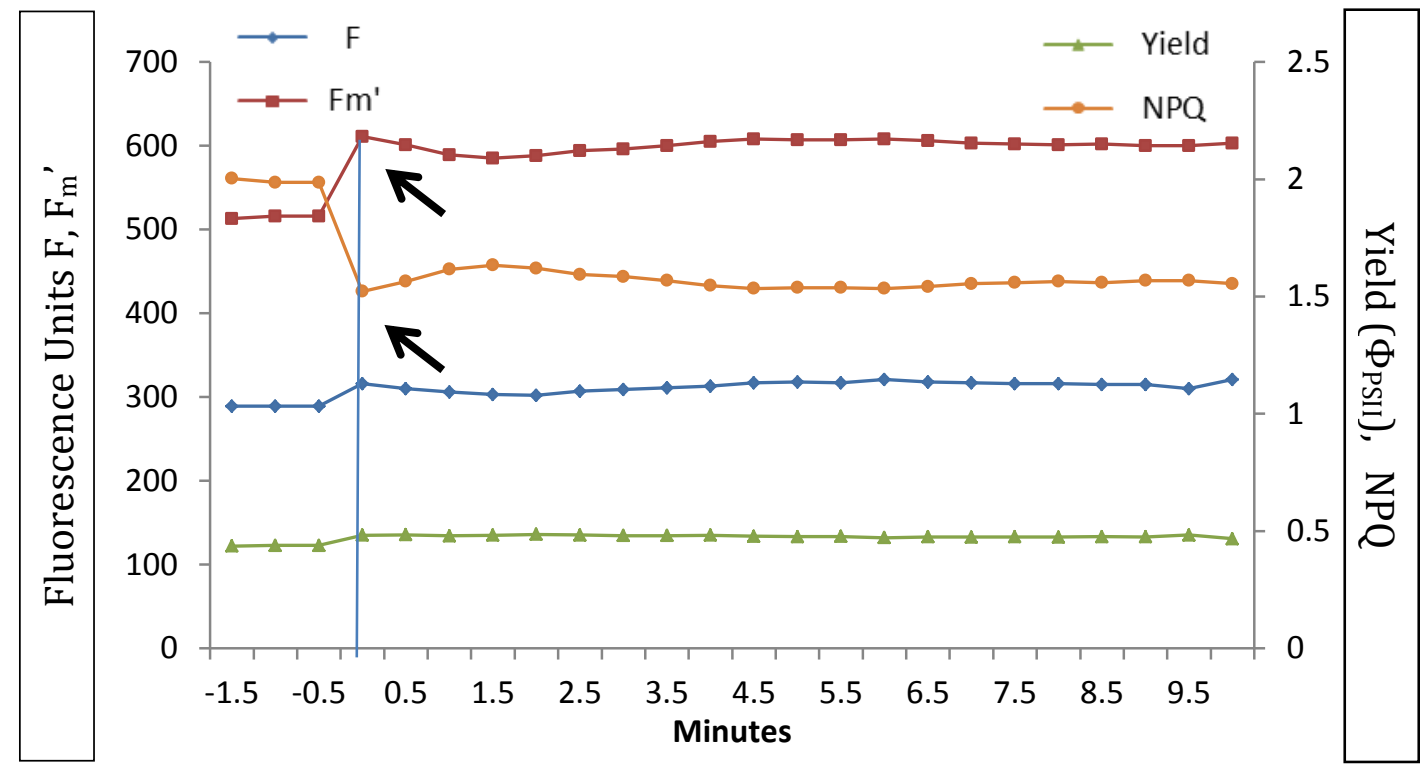

Figure 5-1: Example of no response to the addition of water using the Water-PAM. Similar results were obtained if a nutrient was not considered limiting. The blue line indicates when the nutrient was added, the arrows illustrates decrease or increase of fluorescence parameters caused by light reaching the EDU when the lid was lifted to add a nutrient. 


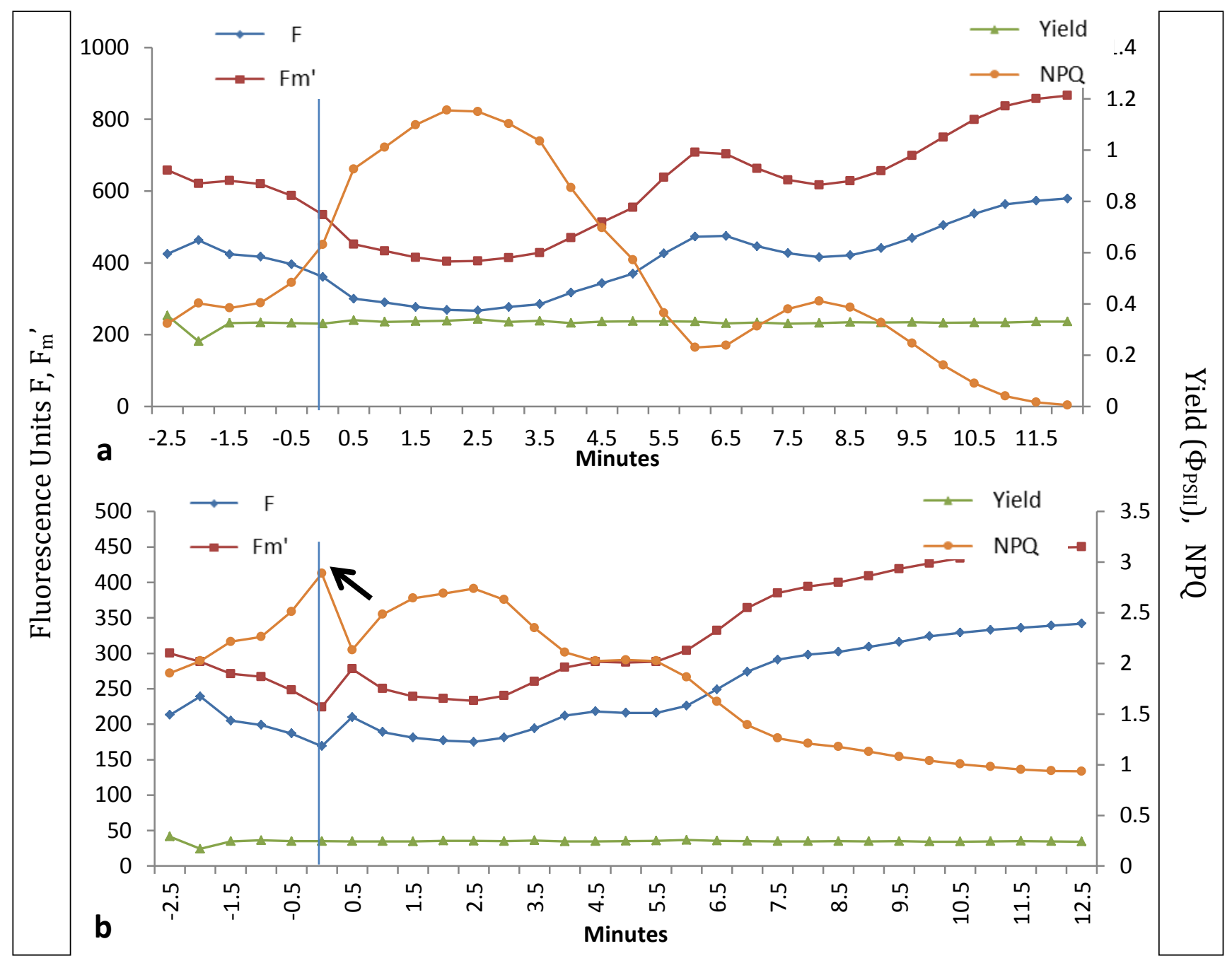

Figure 5-2: Examples of variation in the strength of response after the addition of silica. $F$ and $F_{m}$ ' increased after the addition of silica while NPQ decreased after the addition of silica. Yield ( $\left.\Phi_{\text {PSII }}\right)$ remains constant throughout the measuring time. a) Porosira gliacialis antarctica day 9 showed a NPQ decrease to zero and 200 fluorensence untis increase , b) Porosira glacialis antarctica day 10, the NPQ decreased to around 1 while the fluorensence units increased by about 150. The blue line indicates when the nutrient was added, the arrow illustrates an increase of NPQ caused by light reaching the EDU when the lid was lifted to add a nutrient.

\section{NIFT analysis of low silica cultures using the water-PAM}

All cultures were maintained in the exponential growth phase in nutrient-replete conditions prior to the experiments. An aliquot from the stock culture was then inoculated into a flask containing low silicate culture medium at day 1 . The first NIFT response to silica addition was generally detected 2-3 days later. A proportion of samples from all species gave positive NIFT responses when cultured under low silica 
concentrations (Figure 5-3), indicating silica limitation. The strength of the response varied (Figure 5-2) and responses were categorised as either weak or strong in this analysis. When a sample had a positive NIFT response it was accompanied by a lower yield $\left(F_{v} / F_{m}\right)$ compared to samples that did not have a NIFT response. There was a decrease in yield $\left(\mathrm{F}_{\mathrm{v}} / \mathrm{F}_{\mathrm{m}}\right)$ with time after being placed in low silicate medium. A clear distinction in the frequency of positive NIFT responses can be observed between Arctic and Antarctic cultures. Overall, the Antarctic cultures had more positive responses per day and over the entire period of the 10 days of the experiment and only $23 \%$ of the responses were classified as "weak". Arctic samples had a lower frequency of response; fewer days in which a positive response occurred and had 39\% weak responses. For 2 species, Chaetoceros sp. (Arctic) and Thalassiosira sp. (Arctic), the positive NIFT response disappeared over the duration of the experiment. This disappearance of response did not occur for Porosira sp. (Arctic) and the overall pattern of response (e.g. strength, frequency, total number of responses), in this species was much more like the pattern observed in Antarctic species. 


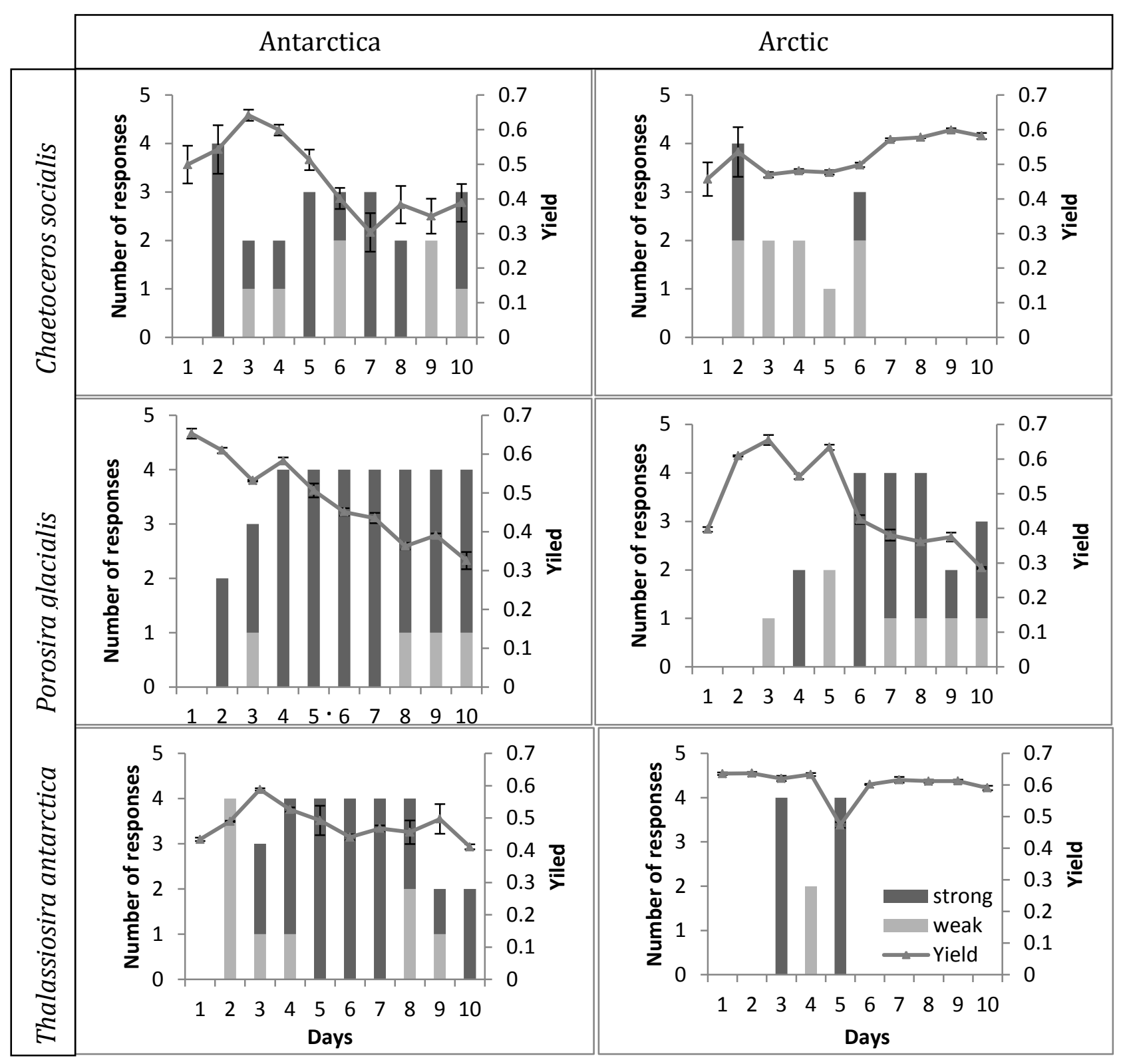

Figure 5-3: Frequency of nutrient response measured by water-PAM for diatoms grown under low silica concentrations $(n=4)$ over time since being placed in low Si media. A value of 4 on this scale indicates all 4 replicates gave positive responses. The maximum yield $\left(\mathrm{F}_{\mathrm{v}} / \mathrm{F}_{\mathrm{m}}\right)$ was determined each day after $20 \mathrm{~min}$ of dark adaptation.

\section{NIFT analysis of silica rich cultures using the water- PAM}

An aliquot from the stock culture was inoculated into a flask containing high silicate culture medium at day 0 . The first NIFT response to silica addition was generally detected 2-3 days later. The time at which the species gave a positive NIFT response was very similar between species and locations. All diatoms tested took up the silica 
from the medium relatively rapidly, causing a NIFT response around the fifth day of culturing, indicating that they became silica limited around that time. As with the low silicate experiment, positive NIFT responses were accompanied with lower yields $\left(\mathrm{F}_{\mathrm{v}} / \mathrm{F}_{\mathrm{m}}\right)$, and this trend was not apparent in samples that did not have a NIFT response. With the progress of the silica limitation the yield decreased further.

Antarctic species had a similar frequency of response (12-15) over the 10 days of the experiment, while the response frequency in the Arctic species was much more varied. In addition, Arctic cultures had weaker responses (27\%) compared to Antarctic species (17\%). Arctic strains of Chaetoceros sp. and Thalassiosira sp. had a low number of weak NIFT responses. This is in contrast with Arctic Porosira sp., which had an overall frequency and strength of response similar to the Antarctic strain. 


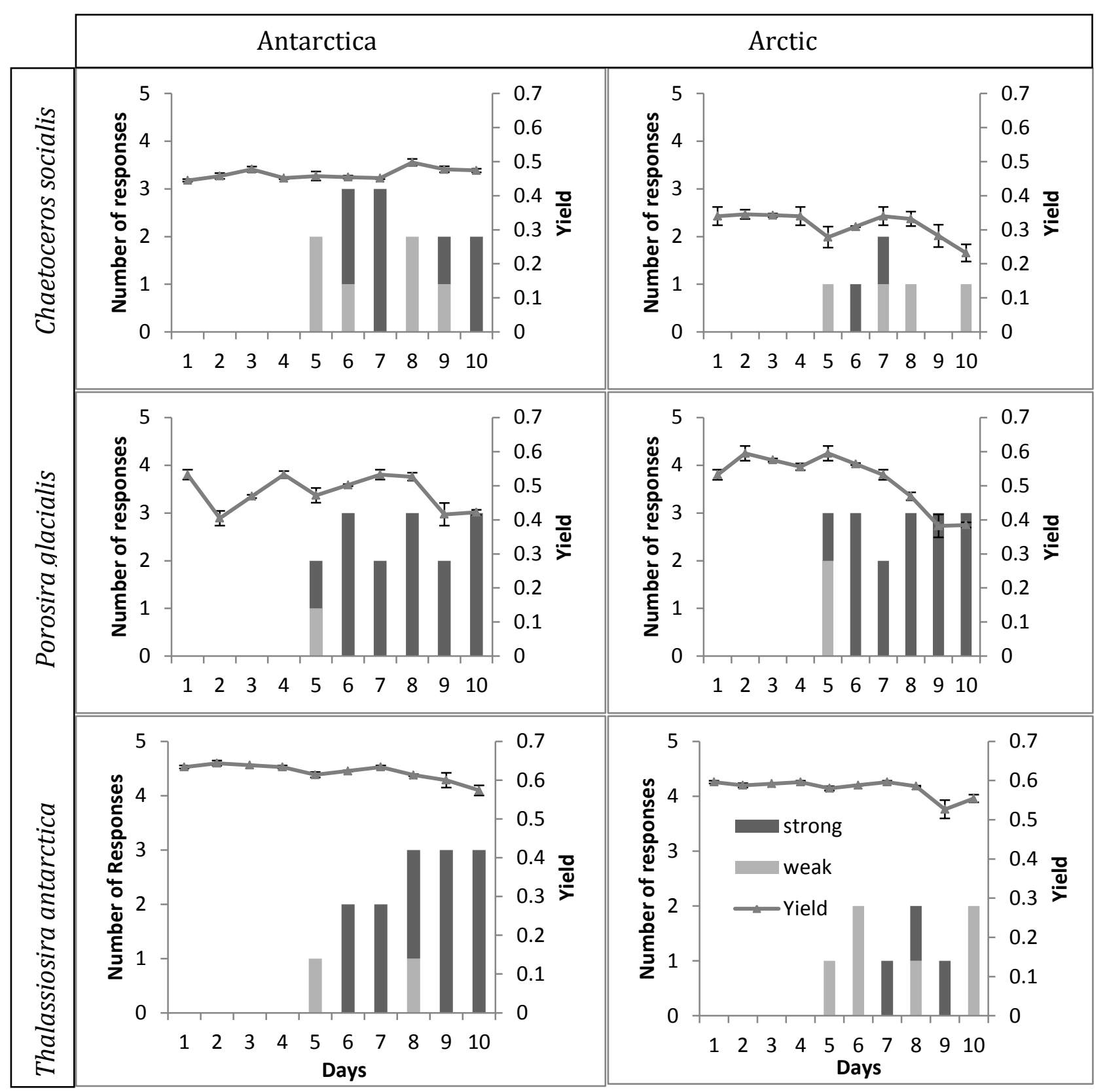

Figure 5-4: Frequency of nutrient response measured by water-PAM for diatoms grown under high silica concentrations $(n=4)$. The yield $\left(\mathrm{F}_{\mathrm{v}} / \mathrm{F}_{\mathrm{m}}\right)$ was obtained after $20 \mathrm{~min}$ of dark adaptation.

\section{I-PAM}

The I-PAM was also used to detect NIFT responses in cultures grown under low silica conditions. Sixteen wells from a 24-well plate were filled with a sample, and this made it possible to run all replicates including the control for one species simultaneously (Figure 5-5). 


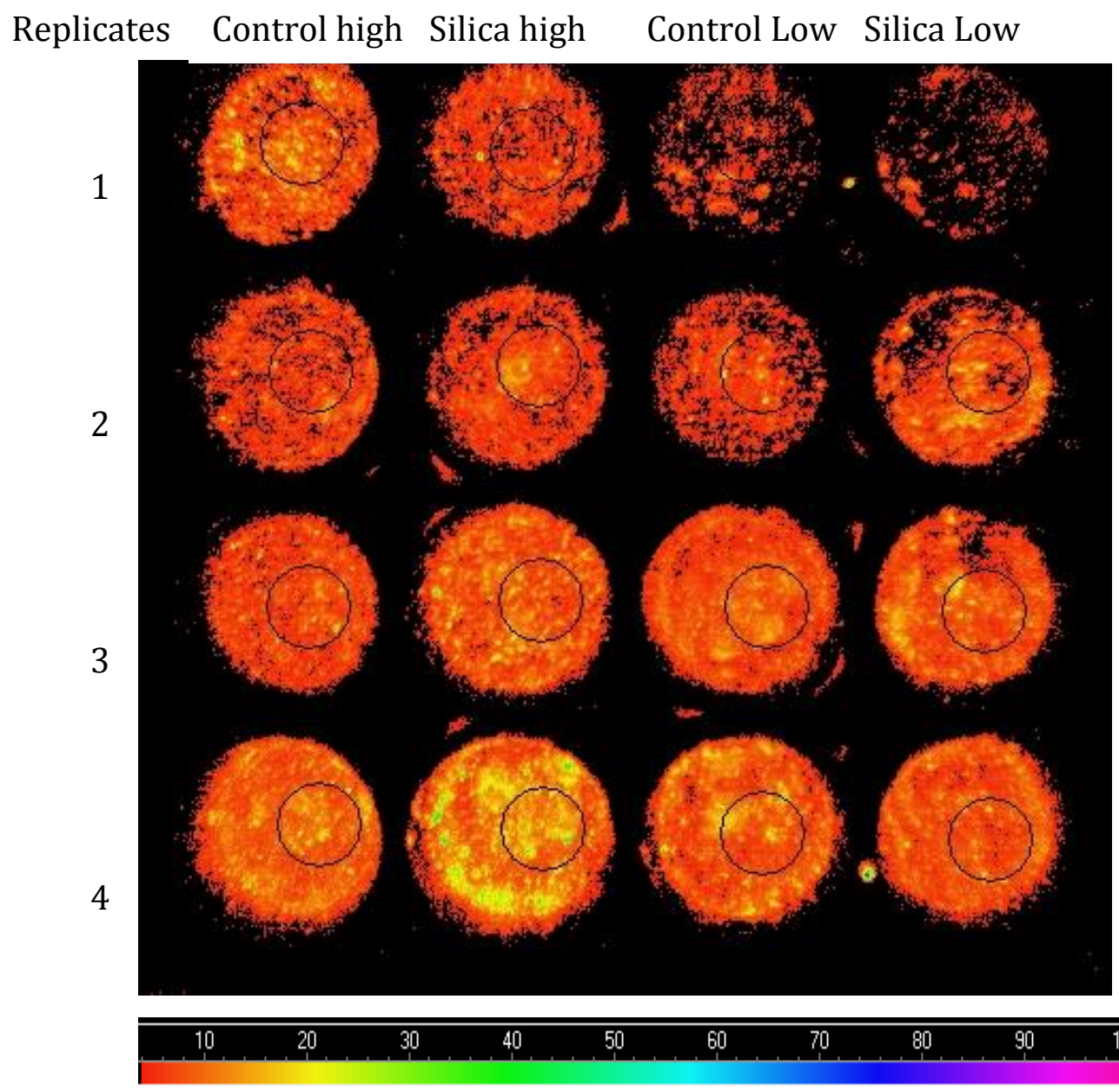

Figure 5-5: Example of a sample plate set-up for the I-PAM. The circles are individually selected regions of interest, which were used to monitor fluorescence signals during the experiment. The colour scale indicates the $\mathrm{F}_{0}$ signal under $47 \mu \mathrm{mol}$ photons $\mathrm{m}^{-2} \mathrm{sec}^{-1}$ of PAR.

All species tested gave a positive NIFT response when cultured under low silica concentrations (Figure 5-6). The response was observed after 2-4 days. The number of cultures that responded to the NIFT was lower than those found with the water-PAM method, although a very similar pattern was observed.

In general, the Arctic samples responded 1-2 days later than the equivalent strain from the Antarctic. In addition, the frequency of samples responding was lower and the NIFT response was shorter for Arctic species compared to the Antarctic species. The response disappeared in Arctic cultures between day 6 and day 8. In the Antarctic 
cultures, the response either disappeared at day 9 or continued for the duration of the experiment. The I-PAM also confirmed the observation made with the water-PAM, that the overall frequency and strength of responses for Porosira sp. (Arctic) was similar to that for the Antarctic species.

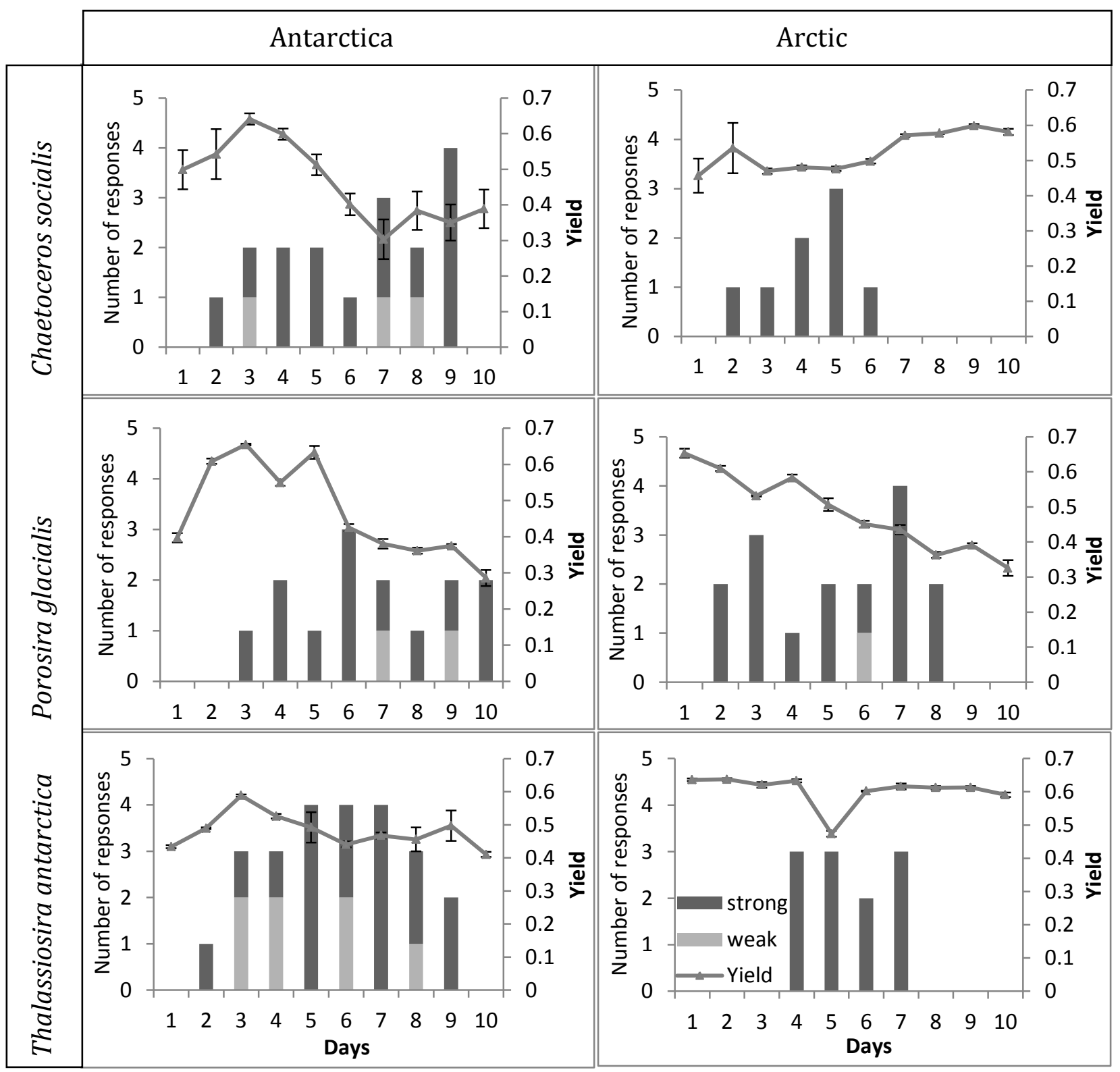

Figure 5-6: Nutrient response measured by I-PAM for diatoms grown under low silica concentrations $(n=4)$. The maximum quantum yield $\left(\mathrm{F}_{\mathrm{v}} / \mathrm{F}_{\mathrm{m}}\right)$ was obtained after $20 \mathrm{~min}$ of dark adaptation each day. 


\section{Nutrient concentration measurements}

The concentrations of $\mathrm{Si}, \mathrm{P}$ and $\mathrm{N}$ in the culture medium were measured for all cultures at day 1, 5 and 10 (Table 5-1). A fast reduction of nutrient concentration occurred in all samples, but silica was the first nutrient to become limiting as illustrated by the positive NIFT responses. By day 5, silica-rich cultures reached levels similar to the starting concentration of silica-poor cultures, and this was when the silica-rich cultures became silica-limiting. During the 10 days of the experiment, the silicate concentration in silicarich cultures was significanlty reduced (One-way ANOVA: $\mathrm{P}<0.005$ ). Especially, Chaetoceros sp. strains had a strong reduction of silica in the medium from74 to $10 \mu \mathrm{M}$ and 66 to $14 \mu \mathrm{M}$ for Antarctic and arctic strains, respectavely. 
Table 5-1: Nutrient concentrations $(\mu \mathrm{M})$ in the growth medium at different time points for 6 different diatom cultures ( $n=4$ nutrient/time point/culture) standard error is shown in brackets. A) Cultures grown in low silica concentrations. B) Cultures grown in high silica concentrations. All other nutrients, trace metals and vitamins were the same starting concentration between the 2 experiments. All samples and nutrients tested had a significant reduction in concentration $(\mathrm{P}<0.005)$.

\begin{tabular}{llllllllll}
\hline \multicolumn{1}{c}{ A) LOW } & & & & & & & & \\
\hline Nutrient & $\mathrm{Si}$ & & & $\mathrm{P}$ & & & $\mathrm{N}$ & \\
DAY & 1 & 5 & 10 & 1 & 5 & 10 & 1 & 5 & 10 \\
& & & & & & & & & \\
Chaetoceros sp. & 74 & 16 & 10 & 206 & 73 & 54 & 135 & 95 & 35 \\
Antarctica & $(2.7)$ & $(1.6)$ & $(2.9)$ & $(9.2)$ & $(3.1)$ & $(16.7)$ & $(24.5)$ & $(26.8)$ & $(1.8)$ \\
Chaetoceros sp. & 66 & 10 & 14 & 113 & 72 & 43 & 76 & 54 & 43 \\
Arctic & $(13.4)$ & $(2.4)$ & $(1.6)$ & $(2.4)$ & $(1.4)$ & $(20.5)$ & $(33.4)$ & $(7.5)$ & $(2.9)$ \\
Porosira sp. & 52 & 26 & 39 & 136 & 69 & 41 & 86 & 82 & 52 \\
Antarctica & $(4.7)$ & $(3.6)$ & $(18.1)$ & $(9.2)$ & $(5.7)$ & $(16.5)$ & $(6.2)$ & $(14.0)$ & $(4.3)$ \\
Porosira sp. & 53 & 8 & 13 & 160 & 65 & 39 & 95 & 81 & 35 \\
Arctic & $(5.1)$ & $(0.6)$ & $(23.9)$ & $(5.2)$ & $(4.8)$ & $(13.9)$ & $(6.2)$ & $(29.8)$ & $(10.6)$ \\
Thallasiosira sp. & 61 & 45 & 9 & 143 & 85 & 46 & 166 & 98 & 49 \\
Antarctica & $(11.6)$ & $(7.8)$ & $(6.58)$ & $(5.5)$ & $(2.7)$ & $(23.9)$ & $(6.6)$ & $(11.5)$ & $(7.4)$ \\
Thallasiosira sp. & 60 & 16 & 22 & 161 & 113 & 35 & 93 & 31 & 46 \\
Arctic & $(15.0)$ & $(1.0)$ & $(1.5)$ & $(11.1)$ & $(5.4)$ & $(20.6)$ & $(7.8)$ & $(17.2)$ & $(4.6)$
\end{tabular}

B) HIGH

\begin{tabular}{llllllllll} 
Nutrient & $\mathrm{Si}$ & \multicolumn{3}{c}{$\mathrm{P}$} & $\mathrm{P}$ & & & $\mathrm{N}$ & \\
DAY & 1 & 5 & 10 & 1 & 5 & 10 & 1 & 5 & 10 \\
Chaetoceros sp. & 150 & 45 & 12 & 245 & 52 & 63 & 78 & 60 & 87 \\
Antarctica & $(14.1)$ & $(2.2)$ & $(5.8)$ & $(27.7)$ & $(1.7)$ & $(9.3)$ & $(2.5)$ & $(20.9)$ & $(38.4)$ \\
Chaetoceros sp. & 124 & 58 & 24 & 153 & 51 & 36 & 137 & 79 & 76 \\
Arctic & $(14.4)$ & $(5.7)$ & $(5.3)$ & $(7.2)$ & $(2.2)$ & $(26.2)$ & $(4.4)$ & $(7.6)$ & $(31.1)$ \\
Porosira sp. & 126 & 79 & 67 & 92 & 94 & 43 & 74 & 69 & 40 \\
Antarctica & $(5.5)$ & $(12.8)$ & $(12.2)$ & $(16.1)$ & $(1.1)$ & $(18.0)$ & $(5.9)$ & $(3.6)$ & $(4.6)$ \\
Porosira sp. & 123 & 61 & 83 & 102 & 97 & 35 & 98 & 36 & 26 \\
Arctic & $(19.5)$ & $(13.5)$ & $(15.6)$ & $(15.7)$ & $(2.2)$ & $(28.0)$ & $(2.6)$ & $(22.2)$ & $(16.5)$ \\
Thallasiosira sp. & 113 & 93 & 35 & 95 & 59 & 44 & 149 & 63 & 62 \\
Antarctica & $(6.7)$ & $(21.1)$ & $(3.7)$ & $(7.2)$ & $(3.7)$ & $(12.3)$ & $(4.5)$ & $(6.9)$ & $(23.2)$ \\
Thallasiosira sp. & 132 & 71 & 85 & 222 & 108 & 52 & 142 & 81 & 47 \\
Arctic & $(29.7)$ & $(24.0)$ & $(7.5)$ & $(21.8)$ & $(2.8)$ & $(19.5)$ & $(7.8)$ & $(14.4)$ & $(9.5)$ \\
\hline
\end{tabular}

The stock culture that was used to inocculate the experimental cultures was in exponential phase. Therefore, if no limitation occurs, cell counts should increase during the 10 days of the experiment. However, there was a signifcant reduction in abundance for 3 cultures: Chaetoceros sp. Arctic (low and high silica concentrations) and Thallasiosira sp. Arctic (low silica concentration) (Table 5-2, 5-3). These species also showed a very weak or zero NIFT response in the final days of the experiment. Species in which the NIFT response was detected during the duration of the experiment had either a slight increase in cell counts or no change at all. 
Table 5-2: Cell counts $\left(10^{4}\right.$ cell.ml-1) of different diatom species over time $(n=4$ time point/species/concentration). Standard error in brackets $\pm 10^{4}$.

\begin{tabular}{lllll}
\hline \multicolumn{1}{c}{ Days } & $\begin{array}{l}\text { Silica } \\
\text { conc. }\end{array}$ & $\mathbf{1}$ & $\mathbf{5}$ & $\mathbf{1 0}$ \\
$\begin{array}{l}\text { Species } \\
\begin{array}{l}\text { Chaetoceros sp. } \\
\text { Antarctica }\end{array}\end{array}$ & Low & $46.7( \pm 0.08)$ & $46.9( \pm 0.04)$ & $46.5( \pm 0.05)$ \\
$\begin{array}{l}\text { Chaetoceros sp. } \\
\text { Antarctica }\end{array}$ & High & $45.9( \pm 0.20)$ & $46.5( \pm 0.36)$ & $45.9( \pm 0.10)$ \\
$\begin{array}{l}\text { Chaetoceros sp. } \\
\text { Arctic }\end{array}$ & Low & $47.9( \pm 0.15)$ & $46.5( \pm 0.09)$ & $46.5( \pm 0.19)$ \\
$\begin{array}{l}\text { Chaetoceros sp. } \\
\text { Arctic }\end{array}$ & High & $47.7( \pm 0.08)$ & $46.9( \pm 0.05)$ & $46.8( \pm 0.08)$ \\
$\begin{array}{l}\text { Porosira sp. } \\
\text { Antarctica }\end{array}$ & Low & $45.8( \pm 0.36)$ & $46.6( \pm 0.10)$ & $48.1( \pm 0.21)$ \\
$\begin{array}{l}\text { Porosira sp. } \\
\text { Antarctica }\end{array}$ & High & $45.9( \pm 0.39)$ & $46.4( \pm 0.39)$ & $48.2( \pm 0.13)$ \\
$\begin{array}{l}\text { Porosira sp. } \\
\text { Arctic }\end{array}$ & Low & $46.8( \pm 0.07)$ & $46.8( \pm 0.08)$ & $49.4( \pm 0.54)$ \\
$\begin{array}{l}\text { Porosira sp. } \\
\text { Arctic }\end{array}$ & High & $46.9( \pm 0.20)$ & $47.2( \pm 0.47)$ & $49.7( \pm 0.41)$ \\
$\begin{array}{l}\text { Thallasiosira sp. } \\
\text { Antarctica }\end{array}$ & Low & $46.8( \pm 0.07)$ & $46.1( \pm 0.07)$ & $47.0( \pm 0.09)$ \\
$\begin{array}{l}\text { Thallasiosira sp. } \\
\text { Antarctica }\end{array}$ & High & $47.0( \pm 0.08)$ & $46.6( \pm 0.21)$ & $46.9( \pm 0.13)$ \\
$\begin{array}{l}\text { Thallasiosira sp. } \\
\text { Arctic }\end{array}$ & Low & $47.4( \pm 0.07)$ & $45.6( \pm 0.17)$ & $46.2( \pm 0.14)$ \\
$\begin{array}{l}\text { Thallasiosira sp. } \\
\text { Arctic }\end{array}$ & High & $48.0( \pm 0.07)$ & $46.9( \pm 0.06)$ & $49.2( \pm 0.10)$ \\
\hline & & & & \\
\hline
\end{tabular}

Table 5-3: Significance of changes in cell counts during the 10 days of the experiment based on one-way ANOVA analysis. Mauchly's Test of Sphericity was not significant and therefore sphericity was assumed. Significance was assumed at $\mathrm{P}<0.05$ and is indicated in bold.

\begin{tabular}{lllll}
\hline & Silica & df & F & Sig. \\
& conc. & & & \\
\hline Chaetoceros sp. Antarctica & Low & 2 & 10.474 & 0.523 \\
Chaetoceros sp. Antarctica & High & 2 & 13.463 & $\mathbf{0 . 0 1 7}$ \\
Chaetocers sp. Arctic & Low & 2 & 43.924 & $\mathbf{0 . 0 0 2}$ \\
Chaetocers sp. Arctic & High & 2 & 27.924 & $\mathbf{0 . 0 3 2}$ \\
Porosira sp. Antarctica & Low & 2 & 207.246 & $\mathbf{0 . 0 0 0}$ \\
Porosira sp. Antarctica & High & 2 & 22.903 & $\mathbf{0 . 0 0 2}$ \\
\hline Porosira sp. Arctic & Low & 2 & 35.235 & $\mathbf{0 . 0 0 0}$ \\
Porosira sp. Arctic & high & 2 & 40.122 & $\mathbf{0 . 0 0 0}$ \\
Thallasiosira sp. Antarctica & Low & 2 & 75.696 & $\mathbf{0 . 0 0 0}$ \\
Thallasiosira sp. Antarctica & High & 2 & 3.811 & 0.118 \\
\hline Thallasiosira sp. Arctic & Low & 2 & 8.430 & $\mathbf{0 . 0 1 8}$ \\
\hline Thallasiosira sp. Arctic & High & 2 & 0.723 & $\mathbf{0 . 0 2 3}$ \\
\hline
\end{tabular}


All species, except Thallasiosira sp. (Antarctica, low), showed a significant reduction of $\mathrm{F}_{\mathrm{v}} / \mathrm{F}_{\mathrm{m}}$. This reduction coincided with the onset of silica limitation (Table 5-4).

Table 5-4: Changes in maximum quantum yield $\left(\mathrm{F}_{\mathrm{v}} / \mathrm{F}_{\mathrm{m}}\right)$ during the 10 days of the experiment tested by one-way ANOVA. Mauchly's Test of Sphericity was not significant and therefore spherity was assumed. Significance was assumed at $\mathrm{P}<0.05$ and is indicated in bold.

\begin{tabular}{|lllll}
\hline Species & Silica & df & F & Sig. \\
& Conc. & & & \\
\hline Chaetoceros sp. Antarctica & Low & 3 & 4.755 & $\mathbf{0 . 0 2 3}$ \\
\hline Chaetoceros sp. Antarctica & High & 3 & 9.352 & $\mathbf{0 . 0 0 0}$ \\
\hline Chaetoceros sp. Arctic & Low & 3 & 1.908 & $\mathbf{0 . 0 0 0}$ \\
\hline Chaetoceros sp. Arctic & High & 3 & 6.591 & $\mathbf{0 . 0 0 0}$ \\
\hline Porosira sp. Antarctica & Low & 3 & .761 & $\mathbf{0 . 0 0 0}$ \\
\hline Porosira sp. Antarctica & High & 3 & 1.272 & $\mathbf{0 . 0 0 2}$ \\
\hline Porosira sp. Arctic & Low & 3 & 1.990 & $\mathbf{0 . 0 0 0}$ \\
\hline Porosira sp. Arctic & High & 3 & .047 & $\mathbf{0 . 0 0 0}$ \\
\hline Thallassiosira sp. Antarctica & Low & 3 & 9.319 & 0.197 \\
\hline Thallassiosira sp. Antarctica & High & 3 & .990 & $\mathbf{0 . 0 0 8}$ \\
\hline Thallassiosira sp. Arctic & Low & 3 & 43.436 & $\mathbf{0 . 0 1 0}$ \\
\hline Thallassiosira sp. Arctic & High & 3 & 2.853 & $\mathbf{0 . 0 0 0}$ \\
\hline
\end{tabular}

\section{Discussion}

\section{NIFT response}

While studies of phytoplankton nutrient limitation are certainly not new, many methods used are time consuming and plagued with constraints (Beardall et al. 2001b; Shelly et al. 2010). Traditional methods such as bioassays and nutrient enrichment assays are time consuming, running over several days to weeks leading to a considerable time lag between collecting and reporting (Beardall et al. 2001b). NIFT assays have proven to be sufficiently sensitive to observe fluorescence perturbations within a shorter time frame and are a rapid and cost effective alternative. The responses reported here are the first short time-frame NIFT determinations of the silica response difference of bipolar 
diatoms. In this study I show that bipolar diatoms from Antarctica have an earlier response to silica limitation than Arctic diatoms. The results presented here give evidence of a NIFT response to silicate re-addition to Porosira glacialis, Chaetoceros socialis and Thalassiosira antarctica. These species can produce large blooms in the Arctic and the Antarctic, and are major primary producers in the polar oceans (Andreoli et al. 1995; Booth et al. 2002; Green and Sambrotto 2006; Kelly 2008; Pike et al. 2009).

\section{Geographical differences}

A clear distinction was observed between diatoms collected from the Arctic and the Antarctic in relation to their silica requirements. The general trend indicated that Arctic cultures were silica limited a day later than the Antarctic cultures and furthermore the frequency of the positive NIFT response was lower and the duration was shorter for Arctic cultures compared to Antarctic cultures. Nelson and Treguer (1992) suggested that Antarctic diatoms may exhibit a much lower affinity for silicate than diatoms do from other sectors of the world's oceans. This indicates that diatom growth could be limited by a silicate deficiency at concentrations that are normally thought to be saturating elsewhere. Generally, nutrient concentrations in the Southern Ocean are high (Thomas and Dieckmann 2002b; Ducklow et al. 2007), however nutrient limitation has previously been found in bottom sea ice and brine (Dieckmann et al. 1991; McMinn et al. 1999; Stoecker et al. 2000). My results showed that Antarctic diatoms can become nutrient limited at an early time when nutrient concentrations are still relatively high. For example, in the Antarctic strain of Thalasssiosira sp., limitation was observed at $57 \mu \mathrm{M}$ (day 2), but not until the concentration had dropped to $38 \mu \mathrm{M}$ (day 3 ) for the Arctic strain. This indicates a requirement for a higher silicate concentration than in the Arctic strain, and a long-term adaptation of the cells to local ambient nutrient conditions. This difference is especially clear for the Thalassiosira and Chaetoceros strains while both Porosira strains became nutrient limited at similar levels. This effect is an important consideration for future studies of nutrient concentrations and primary production in the Southern Ocean. The species studied here are mainly pelagic. They can be found in recently formed sea ice due to dominating the water column in summerautumn, however further growth of these species may be limited within the sea ice 
(Arrigo et al. 2010). These species are important seeders from the sea for the ice edge bloom (Booth et al. 2002; Pike et al. 2009; Mangoni et al. 2009b).

Climate change can influence stratification and mixing of water masses (Smetacek and Nicol 2005; Montes-Hugo et al. 2009) and thus may modify nutrient levels in the future (Arrigo et al. 1999). Macro nutrients in the surface layer of the Southern Ocean are generally high due to a high concentration in the deep water (Ducklow et al. 2007) and at hydrothermal vents (Tréguer et al. 1995). It is not fully understood how nutrient levels will change in the future in Antarctica, but for the Arctic, changes have already been documented. Nutrients are supplied to the upper Arctic Ocean by a variety of sources: river input, currents from adjacent seas and advection. Areas in the Arctic Ocean that remain ice covered until late spring or summer have little vertical replenishment of nutrients due lack of mixing done by wind and wave action and the sun induced melt-water stratification being strong (Tremblay and Gagnon 2009). Surface waters reside in the central Arctic for about 10 years and nutrients are consumed during the first year causing generally lower nutrient levels than compared with the Antarctic (Tremblay and Gagnon 2009). Future climate trends show shorter ice-cover periods in the Arctic (Stroeve et al. 2008; Stroeve et al. 2012). This may result in increased incidence and strength of upwelling events and halocline perturbations (Carmack and Chapman 2003), and an increase in the availability of nutrients in large areas of the Arctic ocean. An increase in ice-free zones could also increase nutrient input from terrestrial sources in the Arctic. Similar processes may also occur in the relatively short term in the West Antarctic Peninsula (Montes Hugo et al 2009). Such nutrient changes have key implications for the dynamics of species (Post et al. 2009). In particular, nutrient changes may cause a shift in species composition, altering the elemental composition (C:N:P:Si) of particulate matter, cell size and the food web pathways (Finkel 2010). The ideal mixture of nutrients for growth varies across phytoplankton taxa and the ratios of the different nutrients in the polar regions are spatially highly variable (Tremblay et al. 2002b). For instance, smaller diatoms will have a smaller half saturation value than larger cells because of their surface to volume ratio (Nelson and Treguer 1992; Lopez et al. 2005; Sarthou et al. 2005) and changes in plankton species size (Montes-Hugo et al. 2009) and taxa (Moline et al. 2008) have been 
recorded for the West Antarctic Peninsula. These issues will be discussed in the following paragraphs.

The NIFT results showed that the Arctic Porosira strain became nutrient limited earlier than Thalassiosira. This is especially interesting when considering these two species have similar sea surface temperature, sea surface salinity and sea ice proximity preferences and similar seasonal occurrences (Pike et al. 2009). Yet, they have different silica requirements. The main difference between these species is that Porosira sp. appears to prefer somewhat higher winter and spring sea ice cover than Thalassiosira sp. (Pike et al. 2009). This small difference could prove vital in the future since sea ice, especially in the Arctic, is rapidly thinning and the sea ice extent is decreasing (Stroeve et al. 2008; Kerr 2009; Stroeve et al. 2012) resulting in an increasing prevalence for Thalassiosira sp., which is also smaller in size, over Porosira sp. Ecological consequences of such a species shift will be discussed later in the chapter.

During the NIFT experiment, Chaetoceros sp. rapidly depleted the nutrient in the silica rich medium, yet the NIFT responses were few in number and relatively weak, showing that this species is capable of growing at concentrations that were limiting for Porosira sp. and Thalassiosira sp. Chaetoceros sp. cells are lightly silicified and very small (Tomas 1997; Scott et al. 2005), which results in a species that can grow at low nutrient concentrations (Booth et al. 2002). Such cells are retained longer in the upper water layer (Booth et al. 2002). Chaetoceros sp. blooms can occur early in spring but is mainly found in summer. Blooms occur over short periods with a high density due to its fast growth rate (Mangoni et al. 2009b). Chaetoceros sp. blooms are often following a Thalassiosira spp. bloom (Booth et al. 2002). Thalassiosira spp. blooms have been recorded when nutrient levels were high, but during subsequent Chaetoceros sp. blooms silica varied from moderate to $<0.05 \mu \mathrm{M}$ (Booth et al. 2002; Mangoni et al. 2009b).

Despite the possibility of higher nutrient levels under future warming scenarios, this will not necessarily lead to an increase in abundance of the species studied in this 
chapter. Thalassiosira sp. and Porosira sp. can form resting spores during nutrient depletion that are heavily silicified (Villareal and Fryxell 1990; Pike et al. 2009), but with more rapid melting and break-up of sea ice in spring the reduced growth of Thalassiosira and Porosira could cause populations sizes that are too low for significant numbers of resting spores to be incorporated in the sea ice during autumn (Pike et al. 2009). Chaetoceros has the additional advantage that its resting spores appear to be uniquely successful at germinating from zooplankton faecal pellets, and this would enable Chaetoceros sp. to repopulate newly enriched waters faster than other species (Booth et al. 2002). The smaller size, lower silification and additional survival strategy in faecal pellets could result in this species becoming more dominant in the future. Changes in plankton composition have implications for higher trophic levels in the food chain. For instance, smaller plankton cells impact grazing efficiency from different zooplankton species such as krill (Eupausia superba) which grazes inefficiently on small cells, however salps are effective small particle grazers (Moline et al. 2008).

\section{Nutrients}

Every species tested incorporated silica from the culture medium into its frustule. It is generally accepted that most of the silica taken up by the cell is incorporated in the frustule ( $>70-97 \%$ ) (Armbrust 2009). Within 5 days only 1/10 of the original nutrient concentration was present in the low silica culture medium. This resulted in a silica limitation within 2-3 days for species grown in a medium with low silica concentration and 5 days for species which started in a silica rich medium. These results were generally consistent across all 4 replicates, although the intensity of the NIFT response e.g. increase in $F^{\prime}$ and $F_{m}$ ' differed with species and per day. The differences observed between each day can be an indication of the amount of nutrient limitation (Shelly et al. 2010), and thus a population in the advanced stages of nutrient limitation will give a larger change in fluorescence parameters than a population in the early stages.

\section{$\underline{\text { Yield }}$}

The decrease in yield $\left(\mathrm{F}_{\mathrm{v}} / \mathrm{F}_{\mathrm{m}}\right)$ corresponded with the period in which the cultures were silicate limited. This decrease was evident for all species regardless of location or culturing condition. Maximum quantum efficiency $\left(\mathrm{F}_{\mathrm{v}} / \mathrm{F}_{\mathrm{m}}\right)$ is a measure of the intrinsic efficiency of PSII. A decline in $\mathrm{F}_{\mathrm{v}} / \mathrm{F}_{\mathrm{m}}$ indicates a decline in the quantum yield of PSII 
photochemistry and a disturbance or damage to the photosynthesis apparatus (Lichtenthaler et al. 2005; Hawes et al. 2012). This results in a reduced fraction of functional PSII reaction centres with increased nutrient starvation (Lippemeier et al. 2001). This indicates that photosynthetic performance of diatoms is dependent on the silica concentration. Reductions in $\mathrm{F}_{\mathrm{v}} / \mathrm{F}_{\mathrm{m}}$ have been reported when natural phytoplankton populations become nutrient stressed (Falkowski and Kolber 1995; McMinn and Hegseth 2004). Nutrient stress in laboratory studies also induces reductions in $\mathrm{F}_{\mathrm{v}} / \mathrm{F}_{\mathrm{m}}$ (Beardall et al. 2001a; Young and Beardall 2003). For example, Lippemeier et al. (2001) reported a decrease in $F_{v} / F_{m}$ from 0.65 to 0.56 in silicatestarved Thalassiosira weissflogii, while Lippemeier et al. (1999) reported a decrease from 0.50 to 0.36 due to silicate limitation in the same species.

\section{Disappearance of response}

The NIFT response depends on both the amount of nutrient added and the extent of the nutrient limitation (Beardall et al. 2001b). The disappearance of a NIFT response in the Arctic Chaetoceros sp. and Thalassiosira sp. cultures, which were grown under low silica concentrations, could have two possible explanations. 1) Cell death could have occurred releasing nutrients back into the medium resulting in a disappearance of the limitation or 2), a disappearance of the NIFT response is an indicator that the cultures had gone from a limitation situation to a starvation situation (Beardall et al. 2001a). The cultures that had a disappearance in response also had a minor but significant increase in nutrient levels (10-14 and $16-22 \mu \mathrm{M}$ respectively) in the medium towards the end of the experiment. Furthermore, there was a slight decrease in cell numbers, indicating that cell death had occurred. While neither of these trends were individually statistically significant, taken together they may suggest that the first explanation is most likely. It is not certain whether these changes are sufficient to progress from a limiting to a non-limiting situation since nutrient limitation actually occurred at much higher nutrient levels $(\sim 50 \mu \mathrm{M})$. When the response disappeared the yield did not return to the values recorded when no limitation was present, suggesting on going damage of PSII, indicating that a limitation/starvation is still present, or that the damage was longer term, and not yet repaired. Data collected in this study cannot positively distinguish between the two hypotheses above. Possible future studies should focus on further exploring this since when applied to field samples it can have impacts on assessing primary production. 


\section{Assessing the NIFT technique}

This is the first time that the I-PAM has been used to test for a NIFT response in plankton cultures. The I-PAM and the water-PAM both recorded similar responses after a Si addition to $\mathrm{S}$ limited cultures. The increase in $\mathrm{F}^{\prime}$ and $\mathrm{F}_{\mathrm{m}}$ continued for the duration (ca. $15 \mathrm{~min}$ ) of the NIFT assays and started 2-4 minutes after a silicate spike. The increase of $\mathrm{F}^{\prime}$ and $\mathrm{F}_{\mathrm{m}}$ ' in nutrient limited samples was consistently less strong in the IPAM than the water-PAM. This is most likely due to a lower sensitivity of the I-PAM (pers comm. K.G. Ryan). Nonetheless, positive responses could be observed with this method. This method still needs refining, especially to increase the sensitivity of the response to detect limitation in the very early stages, but is a very promising alternative with many benefits over other techniques, such as the short time frame and the option to run multiple samples, controls and nutrients simultaneously. In this study, up to 12 tests could be run simultaneously. Furthermore, the fluorescence measurements are non-destructive and highly sensitive, thus requiring only small volumes and low concentrations of experimental samples. These characteristics make the NIFT approach potentially very useful for exploring the nutrient status of algae and their response to environmental changes.

This is one of the first NIFT studies to focus on silica limitation rather than nitrate or phosphate limitation. Previous studies have raised some issues about species specific responses and differences in response (Wood and Oliver 1995; Holland et al. 2004). By using multiple species and culturing these for a longer time it is possible to shed some light on these issues. While the gross direction of the response is relatively consistent for $\mathrm{N}, \mathrm{P}$ and possibly for $\mathrm{Si}$, differences still exist. These may be the result of variations in the protocol (Lippemeier et al. 2001), amount and chemical species of the limiting nutrient added (Holland et al. 2004), or degree of nutrient limitation (Young and Beardall 2003). By running multiple species in the same time period, protocol variations were minimized. Lippemeier et al. (2001) also suggested the possibility that different techniques give varying NIFT responses. Here we found no difference between any of the species in the general trend of responses. The water-PAM and IPAM gave similar responses making it possible to transfer existing protocols for NIFT to 
the I-PAM. Future work should focus on further testing the NIFT technique and I-PAM in field situations.

Even though silicate is not considered to be a nutrient of direct importance for photosynthetic processes, our experiments clearly show strong influences of silica metabolism on the variable chlorophyll fluorescence of diatom cells. If PAM measurements are taken as an indication of electron transport rate and potential and actual photochemical efficiency of the reaction centres of PSII, our results show that the importance of silicate for photosynthetic performance is similar to that of other nutrients like nitrogen and phosphate.

Samples run with the PAM showed an increased NPQ directly after the silicate readdition in silicate starved cultures, which decreased after 2-4min. This decrease coincided with the increase in $\mathrm{F}^{\prime}$ and $\mathrm{F}_{\mathrm{m}}$ '. The short term response in the fluorescence parameters could be explained by the unique biochemical pathways associated with photorespiration of diatoms. Photorespiration in diatoms produces serine and glycine. These 2 amino acids provide the main fraction of a protein matrix that binds silica when the siliceous cell wall is generated (Lippemeier et al. 1999). Thus if silicate becomes limiting, these amino acids will accumulate in the cells. This likely causes a feedback loop to the carboxylase activity of RUBISCO reducing photorespiration (Lippemeier et al. 2001). A reduction in photorespiration causes a reduction in $\mathrm{CO}_{2}$ fixation which decreases ATP consumption in the dark reactions (Lippemeier et al. 1999). Thus, the need for protons to drive the phosphorylation of ADP in the stroma will decrease, leading to an amplified proton gradient across the thylakoid membrane. This will enhance non-photochemical quenching (Lippemeier et al. 1999) as observed by the high NPQ numbers in silica limited cultures prior to re-addition with silica. This can quickly return to the normal operation values by the addition of silica causing the subsequent drop in NPQ. 


\section{Conclusion}

Positive silicate-NIFT responses were observed in all diatom species tested. These responses consisted of an increase in $\mathrm{F}^{\prime}$ and $\mathrm{F}_{\mathrm{m}}$ after the addition of silicate to Sidepleted cultures, as well as a strong immediate decrease in NPQ. Antarctic diatoms tend to have a faster and much stronger response to nutrient limitation compared to their Arctic counterparts. This means that Antarctic diatom growth could be limited by a silicate deficiency at concentrations that were previously thought to be saturating. This observation supports that of Nelson and Treguer (1992) in that Antarctic diatoms may exhibit a much lower affinity for silicate than diatoms do from other sectors of the world's oceans. This is important in future studies of nutrient limitation in the Southern Oceans, since relatively high nutrient levels do not necessarily mean that there is no nutrient limitation present.

Species specific differences in nutrient limitation were observed. Porosira sp. had the highest silica requirement followed by Thalassiosira sp. Chaetoceros sp. had the lowest silica demand and in field situations it may out-compete other species (Booth et al. 2002). This species is also less dependent on the sea ice, which could give it an advantage in the future with reduced sea ice cover as predicted by numerous climate change models.

This is the first time the I-PAM has been used for the detection of nutrient limitation in diatoms. Both the I-PAM and the water-PAM detected nutrient limitation in all cultures. The benefit of the I-PAM over the water-PAM is that multiple samples and thus multiple nutrients can be tested at once, resulting in an almost instantaneous detection of nutrient limitation in samples. 


\section{Chapter 6 General discussion}

\section{General overview}

A central concept in ecology is to understand community diversity, structure and function and its relationships with the environment. In order to understand this concept, an integrated approach must be used. In this thesis, I studied ice algal community structure and diversity at several locations in the sea ice of the Ross Sea, Antarctica. I also studied nutrient limitation in sea ice and examined how this influences Antarctic and Arctic sea ice diatoms. Algal diversity was examined by microscopy while the influence of nutrient limitation was measured using culturing methods. These experiments provide an insight into how different species will cope with reduced light levels caused by snow cover and how they will cope with changing nutrient regimes associated with climate change.

Though many studies have focussed on diversity of algae in sea ice this is the first study to I) compare spatial and temporal differences in sea ice communities stretching over 30 years, II) use the near real time NIFT method to study nutrient limitation in sea ice and further develop this method for use with the I-PAM, and III) report physiological differences between bipolar diatoms for their silica requirements. These results improve the understanding of community structure and how it is influenced by the environment.

In this discussion, I will first summarise the results found in each chapter in order to answer the sub-questions raised in the introduction, specifically:.

Can possible "key" algal species be identified which will play an important role in climate change?

How are these species influenced by changes in snow cover?

How does nutrient limitation influence algal community composition? 
Several key results are highlighted in a subsequent section of this chapter that describes the present day situation, based on the results presented in this thesis. I will then discuss the implications of climate and address the main question raised in the introduction of "How do nutrients and snow cover effect sea ice algal communities and what are the future implications in relation to climate change?"

These results will be discussed based on spatial and temporal variability of the bottom ice communities, changes to the interior of the sea ice, effect of snow cover, and changes to species succession due to nutrient limitation

\section{Summary of findings}

\section{Chapter 2: Spatial and temporal comparisons of sea ice algal communities in Ross Sea, Antarctica}

A baseline of sea ice algal community was constructed for CE and TNB stretching 30 years. My findings show large differences in biomass, up to two orders of magnitude, and variation in community composition, both temporal and spatial. Local differences in the environment have large influences in the species composition. TNB is prone to large physiochemical changes, e.g. currents, ice thickness, snow cover and time of sea ice formation, andthis significantly influences species composition. In contrast, CE is a much more stable site where many species re-occur each year. One trend that can be observed here is the increasing prevalence of Berkeleya adeliensis and Fragillariopsis spp. since 1999 and changes in Entomoneis kjellmannii which was correlated with snow cover. These observed changes made it possible to identify B. adeliensis, Fragilariopsis spp. and E. kjellmannii as "key" species that give an indication of the status of the sea ice environment. These species may show a significant change under future climate change. 


\section{Chapter 3: The influence of snow cover on total particulate organic carbon in bottom and interior sections of Antarctic sea ice}

Large differences were found vertically in the sea ice. Throughout the ice, bacteria dominate in terms of numbers, though not in terms of biomass. Diatoms formed the largest carbon source in the bottom of the sea ice, while the interior of the sea ice was dominated by EPS. In the bottom-ice, increasing snow cover significantly reduced the amount of algal cells and EPS present, while prokaryotic abundance remained constant. Similarly, seasonal measurements showed an increase in algal cells and EPS, but again no difference in prokaryotic abundance. This suggests an uncoupling of the microbial loop. The top and middle sections of the sea ice showed no significant change in any of the carbon sources that could be correlated with increasing snow cover or temporal change. This suggests that production in the interior of the sea ice is limited by a factor other than light, such as nutrient limitation.

\section{Chapter 4: Silica and phosphorus limitation occurs in sea ice brine communities but not in bottom ice or seawater communities}

The lack of primary production could be an indication of nutrient limitation. This study shows for the first time that the NIFTs approach is a highly appropriate method for sea ice as it generates an almost instantaneous assessment of nutrient limitation. Despite relatively high nutrient concentrations, brine communities suffered from both Si and P limitation. These communities consisted of diatoms and dinoflagellates. The two different phylogenetic groups present in the sea ice have different nutrient requirements and therefore caused a dual nutrient limitation in $\mathrm{Si}$ and $\mathrm{P}$. The $\mathrm{Si}$ limitation may perhaps be attributed to the high abundance of the heavily frustulated Fragilariopsis spp. Brine habitats may be particularly vulnerable to nutrient limitation due to the lack of flushing with the nutrient rich waters of the Ross Sea. These results indicate that the brine algae that were collected early in December were already nutrient limited. Generally, sea ice primary production continues until January when the ice breaks up. The nutrient limitation in the brine may severely limit primary production in that part of the sea ice. 


\section{Chapter 5: Antarctic diatoms have a higher silica demand than Arctic diatoms}

Diatoms collected from the Arctic and Antarctic were grown in the laboratory to study their Si requirements. Positive silicate-NIFT responses were observed in all diatoms tested. These responses consisted of an exponential increase in $\mathrm{F}^{\prime}$ and $\mathrm{F}_{\mathrm{m}}$ after the addition of silicate to silica limited cultures, as well as a strong decrease in NPQ. Antarctic diatoms tend to become Si limited compared to Arctic taxa. This is important for future studies on nutrient limitation in the Southern Ocean because even though there were relatively high Si levels, nutrient limitation may still occur. This is the first time the I-PAM has been used to compare nutrient limitation in diatoms. Both the IPAM and the water-PAM detected nutrient limitation in all cultures. The benefit of the IPAM over the water-PAM is that multiple samples and thus multiple nutrients can be tested at once.

\section{Present situation}

The situation in Antarctic sea ice is that the highest biomass (figure 6.1) is found in the bottom $10 \mathrm{~cm}$ of the ice. This is due to the high nutrient availability and stable temperature and salinity regimes. Light does not seem to be a limiting factor since large increases in algal biomass have been found in the bottom of the sea ice. The interior of the sea ice however exhibits lower biomass, diversity of algal species and is nutrient limited (figure 6.1). The low diversity of algal species can be due to the fact that the interior of the sea ice is a very extreme habitat with high salinity and low temperatures which limiting the number of species able to grow in this habitat. The lack of exchange with the nutrient rich seawater was evident in the observed nutrient limitation and lack of algal biomass increase in the interior of the sea ice. 


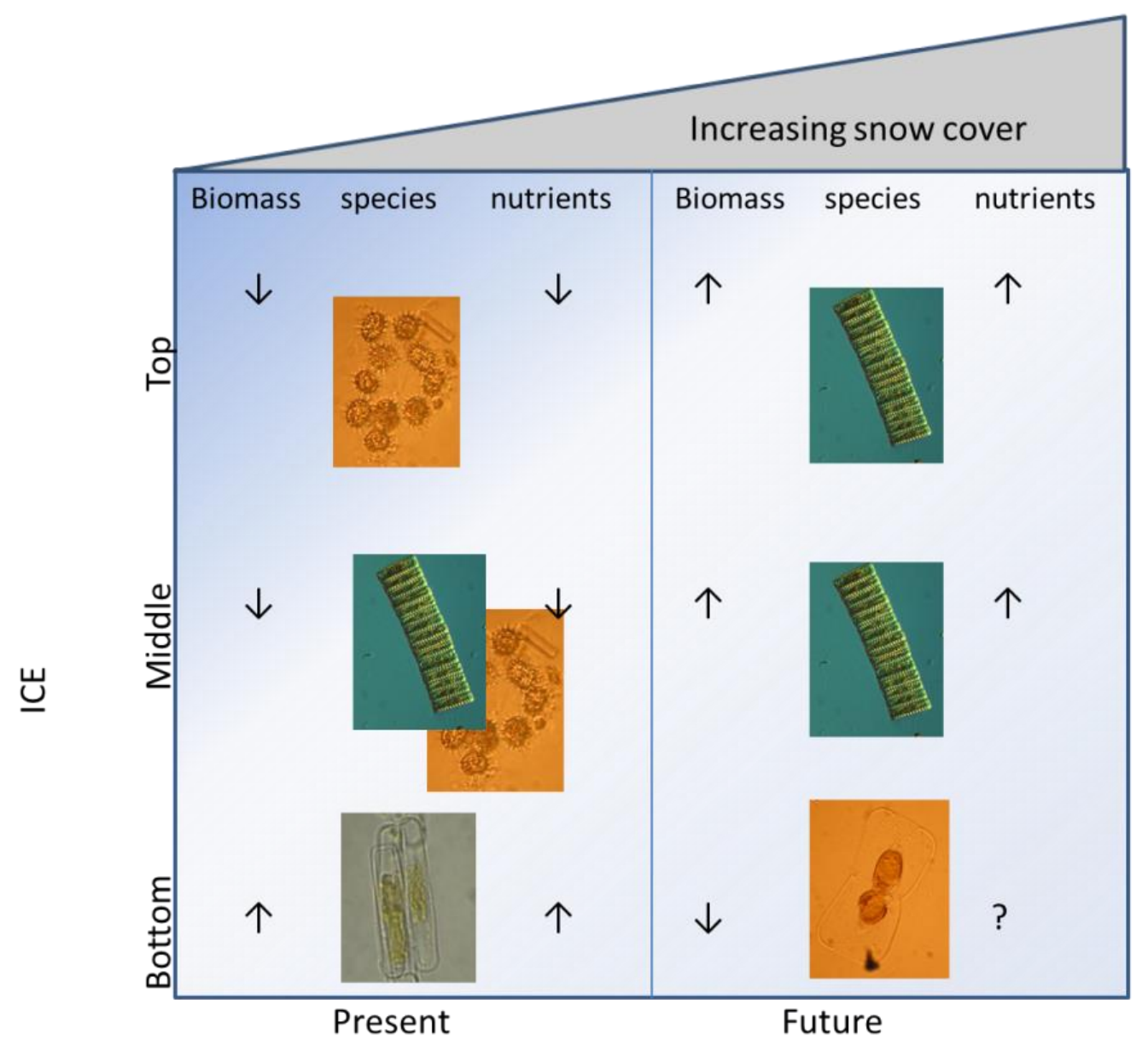

Figure 6-1: Difference in sea ice communities in the present and future in relation to increasing snow cover, when snow cover causes flooding of the sea ice.

\section{Predicted changes}

A climate-driven rise in temperature in polar regions is predicted to shorten the period of annual ice cover and reduce the volume and extent of ice at both poles (Turner and Overland 2009). Increased temperature will also influence ocean circulation, cloud cover (Turner and Overland 2009; Schofield et al. 2010; Doney et al. 2012), upwelling and mixing which in turn could influence current nutrient concentrations (Priddle et al. 1992). This may result in a reduction in annual primary production in the sea ice and an overall increase in total primary production in the open ocean zone due to primary production occurring over a longer period than is possible in the sea ice alone (Arrigo and Thomas 2004). The balance between nutrient availability and nutrient requirements influences fundamental aspects of phytoplankton growth and community structure (Arrigo 2005). Interestingly, changes in community composition could 
increase nutrient utilization efficiency and further increase the overall rate of production in the Southern Ocean (Arrigo 2005). Changes are likely to be complex and wide-ranging. In this thesis I have examined how snow cover and nutrient requirements influence sea ice algal growth in Antarctica. An integrated image of my results (snow cover, community composition at present in the different position of sea ice, the nutrient limitation and diatom silica requirements) along with the changes associated with climate change are illustrated in Figure 6-1. In this figure the main change considered is the increase in snow cover. How sea ice algal communities in the sea ice are affected will be discussed in the next paragraphs.

\section{Spatial and temporal variability of the bottom sea ice communities}

Yearly and seasonally variability was examined for sea ice algal communities at Terra Nova Bay (TNB) and Cape Evans (CE). TNB showed high variability in biomass between years and was also prone to large algal community shifts. TNB had large variations in snow and ice thickness while the timing of ice formation differed significantly each year. At TNB, no clear relationships between ice thickness and biomass could be observed. High variability causes difficulty for long term studies because trends are hard to discern. However, the variability at TNB provides an excellent opportunity for a future integrated study of oceanography and ecology, to understand how these work together to form the current sea ice algal community.

CE has a much more stable algal community composition from year to year, with consistent ice thickness and minimal snow cover. This stability makes it an excellent site for long term studies and data and trends obtained from this site can be extrapolated to other regions, and used for climate change models. CE could therefore prove valuable in the future for assessing climate change since long term studies are easier to conduct and there is an existing base line for algal communities present (Palmisano and Sullivan 1983; McGrath Grossi et al. 1984; Sullivan and Palmisano 1984; McMinn et al. 1999; Arrigo et al. 2000; Stoecker et al. 2000; Arrigo et al. 2003; Garrison et al. 2005; Ryan et al. 2006). My long term data showed that light levels at this location are not the main factor that influences biomass. Ice thickness and thus light levels 
reaching the sea ice communities in summer were very consistent at this site yet biomass varied by up to 2 orders of magnitude. These changes again illustrate the importance of studies that continue to examine changes in algal biomass and composition in detail and incorporate the analyses of abiotic factors such as temperature, salinity and currents, ice thickness and snow cover.

Variation in biomass can be influenced by snow cover, nutrient availability, ice thickness, timing of sea ice formation and the presence of icebergs. The presence of icebergs in coastal Antarctic waters can modify under-ice currents, and affect heat, salt, and other advective fluxes (Arrigo et al. 2003; Dinniman et al. 2007). In the early 2000s, several large icebergs calved off the face of the Ross Ice Shelf $(B-15,2000$ and C-19, 2002) and significantly modified sea ice extent in the region (Dinniman et al. 2007). These icebergs blocked the movement of sea ice north and resulted in multiyear fast ice in regions previously devoid of sea ice in summer. Both B-15 and C-19 caused a reduction in phytoplankton blooms in the Ross Sea, and Dinniman et al. (2007) speculated that these icebergs also reduced phytoplankton growth by reducing the advective input of organic matter in the region.

Not only the pelagic realm showed a reduction in algal biomass (Arrigo and van Dijken 2003; Dinniman et al. 2007). I have also reported a massive biomass reduction in the sea ice of the Ross Sea during the austral summer of 2000-2003 (as illustrated in chapter 2) compared to 1999 (Seibel and Dierssen 2003). This reduction in biomass has consequences further up the food chain. The reduction in algal biomass affected pteropods, which are very abundant in the Ross Sea (Seibel and Dierssen 2003). Limacine helicina, which feeds on plankton, declined in abundance in the austral summer of 2000-2001. The next year there was a reduction in the pteropod Clione antarctic, which feeds exclusively on L. helicina (Seibel and Dierssen 2003). Pteropods in turn form a food source for fish and whales (Seibel and Dierssen 2003). 
Despite the large reduction in biomass, the sea ice algal bloom community composition showed little variation compared to previous years. This is of particular interest for climate models and raises the question about how much and to what extent the iceberg influences communities composition, especially since predicted climate change can further increase the number of ice bergs (Long et al. 2002), and if in the future a change in algal community composition is to be expected. The Ross Ice Shelf will continue to break off large icebergs and, in the future, scenarios as discussed above are likely to continue. This could alter sea ice algal community composition by restricting currents and hence nutrient flow; changes in temperature and timing of the formation and breakup of the sea ice, will in turn influence salinity levels.

\section{Changes to the interior of the sea ice}

In contrast to the large spatial and temporal variability of sea ice algae abundance and community composition in the bottom of the sea ice, the interior showed much less variation in species composition and abundance during early summer (chapter 2). The species present in this habitat are cryo- and halo-tolerant (Stoecker et al. 2000). However the combination of thinner sea ice and increased snow cover in the future could have several consequences for the interior algal community. Thinner sea ice could favour more interior assemblages of algae since thin ice is often associated with higher temperatures and a shorter sea ice season (McMinn et al. 2007).

Significant nutrient limitation was found in the interior of the sea ice (Chapter 4). Exchange of the brine communities in the interior of the sea ice with the under lying sea water is limited and decreases with increasing distance from the seawater-sea ice interface (McMinn et al. 1999). With thinning sea ice, this limitation may become less significant since there will be less distance between the sea water- and sea ice interior, enhancing exchange with the underlying nutrient rich waters and thus exchange and thus biomass could increase. However, along with thinning ice, precipitation is also likely to increase in the future (Turner and Overland 2009) and the extra snow cover is likely to depress the surface of the ice and allow flooding with nutrient-rich seawater (Knox 2009). Flooding will increase nutrient levels favouring diatoms as the dominant 
taxa and also reduce the salinity levels in the brine (figure 6-1). These changes to the brine habitat will significantly influence the species present and the total biomass will likely increase due to the more favourable environment of salinities and temperature which will be similar to seawater. Within the interior of the sea ice, EPS formed the largest carbon source (Chapter 3) meaning the few algal cells present there excrete large amounts of EPS. The excretion protects them against freezing and acts as a barrier against hyper salinity (Krembs et al. 2002; Krembs and Deming 2008). Since flooding and regular flushing of the brine with seawater would eliminate the need for large amounts of EPS against high salinity, the internal sections of the ice could provide a habitat for low EPS producing species in the future. EPS provides food for many zooplankton species and thus a switch to low EPS producing species could affect zooplankton abundance and species composition. Interior assemblages appear to contribute more overall chl $a$ biomass than previously suspected in Antarctica (Meiners et al. 2012) and it can be speculated that future interior ice communities could favour large assemblages of shade-adapted, low EPS producing diatom communities such as $E$. kjellmannii.

As discussed earlier, it is still unclear how exactly nutrient levels are going to change due to the many variables that influences this such as seasonality, ice thickness, glacier run-off, wind and wave action, time of ice melt (Arrigo and Thomas 2004; Arrigo et al. 2008; Annett et al. 2010; Sedwick et al. 2011; Smith Jr et al. 2012). However, even if the nutrients levels are lower than at present it can still provide sufficient for the brine communities which are currently nutrient starved.

At the moment mainly the bottom of the sea ice can be grazed by zooplankton and the interior is not accessible for most grazers except a few ciliates which have occasionally been reported (Knox 2009b). However, with a change in the brine habitat to more favourable salinities and access to the brine communities through flooding it might become accessible for more grazers. Since there is still little data available on the interior of the sea ice it is unclear how all these different variables i.e. lower EPS, 
different algal species, higher biomass, will interact with each other and thus also how this will influence food availability for zooplankton grazers.

\section{The effect of snow cover on bottom sea ice communities}

Reducing sea ice thickness will slightly increase light levels, which could enhance algal growth (Arrigo et al. 2010). Higher precipitation in the form of snow is also predicted under future climate change scenarios (Convey et al. 2009; Turner and Overland 2009). Ten $\mathrm{cm}$ snow cover can reduce light levels by $80 \%$ reaching the bottom of the sea ice (Chapter 2), which causes a much stronger reduction in light than gained by $10 \mathrm{~cm}$ thinner ice cover. Extra snow cover will severely limit algal growth and have a large influence on the algal species present (Chapter 2). Snow thicknesses of over $30 \mathrm{~cm}$ could possibly completely limit algal growth (Arrigo et al. 1991; Arrigo et al. 2003). Understanding snow distribution and variability is crucial, since the timing of snow fall, duration of snow cover and thickness have different effects on the species composition and total biomass present (Sturm and Massom 2010). I have shown that $10-15 \mathrm{~cm}$ of cover had little effect on biomass and species composition, however $30-40 \mathrm{~cm}$ has drastic effects on biomass and species composition (Chapter 2). Sea-ice microalgae from bottom ice communities are highly shade adapted meaning that light-saturated photosynthesis occurs at very low irradiance (Knox 2009b; Ryan et al. 2009; Mangoni et al. 2009a), and an increase of snow cover would favour only the most shade adapted species as illustrated in chapter 2 and figure 6.1 .

A major change with increased snow cover is likely to be a switch from Berkeleya adeliensis to Entomoneis kjellmannii. B. adeliensis excretes large amounts of EPS and forms a valuable food source for many zooplankton species, but this species was only found in high abundance when light levels were sufficiently high. In contrast, $E$. kjellmannii dominates under low light conditions (Tomas 1997; Bellinger et al. 2010). In addition, E. kjellmannii, unlike B. adeliensis, can also occur in high abundance in seawater (pers. obs.) possibly making it important in pelagic blooms (McMinn et al. 2012). E. kjellmannii is one of the dominant species found during the winter to spring transition and is well adapted to those low light levels (McMinn et al. 2010). This 
species is also weakly silicified. The characteristics of these two species make them valuable indicator or "key" species in the study of climate change on primary production and community change. The reduction in algal biomass as well as a change in species composition will impact the organisms grazing at the underside of the sea ice and later in the season when seeding the ice edge bloom. Implications of this on the food web will be discussed later.

Snow cover also reduced the amount of EPS produced (Chapter 3), which is important because EPS forms a vital food source for grazing zooplankton (Decho and Moriarty 1990). EPS varies in molecular size, chemical composition and solubility, depending on the nutrient status, growth phase, behaviour and photosynthetic activity of the cells and species (Thomas et al. 1995; Meiners et al. 2004; Underwood et al. 2010). The switch in algal species with increasing snow cover observed in chapter 2 could therefore have caused a change in the EPS chemical composition. There is a linear relationship between carbon and EPS, which is species-specific (Engel and Passow 2001). This means that algal species composition determines the total amount of EPS present. It is therefore no surprise that the proportion of the carbon contributors varied spatially as illustrated by the difference between the EPS to algal ratio in TNB compared to the one found at TR or CE. In the context of thinner sea ice, shorter seasons and higher precipitation, a switch to lower EPS-producing species is likely to influence the entire food web. Furthermore, the ratio of $\mathrm{Chl} a$ to carbon can vary from 1:20 to 1:40 amongst sea ice species and in response to changes in light (Arrigo et al. 2010). It is clear, therefore, that the species composition is a much more relevant factor to use to assess carbon dynamics than $\mathrm{Chl} a$ measurements, and it is suggested that this is measured routinely in sea ice algal studies in the future.

Sea-ice EPS and algal biomass became decoupled at CE. A rapid decline in algal biomass concentrations was observed during the 2011 season, but EPS concentrations remained stable and high. If the algal biomass is released from the sea ice at a faster rate than EPS, as suggested by Riedel et al (2006), it could indicate that not all EPS was attached to algal cells within the sea ice. Under this scenario, free EPS would remain longer in 
the sea ice than attached EPS (Riedel et al. 2006). This retention of EPS could provide organisms in the water column with an extra pulse of organic carbon after the majority of sea-ice biomass has been released (Riedel et al. 2006). However, the amount of the additional pulse released and occurrence has yet to be quantified. It can be speculated that a shorter sea ice season could influence the timing of the two pulses, causing them to overlap and preventing a second pulse of potential food for zooplankton. In addition, snow cover will result in lower quantities of both EPS and algal biomass available for grazers, which could have similar consequences as discussed earlier for the pteropods L. helocina and C. antarctica.

This thesis analysed the effect of snow cover on the sea ice TPOC from November to December, and depending on season, snow has different effects on the sea ice community. In winter and spring, snow cover insulates the ice from the colder air, and later in the season when the air temperature is warmer, the insulating properties of snow can extend the growth period in summer (Mundy et al. 2005; Mundy et al. 2007). However, results from chapter 2 showed a delay in growth under the high snow cover, which, during the period studied, did not reach the same levels as was found under no or low snow cover. Future studies should include a longer period in order to fully understand the impact of snow cover on algal dynamics and be able to calculate net primary production gain or loss due to snow cover.

\section{Changes to species succession due to nutrient limitation}

With on-going climate change their will be an important shift from sea ice blooms to pelagic blooms (Arrigo and Thomas 2004) which are dominated by different algal species (Montes-Hugo et al. 2009). The algal species present depends on an interaction between nutrient levels and sea ice duration. The reduction of sea ice extent as well as the thinning of sea ice means that upon melting there will be less stratification of the water column (Annett et al. 2010). Diatoms tend to prefer stratified waters (Arrigo et al. 2000; Annett et al. 2010) whereas deep mixing promotes the growth of Phaeocystis antarctica (Arrigo et al. 2000). The colonies of this haptophyte have a positive buoyancy due to a high EPS content, while diatoms tend to sink due to their heavy 
frustules (Annett et al. 2010). Phaeocystis could therefore become more abundant under future warming scenarios (Smith Jr et al. 2012). Currently, the Ross Sea is highly stratified, but as noted above this may reduce in the future as mixed-layer depths might increase due to wind action (Smith Jr et al. 2012). This could result in a similar situation to that observed in the northern West Antarctic Peninsula were reduced sea ice cover caused an increase in the mixed layer and a decrease in primary production (MontesHugo et al. 2009).

As illustrated in chapter 5, diatoms in Antarctica became silica limited at relatively high concentrations of silica, meaning that diatoms grow near limiting concentrations of silica. So, any change to the nutrient levels due to changes in sea ice melt, stratification and, mixing will have large effects on the total diatom biomass and which species will be present. Under nutrient deplete conditions, Thalassiosira sp. and Porosira sp. can form resting spores that are heavily silicified (Pike et al. 2009; Villareal and Fryxell 1990). These spores can be incorporated in the sea ice in autumn and may seed the ice edge bloom the following year (Pike et al. 2009). The more rapid melting and break-up of sea ice in spring, predicted to occur in the future, and reduced of stratification, will have a negative effect on diatoms. This study showed that Chaetoceros sp. was able to grow under a range of silica concentrations (Chapter 5) and has been shown to survive moderate to low nutrient levels (Booth et al. 2002). Chaetoceros sp. has the added advantage that its resting spores appear to be uniquely successful at germinating from faecal pellets, and this would enable Chaetoceros sp. to repopulate newly enriched waters faster than other species (Booth et al. 2002), but only in areas with shallow shelves, such as present in large parts of the Arctic. Furthermore, it also means this species is less dependent of the timing of sea ice formation. The lower requirement of Chaetoceros cells for Si shown here, coupled with their smaller size and survival strategy in faecal pellets together may allow this species to be retained for longer periods in the water column and this may allow it to become more dominant in the ice edge bloom in the future. Studying the responses of species to low nutrient concentrations may be a useful way to predict those species that could dominate in the sea ice under future environmental conditions. Furthermore knowledge of nutrient 
tolerances allows us to speculate on levels of primary production in the future and to predict the effect on all trophic levels in the food chain as discussed earlier.

This discussion has illustrated the importance of understanding the nutrient requirements and niche of individual species rather than the whole algal community. Small changes in nutrients can favour different sized algal species. For instance, smaller size plankton such as cryptophytes impact grazing efficiency from different zooplankton species such as krill (Euphausia superba) which is inefficient at small particle grazing; however salps are effective small particle grazers (Moline et al. 2008). However, small diatoms are better equipped against grazing because a higher mechanical strength is required to break the frustules (Hamm et al. 2003). This will restrict grazing to zooplankton species such as copepods and euphausiids which have a special adaptation to break diatom frustules (Hamm et al. 2003). Changes in taxa to smaller size classes of phytoplankton will affect all trophic levels.

\section{Conclusions}

Combining results from the different chapters showed large spatial and temporal variability in sea ice algal abundance and composition. This study identified that snow cover and nutrient limitation can explain the presence or absence of certain species. Climate change will affect snow cover and nutrient levels causing abundance, community and/or taxa changes in the future (figure 6.1). Fragilariopsis spp., $B$. adeliensis and E. kjellmannii can be seen as "key" species to follow in the future due to their sensitively to either changes in light levels or available nutrients. Recording these changes illustrates the importance of long term studies looking in detail in sea ice microbial abundance, composition and dynamics.

\section{Future research directions}

This thesis has raised several issues that should be studied further. These range from continuing long term studies to further developing and evaluating techniques. The focus of this thesis was on the algal communities in Antarctic sea ice. Although diatoms in general have been widely studied and many species have been identified, good 
descriptions and consensus of identifications for several species in the Antarctic is lacking. This will limit the potential for studies examining the influence of environmental factors on sea ice algal communities or the possibility comparing sea ice communities with each other over time and space. Chapter 2 illustrates the changes that have occurred in sea ice algal species composition during the past 30 years. It is of vital importance to continue these long term studies in order to predict possible changes caused by climate change. Even these simple base line studies, which are so common at other latitudes and other environments are often still lacking for Antarctica, and not only for sea ice algae but the entire sea ice communities. The Cape Evans time series dataset should continue, since it forms a valuable source for observing changes caused by climate change. This study should be extended to incorporate temperature, salinity, nutrient and light levels.

Sea ice communities are influenced by many environmental variables. Many studies have focused on the environmental variables such as temperature and light. Ice thickness and thus light levels reaching the sea ice communities in summer are very consistent at Cape Evans yet biomass varies by up to 2 orders of magnitude. Therefore this site is influenced by other factors than just light. Environmental variables do not work independently of each other and though it might pose difficulties studying them together (both logistically and in analysis) this should be an important next step in order to understand sea ice community, dynamics and changes that will occur during climate change. Terra Nova Bay is a good example of where an integrated study of oceanography and ecology can enhance our understanding of how physicochemical cues influence primary production. Understanding all these processes and how they influence the environment will enhance our understanding of the general Southern Ocean processes. Further research should further focus on i) identify key physical drivers of sea ice algal primary production and, ii) distinguish short- medium term variability from long-term trends.

Since relatively high nutrient levels can still be limiting in the Southern Ocean, future studies should consider this, and by further developing the I-PAM techniques this can be 
done in near real time, this method is also is sensitive and affordable. The NIFT techniques have been proven to be a viable technique in the study of nutrient limitation in diatoms. Most of the studies looking at the mechanisms behind the NIFT have been focused on phosphorus (Shelly et al. 2010). The main change in NIFT response is associated with changes in energy distribution between photosystem I and II as well as light-stress induced non-photochemical quenching (Shelly et al. 2010). Future work should focus on the mechanisms or biochemistry behind this technique in order to understand how the NIFT response is formed in diatoms. The bipolar species used in chapter 5 can form resting spores and/or resting cells (Tomas 1997). Resting spores of Chaetoceros sp. can occur in large numbers reaching high biomass (Booth et al. 2002). It is unclear how the presence of a large proportion of resting spores will influence the NIFT response since the majority of the cells are not vegetative and will be unlikely to respond to nutrient changes. Only by addressing these issues and evaluating this technique for the application in a broader range of environments and algal taxa can be made.

This thesis used bipolar diatoms to focus on physiological responses to nutrient limitation. It is clear that these bipolar diatoms differ in their responses suggesting that data from sea ice in Antarctica cannot be easily extrapolated to the Arctic. Studies on gene expression might give more insight in difference between the response and the onset of nutrient limitation between bipolar diatoms. Targeting genes associated with stress such as the heat shock protein gene group or gene coding for silica depositing vesicles could possibly give insight into why there is a consistent difference between bipolar diatoms.

Though the bipolar species used in this thesis were considered to be the same species, they show clear differences in their nutrient requirements (Chapter 5). Traditionally, diatoms were identified based on morphological characteristic. This however has its limitations since morphological characterise can be influenced by environmental factors such as wave action, temperature, trace metals and, salinity (Villareal and Fryxell 1983; Marchetti and Harrison 2007; Bona et al. 2009; Varela). Therefore, it could be useful to 
examine these diatoms using more modern techniques such as DNA amplification to assess variability (species differences) and RNA for gene expression. Naturally these types of techniques could be used to build a DNA library of sea ice communities which will in the future help making identification of species present in the sea ice easier rather than relying solely on morphological identifications. 


\section{References}

Ackley, S. F. and Sullivan, C. W. (1994). "Physical controls on the development and characteristics of antarctic sea-ice biological communites - A review and synthesis " Deep-Sea Research Part IOceanographic Research Papers 41(10): 1583-1604.

Alldredge, A. L., Passow, U. and Logan, B. E. (1993). "The abundance and significance of a class of large, transparent organic particles in the ocean." Deep-sea research part I- Oceanographic research papers 40(6): 1131-1140.

Andreoli, C., Moro, I., La Rocca, N., Valle, L. D., Masiero, L., Rascio, N. and Vecchia, F. D. (2000). "Ecological, physiological, and biomolecular surveys on microalgae from Ross Sea (Antarctica)." Italian Journal of Zoology 67(sup1): 147-156.

Andreoli, C., Tolomio, C., Moro, I., Radice, M., Moschin, E. and Bellato, S. (1995). "Diatoms and dinoflagellates in Terra Nova Bay (Ross Sea-Antarctica) during austral summer 1990." Polar Biology 15(7): 465-475.

Annett, A. L., Carson, D. S., Crosta, X., Clarke, A. and Ganeshram, R. S. (2010). "Seasonal progression of diatom assemblages in surface waters of Ryder Bay, Antarctica." Polar Biology 33(1): 1329.

Armand, L. K., Cornet-Barthaux, V., Mosseri, J. and Quéguiner, B. (2008). "Late summer diatom biomass and community structure on and around the naturally iron-fertilised Kerguelen Plateau in the Southern Ocean." Deep Sea Research Part II: Topical Studies in Oceanography 55(5-7): 653-676.

Armbrust, E. V. (2009). "The life of diatoms in the world's oceans." Nature 459(7244): 185-192.

Arndt, C. E., Gulliksen, B., Lønne, O. J. and Berge, J. (2009). Ecosystem Barents Sea.

Arrigo, K. R. (2005). "Marine microorganisms and global nutrient cycles " Nature 438(7064): 122-122.

Arrigo, K. R., DiTullio, G. R., Dunbar, R. B., Robinson, D. H., VanWoert, M., Worthen, D. L. and Lizotte, M. P. (2000). "Phytoplankton taxonomic variability in nutrient utilization and primary production in the Ross Sea." Journal of Geophysical Research 105(C4): 8827-8846.

Arrigo, K. R., Mock, T. and Lizotte, M. P. (2010). Primary Producers and Sea Ice. Sea Ice, WileyBlackwell 10.1002/9781444317145.ch8: 283-325.

Arrigo, K. R., Robinson, D. H., Worthen, D. L., Dunbar, R. B., DiTullio, G. R., VanWoert, M. and Lizotte, M. P. (1999). "Phytoplankton community structure and the drawdown of nutrients and $\mathrm{CO}_{2}$ in the Southern Ocean." Science 283(5400): 365-367.

Arrigo, K. R., Sullivan, C. W. and Kremer, J. N. (1991). "A Bio-optical Model of Antarctic Sea Ice." Journal of Geophysical Research 96(C6): 10581-10592.

Arrigo, K. R. and Thomas, D. N. (2004). "Large scale importance of sea ice biology in the Southern Ocean." Antarctic Science 16(4): 471-486.

Arrigo, K. R., van Dijken, G. and Pabi, S. (2008). "Impact of a shrinking Arctic ice cover on marine primary production." Geophysical Research Letters 35(19): L19603.

Arrigo, K. R. and van Dijken, G. L. (2003). "Impact of iceberg C-19 on Ross Sea primary production." Geophysical Research Letters 30(16): 1836.

Arrigo, K. R. and van Dijken, G. L. (2004). "Annual changes in sea-ice, chlorophyll $a$, and primary production in the Ross Sea, Antarctica." Deep Sea Research Part II: Topical Studies in Oceanography 51(1): 117-138.

Arrigo, K. R., Weiss, A. M. and Smith, W. O., Jr. (1998a). "Physical forcing of phytoplankton dynamics in the southwestern Ross Sea." Journal of Geophysical Research 103(C1): 1007-1021.

Arrigo, K. R., Worthen, D., Schnell, A. and Lizotte, M. P. (1998b). "Primary production in Southern Ocean waters." Journal of Geophysical Research 103(C8): 15587-15600.

Arrigo, K. R., Worthen, D. L., Lizotte, M. P., Dixon, P. and Dieckmann, G. (1997). "Primary production in Antarctic sea ice." Science 276(5311): 394-397.

Arrigo, K. R., Worthen, D. L. and Robinson, D. H. (2003). "A coupled ocean-ecosystem model of the Ross Sea: 2. Iron regulation of phytoplankton taxonomic variability and primary production." Journal of Geophysical Research 108(C7): 3231. 
Beardall, J., Berman, T., Heraud, P., Omo Kadiri, M., Light, B. R., Patterson, G., Roberts, S., Sulzberger, B., Sahan, E., Uehlinger, U. and Wood, B. (2001a). "A comparison of methods for detection of phosphate limitation in microalgae." Aquatic Sciences - Research Across Boundaries 63(1): 107-121.

Beardall, J., Young, E. and Roberts, S. (2001b). "Approaches for determining phytoplankton nutrient limitation." Aquatic Sciences - Research Across Boundaries 63(1): 44-69.

Bellinger, B. J., Gretz, M. R., Domozych, D. S., Kiemle, S. N. and Hagerthey, S. E. (2010). "Composition of extracellular polymeric substances from periphytomassemblages in the Florida everglades." Journal of Phycology 46(3): 484-496.

Bidle, K. D., Manganelli, M. and Azam, F. (2002). "Regulation of oceanic silicon and carbon preservation by temperature control on bacteria." Science 298(5600): 1980-1984.

Bona, F., Badino, G., Hoffmann, L. and Ector, L. (2009). "Diatom teratological forms and environmental alterations: a review." Hydrobiologia 623(1): 1-35.

Booth, B. C., Larouche, P., Bélanger, S., Klein, B., Amiel, D. and Mei, Z. P. (2002). "Dynamics of Chaetoceros socialis blooms in the North Water." Deep Sea Research Part II: Topical Studies in Oceanography 49(22-23): 5003-5025.

Boyd, P. W., Watson, A. J., Law, C. S., Abraham, E. R., Trull, T., Murdoch, R., Bakker, D. C. E., Bowie, A. R., Buesseler, K. O., Chang, H., Charette, M., Croot, P., Downing, K., Frew, R., Gall, M., Hadfield, M., Hall, J., Harvey, M., Jameson, G., LaRoche, J., Liddicoat, M., Ling, R., Maldonado, M. T., McKay, R. M., Nodder, S., Pickmere, S., Pridmore, R., Rintoul, S., Safi, K., Sutton, P., Strzepek, R., Tanneberger, K., Turner, S., Waite, A. and Zeldis, J. (2000). "A mesoscale phytoplankton bloom in the polar Southern Ocean stimulated by iron fertilization." Nature 407.

Brinkmeyer, R., Knittel, K., Jurgens, J., Weyland, H., Amann, R. and Helmke, E. (2003). "Diversity and Structure of Bacterial Communities in Arctic versus Antarctic Pack Ice." Applied and Environmental Microbiology 69(11): 6610-6619.

Brzezinski, M. A., Nelson, D. M., Franck, V. M. and Sigmon, D. E. (2001). "Silicon dynamics within an intense open-ocean diatom bloom in the Pacific sector of the Southern Ocean." Deep-sea research part II-Topical studies in oceanography 48(19-20): 3997-4018.

Carmack, E. and Chapman, D. C. (2003). "Wind-driven shelf/basin exchange on an Arctic shelf: The joint roles of ice cover extent and shelf-break bathymetry." Geophysical Research Letters 30(14): 9-1.

Carmack, E. C. and Swift, J. H. (1990). Some aspects of the large-scale physical oceanography of the arctic ocean influencing biological distributions. Cambridge, British Antarctic survey.

Coale, K. H., Johnson, K. S., Fitzwater, S. E., Blain, S. P. G., Stanton, T. P. and Coley, T. L. (1998). "IronEx-I, an in situ iron-enrichment experiment: Experimental design, implementation and results." Deep Sea Research Part II: Topical Studies in Oceanography 45(6): 919-945.

Collins, R. E., Carpenter, S. D. and Deming, J. W. (2008). "Spatial heterogeneity and temporal dynamics of particles, bacteria, and pEPS in Arctic winter sea ice." Journal of Marine Systems 74(3-4): 902-917.

Comiso, J. C. (2010). Variability and Trends of the Global Sea Ice Cover. Sea Ice, Wiley-Blackwell 10.1002/9781444317145.ch6: 205-246.

Convey, P., Bindschadler, R., di Prisco, G., Fahrbach, E., Gutt, J., Hodgson, D. A., Mayewski, P. A., Summerhayes, C. P. and Turner, J. (2009). "Antarctic climate change and the environment." Antarctic Science 21(06): 541-563.

Decho, A. W. and Moriarty, D. J. W. (1990). "Bacterial exopolymer utilization by a harpacticoid copepod - a methodology and results." Limnology and Oceanography 35(5): 1039-1049.

Deming, J. W. (2010). Sea Ice Bacteria and Viruses. Sea Ice, Wiley-Blackwell 10.1002/9781444317145.ch7: 247-282. 
Dieckmann, G. S., Lange, M. A., Ackley, S. F. and Jennings, J. C. (1991). "The nutrient status in sea ice of the Weddell Sea during winter: effects of sea ice texture and algae." Polar Biology 11(7): 449-456.

Dinniman, M. S., Klinck, J. M. and Smith, W. O., Jr. (2007). "Influence of sea ice cover and icebergs on circulation and water mass formation in a numerical circulation model of the Ross Sea, Antarctica." Journal of Geophysical Research 112(C11): C11013.

Doney, S. C., Ruckelshaus, M., Duffy, J. E., Barry, J. P., Chan, F., English, C. A., Galindo, H. M., Grebmeier, J. M., Hollowed, A. B., Knowlton, N., Polovina, J., Rabalais, N. N., Sydeman, W. J. and Talley, L. D. (2012). "Climate Change Impacts on Marine Ecosystems." Annual review of marine sciences 4: 11-37.

Ducklow, H. W., Baker, K., Martinson, D. G., Quetin, L. B., Ross, R. M., Smith, R. C., Stammerjohn, S. E., Vernet, M. and Fraser, W. (2007). "Marine pelagic ecosystems: the west Antarctic Peninsula." Philosophical Transactions of the Royal Society B: Biological Sciences 362(1477): 67-94.

Dumont, I., Schoemann, V., Lannuzel, D., Chou, L., Tison, J. L. and Becquevort, S. (2009). "Distribution and characterization of dissolved and particulate organic matter in Antarctic pack ice." Polar Biology 32(5): 733-750.

Eicken, H. (1992). "The role of sea ice in structuring Antarctic ecosystems." Polar Biology 12(1): 3-13.

Engel, A. and Passow, U. (2001). "Carbon and nitrogen content of transparent exopolymer particles (TEP) in relation to their Alcian Blue adsorption." Marine ecology- progress series 219: 1-10.

Falkowski, P. and Kolber, Z. (1995). "Variations in chlorophyll fluorescence yields in phytoplankton in the world oceans." Functional Plant Biology 22(2): 341-355.

Fiala, M., Kuosa, H., Kopczynska, E. E., Oriol, L. and Delille, D. (2006). "Spatial and seasonal heterogeneity of sea ice microbial communities in the first-year ice of Terre Adélie area (Antarctica)." Aquatic Microbial Ecology 43(1): 95-106.

Fitzwater, S. E., Johnson, K. S., Gordon, R. M., Coale, K. H. and Smith Jr, W. O. (2000). "Trace metal concentrations in the Ross Sea and their relationship with nutrients and phytoplankton growth." Deep Sea Research Part II: Topical Studies in Oceanography 47(15-16): 3159-3179.

Fritsen, C. H., Lytle, V. I., Ackley, S. F. and Sullivan, C. W. (1994). "Autumn bloom of Antarctic pack-ice algae." Science 266(5186): 782-784.

Fry, J. C. and Davies, A. R. (1985). "An assessment of methods for measuring volumes of planktonic bacteria, with particular reference to television image analysis." Journal of Applied Microbiology 58(1): 105-112.

Garrison, D. L., Gibson, A., Coale, S. L., Gowing, M. M., Okolodkov, Y. B., Fritsen, C. H. and Jeffries, M. O. (2005). "Sea-ice microbial communities in the Ross Sea: autumn and summer biota." Marine Ecology Progress Series 300: 39-52.

Geider, R. and La Roche, J. (2002). "Redfield revisited: variability of C:N:P in marine microalgae and its biochemical basis." European Journal of Phycology 37(1): 1-17.

Geider, R., Macintyre, Graziano, L. and McKay, R. M. (1998). "Responses of the photosynthetic apparatus of Dunaliella tertiolecta (Chlorophyceae) to nitrogen and phosphorus limitation." European Journal of Phycology 33(4): 315-332.

Gleitz, M. and Thomas, D. N. (1992). "Physiological-responses of a smal IAntarctic diatom (Chaetoceros sp) to simulate environmental constraints associated with sea-ice formation." Marine ecology- progress series 88(2-3): 271-278.

Golden, K. M., Ackley, S. F. and Lytle, V. I. (1998). "The Percolation Phase Transition in Sea Ice." Science 282(5397): 2238-2241.

Gowing, M. M., Garrison, D. L., Gibson, A. H., Krupp, J. M., Jeffries, M. O. and Fritsen, C. H. (2004). Bacterial and viral abundance in Ross Sea summer pack ice communities. Oldendorf, Allemagne, Inter-Research. 
Gradinger, R. (2009). "Sea-ice algae: Major contributors to primary production and algal biomass in the Chukchi and Beaufort Seas during May/June 2002." Deep Sea Research Part II: Topical Studies in Oceanography 56(17): 1201-1212.

Gradinger, R., Friedrich, C. and Spindler, M. (1999). "Abundance, biomass and composition of the sea ice biota of the Greenland Sea pack ice." Deep Sea Research Part II: Topical Studies in Oceanography 46(6-7): 1457-1472.

Green, S. E. and Sambrotto, R. N. (2006). "Plankton community structure and export of C, N, P and Si in the Antarctic Circumpolar Current." Deep-sea research part II-Topical studies in oceanography 53(5-7): 620-643.

Grossi, S. M. and Sullivan, C. W. (1985). "Sea ice microbial communities .V. The vertical zonation of diatoms in Antarctic fast ice community." Journal of Phycology 21(3): 401-409.

Guglielmo, L., Carrada, G. C., Catalano, G., Cozzi, S., Dell'Anno, A., Fabiano, M., Granata, A., Lazzara, L., Lorenzelli, R., Manganaro, A., Mangoni, O., Misic, C., Modigh, M., Pusceddu, A. and Saggiomo, V. (2004). "Biogeochemistry and algal communities in the annual sea ice at Terra Nova Bay (Ross Sea, Antarctica)." Chemistry and Ecology 20(sup1): 43-55.

Guglielmo, L., Carrada, G. C., Catalano, G., Dell'Anno, A., Fabiano, M., Lazzara, L., Mangoni, O., Pusceddu, A. and Saggiomo, V. (2000). "Structural and functional properties of sympagic communities in the annual sea ice at Terra Nova Bay (Ross Sea, Antarctica)." Polar Biology 23(2): 137-146.

Guillard, R. R. L. (1975). Culture of phytoplankton for feeding marine invertebrates. Culture of marine invertebrate animals. W. L. Smith and M. H. Chanley., New York: Plenum Publishing Corp: 29-60.

Hamm, C. E., Merkel, R., Springer, O., Jurkojc, P., Maier, C., Prechtel, K. and Smetacek, V. (2003). "Architecture and material properties of diatom shells provide effective mechanical protection." Nature 421(6925): 841-843.

Hawes, I., Lund-Hansen, L., Sorrell, B., Nielsen, M., Borzák, R. and Buss, I. (2012). "Photobiology of sea ice algae during initial spring growth in Kangerlussuaq, West Greenland: insights from imaging variable chlorophyll fluorescence of ice cores." Photosynthesis Research 112(2): 103-115.

Hegseth, E. N. (1992). "Sub-ice algal assemblages of the Barents sea - species composition, chemical composition, and growth rates." Polar Biology 12(5): 485-496.

Hegseth, E. N. (2001). Chemical composition of Arctic and Antarctic ice algae - a comparison. SCAR VIII's Symposium on Antarctic Biology. Amsterdam.

Hegseth, E. N. and Von Quillfeldt, C. H. (2002). "Low phytoplankton biomass and ice algal blooms in the Weddell Sea during the ice-filled summer of 1997." Antarctic Science 14(3): 231-243.

Hillebrand, H., Durselen, C.-D., Kirschtel, D., Pollingher, U. and Zohary, T. (1999). "Biovolume calculation for pelagic and benthic microalgae." Journal of Phycology 35(2): 403-424.

Ho, T.-Y., Quigg, A., Finkel, Z. V., Milligan, A. J., Wyman, K., Falkowski, P. G. and Morel, F. M. M. (2003). "The elmental compostion of some phytoplankton." Journal of Phycology 39(6): 1145-1159.

Holland, D., Roberts, S. and Beardall, J. (2004). "Assessment of the nutrient status of phytoplankton: a comparison between conventional bioassays and nutrient-induced fluorescence transients (NIFTs)." Ecological Indicators 4(3): 149-159.

Holland, M. M. and Bitz, C. M. (2003). "Polar amplification of climate change in coupled models." Climate Dynamics 21(3-4): 221-232.

Horner, R. (1990). Ice-associated ecosystems. Cambridge, British Antarctic Survey.

Juhl, A. R., Krembs, C. and Meiners, K. M. (2011). "Seasonal development and differential retention of ice algae and other organic fractions in first-year Arctic sea ice." Marine Ecology Progress Series 436: 1-16.

Junge, K., Eicken, H. and Deming, J. W. (2004). "Bacterial Activity at -2 to $-20^{\circ} \mathrm{C}$ in Arctic Wintertime Sea Ice." Applied and Environmental Microbiology 70(1): 550-557. 
Kelly, B. (2008). Biological cycling of carbon, nitrogen and silicon in Arctic and sub-Arctic marine waters: Insights from phytoplankton studies in the laboratory and the field. Biology, University of Victoria. Master of Science: 157.

Kennish, M. J. (2000a). Marine chemistry. Practical handbook of marine science, Third edition, CRC Press 10.1201/9781420038484.ch2.

Kennish, M. J. (2000b). Physical oceanography. Practical handbook of marine science, Third edition, CRC Press 10.1201/9781420038484.ch3.

Kerr, R. A. (2009). "Arctic Summer Sea Ice Could Vanish Soon But Not Suddenly." Science 323(5922): 1655.

Knox, G. A. (2009a). Phytoplankton and primary production. Biology of the Southern Ocean, Second edition, CRC Press 10.1201/9781420005134.ch2.

Knox, G. A. (2009b). Sea-ice microbial communities. Biology of the Southern Ocean, Second edition, CRC Press 10.1201/9781420005134.ch3: 59-97.

Knox, G. A. (2009c). The Southern Ocean. Biology of the Southern Ocean, Second edition, CRC Press 10.1201/9781420005134.ch1.

Krembs, C. and Deming, J. W. (2008). "The role of exopolymers in microbial adaptation to sea ice." Psychrophiles: From Biodiversity to Biotechnology: 247-264.

Krembs, C., Eicken, H. and Deming, J. W. (2011). "Exopolymer alteration of physical properties of sea ice and implications for ice habitability and biogeochemistry in a warmer Arctic." Proceedings of the National Academy of Sciences 108(9): 3653-3658.

Krembs, C., Eicken, H., Junge, K. and Deming, J. W. (2002). "High concentrations of exopolymeric substances in Arctic winter sea ice: implications for the polar ocean carbon cycle and cryoprotection of diatoms." Deep-sea research part I- Oceanographic research papers 49(12): 2163-2181.

Krembs, C. and Engel, A. (2001). "Abundance and variability of microorganisms and transparent exopolymer particles across the ice-water interface of melting first-year sea ice in the Laptev Sea (Arctic)." Marine Biology 138(1): 173-185.

Krembs, C., Gradinger, R. and Spindler, M. (2000). "Implications of brine channel geometry and surface area for the interaction of sympagic organisms in Arctic sea ice." Journal of Experimental Marine Biology and Ecology 243(1): 55-80.

Kristiansen, S. and Hoell, E. E. (2002). "The importance of silicon for marine production." Hydrobiologia 484(1-3): 21-31.

Kroger, N. (2007). "Prescribing diatom morphology: toward genetic engineering of biological nanomaterials." Current Opinion in Chemical Biology 11(6): 662-669.

Kruskopf, M. and Flynn, K. J. (2006). "Chlorophyll content and fluorescence responses cannot be used to gauge reliably phytoplankton biomass, nutrient status or growth rate." New Phytologist 169(3): 525-536.

Kuzyk, Z. Z. A., Macdonald, R. W., Johannessen, S. C., Gobeil, C. and Stern, G. A. (2009). "Towards a sediment and organic carbon budget for Hudson Bay." Marine Geology 264(3-4): 190-208.

Legendre, L., Ackley, S. F., Dieckmann, G. S., Gulliksen, B., Horner, R., Hoshiai, T., Melnikov, I. A., Reeburgh, W. S., Spindler, M. and Sullivan, C. W. (1992). "Ecology of sea ice biota .2. global significance." Polar Biology 12(3-4): 429-444.

Leonardos, N. and Geider, R. J. (2004). "Responses of Elemental and Biochemical Composition of Chaetoceros muelleri to Growth under Varying Light and Nitrate: Phosphate Supply Ratios and Their Influence on Critical N: P." Limnology and Oceanography 49(6): 2105-2114.

Leventer, A. (1988). Recent biogenic sedimentation on the Antarctic continental margin, Rice University. PhD: 238.

Lichtenthaler, H. K., Buschmann, C. and Knapp, M. (2005). "How to correctly determine the different chlorophyll fluorescence parameters and the chlorophyll fluorescence decrease ratio RFd of leaves with the PAM fluorometer." Photosynthetica 3(43): 379-393. 
Lippemeier, S., Hartig, P. and Colijn, F. (1999). "Direct impact of silicate on the photosynthetic performance of the diatom Thalassiosira weissflogii assessed by on- and off-line PAM fluorescence measurements." Journal of Plankton Research 21(2): 269-283.

Lippemeier, S., Hintze, R., Vanselow, K., Hartig, P. and Colijn, F. (2001). "In-line recording of PAM fluorescence of phytoplankton cultures as a new tool for studying effects of fluctuating nutrient supply on photosynthesis." European Journal of Phycology 36(1): 89-100.

Lizotte, M. P. (2001). "The Contributions of Sea Ice Algae to Antarctic Marine Primary Production." American Zoologist 41(1): 57-73.

Long, D. G., Ballantyn, J. and Bertoia, C. (2002). "Is the number of Antarctic icebergs really increasing?" Eos, Transactions American Geophysical Union 83(42): 469-474.

Lopez, P. J., Descles, J., Allen, A. E. and Bowler, C. (2005). "Prospects in diatom research." $\underline{\text { Current }}$ Opinion in Biotechnology 16(2): 180-186.

Mangoni, O., Carrada, G., Modigh, M., Catalano, G. and Saggiomo, V. (2009a). "Photoacclimation in Antarctic bottom ice algae: an experimental approach." Polar Biology 32(3): 325-335.

Mangoni, O., Saggiomo, M., Modigh, M., Catalano, G., Zingone, A. and Saggiomo, V. (2009b). "The role of platelet ice microalgae in seeding phytoplankton blooms in Terra Nova Bay (Ross Sea, Antarctica): a mesocosm experiment." Polar Biology 32(3): 311-323.

Marchetti, A. and Cassar, N. (2009). "Diatom elemental and morphological changes in response to iron limitation: a brief review with potential paleoceanographic applications." Geobiology 7(4): 419-431.

Marchetti, A. and Harrison, P. J. (2007). "Coupled changes in the cell morphology and the elemental (C, N, and Si) composition of the pennate diatom Pseudo-nitzschia due to iron deficiency." Limnology and Oceanography 52(5): 2270-2284.

Martin-Jezequel, V., Hildebrand, M. and Brzezinski, M. A. (2000). "Silicon metabolism in diatoms: Implications for growth." Journal of Phycology 36(5): 821-840.

Martin, A., Hall, J. A., O'Toole, R., Davy, S. K. and Ryan, K. G. (2008). "High single-cell metabolic activity in Antarctic sea ice bacteria." Aquatic Microbial Ecology 52(1): 25-31.

Martin, A. R. (2005). Antarctic bacteria, sea ice ecosystem dynamics, and global climate change. School of biological sciences. Wellington, Victoria University Wellington. Master of Science: 127.

Martin, A. R. (2009). Microbial loop dynamics in Antarctic sea-ice. School of biological sciences. Wellington, Victoria University, Wellington. Doctor of Philosophy: 186.

Mayewski, P. A., Meredith, M. P., Summerhayes, C. P., Turner, J., Worby, A., Barrett, P. J., Casassa, G., Bertler, N. A. N., Bracegirdle, T., Naveira Garabato, A. C., Bromwich, D., Campbell, H., Hamilton, G. S., Lyons, W. B., Maasch, K. A., Aoki, S., Xiao, C. and van Ommen, T. (2009). "State of the Antarctic and Southern Ocean climate system." Reviews of Geophysics 47(1): n/a-n/a.

McGrath Grossi, S., Kottmeier, S. T. and Sullivan, C. W. (1984). "Sea ice microbial communities. III. Seasonal abundance of microalgae and associated bacteria, Mcmurdo Sound, Antarctica." Microbial Ecology 10(3): 231-242.

McMinn, A. (1997). "Species Succession in Fast Ice Algal Communities." Korean Journal Polar Research 8(1/2): 47-52.

McMinn, A., Ashworth, C., Bhagooli, R., Martin, A., Salleh, S., Ralph, P. and Ryan, K. (2012). "Antarctic coastal microalgal primary production and photosynthesis." Marine Biology 159(12): 28272837.

McMinn, A., Ashworth, C. and Ryan, K. (2000). "In situ net primary productivity of an Antarctic fast ice bottom algal community." Aquatic Microbial Ecology 21(2): 177-185.

McMinn, A. and Hegseth, E. N. (2004). "Quantum yield and photosynthetic parameters of marine microalgae from the southern Arctic Ocean, Svalbard." Journal of the Marine Biological Association of the United Kingdom 84(05): 865-871. 
McMinn, A. and Hegseth, E. N. (2007). "Sea ice primary productivity in the northern Barents Sea, spring 2004." Polar Biology 30(3): 289-294.

McMinn, A., Martin, A. and Ryan, K. (2010). "Phytoplankton and sea ice algal biomass and physiology during the transition between winter and spring (McMurdo Sound, Antarctica)." Polar Biology 33(11): 1547-1556.

McMinn, A., Ryan, K. G., Ralph, P. J. and Pankowski, A. (2007). "Spring sea ice photosynthesis, primary productivity and biomass distribution in eastern Antarctica, 2002-2004." Marine Biology 151(3): 985-995.

McMinn, A., Skerratt, J., Trull, T., Ashworth, C. and Lizotte, M. (1999). "Nutrient stress gradient in the bottom $5 \mathrm{~cm}$ of fast ice, McMurdo Sound, Antarctica." Polar Biology 21(4): 220-227.

Meguro, H., Ito, K. and Fukushim.H (1967). "Ice flora (bottom type) - a mechanism of primary prodcution in polar seas and growth of diaotms in sea ice." Arctic 20(2): 114-133.

Meiners, K., Brinkmeyer, R., Granskog, M. A. and Lindfors, A. (2004). "Abundance, size distribution and bacterial colonization of exopolymer particles in Antarctic sea ice (Bellingshausen Sea)." Aquatic Microbial Ecology 35(3): 283-296.

Meiners, K., Krembs, C. and Gradinger, R. (2008). "Exopolymer particles: microbial hotspots of enhanced bacterial activity in Arctic fast ice (Chukchi Sea)." Aquatic Microbial Ecology 52(2): 195-207.

Meiners, K. M., Vancoppenolle, M., Thanassekos, S., Dieckmann, G. S., Thomas, D. N., Tison, J. L., Arrigo, K. R., Garrison, D. L., McMinn, A., Lannuzel, D., van der Merwe, P., Swadling, K. M., Smith, W. O., Melnikov, I. and Raymond, B. (2012). "Chlorophyll a in Antarctic sea ice from historical ice core data." Geophysical Research Letters 39(21): n/a-n/a.

Menden-Deuer, S. and Lessard, E. J. (2000). "Carbon to Volume Relationships for Dinoflagellates, Diatoms, and Other Protist Plankton." Limnology and Oceanography 45(3): 569-579.

Merwe, P. v. d. and McMinn, A. (unpubl.). "Preliminary investigation of silicate induced fluorescence transients in the marine diatom, Cylindrotheca fusiformis." Unpublised.

Mock, T. (2002). "In situ primary production in young Antarctic sea ice." Hydrobiologia 470(1): 127132.

Mock, T., Samanta, M. P., Iverson, V., Berthiaume, C., Robison, M., Holtermann, K., Durkin, C., BonDurant, S. S., Richmond, K., Rodesch, M., Kallas, T., Huttlin, E. L., Cerrina, F., Sussmann, M. R. and Armbrust, E. V. (2008). "Whole-genome expression profiling of the marine diatom Thalassiosira pseudonana identifies genes involved in silicon bioprocesses." Proceedings of the National Academy of Sciences of the United States of America 105(5): 1579-1584.

Moline, M. A., Karnovsky, N. J., Brown, Z., Divoky, G. J., Frazer, T. K., Jacoby, C. A., Torres, J. J. and Fraser, W. R. (2008). "High Latitude Changes in Ice Dynamics and Their Impact on Polar Marine Ecosystems." Annals of the New York Academy of Sciences 1134(1): 267-319.

Montes-Hugo, M., Doney, S. C., Ducklow, H. W., Fraser, W., Martinson, D., Stammerjohn, S. E. and Schofield, O. (2009). "Recent changes in phytoplankton communities associated with rapid regional climate change along the western Antarctic Peninsula." Science 323(5920): 14701473.

Mundy, C. J., Barber, D. G. and Michel, C. (2005). "Variability of snow and ice thermal, physical and optical properties pertinent to sea ice algae biomass during spring." Journal of Marine Systems 58(3-4): 107-120.

Mundy, C. J., Ehn, J. K., Barber, D. G. and Michel, C. (2007). "Influence of snow cover and algae on the spectral dependence of transmitted irradiance through Arctic landfast first-year sea ice." Journal of Geophysical Research-Oceans 112(C3).

Nelson, D. M., Smith, W. O., Muench, R. D., Gordon, L. I., Sullivan, C. W. and Husby, D. M. (1989). "Particulate matter and nutrient distributions in the ice-edge zon e of the Weddel Sea Relationship to hydrography during late summerarticulate matter and nutreints " Deep-sea research part I- Oceanographic research papers 36(2): 191-209. 
Nelson, D. M. and Treguer, P. (1992). "Role of silicon as a limiting nutrient to Antarctic diatomsEvidence from kinetic-studies in the Ross Sea ice edge zone." Marine ecology- progress series 80(2-3): 255-264.

NSIDC. (2012). "National Snow \& Ice Data Centre." Sea ice index.

Paasche, E. (1973a). "Silicon and ecology of marine plankton diatoms 1.1 Thalassiosira-pseudonana (cyclotella-nana) grwon in a chemostat with silicate as limiting nutrient." Marine Biology 19(2): 117-126.

Paasche, E. (1973b). "Silicon and ecology of marine plankton diatoms .2. silicate-uptake kinetics in 5 diatom species." Marine Biology 19(3): 262-269.

Palmisano, A. C. and Sullivan, C. W. (1983). "Sea ice microbial communities (SIMCO)." Polar Biology 2(3): 171-177.

Passow, U. and Alldredge, A. L. (1995). "A dye-binding assay for the spectrophotometric measurement of transparent exopolymer particles (TEP)." Limnology and Oceanography 40(7): 1326-1335.

Petrich, C. and Eicken, H. (2010). Growth, Structure and Properties of Sea Ice. Sea Ice, WileyBlackwell 10.1002/9781444317145.ch2: 23-77.

Petrou, K., Doblin, M. A., Smith, R. A., Ralph, P. J., Shelly, K. and Beardall, J. (2008). "State transitions and non-photochemical quenching during a nutrient-induced fluorescence transient in phosphorus-starved Dunaliella tertiolecta." Journal of Phycology 44(5): 1204-1211.

Pike, J., Crosta, X., Maddison, E. J., Stickley, C. E., Denis, D., Barbara, L. and Renssen, H. (2009). "Observations on the relationship between the Antarctic coastal diatoms Thalassiosira antarctica Comber and Porosira glacialis (Grunow) Jorgensen and sea ice concentrations during the late Quaternary." Marine Micropaleontology 73(1-2): 14-25.

Post, E., Forchhammer, M. C., Bret-Harte, M. S., Callaghan, T. V., Christensen, T. R., Elberling, B., Fox, A. D., Gilg, O., Hik, D. S. and Høye, T. T. (2009). "Ecological dynamics across the Arctic associated with recent climate change." Science 325(5946): 1355-1358.

Poulin, M. (1990). Ice diatoms: the Arctic. Cambridge, British antarctic survey.

Priddle, J. (1990). The Antarctic planktonic ecosystem. Cambridge, British Antarctic survey.

Priddle, J., Smetacek, V. and Bathmann, U. (1992). "Antarctic marine primary production, biogeochemical carbon cycles and climatic change." Philosophical Transactions of the Roval Society of London B Biological Sciences 338(1285): 89-97.

Pusceddu, A., Dell'Anno, A., Vezzulli, L., Fabiano, M., Saggiomo, V., Cozzi, S., Catalano, G. and Guglielmo, L. (2009). "Microbial loop malfunctioning in the annual sea ice at Terra Nova Bay (Antarctica)." Polar Biology 32(3): 337-346.

Ralph, P. J., Ryan, K. G., Martin, A. and Fenton, G. (2007). "Melting out of sea ice causes greater photosynthetic stress in algae than freezing in." Journal of Phycology 43: 948-956.

Riedel, A., Michel, C. and Gosselin, M. (2006). "Seasonal study of sea-ice exopolymeric substances on the Mackenzie shelf:implications for transport of sea-ice bacteria and algae." Aquatic Microbial Ecology 45: 195-206.

Riedel, A., Michel, C., Gosselin, M. and LeBlanc, B. (2007). "Enrichment of nutrients, exopolymeric substances and microorganisms in newly formed sea ice on the Mackenzie shelf." Marine Ecology Progress Series 342: 55-67.

Riegman, R., Colijn, F., Malschaert, J. F. P., Kloosterhuis, H. T. and Cadée, G. C. (1990). "Assessment of growth rate limiting nutrients in the north sea by the use of nutrient-uptake kinetics." Netherlands Journal of Sea Research 26(1): 53-60.

Rignot, E., Bamber, J. L., van den Broeke, M. R., Davis, C., Li, Y., van de Berg, W. J. and van Meijgaard, E. (2008). "Recent Antarctic ice mass loss from radar interferometry and regional climate modelling." Nature Geosci 1(2): 106-110.

Roberts, S., Shelly, K. and Beardall, J. (2008). "Interactions among phosphate uptake, photosynthesis, and chlorophyll fluorescence in nutrient-limited cultures of the chlorophyte microalga Dunaliella tertiolecta." Journal of Phycology 44(3): 662-669. 
Robinson, D. H., Arrigo, K. R., Kolber, Z., Gosselin, M. and Sullivan, C. W. (1998). "Photophysiological evidence of nutrient limitation of platelet ice algae in McMurdo Sound, Antarctica." Journal of Phycology 34(5): 788-797.

Ryan, K. G., Cowie, R. O. M., Liggins, E., McNaughtan, D., Martin, A. and Davy, S. K. (2009). "The short-term effect of irradiance on the photosynthetic properties of Antarctic microalgal communities." Journal of Phycology 45(6): 1290-1298.

Ryan, K. G., Hegseth, E. N., Martin, A., Davy, S. K., O'Toole, R., Ralph, P. J., McMinn, A. and Thorn, C. J. (2006). "Comparison of the microalgal community within fast ice at two sites along the Ross Sea coast, Antarctica." Antarctic Science 18(4): 583-594.

Ryan, K. G., Ralph, P. and McMinn, A. (2004). "Acclimation of Antarctic bottom-ice algal communities to lowered salinities during melting." Polar Biology 27(11): 679-686.

Sarthou, G., Timmermans, K. R., Blain, S. and Treguer, P. (2005). "Growth physiology and fate of diatoms in the ocean: a review." Journal of Sea Research 53(1-2): 25-42.

Schofield, O., Ducklow, H. W., Martinson, D. G., Meredith, M. P., Moline, M. A. and Fraser, W. R. (2010). "How Do Polar Marine Ecosystems Respond to Rapid Climate Change?" Science 328(5985): 1520-1523.

Schwarz, J. N. and Schodlok, M. P. (2009). "Impact of drifting icebergs on surface phytoplankton biomass in the Southern Ocean: Ocean colour remote sensing and in situ iceberg tracking." Deep Sea Research Part I: Oceanographic Research Papers 56(10): 1727-1741.

Scott, F. J., Marchant, H. J., Study, A. B. R. and Division, A. A. (2005). Antarctic marine protists, Australian Biological Resources Study.

Sedwick, P. N., Marsay, C., Sohst, B., Aguilar-Islas, A., Lohan, M., Long, M., Arrigo, K. R., Dunbar, R. B., Saito, M. A. and Smith, W. (2011). "Early season depletion of dissolved iron in the Ross Sea polynya: Implications for iron dynamics on the Antarctic continental shelf." Journal of Geophysical Research: Oceans (1978-2012) 116(C12).

Seibel, B. A. and Dierssen, H. M. (2003). "Cascading Trophic Impacts of Reduced Biomass in the Ross Sea, Antarctica: Just the Tip of the Iceberg?" The Biological Bulletin 205(2): 93-97.

Shelly, K., Higgins, T., Beardall, J., Wood, B., McNaughton, D. and Heraud, P. (2007). "Characterising nutrient-induced fluorescence transients (NIFTs) in nitrogen-stressed Chlorella emersonii (Chlorophyta)." Phycologia 46(5): 503-512.

Shelly, K., Holland, D. and Beardall, J. (2010). Assessing Nutrient Status of Microalgae Using Chlorophyll a Fluorescence. Chlorophyll a Fluorescence in Aquatic Sciences: Methods and Applications. D. J. Suggett, O. Prášil and M. A. Borowitzka, Springer Netherlands. 4: 223-235.

Sherr, B., Sherr, E., del Giorgio, P. and John, H. P. (2001). Enumeration of total and highly active bacteria. Methods in Microbiology, Academic Press. 30: 129-159.

Simon, M. and Azam, F. (1989). "Protein content and protein synthesis rates of planktonic marine bacteria." Marine Ecology Progress Series 51: 201-213.

Smetacek, V. and Nicol, S. (2005). "Polar ocean ecosystems in a changing world." Nature 437(7057): 362-368.

Smith Jr, W. O., Sedwick, P. N., Arrigo, K. R., Ainley, D. G. and Orsi, A. H. (2012). "The Ross Sea in a Sea of Change." Oceanography 25.

Squire, V. A. (1990). Polar marine diatoms. Cambridge, British Antarctic Survey.

Stammerjohn, S. E., Martinson, D. G., Smith, R. C., Yuan, X. and Rind, D. (2008). "Trends in Antarctic annual sea ice retreat and advance and their relation to El Niño-Southern Oscillation and Southern Annular Mode variability." Journal of Geophysical Research: Oceans 113(C3): c03590.

Steig, E. J., Schneider, D. P., Rutherford, S. D., Mann, M. E., Comiso, J. C. and Shindell, D. T. (2009). "Warming of the Antarctic ice-sheet surface since the 1957 International Geophysical Year." Nature 457(7228): 459-462.

Steward, F. J. and Fritsen, C. H. (2004). "Bacteria-algae relationships in Antarctic sea ice." Antarctic Science 10(2): 143-156. 
Stoecker, D. K., Gustafson, D. E., Baier, C. T. and Black, M. M. D. (2000). "Primary production in the upper sea ice." Aquatic Microbial Ecology 21(3): 275-287.

Stoecker, D. K., Gustafson, D. E., Black, M. M. D. and Baier, C. T. (1998). "Population dynamics of microalgae in the upper-fast sa ice at a snow-free location." Journal of Phycology 34(1): 6069.

Stroeve, J., Serreze, M., Drobot, S., Gearheard, S., Holland, M., Maslanik, J., Meier, W. and Scambos, T. (2008). "Arctic Sea Ice Extent Plummets in 2007." Eos Transactions AGU 89(2).

Stroeve, J., Serreze, M., Holland, M., Kay, J., Malanik, J. and Barrett, A. (2012). "The Arctic's rapidly shrinking sea ice cover: a research synthesis." Climatic Change 110(3-4): 1005-1027.

Sturm, M. and Massom, R. A. (2010). Snow and Sea Ice. Sea Ice, Wiley-Blackwell 10.1002/9781444317145.ch5: 153-204.

Sukhanova, I. N., Flint, M. V., Pautova, L. A., Stockwell, D. A., Grebmeier, J. M. and Sergeeva, V. M. (2009). "Phytoplankton of the western Arctic in the spring and summer of 2002: Structure and seasonal changes." Deep-sea research part II-Topical studies in oceanography 56(17): $1223-1236$.

Sullivan, C. W. and Palmisano, A. C. (1984). "Sea Ice Microbial Communities: Distribution, Abundance, and Diversity of Ice Bacteria in McMurdo Sound, Antarctica, in 1980." Applied and Environmental Microbiology 47(4): 788-795.

Tamelander, T., Reigstad, M., Hop, H. and Ratkova, T. (2009). "Ice algal assemblages and vertical export of organic matter from sea ice in the Barents Sea and Nansen Basin (Arctic Ocean)." Polar Biology 32(9): 1261-1273.

Thomas, D. N. and Dieckmann, G. S. (2002a). "Antarctic Sea Ice-a Habitat for Extremophiles." Science 295(5555): 641-644.

Thomas, D. N. and Dieckmann, G. S. (2002b). "Biogeochemistry of Antarctic sea ice." Oceanography and Marine Biology Annual review(40): 143-169.

Thomas, D. N., Lara, R. J., Eicken, H., Kattner, G. and Skoog, A. (1995). "Dissolved organic matter in Arctic multi-year sea ice during winter: major components and relationship to ice characteristics." Polar Biology 15(7): 477-483.

Thomas, D. N., Papadimitriou, S. and Michel, C. (2010). Biogeochemistry of Sea Ice. Sea Ice, WileyBlackwell 10.1002/9781444317145.ch12: 425-467.

Timmermans, K. R. and Wagt, B. v. d. (2010). "Variability in cell size, nutrient depletion, and growth rates of the Southern Ocean diatom Fragilariopsis kerguelensis (Bacillariophyceae) after prolonged iron limitation." Journal of Phycology 46(3): 497-506.

Tomas, C. R., Ed. (1997). Identifying marine phytoplankton, academic press Harcourt Brace \& Company.

Tréguer, P., Nelson, D. M., Van Bennekom, A. J., DeMaster, D. J., Leynaert, A. and Queguiner, B. (1995). "The Silica Balance in the World Ocean: A Reestimate." Science 268(5209): 375-379.

Tréguer, P. J. and De La Rocha, C. L. (2011). "The World Ocean Silica Cycle." Annual Review of Marine Science(0).

Tremblay, J.-É. and Gagnon, J. (2009). "The effects of irradiance and nutrient supply on the productivity of Arctic waters: a perspective on climate change." Influence of Climate Change on the Changing Arctic and Sub-Arctic Conditions: 73-93.

Turner, J. and Overland, J. (2009). "Contrasting climate change in the two polar regions." Polar Research 28(2): 146-164.

Turpin, D. H. and Weger, H. G. (1988). "Steady-state chlorophyll $a$ fluorescence transients during ammonium assimilation by the $\mathrm{N}$-limited green alga Selenastrum minutum." Plant Physiology 88: 97-101.

Underwood, G. J. C., Fietz, S., Papadimitriou, S., Thomas, D. N. and Dieckmann, G. S. (2010). "Distribution and composition of dissolved extracellular polymeric substances (EPS) in Antarctic sea ice." Marine Ecology-Progress Series 404: 1-19. 
Underwood, G. J. C., Paterson, D. M. and Parkes, R. J. (1995). "The measurement of microbial carbohydrate exopolymers from intertidal sediments." Limnology and Oceanography 40(7): 1243-1253.

Vancoppenolle, M., Goosse, H., de Montety, A., Fichefet, T., Tremblay, B. and Tison, J.-L. (2010). "Modeling brine and nutrient dynamics in Antarctic sea ice: The case of dissolved silica." Journal of Geophysical Research: Oceans 115(C2): C02005.

Varela, D. E. (2012). "Effect of zinc availability on growth, morphology, and nutrient incorporation in a coastal and an oceanic diatom." Journal of Phycology 47: 302-312.

Villareal, T. A. and Fryxell, G. A. (1983). "Temperature effects on the valve structure of the bipolar diatoms Thalassiosira antarctica and Porosira glacialis." Polar Biology 2(3): 163-169.

Villareal, T. A. and Fryxell, G. A. (1990). "The Diatom Genus Porosira Jorg.: Cingulum Patterns and Resting Spore Morphology." Botanica Marina 33(5): 415-422.

Vrieling, E. G., Sun, Q., Tian, M., Kooyman, P. J., Gieskes, W. W., van Santen, R. A. and Sommerdijk, N. A. (2007). "Salinity-dependent diatom biosilicification implies an important role of external ionic strength." Proceedings of the National Academy of Sciences of the United States of America 104(25): 10441-6.

Walsh, J. E. (2009). "A comparison of Arctic and Antarctic climate change, present and future." Antarctic Science 21(03): 179-188.

Wang, M. and Overland, J. E. (2012). "A sea ice free summer Arctic within 30 years: An update from CMIP5 models." Geophysical Research Letters 39(18): L18501.

Wood, M. and Oliver, R. (1995). "Fluorescence Transients in Response to Nutrient Enrichment of Nitrogen- and Phosphorus-limited Microcystis aeruginosa Cultures and Natural Phytoplankton Populations: a Measure of Nutrient Limitation." Functional Plant Biology 22(2): 331-340.

Young, E. B. and Beardall, J. (2003). "Rapid ammonium- and nitrate-induced perturbations to chla fluorescence in nitrogen-stressed Dunaliella tertiolecta (Chlorophyta)." Journal of Phycology 39(2): 332-342. 


\section{Appendix A: Sea ice algae species list}

Table Appendix A 1: Complete algal species list collected in the bottom $10 \mathrm{~cm}$ of the sea ice at CE (Cape Evans), TNB (Terra Nova Bay) and TR (Turtle Rock).

\begin{tabular}{|c|c|c|c|c|c|c|c|c|c|c|c|c|c|}
\hline & $\begin{array}{l}\text { ஓे } \\
\text { ने } \\
\text { ய }\end{array}$ & $\begin{array}{l}\text { ¿' } \\
\text { О } \\
\text { U }\end{array}$ & 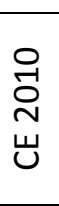 & 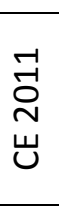 & $\begin{array}{l}\stackrel{\sim}{O} \\
\text { ㄱ } \\
\text { U }\end{array}$ & $\begin{array}{l}\emptyset \\
\varnothing \\
N \\
\mathfrak{p} \\
z\end{array}$ & 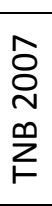 & 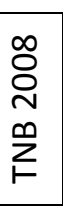 & 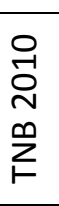 & 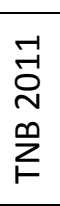 & 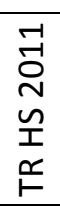 & 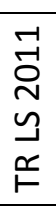 & 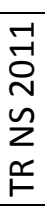 \\
\hline & $\begin{array}{l}\varepsilon \\
\stackrel{\varepsilon}{0} \\
\pm \\
0 \\
\varnothing\end{array}$ & $\begin{array}{l}\varepsilon \\
\stackrel{\Xi}{0} \\
\pm \\
0 \\
\infty\end{array}$ & 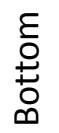 & 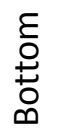 & 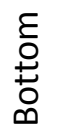 & 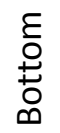 & 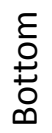 & $\begin{array}{l}\varepsilon \\
\text { E } \\
\pm \\
0 \\
0\end{array}$ & 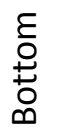 & 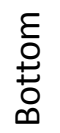 & $\begin{array}{l}\varepsilon \\
\stackrel{\Xi}{0} \\
\pm \\
0 \\
\infty\end{array}$ & $\begin{array}{l}\varepsilon \\
0 \\
\pm \\
0 \\
\varnothing\end{array}$ & 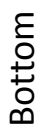 \\
\hline Berkeleya sp. & $x$ & $x$ & $x$ & $\mathrm{x}$ & $x$ & $x$ & $x$ & & $x$ & $x$ & $x$ & $x$ & $x$ \\
\hline Chaetoceros sp. & & $x$ & $x$ & $x$ & & & & & $x$ & $x$ & $x$ & $x$ & $x$ \\
\hline Coconeis sp. & & & & $x$ & & & & & & & $X$ & $X$ & $x$ \\
\hline Cylindrotheca sp. & & $X$ & $x$ & & & & & & $X$ & & & $x$ & \\
\hline Entomoneis sp. & $X$ & $x$ & $x$ & & $X$ & $X$ & $X$ & $X$ & $x$ & & $X$ & $x$ & $X$ \\
\hline $\begin{array}{l}\text { Euchampia Antarctica var.recta } \\
\text { summer stage }\end{array}$ & & $x$ & & & & & & & & & & & \\
\hline Flagellate & & $x$ & & & $X$ & & & & & & & & \\
\hline Fragilariopsis obliqucostata & & $x$ & & $x$ & & $x$ & & $x$ & & $x$ & & $X$ & $x$ \\
\hline Fragilariopsis spp. & $x$ & $x$ & $x$ & $x$ & $x$ & $x$ & $x$ & $x$ & $x$ & $x$ & $x$ & $x$ & $x$ \\
\hline Haptophyte & & & & & & $x$ & & & & & & & \\
\hline Haslea sp. & & & $x$ & & & & & & & $x$ & $x$ & $x$ & \\
\hline Manguinea sp. & & $x$ & $x$ & & $\mathrm{x}$ & & $x$ & & & & $x$ & $x$ & $x$ \\
\hline Navicula sp. & $x$ & $x$ & $x$ & $x$ & $x$ & $x$ & $x$ & $x$ & $x$ & & $x$ & $x$ & $x$ \\
\hline Nitzschia leicointei & $x$ & $x$ & $x$ & & $x$ & $x$ & & $x$ & $x$ & $\mathrm{x}$ & $x$ & $x$ & $x$ \\
\hline Nitzschia stellata & $x$ & $x$ & $x$ & $x$ & $x$ & $x$ & $x$ & $x$ & $x$ & & $x$ & $x$ & $x$ \\
\hline Nitzschia subcurvata & $x$ & $x$ & & $x$ & & $x$ & $x$ & & & $x$ & & & \\
\hline Odonthella sp. & & & & $x$ & & & & & & $x$ & & & \\
\hline Pinnularia sp. & & $x$ & $x$ & & $x$ & $x$ & $x$ & $x$ & $x$ & $x$ & $x$ & $x$ & $x$ \\
\hline Pleurosigma sp. & $x$ & $x$ & $x$ & $x$ & $x$ & $x$ & $x$ & & $x$ & $x$ & $x$ & $x$ & $x$ \\
\hline Polarella sp. & & & $x$ & & & $x$ & $x$ & $x$ & & & & & \\
\hline Porosira sp. & & $x$ & $x$ & $x$ & $\mathrm{x}$ & & & $x$ & $\mathrm{x}$ & $x$ & $x$ & $x$ & $x$ \\
\hline Proboscia sp. & & & $x$ & $x$ & $x$ & & & & & $x$ & $x$ & & \\
\hline Protoperidinium sp. & & $x$ & & & & & & & & & $x$ & & \\
\hline Pseudonitzschia sp. & & $x$ & $x$ & & & $\mathrm{x}$ & & & & & $x$ & $\mathrm{x}$ & $x$ \\
\hline Silicoflagellate & & & & & $x$ & & & & & & & & \\
\hline Stellarima sp. & & & $x$ & & & & $X$ & $X$ & $x$ & & $x$ & & $x$ \\
\hline Thalassiosira sp. & & & $x$ & & & & & & $x$ & & $x$ & & \\
\hline Unidentified & $X$ & & & & & & & & $x$ & $X$ & $x$ & $X$ & $x$ \\
\hline
\end{tabular}


Table Appendix A 2: Complete algal species list collected in the top $10 \mathrm{~cm}$ and middle $10 \mathrm{~cm}$ of sea ice at CE (Cape Evans), TNB (Terra Nova Bay) and TR (Turtle Rock).

\begin{tabular}{|c|c|c|c|c|c|c|c|c|c|c|c|c|c|c|}
\hline & $\begin{array}{l}\stackrel{ }{\Im} \\
\text { ○ } \\
\text { U }\end{array}$ & 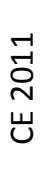 & 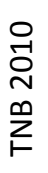 & 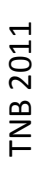 & 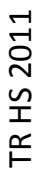 & 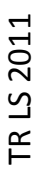 & 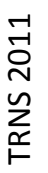 & $\begin{array}{l}\stackrel{ }{-} \\
\text { ㅇ } \\
\text { U }\end{array}$ & 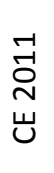 & 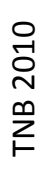 & 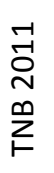 & 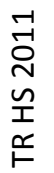 & 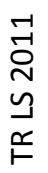 & $\begin{array}{l}\underset{-}{-} \\
\stackrel{\sim}{ } \\
\text { N } \\
z \\
\text { r }\end{array}$ \\
\hline & $\frac{\frac{0}{\overline{0}}}{\frac{0}{2}}$ & $\frac{\frac{0}{0}}{\frac{0}{2}}$ & $\frac{\frac{0}{0}}{\frac{0}{0}}$ & $\frac{\frac{0}{0}}{\frac{0}{0}}$ & $\frac{\frac{0}{D}}{\frac{0}{0}}$ & $\frac{\frac{0}{0}}{\frac{0}{0}}$ & $\frac{\frac{0}{0}}{\frac{0}{0}}$ & 응 & $\stackrel{0}{\circ}$ & $\stackrel{0}{\circ}$ & 응 & 응 & 응 & 응 \\
\hline Dinoflagellate & & $X$ & & $x$ & $x$ & $X$ & $X$ & & $x$ & & $x$ & $\mathrm{X}$ & $x$ & $x$ \\
\hline Algae with flagella & & & & $x$ & $\mathrm{X}$ & & & & & & & & $x$ & $x$ \\
\hline Berkeleya sp. & $\mathrm{x}$ & & & & $x$ & $x$ & $x$ & $x$ & & & & $\mathrm{x}$ & $x$ & $x$ \\
\hline Centric & & & & & & & & & & & $x$ & $x$ & & \\
\hline Chaetoceros (large) & & & & & & & & & & & & $\mathrm{x}$ & $\mathrm{x}$ & $\mathrm{x}$ \\
\hline Chaetoceros sp. & & & & $x$ & & $x$ & & & & & & & & \\
\hline Cheatoceros sp. vegatative & & & & & & $\mathrm{X}$ & & & & & & $x$ & $x$ & \\
\hline Coconeis sp. & & & & $x$ & & & & & & & & & & \\
\hline Corethron sp. & & & & $x$ & & & & & & & & & & \\
\hline Entomoneis sp. & $x$ & & & $x$ & & & & $x$ & $x$ & & $x$ & $x$ & $x$ & $x$ \\
\hline $\begin{array}{l}\text { Euchampia Antarctica var. } \\
\text { recta winter stage }\end{array}$ & & $\mathrm{x}$ & & $\mathrm{x}$ & $x$ & $x$ & $\mathrm{x}$ & & & & $x$ & & $x$ & $\mathrm{x}$ \\
\hline Flagellate & $x$ & & $x$ & & & & & & & & & & & \\
\hline Fragilariopsis obliqucostata & & $\mathrm{x}$ & & $\mathrm{x}$ & $x$ & $\mathrm{x}$ & $\mathrm{x}$ & & & & $x$ & & & \\
\hline Fragilariopsis nana & & $x$ & & $\mathrm{x}$ & & & & & & & & $x$ & & \\
\hline Fragilariopsis spp. & $X$ & & $x$ & $x$ & & & & $x$ & $x$ & $x$ & $x$ & $x$ & $x$ & $x$ \\
\hline Haptophyte & $\mathrm{x}$ & & & & & & & & & & & & & \\
\hline Haslea sp. & $\mathrm{x}$ & & & & & & & & & & & & & \\
\hline Manguinea sp. & $x$ & & & $x$ & & & & & & & & $x$ & $x$ & $x$ \\
\hline Navicula sp. & $\mathrm{x}$ & & $\mathrm{X}$ & $x$ & & & & $\mathrm{X}$ & & $x$ & $x$ & $x$ & $\mathrm{x}$ & $x$ \\
\hline Nitzschia leicointei & $x$ & $x$ & & $x$ & & $x$ & & $x$ & $x$ & & $x$ & $x$ & $x$ & $x$ \\
\hline Nitzschia stellata & $\mathrm{X}$ & $x$ & $x$ & $x$ & & & $x$ & $x$ & & $x$ & & $x$ & $x$ & $x$ \\
\hline Pinnularia sp. & $\mathrm{x}$ & & & $x$ & & & $\mathrm{x}$ & & & & & $x$ & & $x$ \\
\hline Pleurosigma sp. & & & & & $X$ & $x$ & $x$ & & & & & $x$ & & $x$ \\
\hline Polarella sp. & $\mathrm{X}$ & & & & & & & & $x$ & & $x$ & $x$ & $x$ & $x$ \\
\hline Porosira sp. & & & & $x$ & & & $x$ & & & & & & & \\
\hline Pseudonitzschia sp. & & & & & & & $x$ & & & & & & & \\
\hline Silicoflagellate & & & & & & & & & & & & & $\mathrm{x}$ & \\
\hline Stellarima sp. & $x$ & & $x$ & & & & & $x$ & & $x$ & & & & \\
\hline Thalassiosira sp. & & & & & & $\mathrm{X}$ & & & & & & & & \\
\hline Unidentified & & & & & $\mathrm{X}$ & $x$ & $x$ & & & & & $x$ & $x$ & $X$ \\
\hline
\end{tabular}




\section{Appendix B Overview of species found in seawater}

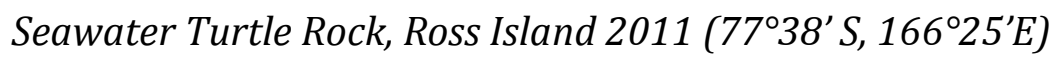

Samples of seawater underneath first year sea ice were collected with a NISKIN $2.3 \mathrm{~L}$ bottle every 3-4 days from 23 November to 6 December 2011. Sample depth was $2.5 \mathrm{~m}$, $5 \mathrm{~m}, 10 \mathrm{~m}$ and, $25 \mathrm{~m}$. The water current under the sea ice was negligible. A total of 64 samples were collected ( 4 replicates, 4 time points, 4 depths). Ten ml of sea was subsequently fixed with Lugol's iodine solution at a final concentration of $2.5 \%$. A minimal of $500 \mu \mathrm{l}$ of sample was counted using an inverted microscope (Zeiss, Germany).

The collected seawater samples consisted mainly of diatoms with small amounts of flagellates $(<1 \%)$. Biomass ranged from 35 to 170 cells.ml $^{-1}$ with one outlier of 370 cells.ml-1. Biomass was lowest at $25 \mathrm{~m}$. No zooplankton was found in these samples.

Table Appendix B 1: Seawater plankton abundance in cells.ml-1 collected from 2.5 to 25 m at Turtle Rock (2011).

\begin{tabular}{|c|c|c|c|c|c|c|c|c|c|c|c|c|c|c|c|}
\hline \multirow[b]{2}{*}{ Species - depth (m) } & \multirow[b]{2}{*}{2.5} & \multicolumn{5}{|c|}{$23 / 11$} & \multicolumn{3}{|c|}{$26 / 11$} & \multicolumn{5}{|c|}{$29 / 11$} & \multirow{2}{*}{$\begin{array}{c}6 / 12 \\
10\end{array}$} \\
\hline & & 5 & 10 & 25 & 2.5 & 5 & 10 & 25 & 2.5 & 5 & 10 & 25 & 2.5 & 5 & \\
\hline Berkeleya sp. & 0 & 0 & 0 & 0 & 0 & 0 & 0 & 0 & 0 & 0 & 0 & 0 & 0 & 0 & 0 \\
\hline Chaetoceros sp. & 0 & 0 & 0 & 0 & 12 & 12 & 42 & 12 & 22 & 6 & 48 & 0 & 12 & 18 & 26 \\
\hline Cylindrotheca sp. & 0 & 0 & 0 & 0 & 0 & 0 & 0 & 0 & 0 & 2 & 4 & 0 & 0 & 0 & 0 \\
\hline Entomoneis sp. & 0 & 2 & 0 & 0 & 0 & 0 & 0 & 0 & 0 & 0 & 0 & 0 & 0 & 2 & 0 \\
\hline Flagellate & 0 & 0 & 0 & 0 & 0 & 0 & 0 & 0 & 0 & 0 & 0 & 0 & 2 & 2 & 0 \\
\hline $\begin{array}{l}\text { Fragilariopsis } \\
\text { curta/cylindrus }\end{array}$ & 2 & 6 & 36 & 0 & 0 & 0 & 24 & 0 & 2 & 246 & 0 & 2 & 4 & 24 & 0 \\
\hline Navicula sp. & 4 & 0 & 0 & 0 & 0 & 0 & 0 & 0 & 0 & 0 & 2 & 0 & 2 & 0 & 2 \\
\hline Nitzschia leicontei & 2 & 10 & 2 & 0 & 10 & 0 & 0 & 0 & 4 & 10 & 6 & 2 & 36 & 16 & 28 \\
\hline Nitzschia stellata & 0 & 2 & 4 & 4 & 6 & 0 & 0 & 0 & 0 & 0 & 2 & 0 & 4 & 0 & 0 \\
\hline Polarella sp. & 0 & 0 & 0 & 0 & 0 & 0 & 0 & 0 & 0 & 2 & 0 & 0 & 0 & 0 & 0 \\
\hline Porosira sp. & 2 & 14 & 8 & 12 & 4 & 12 & 12 & 2 & 0 & 4 & 0 & 6 & 0 & 0 & 2 \\
\hline Proboscia sp. & 0 & 0 & 0 & 0 & 0 & 4 & 0 & 0 & 2 & 0 & 0 & 0 & 0 & 0 & 0 \\
\hline Pseudonitzschia sp. & 34 & 104 & 94 & 22 & 60 & 64 & 34 & 12 & 32 & 90 & 32 & 10 & 10 & 16 & 26 \\
\hline Stellarima sp. & 0 & 2 & 0 & 2 & 0 & 6 & 2 & 2 & 0 & 0 & 0 & 0 & 0 & 0 & 2 \\
\hline Thalassiothrix sp. & 122 & 0 & 0 & 0 & 60 & 42 & 4 & 0 & 0 & 14 & 30 & 0 & 8 & 6 & 0 \\
\hline Total cell.ml ${ }^{-1}$ & 166 & 140 & 144 & 40 & 152 & 140 & 118 & 28 & 62 & 374 & 124 & 20 & 78 & 84 & 86 \\
\hline
\end{tabular}




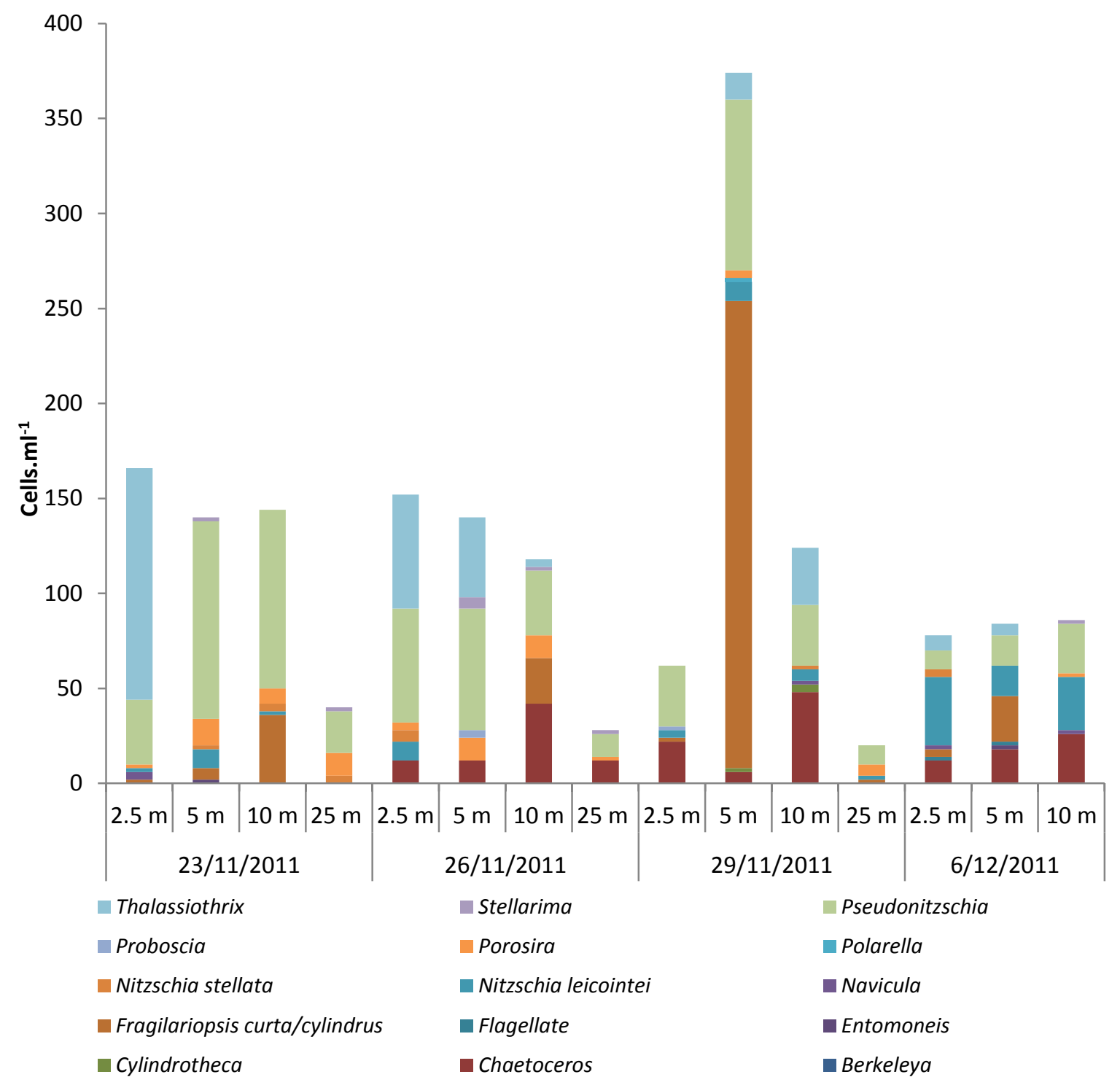

Figure Appendix B 1: Sea water community composition at Turtle Rock in early summer 2011. Samples were taken at $2.5 \mathrm{~m}, 5 \mathrm{~m}, 10 \mathrm{~m}$ and, $25 \mathrm{~m}$ ( $n=4$ per sample point). 


\section{Appendix C: fluorescence parameter calculations}

\section{Light source PAM}

Actinic light: non-saturating continuous red radiation (LED of $650 \mathrm{~nm}$ ) of $47 \mu \mathrm{mol}$ photon $\mathrm{m}^{-2} \mathrm{sec}^{-1}$ PAR.

Saturating light: strong "white light" given as a saturating flash.

\section{Fluorescence definitions}

F0 ground Chl fluorescence yield in the dark-adapted state.

Fm maximum Chl fluorescence induced by a saturating pulse in the dark-adapted state.

Fm' maximum Chl fluorescence in the light-adapted state induced by a saturating pulse.

F0' ground fluorescence measured after an actinic light pulse.

\section{Calculations of fluorescence parameters}

Fv $\quad\left(F_{m}-F_{0}\right) \quad$ variable fluorescence in the dark-adapted state.

$\mathrm{Fv}^{\prime} \quad\left(\mathrm{F}_{\mathrm{m}}{ }^{\prime}-\mathrm{F}_{0}{ }^{\prime}\right) \quad$ variable fluorescence in the light-adapted state.

NF $\quad\left(F_{m}-F_{m}{ }^{\prime}\right)$ or $\left(F_{v}-F_{v}{ }^{\prime}\right)$ decrease of the maximum fluorescence level in the light adapted state.

$\Delta \mathrm{F} \quad\left(\mathrm{F}_{\mathrm{m}}^{\prime}-\mathrm{F}\right) \quad$ saturating light induced by a saturating pulse.

Fv/Fm maximum quantum yield of PS2 photochemistry in the dark-adapted state.

$\Delta \mathrm{F} / \mathrm{Fm}^{\prime}$ effective quantum yield of PS2 in the light-adapted state.

$\mathrm{NPQ}=\mathrm{NF} / \mathrm{Fm}^{\prime}$ non photochemical quenching

Definitions and calculations are based on (Lichtenthaler et al. 2005) 